\title{
CONTROLE INTELIGENTE PARA A NAVEGAÇÃO DE VEÍCULOS SUBMARINOS SEMI-AUTÔNOMOS
}

Dissertação apresentada à Escola Politécnica da Universidade de São Paulo para obtenção do Título de Mestre em Engenharia. 


\title{
CONTROLE INTELIGENTE PARA A NAVEGAÇÃO DE VEÍCULOS SUBMARINOS SEMI-AUTÔNOMOS
}

\author{
Dissertação apresentada à Escola Politécnica \\ da Universidade de São Paulo para obtenção \\ do Título de Mestre em Engenharia. \\ Área de concentração: \\ Engenharia de Controle e Automação Mecânica \\ Orientador: \\ Prof. Dr. Decio Crisol Donha
}





\section{Agradecimentos}

Agradeço primeiro a Deus e a meus pais por me permitir e me dar a oportunidade de demonstralhes que tudo é possível, eles sempre me deram o amor, o exemplo, a ajuda e o apoio para que eu cresça como profissional e como humano.

Um agradecimento especial a meu Orientador o Prof. Dr. Decio Crisol Donha por toda a sua dedicação, apoio e entusiasmo, seu carisma, capacidade intelectual e disponibilidade foram fatores importantes para que este trabalho se realizasse. À Escola Politécnica da USP e ao departamento da Engenharia Mecânica que me outorgou todos os recursos e material necessário para a concretização de este trabalho.

Agradeço também aos membros da banca de mestrado, pela paciência em ler meu trabalho e pelas suas valiosas sugestões e comentários. Agradeço ao grupo de sensores e atuadores de engenharia mecânica da Escola Politécnica da USP por seu companheirismo e amizade.

Um agradecimento a meus irmãos que sempre estiveram comigo em todos meus passos neste projeto, por seu apoio espiritual e moral, muito importante para meu desempenho.

Um agradecimento especial a todas aquelas pessoas que deram seu apoio incondicional com seu tempo, seu conhecimento e sua experiência, como o Prof. Dr. Newton Maruyama, Prof. Dr. Marco Tulio, a Mg. Eric Conrado assim como muitos outros colegas que estiveram sempre no projeto. 


\section{Resumo}

O emprego de técnicas de controle para veículos submarinos, envolve muitas questões de interesse prático e teórico. Neste trabalho apresenta-se o desenvolvimento de um sistema de controle inteligente e adaptativo a ser aplicado na navegação de veículos submarinos semiautônomos (VSSAs). Utiliza-se uma técnica baseada no controle nebuloso (fuzzy), visando gerenciar o veículo submarino no controle de velocidade, profundidade, orientação e na evasão de obstáculos. A operação de veículos submarinos usando a técnica proposta, exige a definição, análise e tratamento de um vasto conjunto de comandos complexos manipulados pelo controlador.

A metodologia utilizada divide a ação de controle em 3 fases. A primeira trata do posicionamento inicial do veículo submarino, a segunda fase trata da sua navegação e a fase final de gerenciar o comportamento do veículo próximo da posição-objetivo.

A implementação funcional do controlador é dividida em módulos. O primeiro módulo informa o comportamento do ambiente e do próprio veículo, fornecendo dados iniciais sobre seu posicionamento e sua profundidade; um segundo módulo trata da presença de obstáculos em diferentes direções com dados fornecidos por sonares e assim determina as ações para a evasão de obstáculos.

A ação de controle é estabelecida usando conceitos da teoria nebulosa (fuzzy) no universo de discurso, através de variáveis lingüísticas e de regras de inferência definidas a partir do conhecimento de especialistas, que envolvem a imprecisão característica do comportamento humano. As informações no final do processo são concentradas, de forma que a ação de controle é determinada para que possa enviar sinais de controle aos atuadores. 


\section{Abstract}

The design of underwater vehicle involves a very large number of practical and theoretical problems. In this work, it is tackled the development of a intelligent and adaptive controller, to be used in the navigation of semi-autonomous underwater vehicles (SAUV). To achieve this goal, a technique based on the fuzzy theory was employed to control the vehicle movements, including the evasion of obstacles.

The operation of underwater vehicles using this approach demands the definition and treatment of a vast set of complex commands, manipulated by the controller.

The control action is subdivided into three stages, the first one deals the control action during the initial positioning of the vehicle, a second stage deals with the navigation itself and the final stage deals the control action when the vehicle is close to the objective-position.

The functional development of the controller was also subdivided into modules. The first module deals with the management of input data such as environmental disturbances and initial vehicle position, such as depth of the vehicle. The second module deals the detection of obstacles in different directions and the optimal evasion action to avoid collisions.

The control action during a mission is established using concepts of the Fuzzy theory in the universe of speech, through linguistic variables and rules of inference defined from the knowledge of specialists, involving the characteristic imprecision of human behavior. In the end of the process, the information is defuzzificated, so that control actions are determined, allowing a practical implementation. 


\title{
Conteúdo
}

\section{Lista de Figuras}

\author{
Lista de Tabelas
}

\section{Lista de Abreviaturas}

1 Introdução e Motivação $\quad 1$

1.1 Revisão Bibliográfica . . . . . . . . . . . . . . . . . . . . . . 3

1.2 Estudo de Caso e Objetivos . . . . . . . . . . . . . . . . . . . . 6

1.2 .1 Estudo de Caso . . . . . . . . . . . . . . . . . . . . . . 6

1.2 .2 Objetivo da Dissertação . . . . . . . . . . . . . . . . 6

1.3 Escopo da Pesquisa . . . . . . . . . . . . . . . . . . . . 7

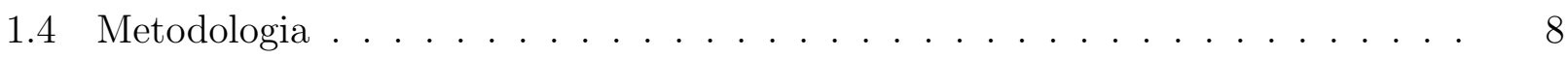

1.4.1 Projeto Funcional e Síntese . . . . . . . . . . . . . . . 9

1.4 .2 Projeto Modular . . . . . . . . . . . . . . . . . . 10

1.5 Estrutura do Trabalho . . . . . . . . . . . . . . . . . . . . 11

2 Lógica Nebulosa e Controladores Nebulosos $\quad 13$

2.1 Teoria de Conjuntos Nebulosos . . . . . . . . . . . . . . . . 14

2.1.1 Funções de Pertinência da Lógica Nebulosa . . . . . . . . . . . . . . . . 15

2.1.2 Tipos de Funções de Pertinência . . . . . . . . . . . . . . . . . . 15

2.1.3 Operações em Conjuntos Nebulosos . . . . . . . . . . . . . . . 17

2.1.4 Variáveis Lingüísticas (Hedges Lingüísticos) . . . . . . . . . . 18

2.2 Controladores Nebulosos . . . . . . . . . . . . . . . . . . . . . 19

2.2.1 Interface de Nebulização . . . . . . . . . . . . . . . . . . . 20 
2.2.2 Base de Conhecimento . . . . . . . . . . . . . . . . . . 21

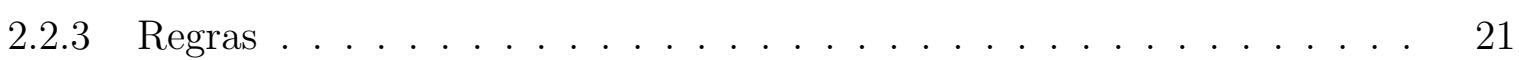

2.2.4 Interface de Concentração . . . . . . . . . . . . . . . . . . 24

2.3 Tipos de Controladores Nebulosos . . . . . . . . . . . . . . . 26

2.3.1 Controle Nebuloso Clássico . . . . . . . . . . . . . . . . 26

2.3.2 Controle Nebuloso de Interpolação . . . . . . . . . . . . . . . . . . 28

2.4 Projeto de Controladores Nebulosos . . . . . . . . . . . . . . . . . . . 29

3 Descrição e Instrumentação do Veículo Submarino Semi-Autônomo (VSSA) 31

3.1 Veículo Submarino Semi-Autônomo $(\mathrm{VSSA}) \ldots \ldots \ldots$. . . . . . . . 31

3.1.1 Sistema de Aquisição de Dados . . . . . . . . . . . . . . . . . . 34

3.1.2 Características de Operação dos Sensores Embarcados . . . . . . . . . . 35

3.2 Subsistemas no Projeto do VSSA . . . . . . . . . . . . . . 36

3.3 Arquitetura no Comando do Controle . . . . . . . . . . . . . . . 38

4 Fundamentos do Controlador $\quad 40$

4.1 Plano de Operação do VSSA . . . . . . . . . . . . . . . . . . . . 41

4.1 .1 Plano de Operação Pré-definido . . . . . . . . . . . . . . . . . . . 41

4.1 .2 Plano de Operação Autônomo . . . . . . . . . . . . . . . . . . . . 42

4.2 Modo de Navegação do VSSA . . . . . . . . . . . . . . . . . . . . 43

4.2.1 Evasão de Obstáculos no Plano Horizontal . . . . . . . . . . . . . . . 43

4.2.2 Evasão de Obstáculos no Plano Vertical . . . . . . . . . . . . . 43

4.2.3 Evasão de Obstáculos Otimizada no Plano Ideal . . . . . . . . . . . . . 44

4.3 Parâmetros do Projeto . . . . . . . . . . . . . . . . . 45

4.3.1 Constantes e Variáveis do Plano de Operação . . . . . . . . . . . . 45

4.3.2 Definição das Variáveis do Controlador . . . . . . . . . . . . . . . . 49

4.4 Regras no Plano de Operação . . . . . . . . . . . . . . . . . 50

4.4.1 Profundidade Relativa Equivalente . . . . . . . . . . . . . . 50 
4.4 .2 Evasão de Obstáculos . . . . . . . . . . . . . . . . . . . 50

4.5 Passos de Projeto de um Controlador Nebuloso . . . . . . . . . . . . . . 51

4.5.1 Definindo as Variáveis Lingüísticas . . . . . . . . . . . . . . . 52

4.5.2 Mecanismo de Inferência . . . . . . . . . . . . . . . . 52

4.5.3 Método de Concentração . . . . . . . . . . . . . . . . . . 52

5 Síntese do Controlador Modular para o VSSA Via Lógica Nebulosa $\quad 55$

5.1 Estratégia do Controlador Nebuloso . . . . . . . . . . . . . . . . 55

5.1 .1 Etapas na Navegação do Veículo . . . . . . . . . . . . . 56

5.1 .2 Módulos Operacionais do Controlador Nebuloso . . . . . . . . . . . 56

5.2 Síntese do Controlador Modular . . . . . . . . . . . . . . . . 57

5.2.1 Síntese do Controlador na Etapa Orientação e Posicionamento $t_{0} \ldots$. . 57

5.2 .2 Síntese do Controlador na Etapa de Navegação $t_{n} \ldots \ldots$. . . . . . . 58

5.2 .3 Síntese do Controlador na Etapa Final $t_{f} \ldots \ldots \ldots \ldots$

5.3 Módulo 1: Orientação e Posicionamento . . . . . . . . . . . . . . . 60

5.3.1 Camada 1: Controle Horizontal . . . . . . . . . . . . . . . . 60

5.3.2 Camada 2: Controle Vertical . . . . . . . . . . . . . . . 67

5.4 Módulo 2: Evasão de Obstáculos . . . . . . . . . . . . . . . 73

5.5 Módulo 3: Navegação e Controle dos Propulsores . . . . . . . . . . . . . 75

5.5.1 Camada 1: Controle de Velocidade de Avanço . . . . . . . . . . . 76

5.5.2 Camada 2: Controle de Profundidade . . . . . . . . . . . . 82

5.6 Diagrama do Controlador final . . . . . . . . . . . . . . 87

6 Aplicações, Resultados e Análises $\quad 88$

6.1 Etapa $t_{0}$ : O VSSA é Posicionado na Água e Preparado para Desenvolver suas

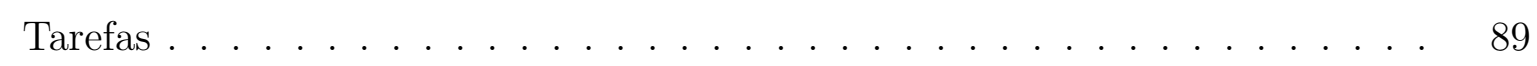

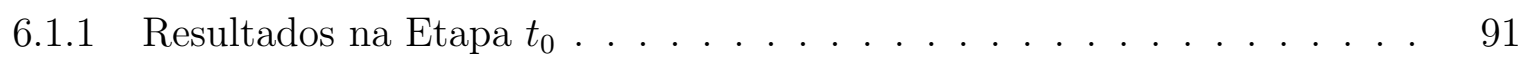

6.2 Etapa $t_{n}$ : O VSSA Avança e Evita Obstáculos no Plano Horizontal . . . . . 93

6.2.1 Resultados na Etapa $t_{n} \ldots \ldots \ldots \ldots \ldots$. . . . . . . . . . 103 
6.3 Etapa $t_{f}$ : O VSSA Ingressa no Volume da Posição Objetivo . . . . . . . . 106

6.3.1 Resultados na Etapa $t_{f} \ldots \ldots \ldots \ldots \ldots$. . . . . . . . . 107

7 Considerações Finais 113

7.1 Conclusões . . . . . . . . . . . . . . . . . . . 113

7.2 Sugestões para Trabalhos Futuros . . . . . . . . . . . . . . . . 115

$\begin{array}{ll}\text { Referências } & 118\end{array}$

Apêndice A - Modelagem do Veículo Submarino Semi-Autônomo (VSSA) 122

A.1 Introdução . . . . . . . . . . . . . . . . . . . . . . 122

A.2 Sistema de Coordenadas . . . . . . . . . . . . . . . . . 123

A.3 Cinemática do VSSA . . . . . . . . . . . . . . . . . . 124

A.4 Dinâmica do VSSA . . . . . . . . . . . . . . . . . 126

A.4.1 Dinâmica do Corpo Rígido . . . . . . . . . . . . . . . . . 126

A.4.2 Forças e Momentos Hidrodinâmicos . . . . . . . . . . . . . . . . . . 127

A.5 Considerações Sobre a Modelagem do VSSA . . . . . . . . . . . . . . 130

A.6 Modelo do Sistema Propulsor . . . . . . . . . . . . . . . . . . . 130

A.6.1 Modelo do Propulsor . . . . . . . . . . . . . . . . . . . . 131

Apêndice B - Coeficientes Hidrodinâmicos do Veículo Submarino Semi-Autônomo

$\begin{array}{ll}\text { (VSSA) } & 133\end{array}$

B.1 Coeficientes da Força de Arrasto . . . . . . . . . . . . . . . . 133

B.2 Massa Adicionada do VSSA . . . . . . . . . . . . . . . . 135

B.3 Freqüências Naturais de Operação do VSSA . . . . . . . . . . . . . . . . 135

B.4 Coeficientes de Força dos Propulsores do VSSA . . . . . . . . . . . . 136

B.5 Coeficientes Hidrodinâmicos em 3 Graus de Liberdade do VSSA . . . . . . . . 136

Apêndice C - Sistema Propulsor do VSSA 137

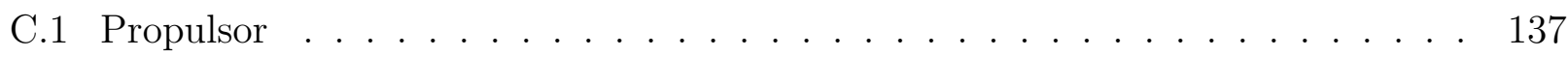


C.2 Distribuição Espacial dos Propulsores . . . . . . . . . . . . . . . . . . 138 


\section{Lista de Figuras}

1.1 Evolução da Profundidade da Prospecção de Petróleo em Águas Profundas. . . 2

1.2 Protótipo de VSSA da EPUSP . . . . . . . . . . . . . . . . . . . . 7

1.3 Metodologia do Projeto Controlador Neuro-Nebuloso. . . . . . . . . . . . . . 8

2.1 Funções de Pertinência Nebulosas. . . . . . . . . . . . . . . . . . . . . . . . . . 15

2.2 Função Triangular. . . . . . . . . . . . . . . . . . . . . . . . . 16

2.3 Função Trapezoidal. . . . . . . . . . . . . . . . . . . . . . . . 16

2.4 Função Gaussiana. . . . . . . . . . . . . . . . . . . . . . . . 17

2.5 Termos Lingüísticos Mapeiam a Variável Velocidade. . . . . . . . . . . . . . . 18

2.6 Fluxo do Controlador Nebuloso. . . . . . . . . . . . . . . . . . . . . . . . . . . 19

2.7 Estrutura do Controlador Nebuloso. . . . . . . . . . . . . . . . . . . . . 20

2.8 Nebulização de Valores Numéricos. . . . . . . . . . . . . . . . . . . . . . . . . 21

2.9 Mecanismo de Inferência. . . . . . . . . . . . . . . . . . . . . . . . . 22

2.10 Mecanismo de Inferência : Agregação. . . . . . . . . . . . . . . . . . . . . . 23

2.11 Mecanismo de Inferência : Ativação. . . . . . . . . . . . . . . . . . . . . . 23

2.12 Mecanismo de Inferência : Acumulação. . . . . . . . . . . . . . . . . . . . . . . 24

2.13 Concentração: Centro da Gravidade. . . . . . . . . . . . . . . . . . 25

2.14 Concentração: Método do Centro da Área. . . . . . . . . . . . . . . . . . . . . 25

2.15 Concentração: Método da Média do Máximo. . . . . . . . . . . . . . . 26

2.16 Sistema de Inferência Nebuloso de Mamdani Usando min e max Como Operadores AND e OR Respectivamente. . . . . . . . . . . . . . 27

2.17 Configuração Básica de um Sistema TSK. . . . . . . . . . . . . . . . . . . 29

3.1 Protótipo do VSSA. . . . . . . . . . . . . . . . . . 31

3.2 Configuração Estrutural do VSSA . . . . . . . . . . . . . . . . 32 
3.3 Sensores Embarcados no VSSA. . . . . . . . . . . . . . . . 35

3.4 Representação do Sensor de Pressão. . . . . . . . . . . . . . . . . . . . 36

3.5 Diagrama da Arquitetura de Comando e Controle (LOBO, 2005) . . . . . . . 38

4.1 Lançamento do VSSA. . . . . . . . . . . . . . . . . . . 40

4.2 Sistema de Referência Inercial. . . . . . . . . . . . . . . . . . 41

4.3 Plano de Operação Pré-definido. . . . . . . . . . . . . . . . . . . 42

4.4 Plano de Operação Autônomo. . . . . . . . . . . . . . . . . . . . . . 42

4.5 Evação de Obstáculos no Plano Horizontal. . . . . . . . . . . . . . . . . . . 43

4.6 Evação de Obstáculos no Plano Vertical. . . . . . . . . . . . . . . . . . . 44

4.7 Evação de Obstáculos no Plano Horizontal e Vertical. . . . . . . . . . . . . . . 44

4.8 Alcance Máximo do Sensor Sonar. . . . . . . . . . . . . . . . . 45

4.9 Ciclo de Leitura do Controlador. . . . . . . . . . . . . . . . . . . 46

4.10 Faixa de Operação do VSSA . . . . . . . . . . . . . . . . . 47

4.11 Direções de Leitura do Sensor Sonar. . . . . . . . . . . . . . . . . . . . . 48

4.12 Metodologia de Projeto do Controlador Nebuloso do VSSA. . . . . . . . . . 51

4.13 Concentração Mediante do Centro das Massas. . . . . . . . . . . . . . . . . 53

4.14 Valor Médio no topo Esquerdo no Método de Concentração. . . . . . . . . . 53

4.15 Método de Concentração. . . . . . . . . . . . . . . . . . . . 54

4.16 Método de Concentração para a Velocidade de Avanço Zero . . . . . . . . . . . 54

5.1 Esquema de Etapas e Módulos. . . . . . . . . . . . . . . . . . . 55

5.2 Etapas de Navegação. . . . . . . . . . . . . . . . . . . . . 56

5.3 Diagrama de Fluxo da Etapa $t_{0}$ do Controlador. . . . . . . . . . . . . . 57

5.4 Diagrama de Fluxo para Evasão de Obstáculos do Controlador. . . . . . . . . 58

5.5 Diagrama de Fluxo da Etapa $t_{n}$ e Etapa $t_{f}$ do Controlador. . . . . . . . . . 59

5.6 Variáveis Lingüísticas de Entrada e Saída Para o Controle Horizontal (Correção de Rumo) . . . . . . . . . . . . . . . . . . . . 6 60

5.7 Conjuntos Nebulosos que Definem a Variável Erro de Rumo. . . . . . . . . . . 62

5.8 Conjuntos Nebulosos que Definem a Variável Correção Horizontal. . . . . . . . 62 
5.9 Conjuntos Nebulosos que Definem a Variável Verro de Rumo. . . . . . . . . .

5.10 Conjuntos Nebulosos que Definem a Variável Velocidade de Avanço. . . . . . .

5.11 Resultados da Camada de Correção Horizontal, (a)Resposta da Correção de Rumo e a Velocidade de Mudança de Erro de Rumo, (b) Resposta da Correção de Rumo e a Velocidade de Avanço (c)Resposta da Sobreposição dos dois Controladores Anteriores. . . . . . . . . . . . . . . . . . .

5.12 Variáveis Lingüísticas de Entrada e Saída para o Controle Vertical (Correção de Cabeceio). . . . . . . . . . . . . . . . . .

5.13 Movimento de Cabeceio no VSSA . . . . . . . . . . . . . . . 68

5.14 Conjuntos Nebulosos que Definem a Variável Cabeceio. . . . . . . . . . . . . . 69

5.15 Conjuntos Nebulosos que Definem a Variável Correção Vertical. . . . . . . . .

5.16 Resultados da Camada de Controle Vertical (Correção de Cabeceio)(a)Resposta da Correção de Cabeceio e a Velocidade de Mudança de Erro de Cabeceio, (b) Resposta da Correção de Cabeceio e a Velocidade de Avanço (c)Resposta da Sobreposição dos Dois Controladores Anteriores . . . . . . . . . . . . . . . .

5.17 Resultados da Sobreposição do Controlador Vertical sobre o Controlador Horizontal. . . . . . . . . . . . . . . . . . . .

5.18 Variáveis Lingüísticas de Entrada e Saída para o Controle de Evasão de Obstáculos. 73

5.19 Conjuntos Nebulosos que Definem a Variável de Distância 1. . . . . . . . . . . 74

5.20 Diagrama de Sequência Para Projetar a Tarefa de Evasão de Obstáculos no VSSA. 74

5.21 Respostas de Cada Bloco na Evasão de Obstáculos. . . . . . . . . . . . . . . . 75

5.22 Distribuição dos Propulsores no VSSA . . . . . . . . . . . . . . . . 76

5.23 Variáveis Lingüísticas de Entrada e Saída para o Controle de Velocidade. . . . 76

5.24 Conjuntos Nebulosos que definem a Variável Distância. . . . . . . . . . . . . . 78

5.25 Conjuntos Nebulosos que Definem a Variável Velocidade Diferencial. . . . . . . 79

5.26 Resultados no Controle de Velocidade . . . . . . . . . . . . . . . . . . . . 80

5.27 Trajetória de Aproximação Indesejada. . . . . . . . . . . . . . . . . . . . . . 81

5.28 Resultados da Camada de Sobrepocição no Controle Horizontal (Correção de Rumo) Relativamente à Distância. . . . . . . . . . . . . . . . . . . . . . . . 82

5.29 Variáveis Lingüísticas de Entrada e Saída para o Controle de Profundidade. . . 
5.30 Conjuntos Nebulosos que Definem a Variável Profundidade. . . . . . . . . . .

5.31 Conjunto Nebuloso da Variável Velocidade Vertical. . . . . . . . . . . . . . 84

5.32 Resultados do Controle de Profundidade. . . . . . . . . . . . . . . . . . 85

5.33 Resultados da Sobreposição do Controle de de Profundidade Frente o Controle Vertical. . . . . . . . . . . . . . . . . . . . .

5.34 Diagrama da União de Todos os Controladores para a Navegação e Evasão de Obstáculos de um VSSA . . . . . . . . . . . . . . . . . . . .

6.1 Rastreamento da Profundidade Relativa do Planejador, (a) Profundidade Desejada, (b) Resposta do Controlador para a Profundidade. . . . . . . . . . . . . 91

6.2 Sinais de Erro para Cada Variável de Posição e Orientação na Etapa $t_{0}$ . . . 92

6.3 Repostas das Velocidades de erro dos Posicionamentos e Orientações na Etapa $t_{0} .93$

6.4 Repostas de Posições e Orientações. . . . . . . . . . . . . . . . . . . . . . . . . 94

6.5 Sinais de Referencia Frente as Sinais Reais na Navegação. . . . . . . . . . . . . 95

6.6 Sinais de Erro das Posições e Orientações do VSSA . . . . . . . . . . . . . . . . 96

6.7 Sinais de Erro de Cada Posição e Cada Orientação do VSSA. . . . . . . . . . . . 96

6.8 Velocidades do Veículo. . . . . . . . . . . . . . . . . . . . . . . . 97

6.9 Empuxo dos Propulsores Para cada Movimento. . . . . . . . . . . . . . . . . . 97

6.10 Sinais de Controle para Cada Movimento. . . . . . . . . . . . . . . . . . . 98

6.11 Velocidade do Erro Como variável de Controle. . . . . . . . . . . . . . . . . . 99

6.12 Correnteza no Sistema Inercial. . . . . . . . . . . . . . . . . . . . . 100

6.13 Pontos: de Partida e de Chegada do VSSA . . . . . . . . . . . . . . . . . . 104

6.14 Trajetória do VSSA sem Obstáculos . . . . . . . . . . . . . . . . . . . . . 104

6.15 Mapeamento dos Obstáculos no Ambiente em que o VSSA vai se Movimentar 104

6.16 Visualização do Ambiente com Profundidade . . . . . . . . . . . . . . . . . . . 104

6.17 Vista de Acima do Ambiente . . . . . . . . . . . . . . . . . . 105

6.18 Sobreposição da Trajetória sem Obstáculos sobre o Scenario com Obstáculos 105

6.19 Evasão de Obstáculos com Controle Nebuloso. . . . . . . . . . . . . . . . . . 105

6.20 Repostas de Posições e Orientações. . . . . . . . . . . . . . . . . . . . . . 107 
6.21 Sinais de Referência Frente a Sinais Reais na Navegação. . . . . . . . . . . . 108

6.22 Sinais de Erro das Posições e Orientações do VSSA . . . . . . . . . . . . . . 109

6.23 Sinais de Erro de Cada Posição e Cada Orientação do VSSA. . . . . . . . . . . 109

6.24 Velocidades Inerciais e Relativas. . . . . . . . . . . . . . . . . . . 110

6.25 Empuxo dos Propulsores para cada Movimento. . . . . . . . . . . . . . 110

6.26 Sinais de Controle para Cada Movimento. . . . . . . . . . . . . . . 111

6.27 Velocidade do Erro Como variável de Controle. . . . . . . . . . . . . . . . 112

A.1 Sistemas de Coordenadas do VSSA. . . . . . . . . . . . . . . . . 124

C.1 Esquema do Propulsor Usado no VSSA. . . . . . . . . . . . . . . . 137

C.2 Distribuição dos Propulsores no VSSA. . . . . . . . . . . . . . . . . 138

C.3 Identificação dos Propulsores no Plano Horizontal. . . . . . . . . . . . . . . . . 138 


\section{Lista de Tabelas}

2.1 Operações Básicas de Conjuntos . . . . . . . . . . . . . . . . . 18

3.1 Características Físicas do VSSA . . . . . . . . . . . . . . 33

3.2 Características Eletro-eletrônicas do VSSA . . . . . . . . . . . . . . . 34

5.1 Regras para o Controle Correção Horizontal Dependendo da Variação de Velocidade de Erro . . . . . . . . . . . . . . . . . . . . . . 65

5.2 Regras para o Controle Correção Horizontal Dependendo da Velocidade de Avanço 65

5.3 Regras de Sobreposição Para a Correção de Rumo . . . . . . . . . . . . . . . . 66

5.4 Regras para a Variável Correção Vertical . . . . . . . . . . . . . . . . . 70

5.5 Regras para a Variável Correção Horizontal com Sobreposição da Variável Correção Vertical . . . . . . . . . . . . . . . . . . . 72

5.6 Regras para o Controle da Aceleração . . . . . . . . . . . . . . . . 78

5.7 Regras Otimizadas para a Variável Aceleração . . . . . . . . . . . . . . . . 79

5.8 Regras para a Variável Correção Horizontal com Sobreposição da Variável Distância 81

5.9 Regras para o Controle dos Propulsores Verticais . . . . . . . . . . . 85

5.10 Regras para a Variável Propulsores Verticais com Sobreposição da Variável Correção Vertical . . . . . . . . . . . . . . . . . 86

A.1 Variáveis de Estado para cada Grau de Liberdade . . . . . . . . . . . . . . 123

B.1 Coeficientes da Força de Arrasto Total (direção do fluxo coincide com o eixo x do Veiculo) . . . . . . . . . . . . . . . . . . . . 133

B.2 Coeficiente de Arrasto e Número de Reynolds para Movimento Longitudinal do

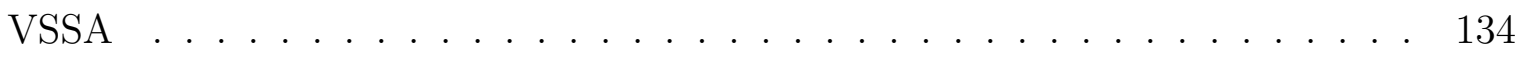

B.3 Massa Adicionada do VSSA . . . . . . . . . . . . . . . . 135

B.4 Coeficiente da Massa Adicionada do VSSA . . . . . . . . . . . . . . . 135

B.5 Freqüências Naturais de Operação do VSSA . . . . . . . . . . . . . . . . 135 
B.6 Coeficientes dos Propulsores do VSSA f . . . . . . . . . . . . 136

B.7 Parâmetros Envolvidos na Equação Simplificada no Movimento do VSSA ․ . . 136 


\section{Lista de Abreviaturas}

AUVs Autonomous Underwater Vehicles

B2B Business to Business

Ca Matriz de Forças Hidrodinâmicas de Coriolis e Centrífugas

CA Método do Centro da Área

CC Corrente Contínua

CG Centro da Gravidade

CI Computação Inteligente

ED Especificação Deôntica

EE Especificação Estrutural

EF Especificação Funcional

EnO Entidade Organizacional

EO Especificação Organizacional

EPUSP Escola Politécnica da Universidade de São Paulo

ES Esquema Social

GPS Global Positioning System

IA Inteligência Artificial

IAD Inteligência Artificial Distribuída

KQML Knowledge Query and Manipulation Language

LDC Laboratório de Dinâmica e Controle

LQ Linear Quadratic

LQG Linear Quadratic Gaussian 
LQR Linear Quadratic Regulator

Ma Matriz de Inércia Adicionada

MCP Modelo de McCulloch e Pitts

MIMO Múltiplas Entradas e Múltiplas Saídas

MISO Múltiplas Entradas e uma Saída

MLP Multi Layer Perceptron

MOISE Model of Organization for Multi-agent Systems

MM Método da Média dos Máximos

OO Orientação a Objetos

PD Proporcional Derivativo

PI Proporcional - Integral

PID Proporcional - Integral - Derivativo

RDP Resolução Distribuída de Problemas

RNA Rede Neural Artificial

RNAs Redes Neurais Artificiais

ROVs Remotely Operated Vehicles

SAUV Semi-Autonomous Underwater Vehicles

SMA Sistemas Multiagentes

SR Sistema Robótico

TAEMS Task Analysis, Environment Modeling, and Simulation

USP Universidade de São Paulo

UUVs Unmanned Untethered Vehicles

VF Valores Nebulosos

VN Valores Numéricos

VSA Veículos Submarinos Autônomos 
VSOR Veículos Remotamente Operados

VSSA Veículo Submarino Semi-autônomo

VSSAs Veículos Submarinos Semi-autônomos 


\section{Introdução e Motivação}

Impulsionada pela crescente demanda por operações submarinas nos campos de prospecção e extração de petróleo, a robótica submarina tem se desenvolvido rapidamente. O aumento das atividades de exploração, prospecção, avaliação e segurança no mar, tanto para aplicações comerciais como em aplicações científicas, têm levado grandes empresas e centros de pesquisa a investir no desenvolvimento de veículos submarinos de pequeno porte.

Particularmente no Brasil, onde $75 \%$ das reservas de petróleo estão localizadas em águas profundas (de $400 \mathrm{~m}$ a $1000 \mathrm{~m}$ de profundidade) e ultra profundas (com profundidade superior a $1000 m$ ), esses veículos submarinos vem encontrando grande aplicação (MOREIRA, 2004).

A Petrobrás tem cerca de $65 \%$ da área de seus blocos exploratórios em profundidades de água de mais de $400 \mathrm{~m}$. Em conseqüência, nos últimos anos, a empresa tem aumentado suas atividades de perfuração exploratória em águas cada vez mais profundas. O PROCAP 3000 - Programa Tecnológico da Petrobrás em Sistemas de Exploração em Águas Ultra-profundas, visa desenvolver tecnologias para permitir a produção em até 3000 metros de lâmina de água. Nessas condições, os riscos e os custos da operação aumentam e todo equipamento precisa estar adaptado para suportar as altas tensões e pressões a que é submetido. Na figura 1.1 observa-se que os poços de petróleo, cujas lâminas de água não passavam de poucas centenas de metros na década de 80, em 2003 atingiram a profundidade de 1886 metros (PETROBRAS, 2006).

No rastro do aumento das atividades em alto mar, não só pela demanda da indústria de gás e petróleo, a robótica submarina vem se desenvolvendo rapidamente impulsionada pela crescente demanda por operações submarinas como coleta e transmissão de dados, monitoramento, recuperação e acionamento de equipamentos no auxílio nas atividades de mergulhadores e atividades ecológicas.

Neste contexto, os Veículos Autônomos Submarinos ou Autonomous Underwater Vehicles (AUVs), tem se apresentado como uma nova tendência e como uma opção aos tradicionais Veículos Remotamente Operados ou Remotely Operated Vehicles (ROVs). A limitação em profundidade de operação dos ROVs está ligada à transmissão de dados e potência pelo cabo umbilical. Cabos muito longos implicam em grandes perdas de energia na transmissão e cabos 


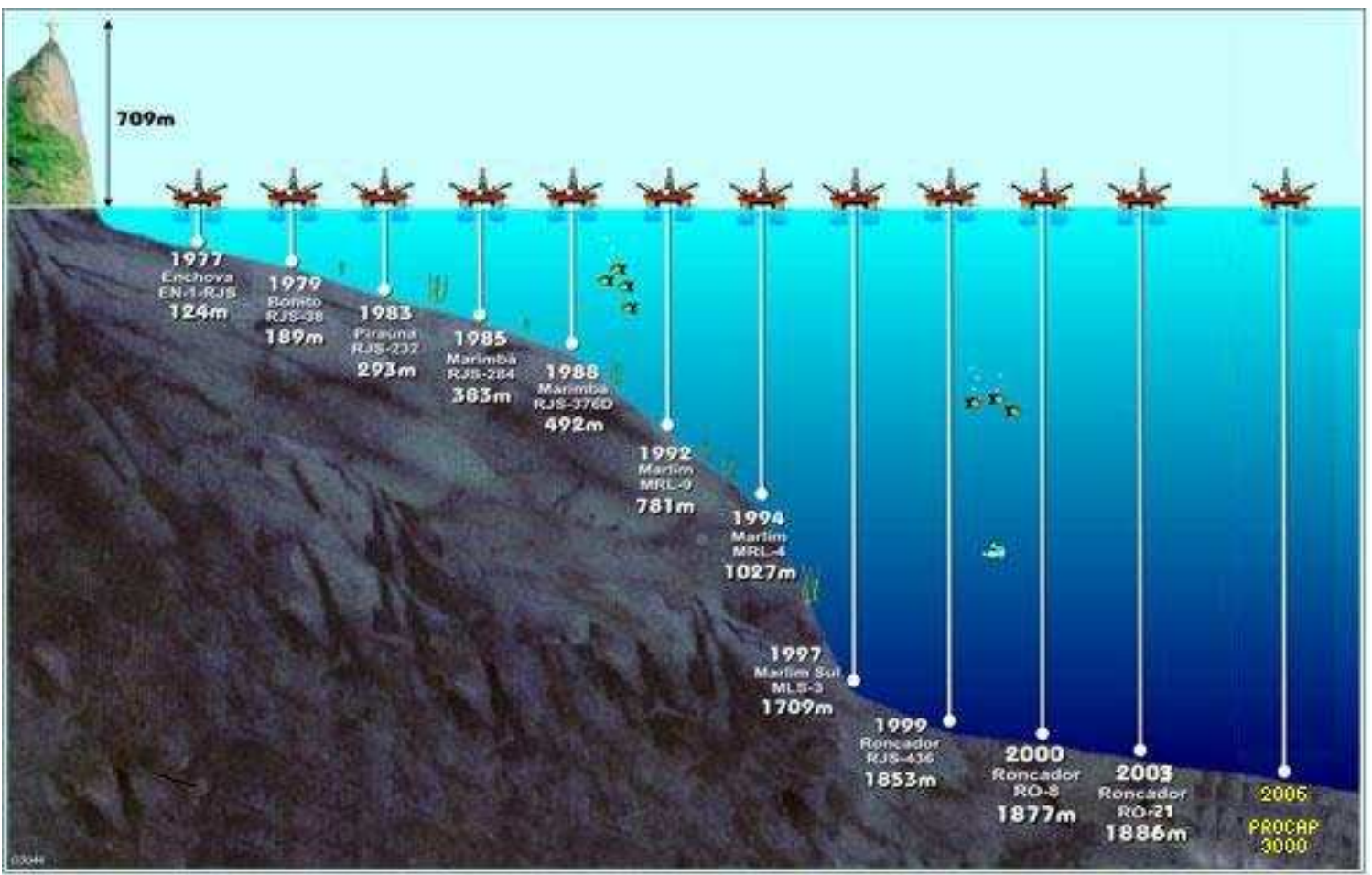

Figura 1.1: Evolução da Profundidade da Prospecção de Petróleo em Águas Profundas.

de maior diâmetro resultam em grande arrasto hidrodinâmico, interferindo na dinâmica do veículo. A distância de operação e diâmetro do cabo representam um compromisso de projeto (PAIM; JOUVENCEL; BORGES, 2005).

Por não estarem fisicamente ligados por um cabo, a operação eficiente dos AUVs, por outro lado, encontra problemas referentes ao armazenamento de energia e transmissão de dados. Devido à rápida atenuação de ondas eletromagnéticas na água, a comunicação acústica se torna a única alternativa viável, porém limitada pela velocidade de propagação do som na água, por volta de $1500 \mathrm{~m} / \mathrm{s}$, sofrendo um atraso devido à velocidade de propagação. Outro grande desafio para o projeto de AUVs está em sua navegação e controle. Estes requerem informações confiáveis sobre a localização e atitude do veículo, o que é obtido através de complexos sistemas de fusão sensorial. O controle de alto-nível, permitindo a programação de combinações de tarefas como navegação, rastreamento de fundo ou retorno à base, ainda constitui objeto de intensa pesquisa (PAIM, 2005).

Contornar essas limitações representa um desafio para a evolução e o emprego prático de robôs submarinos. Por isso, muitas vezes opta-se pelos Veículos Submarinos Semi-autônomos (VSSAs) que dispõem de um cabo de comunicação que os liga fisicamente a uma plataforma de operação, mas possuem um certo grau de autonomia (por exemplo, podem parar de modo a evitar o choque com obstáculos). 
No desenvolvimento de veículos submarinos, devido à complexidade dos problemas envolvidos, há muitas questões e problemas a serem abordados. Neste trabalho, optou-se por tratar o problema de controle de um Veículo Submarino Semi-autônomo (VSSA), utilizando técnicas de controle nebulosas para a posição, orientação e evasão de obstáculos.

A lógica nebulosa foi inicialmente introduzida por Zadeh (1965), com o início do tratamento do aspecto vago da informação através da teoria dos conjuntos nebulosos ou difusos (Fuzzy). Está técnica tem sido cada vez mais usadas em sistemas que utilizam informações fornecidas por seres humanos para automatização (para automatizar procedimentos), como por exemplo, no controle de processos, no auxílio à decisão, etc. Estas teorias têm sido utilizadas em aplicações que vão do controle de eletrodomésticos ao controle de satélites, do mercado financeiro à medicina, e tendem a crescer cada vez mais, sobretudo em sistemas híbridos, que incorporam abordagens conexionistas e evolutivas, no que é chamado hoje em dia de "soft computing" (ZADEH, 1965).

O termo soft computing (computação flexível) foi introduzido por Zadeh (1965) como uma extensão da lógica nebulosa, abrangendo também redes neurais e computação evolucionária. Hoje em dia, a computação flexível é mais conhecida como Computação Inteligente (CI) e abrange também técnicas de raciocínio probabilístico capaz de tratar informação imprecisa, incerta ou vaga como algoritmos genéticos, sistemas caóticos, redes de crença (belief networks) e partes da teoria da aprendizagem. A essência da CI é, diferentemente da computação rígida (hard) ou tradicional, acomodar a imprecisão intrínseca ao mundo real. Assim, o princípio norteador da CI é explorar a tolerância para a imprecisão, a incerteza e a verdade parcial, no sentido de obter soluções robustas e de baixo custo para problemas envolvendo aspectos do mundo real (ZADEH, 1965).

\section{$1.1 \quad$ Revisão Bibliográfica}

Grupos de pesquisa em robótica submarina concentram seus esforços na área de controle robusto, controle de alto nível e controle distribuído para frotas de AUVs. Segundo Paim (2005) a execução de uma tarefa complexa realizada de forma eficiente por uma frota de AUVs representará a integração do controle embarcado e as técnicas de navegação.

No controle de navegação dos robôs submarinos, podem ser aplicadas diferentes estratégias de controle. A seleção de uma estratégia não só depende do sistema ou processo a controlar, mas também das condições de operação às quais os robôs submarinos estão sujeitos. Podemos dividir estas estratégias em dois grupos principais: 
1. O grupo de controladores desenvolvidos para trabalhar com modelos matemáticos são denominados analíticos e dividem-se em controladores clássicos convencionais e sistemas de controle moderno. Esta técnica, no entanto, tem fortes limitações devido a sua dependência do modelo matemático em que está baseada, além do problema de acoplamento das variáveis em ambientes muito estocásticos.

Controladores Clássicos Convencionais: Proporcional - Integral (PI), Proporcional Derivativo (PD) e Proporcional - Integral - Derivativo (PID) utilizados para o controle de posição e orientação do VSSA (CUNHA et al., 1994), devido a sua estrutura simples e a facilidade de implementação, é a técnica de controle mais empregada para o controle de veículos submarinos. Baseada em estratégias lineares utilizadas em sistemas não lineares, que possui validade de aplicação local, em torno a um ponto de operação.

Sistemas de Controle Moderno: como os controladores ótimos Linear Quadratic Regulator (LQR) ou Linear Quadratic Gaussian (LQG), que têm sua maior limitação na falta de robustez do controlador frente a incertezas de modelagem e distúrbios, como os induzidos por um cabo umbilical (LIN; LEE, 1985). O controle robusto ótimo pode ser usado como uma alternativa aos Linear Quadratic (LQ) em casos onde o desempenho e a estabilidade são muito importantes a despeito de distúrbios e incertezas de natureza diversa (LIN, 1994).

Algumas técnicas de controle robusto aplicadas ao controle de veículos submarinos são $H \infty$, e a análise $\mu$, que podem ser utilizados para sistemas multivariáveis (INNOCENTI; CAMPA, 1999) (DONHA; LUQUE, 2006) . Nestas estratégias precisa-se de uma modelagem adequada do veículo submarino, para atingir os requisitos de controle (LIN; SU, 2000). O controle robusto é usado em casos onde o desempenho e a estabilidade são considerados muito importantes relativamente aos distúrbios da natureza diversa (STALLARD, 1991) (LIN; CLOUTIER; EVERS, 1993). Entretanto, com controles robustos não há garantias da obtenção da convergência da solução, o que dificulta determinar o controlador ótimo, podendo haver a necessidade do uso de técnicas de nebulização (DONHA; LUQUE, 2006). A maioria de sistemas físicos são sistemas não lineares, no entanto, muitos destes sistemas podem ser considerados como sistemas aproximadamente lineares em uma determinada faixa de operação (OGATA, 1997). Os controladores que podem responder a um sistema não linear são muito robustos e apresentam um bom desempenho, mas estes sistemas são muito difíceis de projetar para sistemas multivariáveis.

Diante da necessidade de estabelecer instrumentos de análise e síntese de controladores voltados para sistemas não lineares, complexos e variantes no tempo, surgiu, uma nova vertente de pesquisa e de desenvolvimento de controladores, os sistemas híbridos inteligentes baseados no uso de uma ou mais tecnologias de inteligência artificial. 
2. O segundo grupo de controladores, aqui denominados de controladores inteligentes ou controladores adaptativos, são aqueles que não precisam de um modelo matemático por opção ou em casos onde o comportamento do sistema é complexo ou desconhecido. Este grupo inclui os controladores de tipo nebuloso ou difuso, por exemplo, controladores nebulosos do tipo PID e PD. A maior desvantagem deste grupo de controladores é que apesar do bom desempenho obtido, nem sempre é possível assegurar robustez e a estabilidade ao sistema controlado (YAMAMOTO, 2005).

A lógica nebulosa é uma das tecnologias atuais mais bem sucedidas no controle de processos sofisticados como a navegação e inteligência de um veículo submarino num ambiente rigorosamente dinâmico (GUO; SIMAAN; SUN, 2003), (SONG; SMITH, 2000), (YAMAMOTO, 1989), (WANG; LEE; YUH, 1999), (WANG; LEE, 2003). Com sua utilização, requerimentos complexos podem ser implementados em controladores simples, de fácil manutenção e baixo custo, o que é especialmente interessante quando não se tem o modelo matemático ou está sujeito a incertezas (DAí-JU; XINOGUANG, 2002), (SONG; SMITH, 2000), (YAMAMOTO, 2005). Kanakakis mostra no seu trabalho o desenvolvimento do um controlador nebuloso baseado numa arquitetura modular, faz a análise da orientação e evasão de obstáculos de um veículo submarino, mostrando um controlador estável e robusto (KANAKAKIS; VALAVANISA, 2004).

O controle neuro-nebuloso trabalha com algoritmos de aprendizagem baseados em redes neurais adaptativas que muitas vezes têm melhorado o desempenho dos controladores clássicos PID (GUO; SIMAAN; SUN, 2003) (MILLS; HARRIS, 1996). Outras vezes mostram resultados melhores que estratégias de controle multivariável no que se refere a estabilidade e robustez (CHUN-LIANG; HUAT-WEN, 1999) (SUTTON; ROBERTS; DEARDEN, 1989). Controladores híbridos utilizados para a navegação de robôs submarinos, sejam autônomos ou semi-autônomos, têm mostrado um bom desempenho e estabilidade. Além disso podese fazer uso de técnicas da teoria de controle por modos deslizantes, que reduz o número de regras necessárias na implementação do controle adaptativo (CHIU et al., 1999) (BATLLE; RIDAO; CARRERAS, 2000). Estes controladores também melhoram os tradicionais controladores PID, permitindo obter melhores resultados em alguns casos, como mostra o trabalho de Akizidis (AKKIZIDIS; ROBERTS, 2003).

Através dos controladores neuro-difusos, os AUVs podem ser capazes de aprender estratégias de navegação, adaptar-se a novas situações e construir conceitos complexos e abstratos. Na procura de autonomia e inteligência, os sistemas inteligentes dos AUVs processam representações simbólicas adquiridas pelos sensores a partir das interações com o ambiente, podendo ser capazes de se auto-governarem, isto é, desenvolverem suas próprias regras que regulam seus comportamentos (STEELS, 1995). 
Nesse caso, no desenvolvimento do comportamento do VSSA é empregada uma estrutura hierárquica e técnicas de redes neurais e conjuntos nebulosos. As decisões são baseadas na penalização de situações críticas do VSSA, conhecidas por tipo reativo (FIGUEIREDO, 1999).

A utilização do controle nebuloso na navegação de veículos submarinos, visto que sua metodologia de implementação não exige uma modelagem do veículo muito precisa, pode reduzir o tempo de síntese e sintonia do controlador quando comparado a outras estratégias de controle, na qual os conjuntos de regras simulam de forma qualitativa, a experiência de operadores especialistas e o conhecimento das estratégias de controle (FIGUEIREDO, 1999).

\subsection{Estudo de Caso e Objetivos}

\subsubsection{Estudo de Caso}

O Laboratório de Sensores e Atuadores do Departamento de Engenharia Mecatrônica, junto com o Laboratório de Dinâmica e Controle (LDC) do Departamento do Engenharia Mecânica, o Departamento de Engenharia Naval e o Instituto Oceanográfico da Universidade de São Paulo (USP), vêm desenvolvendo um VSSA, cuja tarefa será a recuperação de transponders utilizados no posicionamento dinâmico de navios. Este projeto iniciou-se em 2000 com a construção do protótipo e atualmente se encontra na fase de testes hidrodinâmicos para determinar seu comportamento dinâmico.

Mostra-se na figura 1.2 o VSSA construído na Escola Politécnica da Universidade de São Paulo (EPUSP), que é um submersível de estrutura mecânica tubular aberta tipo open frame, de forma quadrada, com um sistema de 8 propulsores para a movimentação, vasos de pressão para a instrumentação, módulos de controle, assim como os flutuadores. O veículo dispõe de um sistema sensorial para a determinação do seu comportamento no mar.

O objetivo principal do veículo é a recuperação de transponders, instalação e transporte de equipamentos em poços petrolíferos localizados em águas profundas.

No capítulo 3, é apresentada uma descrição mais detalhada do VSSA estudado.

\subsubsection{Objetivo da Dissertação}

Desenvolver um sistema de controle para o VSSA para a missão anteriormente descrita. Para tanto, vão ser utilizadas técnicas de controle nebuloso que permitam controlar o posicionamento, orientação e a evasão de obstáculos do VSSA, bem como a sua navegação em águas profundas. 


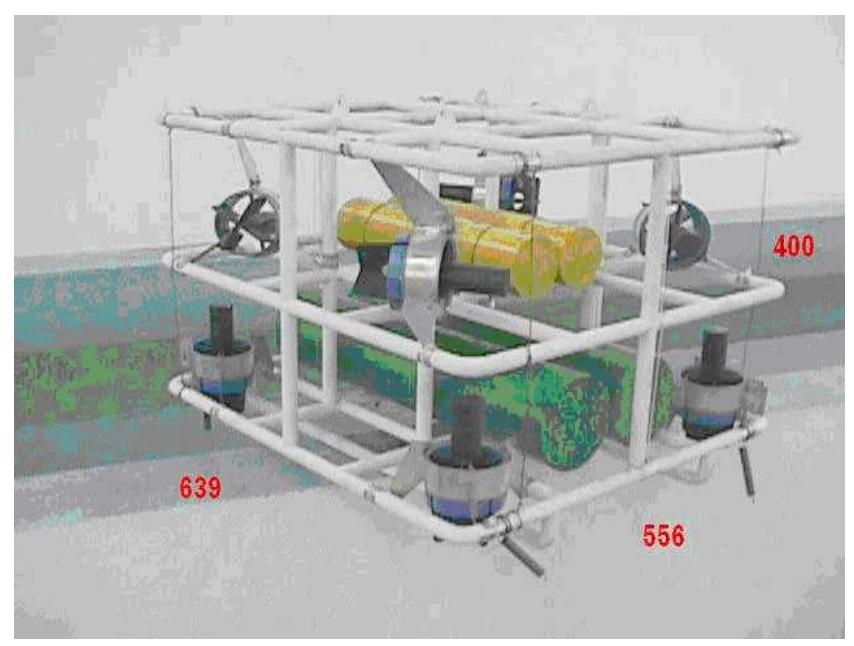

Figura 1.2: Protótipo de VSSA da EPUSP.

\subsection{Escopo da Pesquisa}

O escopo da pesquisa é aplicar uma técnica de controle nebuloso para a obtenção de um algoritmo adaptativo eficiente e robusto para o controle da navegação de veículos submarinos semi-autônomos. Esta abordagem permite analisar e estimar o grau de robustez e estabilidade do VSSA num ambiente dinâmico como é o mar profundo.

Desenvolver um sistema desta complexidade como um todo e de uma vez só, é uma tarefa bastante complicada, por isso o desenvolvimento realizou-se por etapas, como descrito a seguir:

- Estudo e análise dos diferentes tipos de controladores clássicos e modernos aplicados para o controle de veículos submersíveis.

- Estudo dos robôs submarinos, sua dinâmica, modelo matemático, etc.

- Obtenção de dados para a determinação dos coeficientes hidrodinâmicos necessários para a criação de um modelo matemático para a simulação do comportamento dinâmico do veículo no mar. Este modelo embora não seja usado diretamente no desenvolvimento do controlador proposto, que prescinde de modelos, será utilizado para validar as simulações computacionais do veículo controlado antes da implementação do controlador no protótipo.

- Estudo e análise dos controladores adaptativos para escolher o método adequado que atenda ao objetivo proposto.

- Síntese do projeto do controlador para a navegação do VSSA. Foi utilizado um controlador nebuloso, usando a informação obtida pelos sensores, para atuar os propulsores. 
- Desenvolvimento de simulações computacionais para a avaliação do comportamento controlado do VSSA.

\subsection{Metodologia}

O levantamento bibliográfico, baseado em livros, teses, artigos técnicos, publicações em congressos e revistas, é o primeiro passo para a compreensão da história da tecnologia em questão. As técnicas de controle a serem utilizadas dependem muito de seu objetivo e área de aplicação. O controlador é uma peça fundamental da arquitetura de um veículo robótico submarino, e suas características (vantagens e desvantagens) representam um dos principais critérios na hora da escolha de qual veículo será empregado em uma missão (MOREIRA, 2004).

No desenvolvimento do trabalho foi criada uma estrutura por fases, que permite enfocar cada sistema separadamente. O desenvolvimento da pesquisa é seqüencial e com um processo cíclico para o aperfeiçoamento do controlador. A figura 1.3 apresenta a metodologia proposta especificamente para esta dissertação.

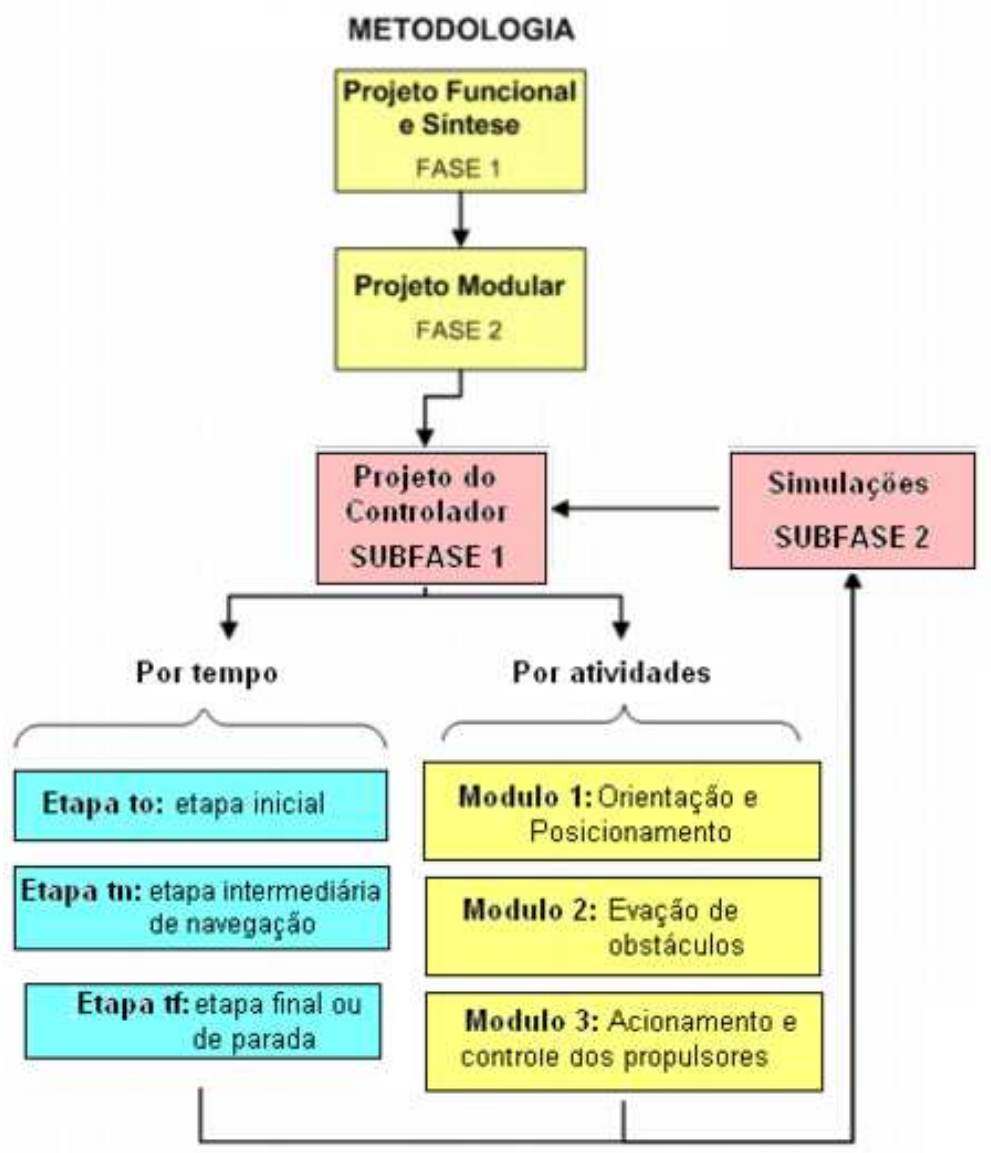

Figura 1.3: Metodologia do Projeto Controlador Neuro-Nebuloso. 


\subsubsection{Projeto Funcional e Síntese}

Nesta fase, é realizado o estudo e análise das técnicas de controle utilizadas em navegação de veículos submarinos, para determinar a técnica de controle mais adequada para o VSSA, sabendo-se que suas operações serão realizadas num ambiente completamente dinâmico.

No controle de veículos submarinos, em geral, são empregados controladores de tipo PID, onde os ganhos do controle são determinadas pela teoria de controle clássico usando como elementos os métodos de Lugar de Raízes, método de Bode ou o critério de estabilidade de Nyquist (NESLINE; WELlS; ZARCHAN, 1981), (NESLINE; NESLINE, 1984). A teoria de Controle Moderno é tema de pesquisa atual no projeto de controladores para a navegação de robôs submarinos, em especial a técnica linear quadrática (STALLARD, 1991), (LIN; CLOUTIER; EVERS, 1993), a técnica linear quadrática singular generalizada (LIN; LEE, 1985), técnica de controle robusto $H \infty$ (LIN, 1994), (DONHA; LUQUE, 2006) e a técnica de síntese $\mu$ (LIN, 1994).

O uso de sistemas de controle inteligente ou adaptativo se infiltrou na abordagem moderna. Características específicas do controle inteligente, como a capacidade de tomada de decisões, a adaptação a um meio incerto, a auto organização, planejamento e projeto de operações (CHUN-LIANG; HUAT-WEN, 1999), que dão grande flexibilidade ao controlador, têm favorecido o uso desta alternativa em diversas aplicações. Por outro lado, para o projeto da maioria dos controladores freqüentemente se presume a existência de um modelo matemático na formulação do problema, e a informação é apresentada de uma maneira descritiva.

O controle inteligente é uma tecnologia de controle que procura simular a tomada de decisões da mente humana, planejando estratégias de controle e no aprendizado de novas funções. Redes neurais, a lógica nebulosa é os algoritmos genéticos formam o tripé básico desta abordagem e são ferramentas poderosas para aplicações em engenharia de controle inteligente.

A complexidade na navegação submarina parece ser um problema adequado para a aplicação da técnicas de controle inteligente. Escolhida a técnica de controle é possível começar o trabalho de análise dos fatores que apresentam maior influência na movimentação do robô. Os principais fatores que afetam na navegação do VSSA são (DAí-JU; XINOGUANG, 2002):

- O ambiente em que se desenvolvem as tarefas;

- Os obstáculos fixos e móveis do ambiente;

- O sistema sensorial do veículo e

- O seu sistema propulsor. 
No final desta fase a aplicação estará devidamente analisada e dividida, a técnica de controle a ser utilizada bem definida, e todos os arquivos necessários para a execução do projeto modular estarão disponíveis.

\subsubsection{Projeto Modular}

Esta fase é composta por duas subfases, que desenvolvem o projeto do controlador, a avaliação e aperfeiçoamento do mesmo, as quais são apresentadas nos capítulos 4 e 5 . Esta fase é realizada depois de se concluir o "Projeto Funcional e Síntese".

\subsubsection{Projeto do Controlador}

Aqui realiza-se o desenvolvimento da lógica do controlador. Para reduzir o grau de complexidade de desenvolvimento, esta subfase foi divida em tarefas denominadas "etapas" e "módulos", as quais enfocam sistemas mais restritos em função do tempo em que são executas as ações de controle e pelas atividades que o controle executa, conforme ilustrado na figura 1.3.

A etapa inicial (Etapa $t_{0}$ ) do controlador, consiste na aquisição de dados e sinais, pelo sistema sensorial do VSSA no instante que é colocado na água. O sistema de sensores está constituído por sonares, bússolas, giroscópios e sensores inerciais que provê informação sobre o ambiente, como obstáculos, a pressão local e a velocidade da água e informações sobre o próprio veículo, como sua orientação, posicionamento e velocidade. Essas informações são enviadas ao controlador nebuloso que as manipula e de acordo com regras nele implantadas é determina a forma de atuação dos propulsores para realizar uma determinada tarefa.

\subsubsection{Simulações (Avaliação do Projeto Controlador)}

A implementação do controlador é avaliada com a utilização de ferramentas de simulação computacional como o MatLab Fuzzy Logic Toolbok e Simulink. A análise das regras, funções de pertinência e a lógica implementada, determina o grau de desempenho que atinge o controlador. O processo cíclico e de realimentação desta subfase permite redefinir ou refinar toda a lógica do controlador na busca de um melhor desempenho. 


\subsection{Estrutura do Trabalho}

A seguir, descreve-se a estrutura e o conteúdo dos capítulos desta dissertação de mestrado:

\section{- Capítulo 1: Introdução}

Neste capítulo, o problema de controle dos VSSA é contextualizado. São descritos os objetivos, a motivação, o estudo do caso, o escopo, a estrutura e a metodologia da pesquisa. Além disso, o conteúdo dos capítulos seguintes é brevemente descrito.

\section{- Capítulo 2: Lógica Nebulosa e Controladores Nebulosos}

É apresentada a relevância e o desenvolvimento da lógica nebulosa no tipo de problemas tratado, que com apoio dos algoritmos adaptativos, torna o projeto de controle robusto e eficiente. Este capítulo é importante para o entendimento dos capítulos subseqüentes, já que dá uma visão detalhada das ferramentas estudadas para o desenvolvimento do controlador proposto.

- Capítulo 3: Descrição e Instrumentação do Veículo Submarino SemiAutônomo (VSSA)

Neste capítulo apresentam-se as principais características físicas e dinâmicas do VSSA da EPUSP, que se divide em duas partes: características gerais do VSSA e sistema de sensores. São mostrados, os sub-sistemas e a arquitetura de controle para o desenvolvimento do projeto de controlador.

\section{- Capítulo 4: Fundamentos do Controlador}

Neste capítulo analisam-se e apresentam-se os conceitos sobre os planos de operação de um robô submarino assim como os modos de navegação para finalmente definir os parâmetros do projeto que serão utilizados no projeto do controlador.

\section{- Capítulo 5: Síntese do Controlador Modular no VSSA Via Lógica Nebulosa}

Neste capítulo desenvolve-se a implementação do controlador Nebuloso. No princípio se descreve a estratégia de controle, para depois desenvolver o módulo de orientação e posicionamento, o módulo que trata a evasão de obstáculos e o módulo de navegação e controle de propulsores controladores. Neste capitulo são criadas as regras, funções de pertinência e toda a lógica do controlador nebuloso. 
- Capítulo 6: Estudos de Casos do Projeto Controlador do VSSA e Análise de Resultados

Neste capítulo, avalia-se o desempenho do controlador através de simulações numéricas, onde se utiliza um modelo matemático simplificado para simular os movimentos controlados do VSSA. Os movimentos do VSSA, são divididos em 3 partes, analisado-se cada caso.

\section{- Capítulo 7: Considerações Finais}

São apresentadas as conclusões do trabalho, fazendo uma avaliação geral da pesquisa, dos resultados alcançados e das dificuldades encontradas e finalmente é apresentado sugestões para trabalhos futuros. 


\section{Lógica Nebulosa e Controladores Nebulosos}

Um sistema adaptativo é aquele cuja estrutura é alterável ou ajustável, de tal forma que seu comportamento e desempenho melhore, de acordo algum critério desejado e com a exposição ao ambiente na qual está inserido (FRANCO; CASTRO, 2001).

Entre as aplicações adaptativas da teoria inteligente estão: a Lógica Nebulosa, as Redes Neurais Artificiais (RNAs) e os Algoritmos Genéticos que constituem três temas independentes de pesquisa (KUO; WU; WANG, 2000).

A Lógica Nebulosa, as Redes Neurais Artificiais e Algoritmos Genéticos têm sido utilizados para resolver problemas bastante complexos, mas mesmo assim, ainda não chegaram perto de resolver problemas tão complexos quanto seus equivalentes biológicos (raciocínio humano, redes neurais biológicas e sistemas genéticos). Para tentar melhorar o desempenho destas técnicas, elas têm sido combinadas para que se possam corrigir as falhas em uma técnica com as capacidades das outras (AZEVEDO, 1999). Estes sistemas procuram fornecer respostas que solucionam problemas, de forma apropriada às situações específicas destes problemas, mesmo sendo novas ou inesperadas (SHAW; SIMÕES, 1999).

A capacidade criativa dos seres humanos, de raciocinar de maneira incerta ou nebulosa contrasta com a forma de operar de computadores e máquinas, regidos por raciocínio binário e preciso (BAUCHSPIESS, 1995). No momento em que estas máquinas transcenderem esta restrição se tornarão inteligentes, podendo raciocinar de forma nebulosa. Esta forma de raciocínio é conhecida em inglês por "Fuzzy", tendo como tradução em português para "nebuloso" ou "difuso". O Controle "Fuzzy", então, procura incorporar a forma humana de pensar em sistemas de controle. Os controladores obtidos têm uso em sistemas dinâmicos complexos, de comportamento não-linear. (MELO; GOSMANN; BAUCHSPIESS, 2002).

A lógica nebulosa além de reconhecer os valores de verdadeiro e falso, representa estes valores com graus de veracidade ou falsidade. Por exemplo: a frase "hoje é um dia ensolarado", pode ser $100 \%$ verdade se não há nuvens, $80 \%$ verdade se há poucas nuvens, $50 \%$ verdade se há neblina e $0 \%$ se chove todo o dia. 


\subsection{Teoria de Conjuntos Nebulosos}

A teoria dos conjuntos nebulosos quando utilizada em um contexto lógico, como nos sistemas baseados em conhecimento, é conhecida como lógica nebulosa, lógica difusa ou lógica fuzzy. A lógica nebulosa (Fuzzy Logic) é uma ferramenta capaz de capturar informações vagas, em geral descritas em uma linguagem natural, e convertê-las para um formato numérico de fácil manipulação pelos computadores atuais.

A teoria dos conjuntos nebulosos foi desenvolvida a partir dos trabalhos de Zadeh (1965) para tratar o aspecto vago da informação. A partir de 1978, Zadeh desenvolveu a teoria das possibilidades que trata a incerteza da informação, podendo ser comparada com a teoria de probabilidades. Esta teoria, por ser menos restritiva, é considerada mais adequada para o tratamento de informações fornecidas por seres humanos que a de probabilidades (FREIRE, 2005).

Segundo Jang e Sun (1995), a teoria de conjuntos nebulosos permite o tratamento de conceitos vagos, imprecisos, incertos e de conhecimento mal definido, proporcionando uma nova visão além da matemática exata.

Os conjuntos clássicos definem-se num predicado que gera uma clara divisão no Universo de Discurso X entre os valores "Verdadeiro" e "Falso". No entanto, o raciocínio humano utiliza freqüentemente predicados que não são parte desta divisão, denominados de predicados vagos.

Por exemplo, se o Universo de Discurso está formado pelas temperaturas ambientais possíveis na cidade de São Paulo, pode se definir o conjunto nebuloso A formado pelas temperaturas "altas". Mesmo assim, é impossível dar ao conjunto A uma definição clássica, pela razão que seu predicado não divide o Universo de Discurso X em duas partes claramente diferenciadas. Não se pode dizer que uma temperatura é "alta" ou não é, com total certeza. O problema poderia se resolver parcialmente considerando uma temperatura "alta" quando o valor desta temperatura ultrapassasse um valor limite definido com antecedência. Disse-se que o problema é só resolvido parcialmente por duas razões: a primeira é que o limite definido é estabelecido arbitrariamente; e segundo, poderia acontecer que duas temperaturas com valores muito diferentes seriam consideradas "altas" só pelo fato de ultrapassar o limite. O que demostra que o termo "alta" assim definido, gera uma informação muito imprecisa sobre a temperatura ambiental.

O método apropriado para dar uma solução para este problema é considerar que a pertinência ou a não pertinência de um elemento x ao conjunto A não é absoluta, mas gradual, com o que se define o conjunto A como um conjunto nebuloso. 


\subsubsection{Funções de Pertinência da Lógica Nebulosa}

Ao contrário dos conjuntos clássicos, representados por um intervalo definido, os conjuntos nebulosos possuem um intervalo entre $[0,1]$, indicando assim um grau de pertinência.

Um conjunto nebuloso $A$ do universo de discurso X é definido por uma função de pertinência por $\mu_{A}: X \longrightarrow[0,1]$. Essa função associa a cada elemento $x$ de $X$, o grau $\mu_{A}(x)$ com que $x$ pertence a $A$ (SHAW; SIMÕES, 1999). Ou formalmente:

$$
A=\left\{\left(x, \mu_{A}(x)\right), \forall x \in X\right\} \quad \text { ou } \quad \mu_{A}(x): x \rightarrow[0 \quad 1]
$$

A função de pertinência $\mu_{A}(x)$ indica o grau de compatibilidade entre x e o conceito expresso por A:

- $\mu_{A}(x)=1$ indica que $x$ é completamente compatível com $A$;

- $\mu_{A}(x)=0$ indica que $x$ é completamente incompatível com $A$;

- $0<\mu_{A}(x)<1$ indica que $x$ é parcialmente compatível com $A$, com grau $\mu_{A}(x)$.

A função de pertinência é definida arbitrariamente, o que tornam flexíveis os conjuntos nebulosos. Por exemplo, pode-se concordar que o grau de pertinência de uma temperatura de $45^{\circ} \mathrm{C}$ para o conjunto A é 1 , o de $25^{\circ} \mathrm{C}$ é 0,4 , o de $6^{\circ} \mathrm{C}$ é 0 , etc. Com isso, quanto maior o valor da temperatura, maior seu grau de pertinência ao conjunto A

\subsubsection{Tipos de Funções de Pertinência}

Uma função de pertinência é uma função numérica, gráfica ou tabulada, que atribui valores de pertinência para valores discretos de uma variável, dentro de seu universo de discurso, o qual representa o intervalo numérico de todos os valores possíveis que uma variável pode assumir.

As funções de pertinência assumem diversas formas, sendo as mais utilizadas a triangular, a trapezoidal e a gaussiana, formalmente descritas e ilustrada na figura 2.1.

\begin{tabular}{|l|l|l|l|l|}
\hline Triangular & Retangular & Trapezoidal & Gaussiana & Sigmóide \\
\hline N & & & \\
\hline
\end{tabular}

Figura 2.1: Funções de Pertinência Nebulosas. 
Segundo Jang e Sun (1995), as funções de pertinência permitem que se definam os conjuntos nebulosos, a função de pertinência associada e seus respectivos valores. Os conjuntos podem possuir qualquer nome, desde que sejam diferentes entre si.

1. Função Triangular: esta função utiliza três parâmetros (a,b,c), mais a variável de entrada a ser fuzzificada;

$$
\operatorname{Triangular}(x ; a, b, c)=\max \left(\min \left(\frac{(x-a)}{(b-a)}, \frac{(c-x)}{(c-b)}\right), 0\right)
$$

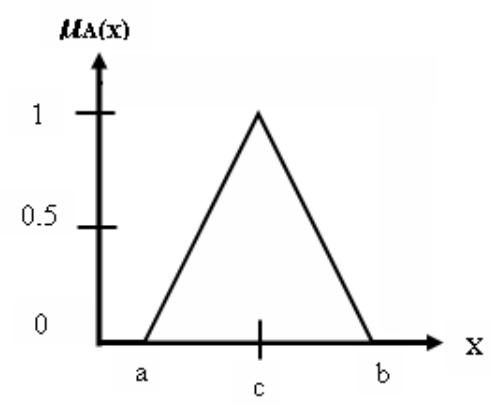

Figura 2.2: Função Triangular.

2. Função Trapezoidal: esta função utiliza quatro parâmetros (a,b,c,d), mais a variável de entrada a ser fuzzificada;

$$
\text { Trapezoidal }(x, a, b, c, d)=\max \left(\min \left(\frac{(x-a)}{(b-a)}, 1, \frac{(d-x)}{(d-c)}\right), 0\right)
$$

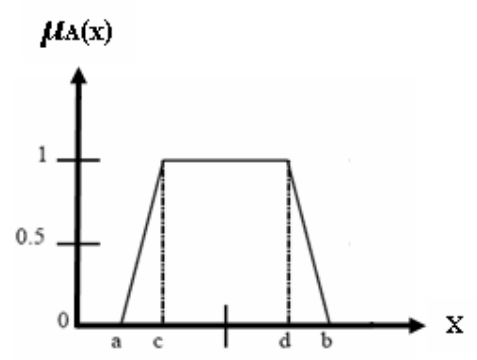

Figura 2.3: Função Trapezoidal.

3. Função Gaussiana: pode ser representada da seguinte forma:

$$
B(x, \gamma, \beta)=\frac{1}{1+\left(\frac{x-\gamma}{\beta}\right)^{2}}
$$

Onde: $\gamma$ é o valor central da curva e $\beta$ se define quanto o meio da curva está afastado do centro. 


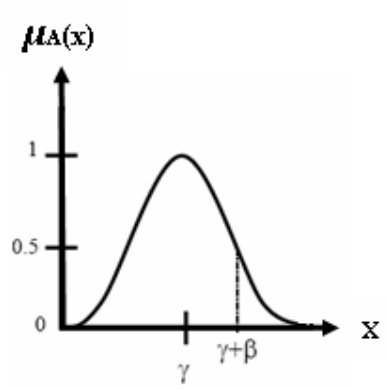

Figura 2.4: Função Gaussiana.

A quantidade de funções de pertinência e seus formatos, a ser utilizadas em um universo de discurso são geralmente baseados na experiência. Apesar disso, algumas indicações práticas podem ser utilizadas:

- O número de funções de pertinência deve variar entre 2 e 7. Quanto maior o seu número, maior a precisão mas também maior o custo computacional.

- Recomenda-se o formato das funções de pertinência como triangular ou trapezoidal. Caso seja necessário um comportamento mais suave do sistema, devem ser utilizadas funções como a gaussiana ou a sigmóide.

- A precisão do sistema é dependente do grau de superposição entre as funções de pertinência. Geralmente, aconselha-se para testes iniciais 50\% de superposição, para o sistema otimizado um mínimo de $25 \%$ e um máximo de $75 \%$ de superposição em sistemas de malha fechada.

- Caso haja dados experimentais, é possível utilizar sistemas neuro-nebulosos para gerar automaticamente as funções de pertinência.

- As funções de pertinência devem preferivelmente abranger todo o universo de discurso da variável analisada.

\subsubsection{Operações em Conjuntos Nebulosos}

As operações básicas de conjuntos clássicos podem ser representadas na forma de conjuntos nebulosos, conforme à tabela 2.1 (ZEMANKOVA-LEECH; KANDEL, 1984) (JANG; SUN, 1995). 
Tabela 2.1: Operações Básicas de Conjuntos

\begin{tabular}{|l|c|c|}
\hline União (disjunção) & $\mathrm{A} \cup \mathrm{B}$ & $\max \left(\mu_{A}(x), \mu_{B}(x)\right)$ \\
\hline Intersecção (conjunção) & $\mathrm{A} \cap \mathrm{B}$ & $\min \left(\mu_{A}(x), \mu_{B}(x)\right)$ \\
\hline Complemento (negação) & $\neg \mathrm{A}$ & $1-\mu_{A}(x)$ \\
\hline
\end{tabular}

O uso desses operadores permite determinar o grau de pertinência de cada ponto em relação a um conjunto nebuloso, onde um valor perto de 0 (zero) significa que o valor não pertence ao conjunto, e valor próximo de 1 (um) significa que o valor pertence àquele conjunto. Desta maneira, um item pode ou não pertencer a um conjunto.

\subsubsection{Variáveis Lingüísticas (Hedges Lingüísticos)}

A lógica nebulosa é representada mediante termos lingüísticos como numa linguagem natural. Utiliza-se o conceito de qualificadores de conjuntos nebulosos, chamados de hedges, para mudar a forma dos conjuntos nebulosos, permitindo a utilização de conceitos expressivos. Tem-se, por exemplo, como variáveis lingüísticas os termos: mais rápido, rápido, devagar, muito devagar (KLIR; YUAN, 1995).

Uma variável lingüística pode ser definida por uma quádrupla $(\mathrm{N} ; \mathrm{X} ; \mathrm{T}(\mathrm{x}) ; \mathrm{M})$, onde $\mathrm{N}$ é o nome da variável, $\mathrm{X}$ é o universo de discurso de $\mathrm{x}, \mathrm{T}(\mathrm{x})$ é um conjunto de nomes para valores de $\mathrm{x}$, e M é uma função que associa uma função de pertinência a cada elemento de $\mathrm{T}(\mathrm{x})$.

Chamam-se de termos lingüísticos, indistintamente, tanto os elementos de $\mathrm{T}(\mathrm{x})$ quanto suas funções de pertinência. A figura 2.5 ilustra a variável lingüística velocidade com os termos nebulosos dados por: Negativa Alta; Negativa Baixa; Zero; Positiva Baixa; Positiva Alta.

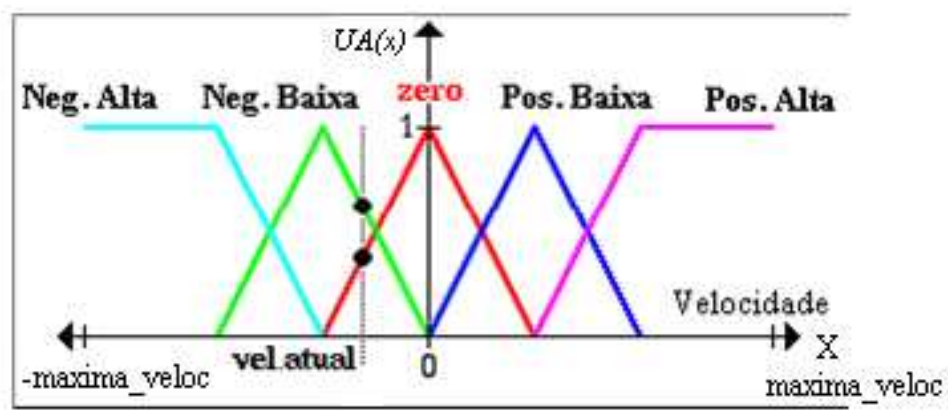

Figura 2.5: Termos Lingüísticos Mapeiam a Variável Velocidade.

A lógica nebulosa descreve propriedades que têm variação contínua de valores, associando partes desses valores de um modo semântico, sendo que essas partes podem criar um conjunto 
de intersecção, que vai conter alguns valores e que correspondem à transição de um estado para outro (KRUSE; KLAWONN; NAUCK, 1992).

\subsection{Controladores Nebulosos}

A lógica nebulosa é uma das tecnologias atuais bem sucedidas para o desenvolvimento de sistemas para controle de processos sofisticados. Com sua utilização, requerimentos complexos podem ser implementados em controladores simples, de fácil manutenção e baixo custo. $\mathrm{O}$ uso de sistemas construídos desta maneira, chamados de controladores nebulosos, são especialmente interessantes quando o modelo matemático está sujeito a incertezas ou não-linearidades (FREIRE, 2005).

As técnicas de controle nebuloso originaram-se com as pesquisas e projetos de Mamdani (MAMDANI, 1975) e ganharam espaço como área de estudo em diversas instituições de ensino, pesquisa e desenvolvimento do mundo, sendo hoje uma importante aplicação da teoria dos conjuntos nebulosos (FREIRE, 2005).

Ao contrário dos controladores convencionais em que o algoritmo de controle é descrito analiticamente por equações algébricas ou diferenciais, por meio de um modelo matemático, no controle nebuloso a estratégia de controle é descrita por meio de regras lingüísticas, com a intenção de descrever numa rotina a experiência humana, intuição e heurística para controlar um processo (SANDRI; CORREA, 1999).

Para o desenvolvimento de um controlador nebuloso, é necessário ter claras as partes em que ele se divide, como se apresenta na figura 2.6 e figura 2.7 :

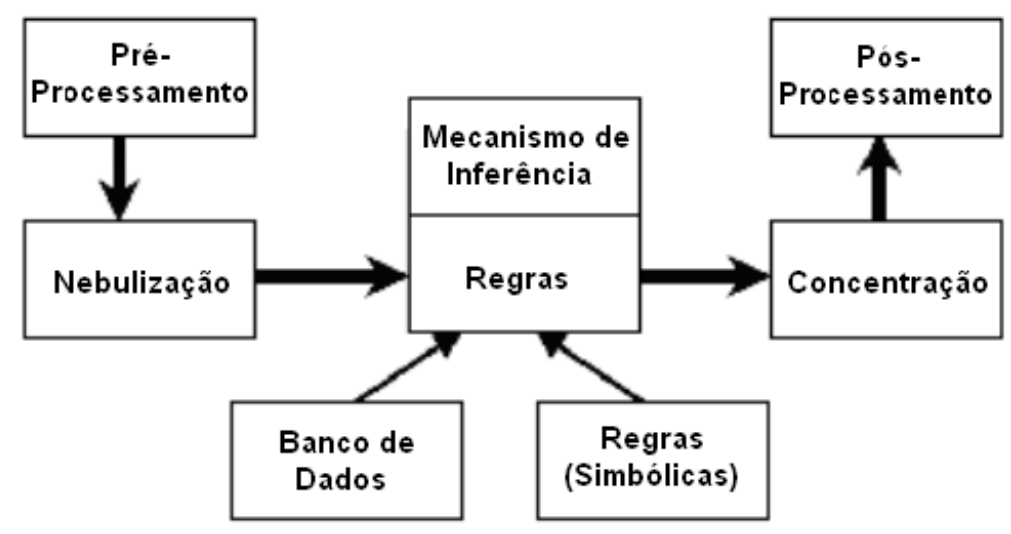

Figura 2.6: Fluxo do Controlador Nebuloso. 


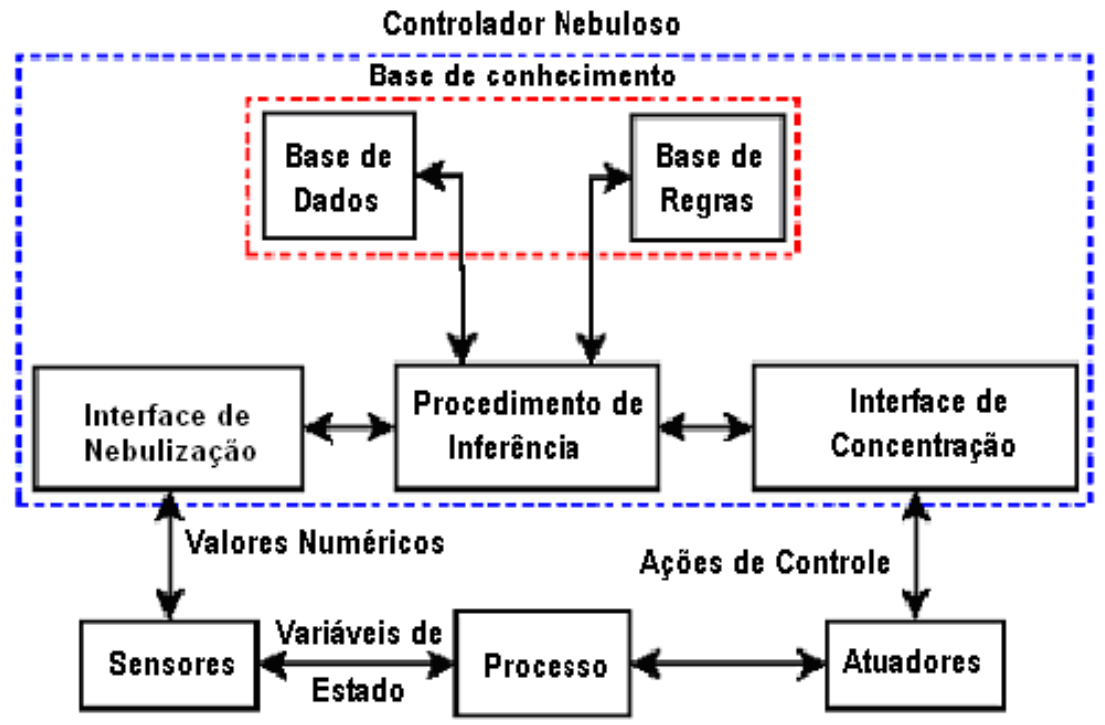

Figura 2.7: Estrutura do Controlador Nebuloso.

Em geral, um controlador nebuloso é composto dos seguintes blocos funcionais:

- Interface de nebulização ou fuzzificação;

- Base de conhecimento (regras);

- Sistema de inferência;

- Interface de concentração ou defuzzificação.

\subsubsection{Interface de Nebulização}

A nebulização ou fuzzificação descreve o grau de parentesco num conjunto nebuloso. Este grau de parentesco pode ser visto como um nível de compatibilidade entre uma instância ou valor do domínio de um conjunto (ZEMANKOVA-LEECH; KANDEL, 1984). Já para MENDEL (1995), a interface de nebulização faz a identificação dos valores das variáveis de entrada, as quais caracterizam o estado do sistema (variáveis de estado), e as normaliza em um universo de discurso padronizado. Estes valores são então nebulizados, com a transformação da entrada concentrada (crisp) em conjuntos nebulosos para que possam se tornar instâncias de variáveis lingüísticas.

A nebulização é o mapeamento do domínio de Valores Numéricos (VN) reais (como valores obtidos de um sensor) para Valores Nebulosos (VF), definidos pelas funções de pertinência. Como pode ser visto na figura 2.8, o valor nebuloso para a variável $X$ é dado por 0,3 para a função $M$ e por 0,7 para $L$. 


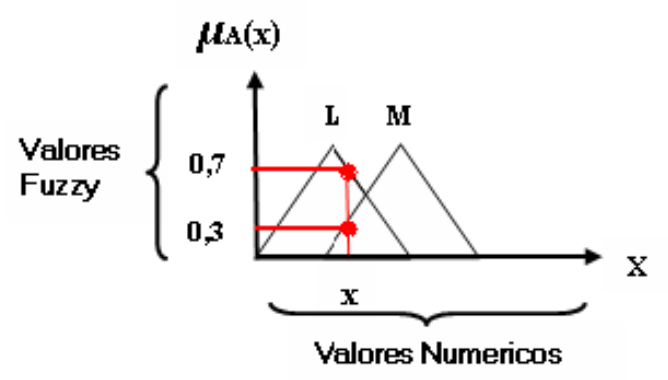

Figura 2.8: Nebulização de Valores Numéricos.

\subsubsection{Base de Conhecimento}

A base de conhecimento consiste de uma base de dados de regras, de maneira a caracterizar a estratégia de controle e suas metas. Na base de dados ficam armazenadas as definições sobre a concentração e a normalização dos universos de discurso, e as definições das funções de pertinência dos termos nebulosos.

\subsubsection{Regras}

A base de regras é formada por estruturas do tipo:

Se premissa Então conclusão

A base de regras armazena todo conhecimento sobre o assunto em forma de regras com um formato do tipo:

\section{Se x é A Então B}

Onde A e B são valores ou expressões lingüísticas definidas por conjuntos nebulosos com universos de discurso X e Y respectivamente. Freqüentemente, "x é A" é denominado premissa ou antecedente enquanto "y é B" é denominado conseqüente ou conclusão.

Essas regras, no campo simbólico e de planejamento, são regras lingüísticas, porém podem ser armazenadas de diferentes maneiras em um banco de dados ou em arquivos. Geralmente são armazenadas em forma de matrizes.

Exemplos de regras lingüísticas estão espalhados nas expressões lingüísticas usadas no dia a dia e a isso deve-se a isso sua enorme importância. Têm-se exemplos como:

Se Probabilidade de chuva é Negativa Grande e $\triangle$ Probabilidade de chuva é Positiva Pequena então Necessidade de Guarda-chuva é Positiva Pequena. 
Estas regras, juntamente com os dados de entrada, são processadas pelo procedimento de inferência, o qual infere as ações de controle de acordo com o estado do sistema, conforme o procedimento de inferência que será descrito na seção seguinte.

Em um dado controlador nebuloso, é importante que existam tantas regras quantas forem necessárias para mapear totalmente as combinações dos termos das variáveis, isto é, que a base seja completa, garantindo que exista sempre ao menos uma regra a ser disparada para cada entrada. Também são essenciais as consistências, onde procura-se evitar a possibilidade de contradições e inconsistências entre as regras gerenciadas pela função de implicação.

As premissas são relacionadas pelos conectivos lógicos, dados pelo operador de conjunção (e) e o operador de disjunção (ou). Em geral, as regras têm a forma de um sistema de Múltiplas Entradas e Múltiplas Saídas (MIMO), mas que pode ser transformado em vários sistemas com Múltiplas Entradas e uma Saída (MISO). Por exemplo, a regra MIMO:

$$
\begin{gathered}
\text { Se } x 1 \text { é } A 1 \text { e. . e e } x n \text { é } A n \\
\text { então } y 1 \text { é } C 1 \text { e. . e ym é } C m
\end{gathered}
$$

É equivalente a $\mathbf{m}$ regras MISO:

$$
\begin{gathered}
\text { Se } x 1 \text { é } A 1 \text { e } \ldots \text { e } x n \text { é } A n \\
\text { então } y_{j} \text { é } C_{j}
\end{gathered}
$$

Em geral, não se aceitam conectivos "ou" na conclusão.

Depois de disparar as regras, cada uma delas terá um grau de pertinência associado, este valor será então utilizado para calcular a saída desta regra da maneira como é mostrada na figura 2.9 (SANDRI; CORREA, 1999).

Se [entrada 1] é [valor] então [saída 1] é [valor]

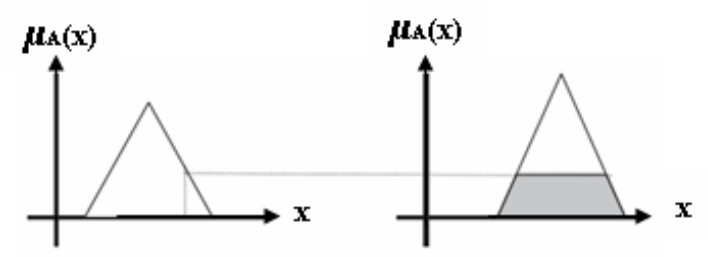

Figura 2.9: Mecanismo de Inferência.

No final tem-se um segmento de área como valor de saída para cada uma das regras disparadas. É necessário juntar essas saídas todas em um único valor para que seja concentrado e seja retornada uma resposta ao sistema. Existem 3 tipos de mecanismos de inferência para agrupar esses segmentos de área: Agregação, Ativação e Acumulação. 


\subsubsection{Agregação}

O resultado final será a união desses valores usando o operador AND como é mostrado na figura 2.10

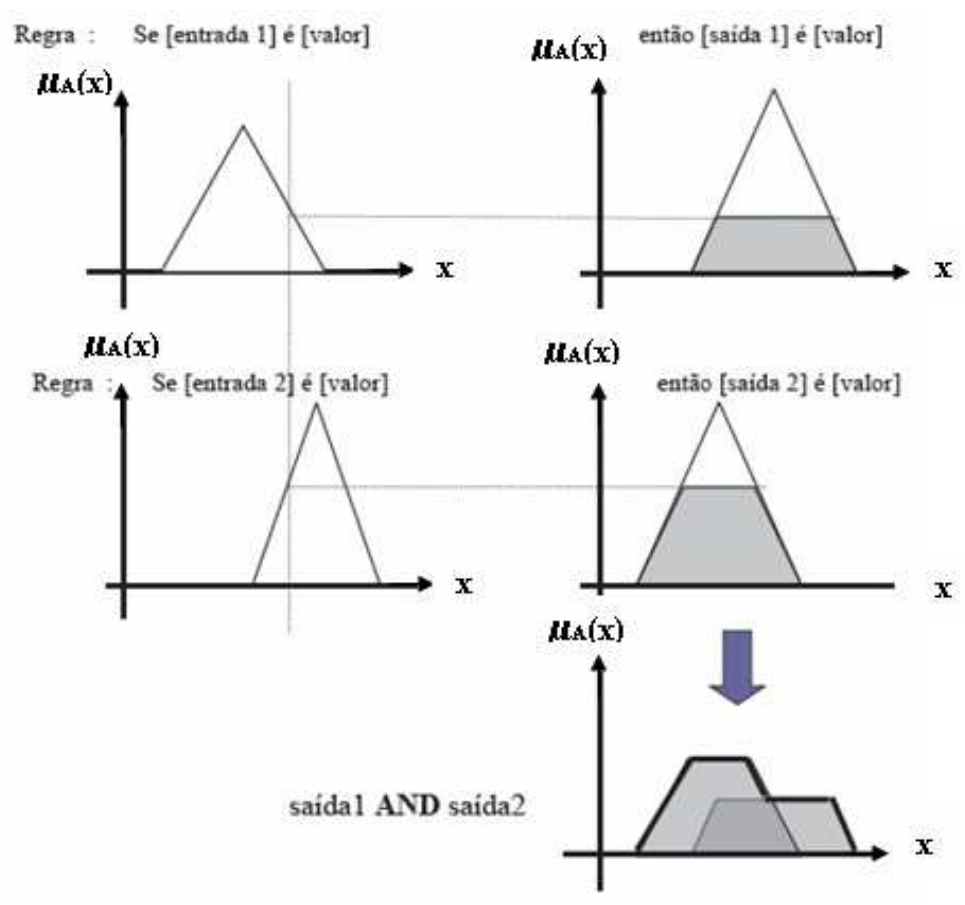

Figura 2.10: Mecanismo de Inferência : Agregação.

\subsubsection{Ativação}

O resultado final será o produto (interseção) desses valores usando o operador MIN. Para as regras no exemplo anterior ter-se-ia o valor final das regras como é mostrado na figura 2.11

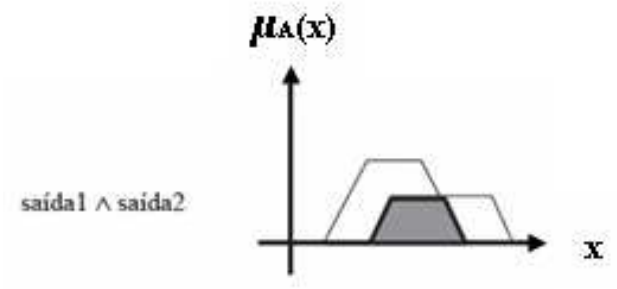

Figura 2.11: Mecanismo de Inferência : Ativação.

\subsubsection{Acumulação}

O resultado final será a soma de todos segmentos de área usando o operador MAX. No final todos segmentos em comum entre as áreas serão contados mais de uma vez como é mostrado 
na figura 2.12 a área resultante é bem maior que no caso da ativação.

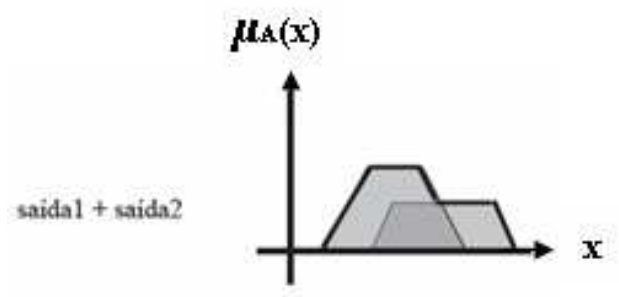

Figura 2.12: Mecanismo de Inferência : Acumulação.

\subsubsection{Interface de Concentração}

Na concentração o valor das variáveis lingüísticas de saída será traduzido para um valor numérico discreto, com o objetivo de obter-se o melhor valor que represente o valor desejado.

Nos controladores nebulosos a interface de concentração ou defuzzificação é utilizada para obter uma única ação de controle precisa, a partir do conjunto nebuloso. O procedimento compreende a identificação do domínio das variáveis de saída num correspondente universo de discurso e com a ação de controle nebulosa inferida evolui-se para uma ação de controle não nebulosa.

A seleção do método está diretamente relacionada com as características do processo controlado e o comportamento de controle necessário. Os métodos mais comumente empregados são os seguintes (TEIXEIRA, 2001):

\section{Centro da Gravidade (CG):}

Consiste na técnica do cálculo do centróide de figuras planas, este cálculo é baseado na região resultante da agregação de todas as regras. No método do centróide, o valor numérico retornado é calculado a partir da seguinte expressão:

$$
U_{C G}=\frac{\sum_{i=1}^{n} u_{i} \mu_{u}\left(u_{i}\right)}{\sum_{i=1}^{n} \mu_{u}\left(u_{i}\right)}
$$

Onde a somatória é tomada sobre os valores discretos dos universos de discurso de $u_{i}$, amostrados em $\mathrm{N}$ pontos. $\mu_{u}$ é o valor de pertinência para um dado valor de controle $u_{i}$, então o valor do controle $U_{C G}$ tem a propriedade de dividir a figura resultante da agregação em duas áreas iguais assim como se mostra na figura 2.13 


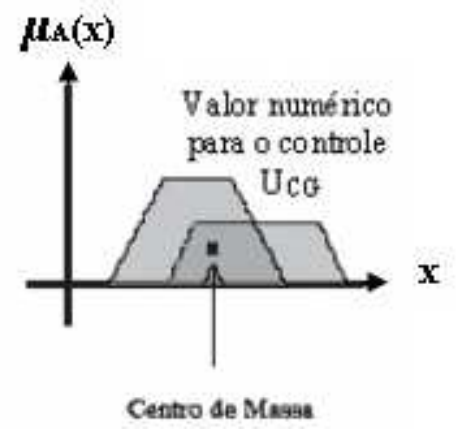

Figura 2.13: Concentração: Centro da Gravidade.

\section{Centro da Área ou Método do Centróide (CA):}

Este método considera a área obtida do conseqüente de cada regra, o método de concentração do centro da área é definida pela seguinte equação:

$$
U_{C A}=\frac{\sum_{i=1}^{N} u_{i} \sum_{k=1}^{n} \mu_{B k}\left(u_{i}\right)}{\sum_{i=1}^{N} \sum_{k=1}^{n} \mu_{B k}(u i)}
$$

Onde os valores discretos do universo de discurso de $u_{i}$, amostrados em $\mathrm{N}$ pontos para todas as n regras são tomados, $\mu_{B k}(u i)$ é o valor de pertinência para um valor do controle $u_{i}$ conseqüente da k-ésima regra. Como se mostra na figura 2.14, o valor do controle $U_{C A}$ é obtido somando-se os dois valores para os trapézios resultantes da agregação. Então, neste caso em que existem regiões comuns pelas duas regras, essa área utiliza o cálculo do centro da área por duas vezes.

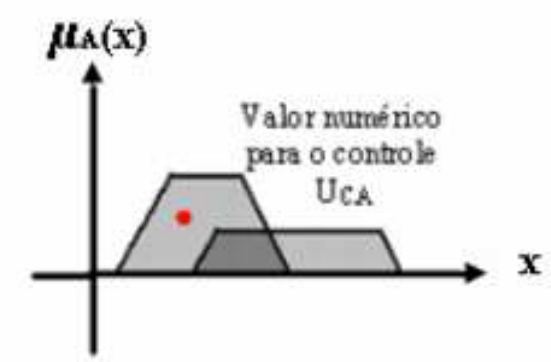

Figura 2.14: Concentração: Método do Centro da Área.

\section{Método da Média do Máximo (MM):}

Esta abordagem consiste em atribuir ao valor $U_{M M}$ de controle, o maior valor de pertinência da figura resultante da agregação das regras. Muitas vezes, no entanto, acontece que o máximo se encontre em mais de um ponto do universo de discurso, como se mostra na figura 2.15. Neste caso, o centro é calculado pela média de todos os valores de $u_{i}$, 
que possuem função de pertinência máxima, resultante da agregação de todas as regras. Esse método é definido pela seguinte equação:

$$
U_{M M}=\sum_{m=1}^{M} \frac{U_{m}}{M}
$$

Onde a somatória são todos os valores discretos do universo de discurso de $u_{i}$ amostrados em M pontos, $u_{m}$ são as maiores alturas que existem no conjunto resultante da agregação.

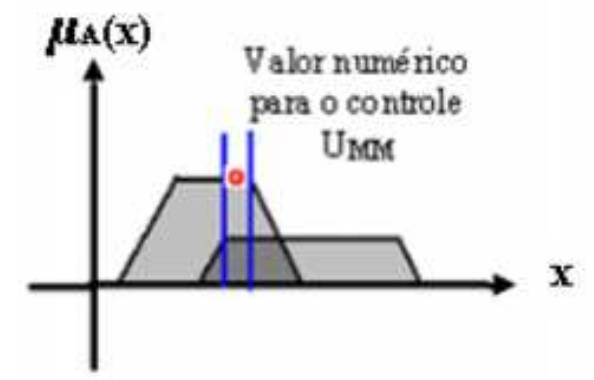

Figura 2.15: Concentração: Método da Média do Máximo.

Existem ainda outros métodos de concentração, apresentando diferenças em termos de velocidade e eficiência, características que devem ser analisadas em conjunto com os requisitos do projeto. (SANDRI, 1997) (GOMIDE; GUDWIN; TANSCHEIT, 1995) (GUERRA, 1998) (DRIANKOV; HELLENDOORN; REINFRANK, 1993)

\subsection{Tipos de Controladores Nebulosos}

Os tipos de controladores nebulosos encontrados na literatura são os modelos de Mamdani e de Larsen, e os modelos de interpolação, compreendendo o modelo de Takagi-Sugeno e o de Tsukamoto (DRIANKOV; HELLENDOORN; REINFRANK, 1993) (Lee (1990a, 1990b)).

Os modelos diferem quanto à forma de representação dos termos na premissa, quanto à representação das ações de controle e quanto aos operadores utilizados para implementação do controlador.

\subsubsection{Controle Nebuloso Clássico}

Nos modelos clássicos, a conclusão de cada regra aponta para um termo nebuloso dentre um conjunto fixo de termos (geralmente, o número de termos é menor que o número de regras). Estes termos são usualmente conjuntos nebulosos convexos como triângulos, gaussianas e trapézios. 
Estes conjuntos nebulosos representam uma ordenação no conjunto de ações de controle aceitáveis naquele momento. Finalmente, uma ação de controle global é selecionada dentre aquelas aceitáveis no processo de concentração.

\subsubsection{Modelos de Mamdani e de Larsen}

Foi proposto como a primeira tentativa de inferência nebulosa, para controlar um motor a vapor e uma caldeira, por meio de regras de controle lingüísticas obtidas a partir de especialistas humanos. Foram determinadas duas entradas x e y, e uma saída z como se mostra na figura 2.16 (SOUTO, 2005).

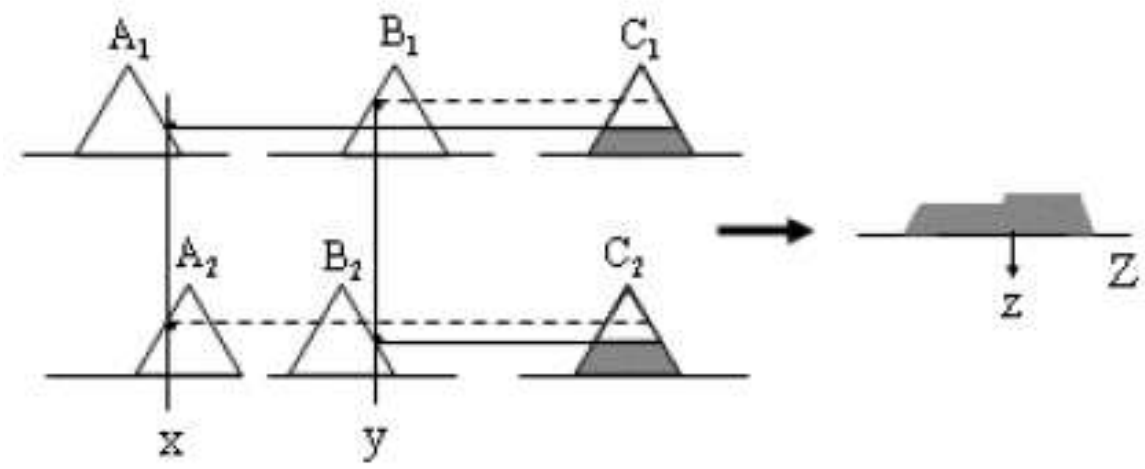

Figura 2.16: Sistema de Inferência Nebuloso de Mamdani Usando min e max Como Operadores AND e OR Respectivamente.

Note que no sistema de inferência Mamdani clássico, representado pela figura 2.16, quando as entradas estão relacionadas por arco do tipo AND, estas são mapeadas no conjunto de saída pela pertinência min das entradas. Enquanto que se as mesmas estiverem relacionadas por arco do tipo OR, serão mapeadas no conjunto de saída pela pertinência max das entradas.

Modificações do tipo de raciocínio empregado no trabalho original de Mamdani, são freqüentemente encontradas na literatura, como por exemplo: a utilização do produto e max como operadores AND e OR respectivamente, no lugar do min e max. De forma geral, estas estratégias são computacionalmente muito intensivas e não existe uma forma rigorosa de analisá-las, a não ser através de estudos experimentais. 


\subsubsection{Controle Nebuloso de Interpolação}

\subsubsection{Módelo Takagi-Sugeno-Kang}

Uma desvantagem dos modelos lingüísticos, por exemplo, o modelo de Mandani, é que os mesmos não contêm uma forma explícita do conhecimento objetivo sobre o sistema se tal conhecimento não puder ser expresso ou incorporado na estrutura do conjunto nebuloso. Uma alternativa é o uso do método de raciocínio de Takagi-Sugeno-Kang (TSK) que é associada com uma base de regras de formato especial com a parte conseqüente sendo funcional ao invés de nebulosa como usado nos modelos lingüísticos (YAGER, 1994). Com esse modelo de saída de um número real exato, o conjunto nebuloso concentrado de inferência será um conjunto nebuloso concentrado com um número finito de pontos, simplificando os cálculos envolvidos no processo computacional, elevando sua eficiência de processamento.

No modelo TSK as regras antecedentes descrevem regiões difusas no espaço de entrada (como no modelo lingüístico) e as regras conseqüentes são funções exatas do modelo de entradas, ou seja:

$$
\text { Se } x_{1} \text { é } A_{1} \text { e } \ldots \text { e } x_{n} \text { é } A_{n} \text { Então } y_{i}=f\left(x_{i}, \ldots, x_{n}\right)
$$

Onde, $A_{1}$ até $A_{n}$ são conjuntos difusos atingidos pelos respectivos valores físicos (exatos) $x_{1}$ até $x_{n}, y_{i}$ é $a$ i-ésima relação difusa devido a regra na relação acima e f normalmente representa uma combinação linear aplicada aos valores exatos.

Segundo Wang (1994), a saída do modelo TSK devido a r regras difusas solicitadas é a média ponderada:

$$
Y=\frac{\sum_{i=1}^{r} w_{i} y_{i}}{\sum_{i=1}^{r} w_{i}}
$$

Onde, $y_{i}$ é o resultado da saída da i-ésima regra e para $\mu$ denotando uma função de associação, os valores $w_{i}$ são:

$$
Y=\prod_{i=1}^{r} \mu_{A_{i}} x_{i}
$$

A vantagem do modelo TSK é sua capacidade em descrever sistemas complexos em subsistemas mais simples (em alguns casos até sistemas lineares). Um modelo esquemático dessas regras mostra-se na figura 2.17 : 


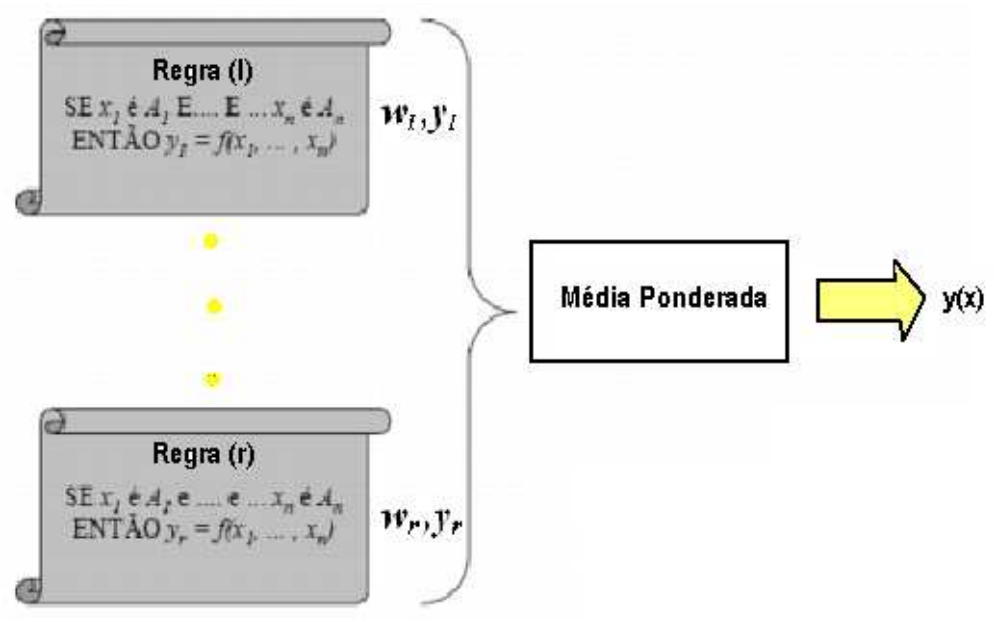

Figura 2.17: Configuração Básica de um Sistema TSK.

\subsection{Projeto de Controladores Nebulosos}

O desenvolvimento do projeto de sistemas de controle baseados em lógica nebulosa é um processo interativo, composto das seguintes etapas (GOMIDE R, 1992):

- Identificação das variáveis de entrada e saída do processo.

- Definição das partições de cada variável lingüísticas do sistema.

- Edição da base de regras nebulosas.

- Compilação da base de regras.

- Edição das funções de pertinência associadas a cada termo lingüístico previamente definido.

- Transferência da base de conhecimento (regras e funções de pertinência) do ambiente de desenvolvimento para o controlador nebuloso.

- Execução e depuração da base de conhecimento.

- Análise de desempenho do sistema.

- Alteração nas regras da base ou funções de pertinência, até o sistema atingir o desempenho desejado.

Alternativamente, o engenheiro de controle pode desenvolver heuristicamente as regras para o algoritmo nebuloso, através do conhecimento do sistema e do objetivo de controle desejado. O conhecimento profundo do funcionamento do sistema pode ser adquirido pela 
familiaridade com o protótipo de um sistema similar e/o uma apreciação intuitiva da resposta dinâmica do sistema. O objetivo de controle se define de uma percepção desejada do sistema e de uma resposta desejada que pode ser expressa em termos de um critério de domínio de tempo. (SUTTON; ROBERTS; DEARDEN, 1989)

O controlador nebuloso descrito na presente dissertação foi desenvolvido usando esta idéia, com o objetivo de controlar a navegação, profundidade e velocidade do VSSA, considerando a otimização e minimização do número de regras para o tempo de resposta, e melhorar o uso de recursos de processamento no controlador nebuloso sobre o sistema propulsor do VSSA.

Para este estudo foram escolhidas as funções de pertinência de forma trapezoidal e triangular para o desenvolvimento e implementação do controle nebuloso. Os níveis lingüísticos definidos são: Negativo grande (NG), Negativo Médio (NM), Negativo Pequeno (NP), Zero (Z), Positivo grande (PG), Positivo Médio (PM), Positivo Pequeno (PP).

Embora o controle convencional baseado em controladores PID e funções de transferência seja adequado para a maior parte das situações, as implementações por lógica nebulosa freqüentemente são mais eficientes, devido às seguintes características:

- O controle nebuloso nasce da experiência humana ao invés de modelos matemáticos dos fenômenos físicos, tornando uma implementação lingüística muito mais fácil e rápida de ser definida;

- Condições raras ou excepcionais no controle podem ser incorporadas com pouco custo computacional, permanecendo o sistema ainda transparente e compreensível;

- A implementação da lógica nebulosa é freqüentemente mais eficiente em termos de codificação e tempo de execução computacional. 


\section{Descrição e Instrumentação do Veículo Submarino Semi-Autônomo (VSSA)}

\subsection{Veículo Submarino Semi-Autônomo (VSSA)}

O veículo utilizado no estudo de caso deste trabalho, ilustrado na figura 3.1 foi desenvolvido pelos Laboratórios de Sensores e Atuadores do Departamento de Engenharia Mecatrônica da Universidade de São Paulo. É um sistema robótico semi-autônomo, projetado para atuar em grandes profundidades na recuperação de transponders em alto mar.

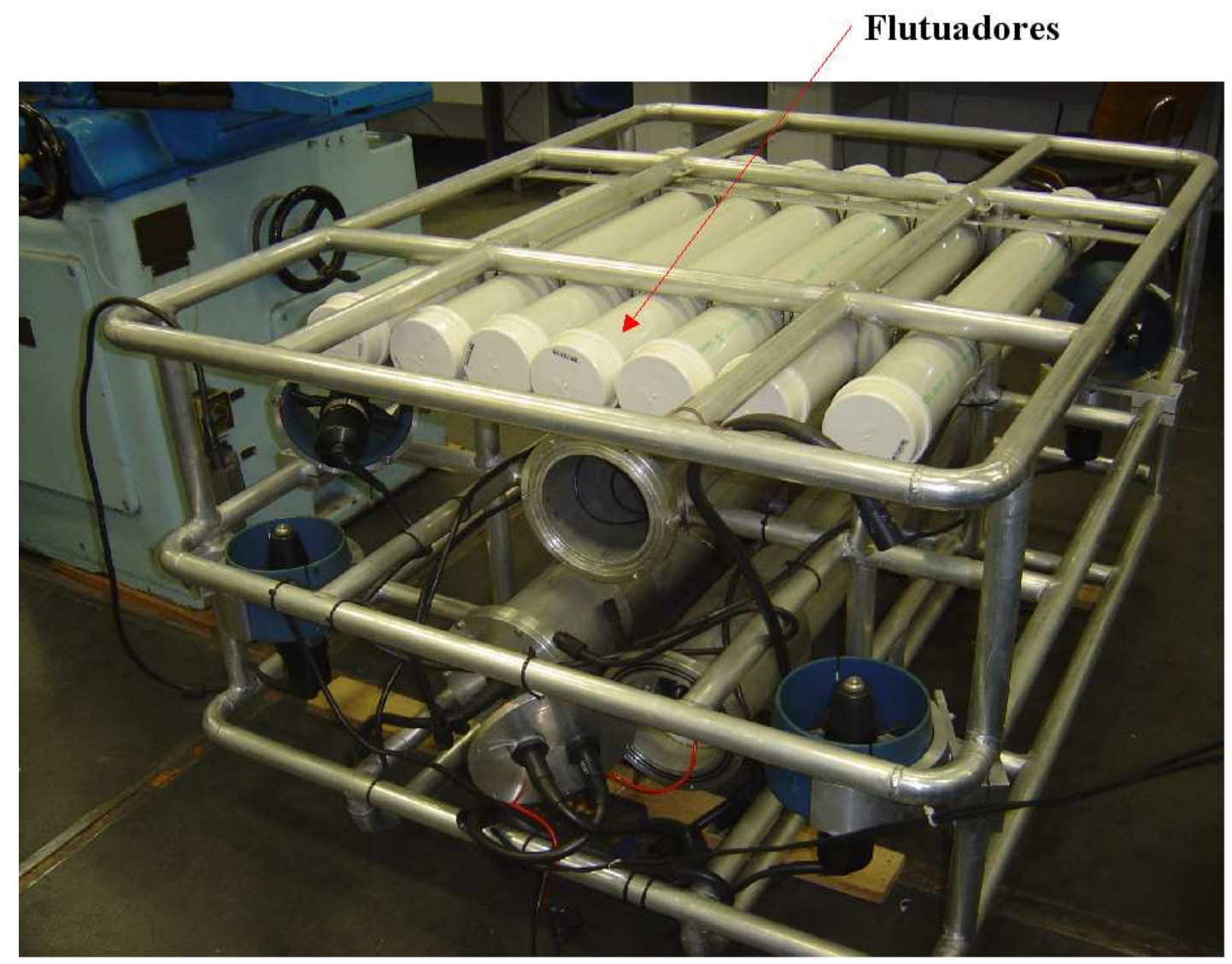

Figura 3.1: Protótipo do VSSA. 
Sua estrutura tubular de aço inoxidável tem a forma de gaiola, onde foram instalados os 8 propulsores responsáveis pela movimentação do veículo; sendo 4 propulsores utilizados para os movimentos no plano horizontal e outros 4 para os movimentos no plano vertical. O protótipo também está equipado com transdutores de ultra-som para seu posicionamento, assim como dois vasos de pressão para acondicionar a eletrônica de bordo e dois vasos para as baterias de alimentação, assim como disposto na figura 3.2.

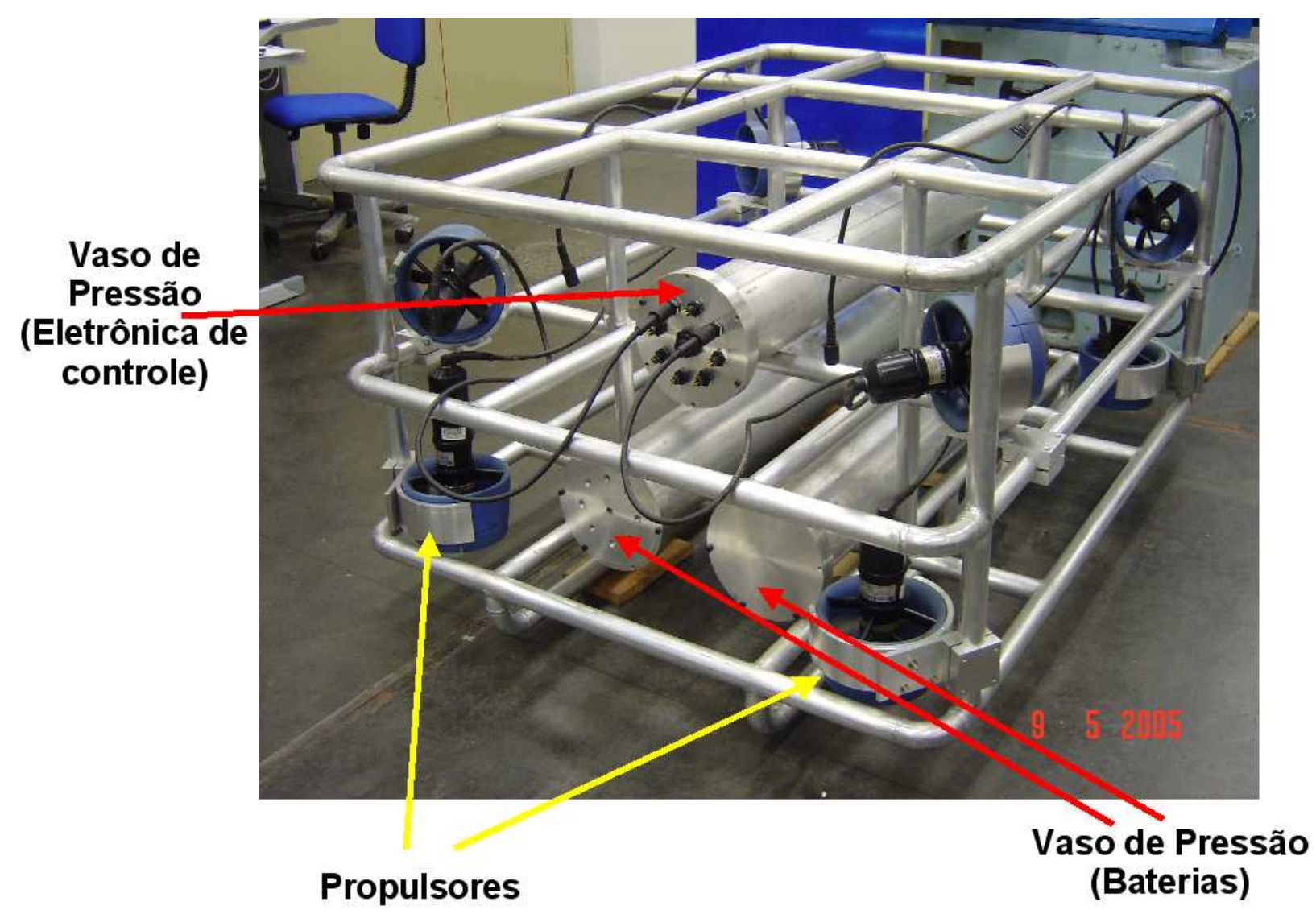

Figura 3.2: Configuração Estrutural do VSSA. 
O VSSA tem as características físicas descritas na tabela 3.1.

Tabela 3.1: Características Físicas do VSSA

\begin{tabular}{|c|c|}
\hline Estrutura mecânica & aberta tipo open frame \\
\hline Material: & Aço inoxidável AISI 316 \\
\hline Profundidade de operação: & 1000 m de profundidade \\
\hline Dimensões: & $\begin{array}{l}\text { 1,278 } \mathrm{m} \text { de comprimento } \\
1,114 \mathrm{~m} \text { de largura } \\
0,8 \mathrm{~m} \text { de altura. }\end{array}$ \\
\hline Massa: & $200 \mathrm{~kg}$ \\
\hline Volume: & $0,189 \mathrm{~m}^{3}$ \\
\hline Unidades de flutuação & $\begin{array}{l}7 \text { tubos PVC de } 1 \mathrm{~m} \text { de cumprimento } \\
\text { e } 0,1 \mathrm{~m} \text { de diâmetro }\end{array}$ \\
\hline Sistema de propulsão e governo & $\begin{array}{l}8 \text { propulsores: } \\
-4 \text { para movimento horizontal } \\
-4 \text { para movimento vertical }\end{array}$ \\
\hline Vasos de Pressão & $\begin{array}{l}3 \text { vasos de pressão de : } \\
1,055 \mathrm{~m} \text { de cumprimento } \\
1,65 \mathrm{~m} \text { de diâmetro } \\
\text { e } 8 \mathrm{~cm} \text { de espessura da parede } \\
\text { - } 2 \text { para baterias } \\
\text { - } 1 \text { para a eletrônica de controle }\end{array}$ \\
\hline Operação Autônoma & 3 horas \\
\hline
\end{tabular}

O VSSA é equipado com três vasos de pressão. Os dois vasos localizados na parte inferior da estrutura contêm 12 baterias de chumbo ácido conectadas em série fornecendo tensão de 156 Volts para a alimentação dos propulsores. A capacidade de carga do módulo de baterias é de 12Ah. O vaso de pressão localizado na parte superior da estrutura contém toda a eletrônica de controle do VSSA: sensores, PC-104, placas conversoras A/D e D/A, fonte de alimentação, e duas baterias conectadas em série $(24 \mathrm{~V})$ para a alimentação elétrica da eletrônica. Verificou-se experimentalmente que o módulo de baterias embarcado fornece energia elétrica suficiente para manter 3 horas de operação autônoma do VSSA.

Foi projetado um sistema de flutuação que permita garantir uma pequena flutuação positiva do VSSA. O empuxo total é obtido ao somar o empuxo de $50 \mathrm{kgf}$ produzido pelo sistema de flutuação e o empuxo de 150 kgf produzido pelo VSSA sem os flutuadores. Quando o VSSA está na água, seu peso total medido no ar (200 kgf) é equilibrado pelo empuxo total produzido. Os flutuadores foram colocados na sua parte superior para aumentar sua estabilidade. 
O Sistema de flutuação do veículo, mostrado na figura 3.1, é formado por um conjunto de sete tubos de PVC distribuídos simetricamente. As dimensões de cada flutuador são: 0,1m de diâmetro e $1 \mathrm{~m}$ de comprimento.

A tabela 3.2 apresenta as principais características eletro-eletrônicas do VSSA

Tabela 3.2: Características Eletro-eletrônicas do VSSA

\begin{tabular}{|l|l|}
\hline Computador embarcado & PC/104 \\
\hline Placas: & $\begin{array}{l}\text { Aquisição de dados; } \\
\text { placa de vídeo; } \\
\text { placa conversora digital - analógica } \\
\text { (A/D - D/A). }\end{array}$ \\
\hline Sensores e instrumentação & $\begin{array}{l}\text { Sensores de atitude: Bússola e inclinômetro, } \\
\text { sensores de pressão, acelerômetros, } \\
\text { giroscópio, sensores de ultra som. }\end{array}$ \\
\hline $\begin{array}{l}\text { Sistema de fornecimento } \\
\text { de } 12 \text { baterias de energia } \\
\text { para navegação (Propulsores). }\end{array}$ & $\begin{array}{l}\text { Chumbos ácidos de 156V. } \\
\text { A capacidade de carga do módulo } \\
2 \text { Baterias para o sistema } \\
\text { eletrônico }\end{array}$ \\
\hline
\end{tabular}

\subsubsection{Sistema de Aquisição de Dados}

A capacidade de sensoriamento é imprescindível para um robô operar em um ambiente completamente desconhecido, visto que não há informações prévias a respeito dos objetos presentes no ambiente. Além disso, mesmo que se disponha de informações prévias sobre o ambiente, devem-se considerar as possíveis mudanças na configuração do ambiente, o que praticamente obriga a fazer atualizações sucessivas das informações armazenadas, novamente usando as informações provenientes de sensores (SOUZA, 2003). São importantes também para conhecer o que está acontecendo no próprio VSSA.

No projeto do VSSA foram usados os seguintes sensores:

\section{Sistema Sensorial do Ambiente Exterior:}

- Sensores transdutores acústicos 


\section{Sistema Sensorial do Comportamento Interno:}

O sistema de navegação do VSSA está composto pelos seguintes sensores:

- Bússola,

- Inclinômetro,

- Medidor de pressão,

- Giroscópio.

A figura 3.3 mostra o módulo da eletrônica embarcada.

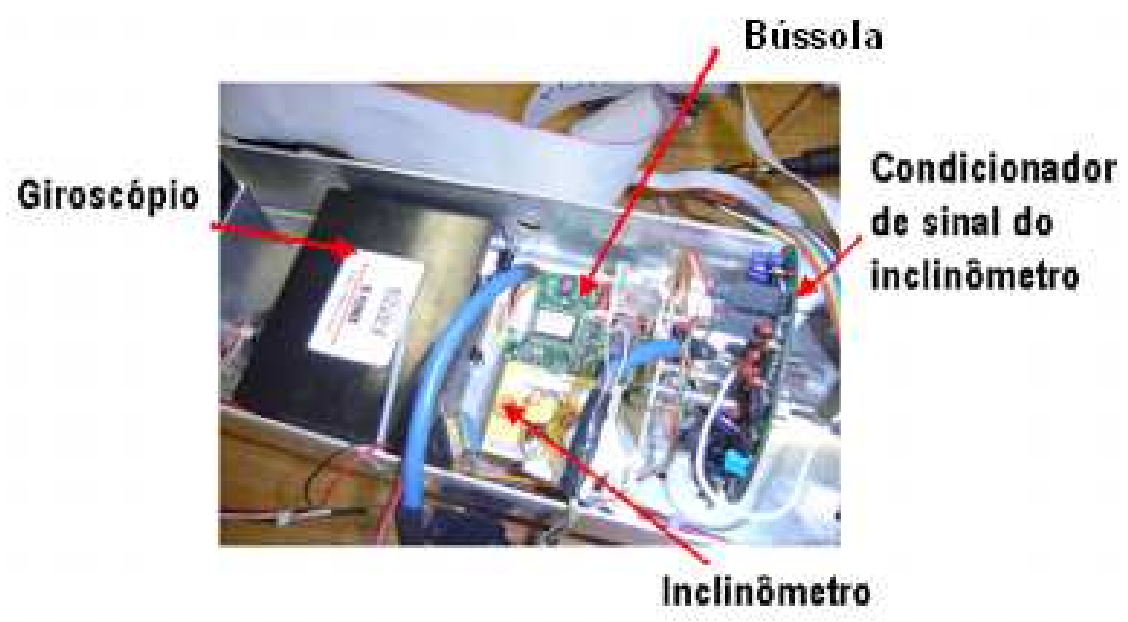

Figura 3.3: Sensores Embarcados no VSSA.

\subsubsection{Características de Operação dos Sensores Embarcados}

Inclinômetro: O inclinômetro tem 3 saídas analógicas: dois sinais para os ângulos de rotação em relação ao vetor de gravidade e um sinal para a temperatura. A aquisição dos sinais do inclinômetro é feita pelo PC-104 usando uma placa conversora A/D de padrão embarcado. Os sinais adquiridos são armazenados no disco rígido do PC-104. A placa A/D digitaliza o sinal com uma taxa de amostragem de $1670 \mathrm{~Hz}$.

Bússola: O sinal de saída da bússola do VSSA é em formato digital. Os dados de saída da bússola adquiridos pelo PC-104 são três: a orientação angular em relação ao norte magnético e duas rotações angulares em relação ao vetor de gravidade. A aquisição do sinal da bússola é feita através um canal de comunicação serial RS-232, em uma taxa de amostragem de $13 \mathrm{~Hz}$, sendo este valor o máximo que a bússola pode fornecer. 
Medidor de Pressão: O medidor de pressão do VSSA é um dispositivo que calcula a profundidade a partir da medição da pressão. O sensor de pressão usado é o tipo diferencial. A figura 3.4 é uma fotografia do medidor de pressão do VSSA.

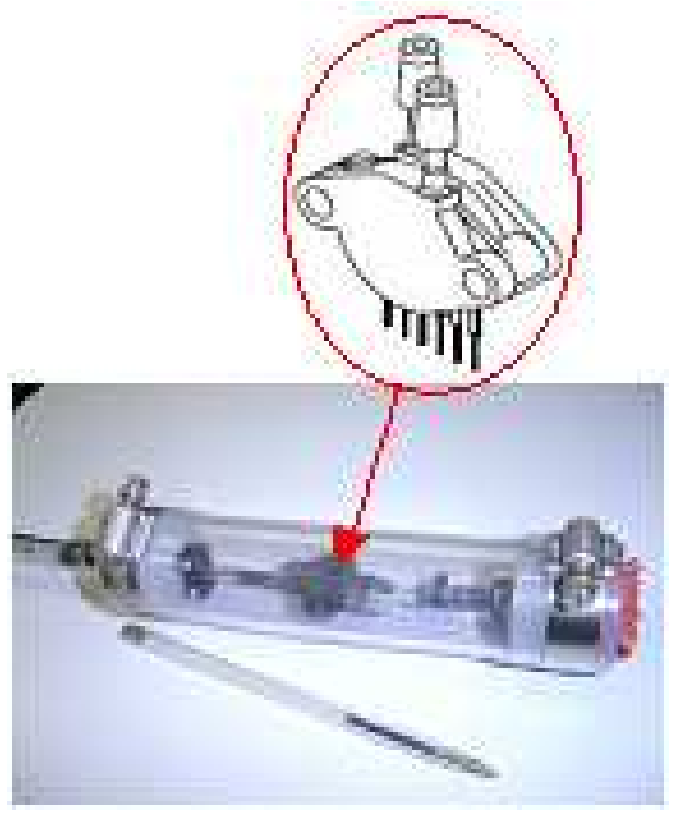

Figura 3.4: Representação do Sensor de Pressão.

O medidor de pressão tem as seguintes características:

- Capacidade de leitura: 0 - 100kPa ( 0 a 10m de coluna de água);

- Tensão de alimentação: $+5 \mathrm{~V}$;

- Tensão de saída: $0,2 \mathrm{~V}<$ Vout $<4,7 \mathrm{~V}$;

- Precisão $\pm 2,5 \%$ da tensão de saída de fundo de escala.

A seguinte equação modela a função de transferência do medidor de pressão

$$
V=0,4299 P+0,1799
$$

Onde: $V$ é tensão de saída do sensor [Volts], $P$ é profundidade em que se encontra o medidor de pressão $[\mathrm{m}]$.

\subsection{Subsistemas no Projeto do VSSA}

Os veículos submarinos por serem robôs autônomos ou com um grau de autonomia são unidades muito complexas por requererem o processamento de conjuntos muito diversificados de informação e o recrutamento adequado de recursos também muito variados. Estes podem 
ser arranjados nos seguintes subsistemas (SOUSA; PEREIRA; SILVA, 1994) (HEALEY; PASCOAL; PEREIRA, 1995).

- Energético: Efetua a administração e distribuição da energia disponível.

- Atuação: Controla os atuadores, determinando suas velocidades de rotação, que corresponde à referência gerada pelo sistema de pilotagem e controle.

- Suporte: Além da verificação do estado inicial e a monitoração contínua do veículo, este subsistema tem como objetivo detectar falhas de "hardware" e erros de comportamento, além de promover a recuperação das falhas correspondentes. Neste contexto, este subsistema identificará comportamentos que degradem a execução da missão ou ativará ações reflexivas para evitar a perda do veículo.

- Navegação: Disponibiliza estimativas de posição, velocidades e acelerações lineares e angulares, utilizando os sensores internos (giroscópio, inerciais, profundidade, efeito doppler, fluxômetro, etc.) ou as fontes de informação externa (GPS, sistema LBL de posicionamento acústico, sonar, etc.) e integrando-as para garantir a confiabilidade da estimativa.

- Pilotagem e Controle: Recebe as trajetórias de referência do nível de coordenação da gestão de missões, dados da navegação do veículo e produz os sinais de referência para a Atuação.

- Comunicações: Este sistema faz a gestão das comunicações entre o operador e o veículo ou entre este e outros sistemas ou veículos com os quais alguma forma de cooperação está prevista no decorrer da missão.

- Carga Útil: Efetua a gestão dos dispositivos específicos à classe de missões - sensores e atuadores - sendo os dados decorrentes da sua ativação armazenados para a análise pós-missão ou transmitidos no decorrer da missão. Sensores e atuadores como: sonares, hidrofones, vídeos-câmaras, câmaras acústicas, sensores de temperatura, umidade, oxigênio, pH, turbidez, fluorescência, etc. Assim como dispositivos de iluminação, de recolhimento de amostras, braços, manipuladores e outros dispositivos mecânicos.

- Interface Homem-Máquina: Apóia o operador na sua interação com o veículo. Esta poderá consistir num simples acompanhamento da missão por parte do operador, troca de dados entre este e o veículo ou então permitir o envio de comandos pelo operador, criando uma alteração da missão original.

- Gestão de Missões e do Veículo: Este subsistema transforma o plano da missão - tipicamente definido pelo operador numa linguagem de alto nível - num conjunto de comandos 
para cada um dos subsistemas, considerando o estado do veículo e do seu ambiente ao ser executadas as diversas atividades necessárias para a atingir os objetivos da missão, em concordância com os requisitos pré-definidos.

Em particular, poderá governar as atividades em cooperação com outros subsistemas. Este subsistema tem a seu cargo a interpretação, nos diversos níveis hierárquicos, da informação recolhida durante a execução da missão e a produção de decisões com respeito à utilização dos recursos do veículo, maximizando o valor das atividades para o cumprimento da missão.

\subsection{Arquitetura no Comando do Controle}

Lobo (2005) propõe uma arquitetura de comando e controle para o projeto do um robô móvel, como é apresentada na figura 3.5 na qual a movimentação e a localização do robô é o nível mais baixo do controle.

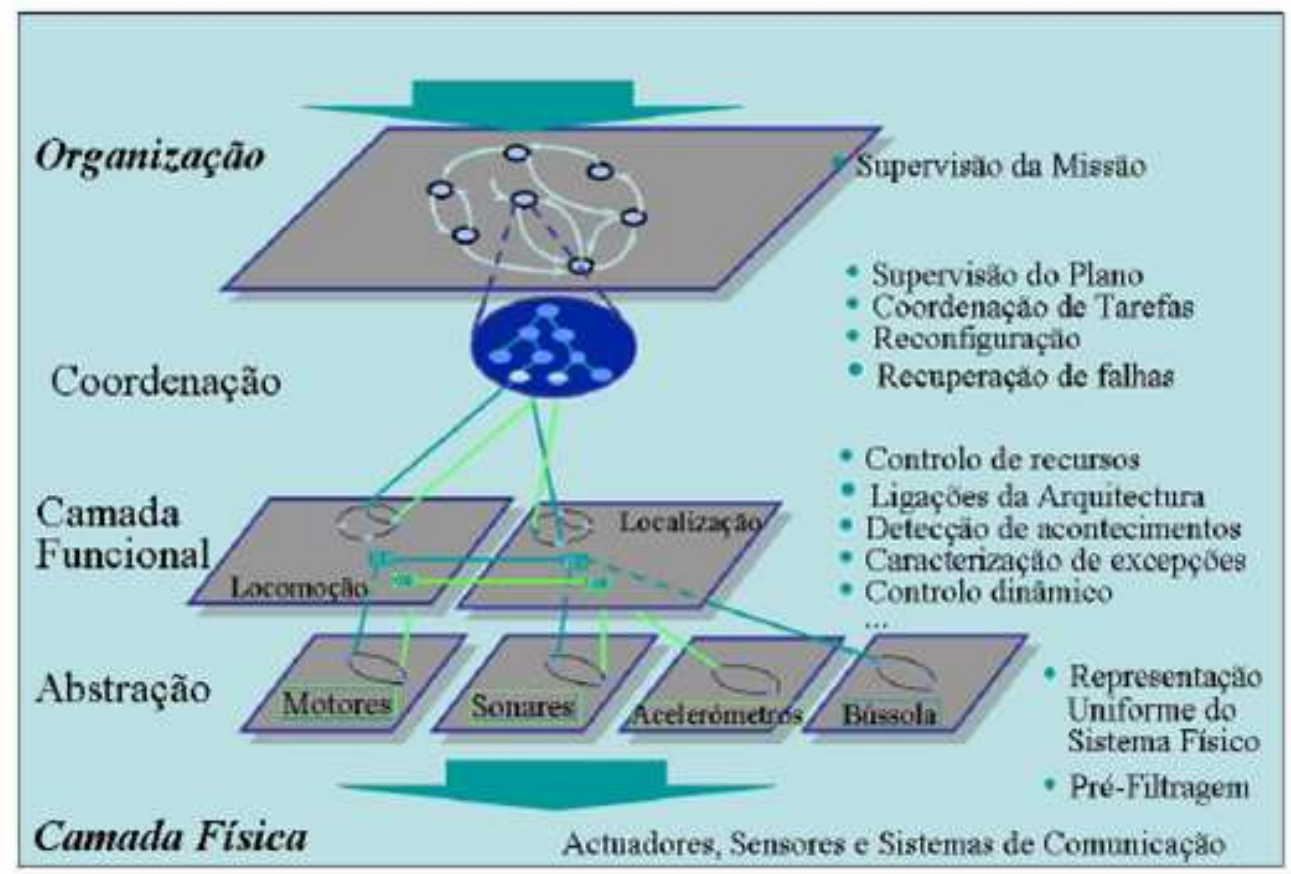

Figura 3.5: Diagrama da Arquitetura de Comando e Controle (LOBO, 2005).

Física: Representa os recursos do veículo, sendo cada componente caracterizado por um conjunto de variáveis - de entrada ou de saída - num determinado domínio e cujos valores satisfazem certas restrições.

Abstrata: Filtra e formata a informação que flui entre as camadas física e funcional, para satisfazer as especificações e os requisitos da arquitetura. Assim, esta camada pode 
ser vista como um conjunto de variáveis que, além das variáveis da camada física, inclui mensagens sobre a evolução discreta.

Funcional: Estrutura operacional que assegura o desenvolvimento das atividades. O grau e a natureza da reatividade (anéis de realimentação) é implementada neste nível mediante a especificação dos controladores.

Esta camada está organizada em:

- Funcionalidades elementares: Conjunto de módulos não decomponíveis, implementando o recolhimento de dados, o processamento e a atuação.

- Funcionalidades complexas: Atividades que combinam, agregam ou geram informação entre componentes de natureza diversa e que são organizados em camadas hierárquicas sucessivas.

- Controladores de recursos: Estrutura hierárquica e dinamicamente reconfiguráveis para assegurar a emergência das funcionalidades necessárias para a execução de uma dada tarefa.

Coordenação: Composta por um conjunto de autômatos que implementam a coordenação de cada tarefa, isto é, para cada estado na execução da tarefa, verifica-se as condições a preencher e sendo o caso, ativa os componentes associados. A composição destes autômatos é comandada de forma a controlar a execução da missão.

Supervisão/Organização: Apóia o operador no topo da hierarquia do sistema de decisão, assim como em todas as atividades de planejamento e interação com outros sistemas. 


\section{Fundamentos do Controlador}

Neste capítulo apresenta-se as considerações para o desenvolvimento do controlador de orientação e navegação de um veículo submarino baseado na técnica de lógica nebulosa.

Inicialmente, o VSSA é transportado dentro de um container por um navio até uma posição no mar. Nesta posição o container deverá descer até a profundidade na qual o VSSA começará suas operações. O VSSA deverá sair do container, iniciando sua navegação até chegar a um objetivo escolhido. Por exemplo, a posição objetivo poderá ser a posição na qual tem-se que recuperar um transponder.

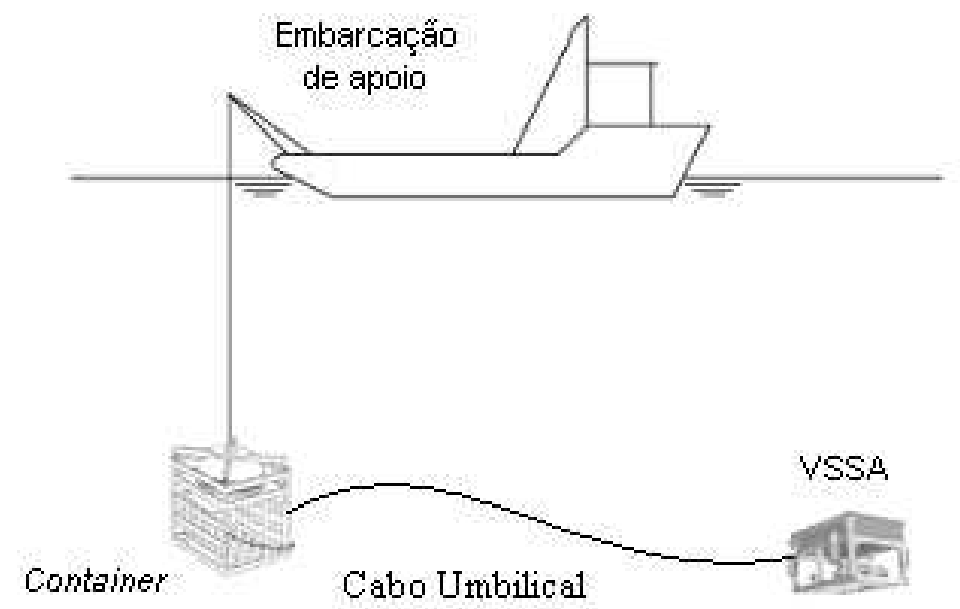

Figura 4.1: Lançamento do VSSA.

O veículo submarino estabelece um plano de operação e um modo de navegação para poder atingir seus objetivos. À forma como o controlador divide as tarefas de controle denomina-se "etapas" e "módulos", as quais enfocam sistemas mais restritos em função do tempo em que são executadas as ações de controle. 


\subsection{Plano de Operação do VSSA}

O plano de operação é o conjunto de operações que o VSSA terá que efetuar para chegar até seu objetivo.

Utiliza-se um sistema de referência inercial como apresentado no apêndice A que permite identificar as posições de interesse do VSSA. Todos os parâmetros estão referidos a este sistema de referência, como ilustra a figura 4.2 .

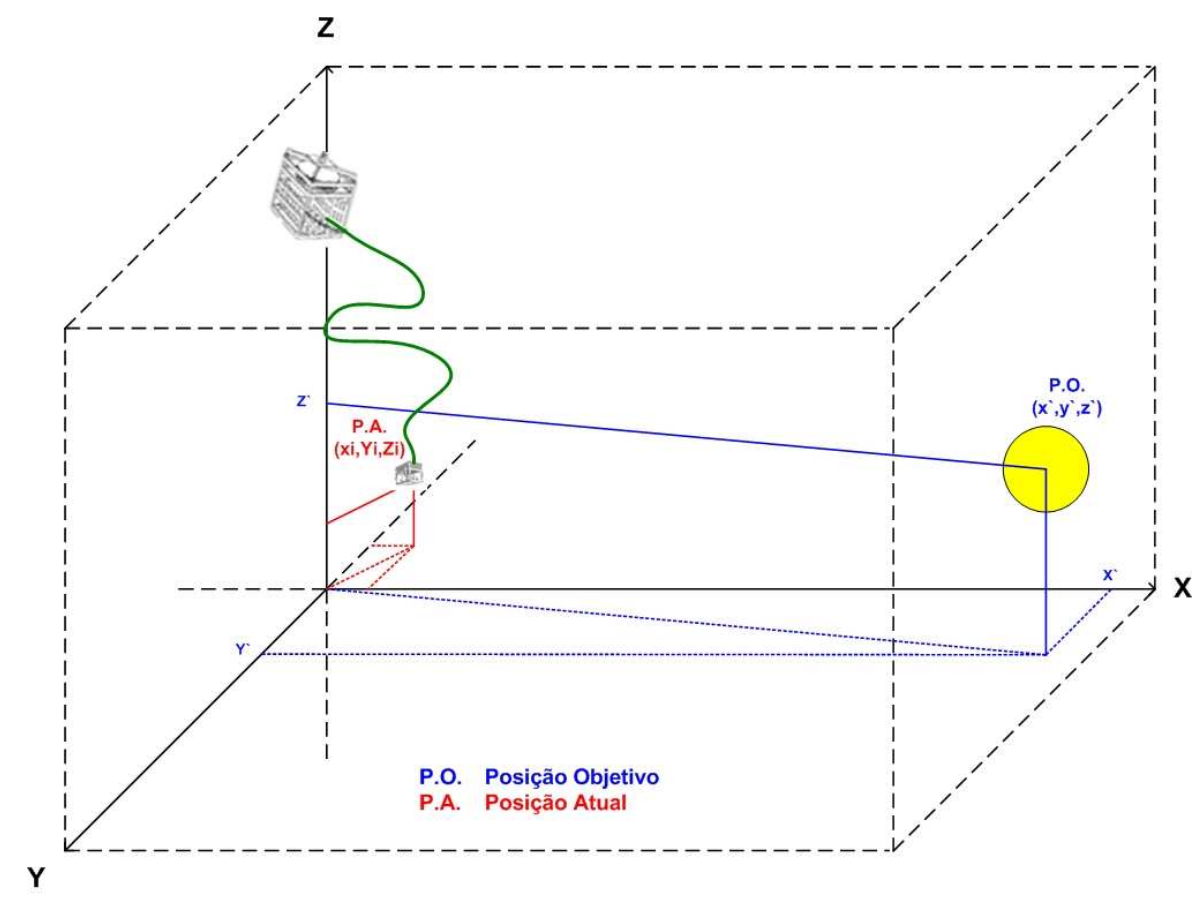

Figura 4.2: Sistema de Referência Inercial.

Definem-se dois tipos de planos de operação:

\subsubsection{Plano de Operação Pré-definido}

Neste caso o VSSA tem uma rota específica pré-planejada, na qual tem-se todo o planejamento da navegação, evasão de obstáculos e outras informações relevantes para atingir o objetivo, como é apresentado na figura 4.3.

Neste plano de operação, determina-se uma posição $P A$ (posição atual com respeito ao sistema de referência inercial), que é a posição onde começam as operações do VSSA, na rota planejada; e uma posição $P O$ (posição do objetivo com respeito ao sistema de referência inercial) que é o ponto ao qual o VSSA deverá chegar depois de percorrer a rota determinada entre essas duas posições. 


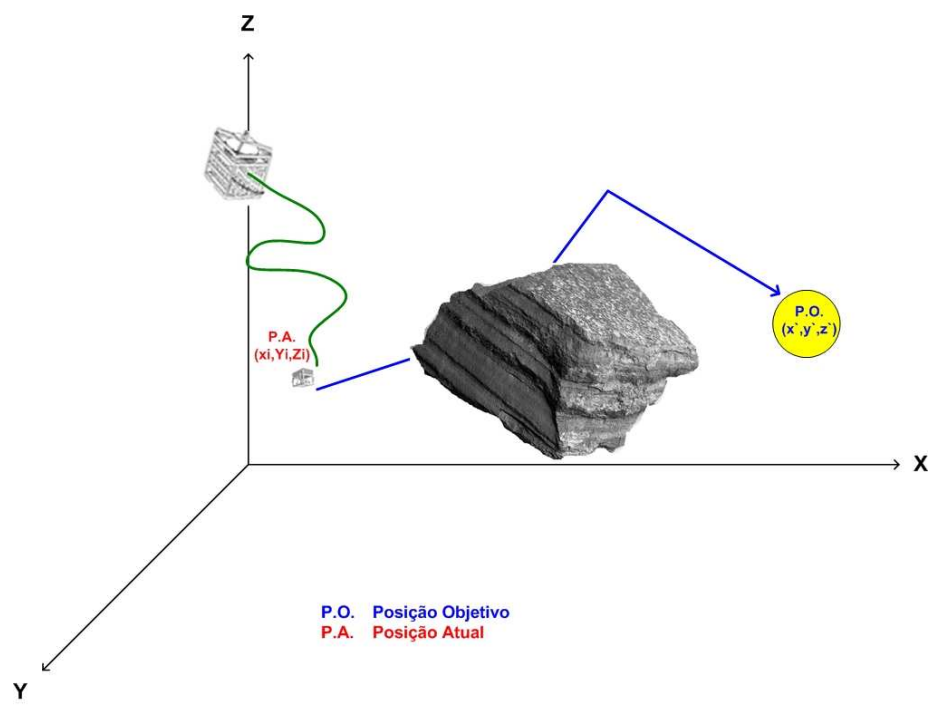

Figura 4.3: Plano de Operação Pré-definido.

\subsubsection{Plano de Operação Autônomo}

Neste caso o VSSA deve atingir o objetivo sem ter um caminho ou rota pré-planejada. Para isso, o VSSA deverá começar suas operações na posição onde é deixado pelo container e planejar uma rota por si mesmo até o objetivo. Ilustrado na figura 4.4.

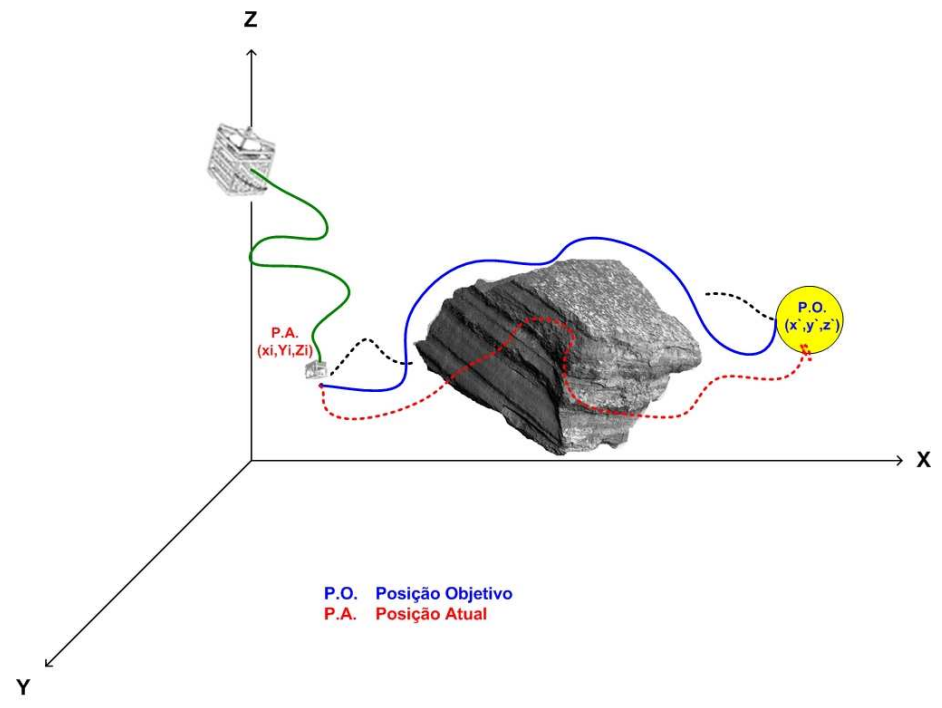

Figura 4.4: Plano de Operação Autônomo.

Neste plano de operação, determina-se uma posição $P A$ (posição atual com respeito ao sistema de referência inercial) que é a posição onde encontra-se o VSSA num primeiro instante de tempo (t0), e uma posição $P O$ que é a posição na qual o VSSA deverá chegar depois de planejar a trajetória a seguir, incluindo a evasão de obstáculos. 


\subsection{Modo de Navegação do VSSA}

O modo de navegação é a estratégia que o veículo segue na evasão de obstáculos para atingir o objetivo. São considerados 3 modos de navegação utilizando o sistema de referência inercial $X Y Z$.

\subsubsection{Evasão de Obstáculos no Plano Horizontal}

Neste modo de navegação segue-se um plano horizontal de avanço descrito pelos eixos $X Y$, com uma profundidade relativa determinada, e a evasão de obstáculos só ocorre no plano horizontal $X Y$ na profundidade relativa determinada no eixo $Z$. Ilustrado na figura 4.5 .

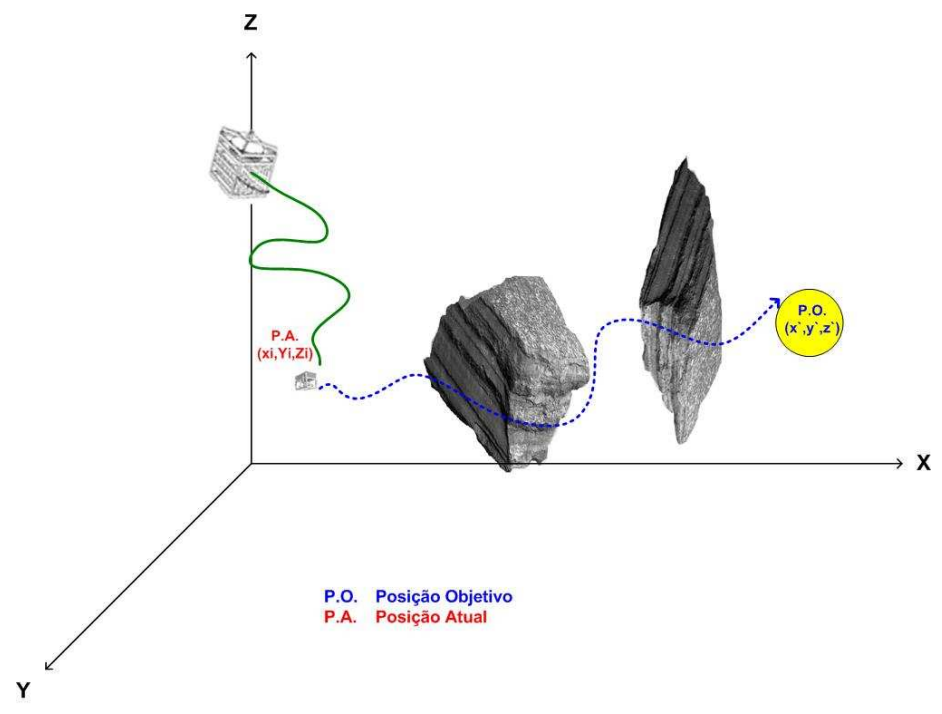

Figura 4.5: Evação de Obstáculos no Plano Horizontal.

\subsubsection{Evasão de Obstáculos no Plano Vertical}

Neste modo de navegação segue-se um plano horizontal de avanço descrito pelos eixos $X Y$, com uma profundidade relativa medida a partir da superfície do solo marino no eixo $Z$, e a evasão de obstáculos só ocorre no plano vertical $Z$ e alinhada com a posição objetivo. Ilustrado na figura 4.6 . 


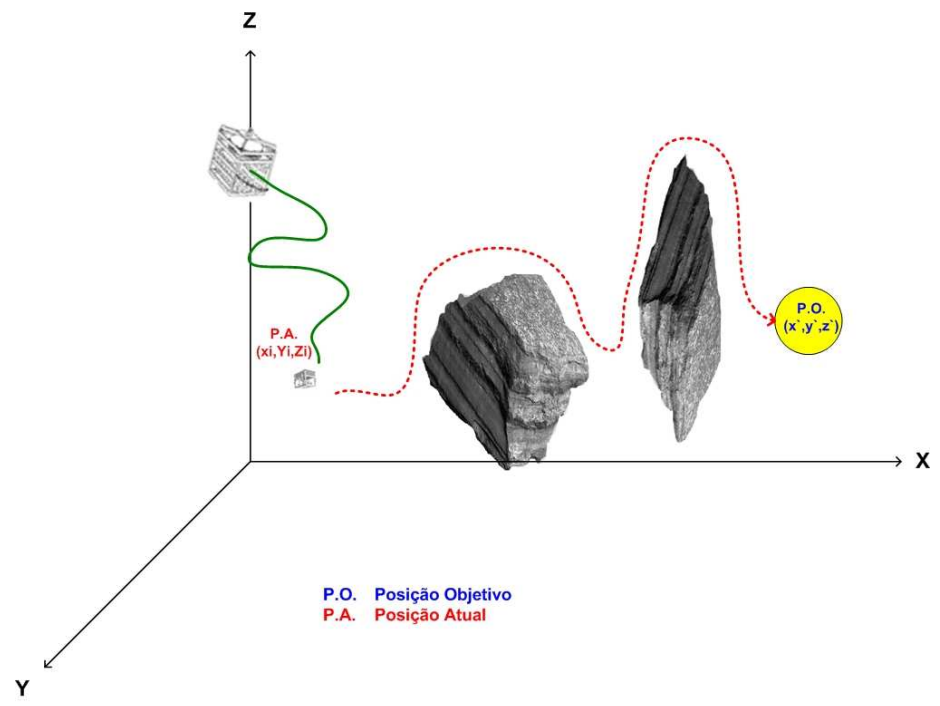

Figura 4.6: Evação de Obstáculos no Plano Vertical.

\subsubsection{Evasão de Obstáculos Otimizada no Plano Ideal}

Neste modo de navegação utilizam-se os dois casos anteriores, seguindo um plano horizontal de avanço descrito pelos eixos $X Y$, e um plano vertical que pode variar entre a profundidade determinada e a profundidade relativa à superfície do solo marino no eixo $Z$. Neste caso, a evasão de obstáculos é feita nos planos horizontal $X Y$ e vertical $Y Z$. Para otimizar a decisão para a evasão de obstáculos, é necessário conhecer previamente a superfície do solo marino onde desenvolvem-se as operações, para tomar-se a melhor decisão em função de que eixo ou combinação de eixos em que se faria a evasão do obstáculo para otimizar o navegação do VSSA. Ilustrado na figura 4.7.

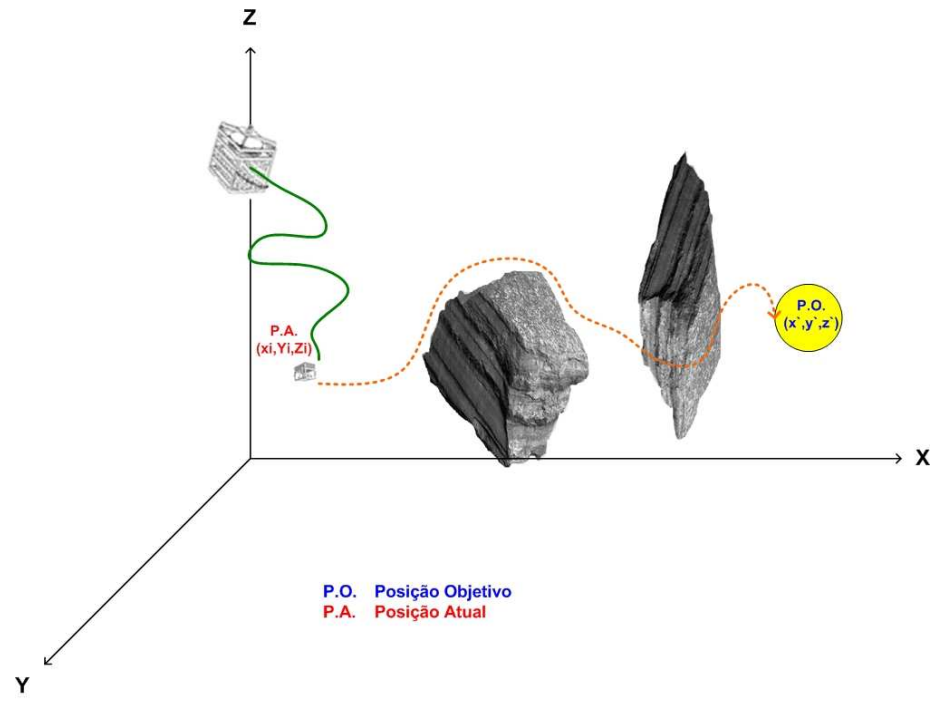

Figura 4.7: Evação de Obstáculos no Plano Horizontal e Vertical. 


\subsection{Parâmetros do Projeto}

Neste trabalho vai se implementar apenas o controle para o "plano de operação autônomo" e o "modo de navegação para evasão de obstáculos no plano horizontal $X Y$ ". O objetivo do plano de operação e do modo de navegação é garantir a chegada à posição objetivo de forma autônoma, evitando obstáculos no plano $X Y$, tendo como premissa principal manter-se dentro da faixa permitida para o eixo $Z$ (profundidade relativa) e estar sempre orientado ou alinhado no rumo da posição objetivo.

O plano de operação utilizado é descrito por um conjunto de constantes, variáveis e de regras pré-definidas pelos usuários dos VSSAs, e que o controlador deve cumprir para garantir a navegabilidade do veículo. Além disso, outros dados de entrada são fornecidos pelo sistema de sensores.

\subsubsection{Constantes e Variáveis do Plano de Operação}

As constantes do plano de operação são definidas pelo operador antes de jogar o VSSA no mar, e variáveis do plano de operação são os dados que o operador pode definir, modificar ou atualizar antes e depois de jogar o VSSA no mar.

- Alcance Máximo do Sonar (DS): É a constante que define o alcance máximo do sensor sonar para detectar obstáculos, denominada $D S$. Este valor dependerá do tipo do sensor instalado no VSSA.

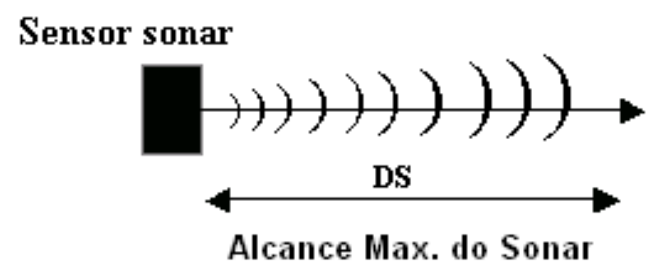

Figura 4.8: Alcance Máximo do Sensor Sonar.

- Velocidade de Operação (VO): É a velocidade média de avanço que o VSSA pode assumir durante suas operações. Neste caso a velocidade máxima do VSSA da EPUSP é de $0,4 \mathrm{~m} / \mathrm{s}$ para o plano horizontal, porem a velocidade de operação (VO) e definida pelo operador dependendo da tarefa a realizar.

- Tempo para Percorrer DS $\left(\boldsymbol{T}_{\boldsymbol{D} S}\right)$ : É o tempo que leva o VSSA para percorrer a distância $D S$ em função da sua velocidade de operação (VO). 
- Ciclo de Leitura $\left(t_{\boldsymbol{L}}\right)$ : É a constante que define leitura do sistema de sensores, e que também é o intervalo de tempo que o VSSA tem para executar alguma ação determinada pelo controlador. Este intervalo vai de $t_{L}$ até $t_{L+1}$, onde $t_{L}$ é o tempo no qual se faz a última leitura dos sensores e se executa uma ordem do controlador aos propulsores; e $t_{L+1}$ é o tempo seguinte onde se faz uma nova leitura dos sensores e que se converte então em $t_{L}$, executando um novo ciclo de operações nos propulsores. O intervalo de tempo pode ser por exemplo equivalente a $1 / 3$ do tempo para percorrer a distância $D S$, isto é $T_{D S}$, definido assim para garantir que o VSSA possa executar alguma ação como a evasão de um obstáculo ou parada.

Então: Se por exemplo, $T_{D S}=12 \mathrm{~s}, t_{L}=0 s ; t_{L+1}=0 s ; 1 / 3\left(T_{D S}\right)=1 / 3(12 s)=4 s$ num estado inicial, o valor da constante será $\left(\boldsymbol{t}_{\boldsymbol{L}}\right)=\mathbf{4} \mathbf{s}$. Na figura 4.9 apresenta-se os instantes para os ciclos de leitura:

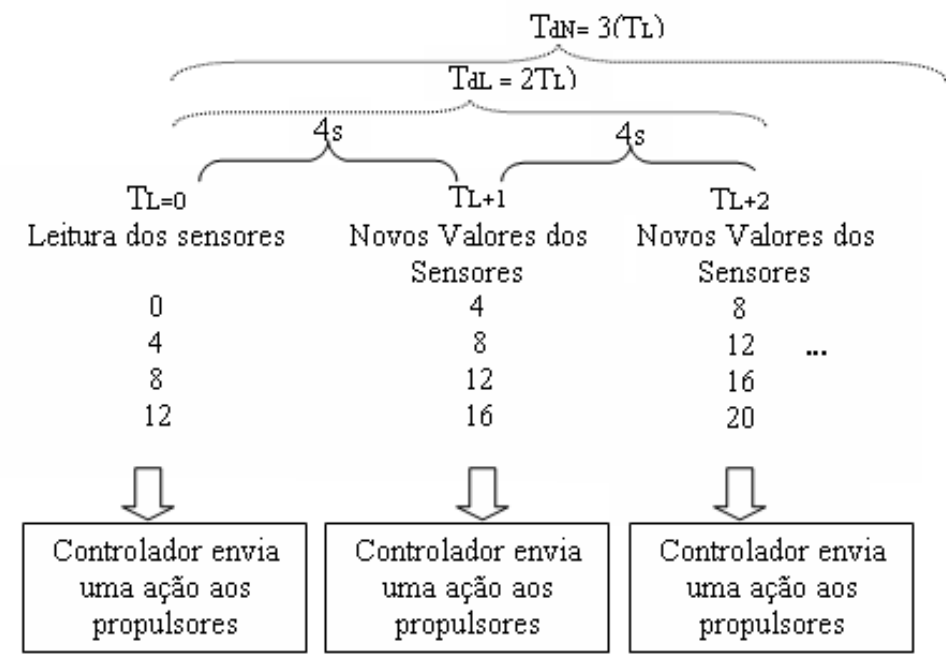

Figura 4.9: Ciclo de Leitura do Controlador.

- Constantes de Avanço $\boldsymbol{T}_{\boldsymbol{d} \boldsymbol{L}}$ e $\boldsymbol{T}_{\boldsymbol{d N}}$ : As constantes $T_{d L}$ e $T_{d N}$ representam intervalos de tempo onde são ignorados os ciclos de leitura do sistema de sensores para realizar a operação de avanço (sem ter que avaliar qualquer outro tipo de operação). Estas constantes são geradas em função da constante $\left(\boldsymbol{t}_{\boldsymbol{L}}\right)$, e representadas pelas funções:

$$
\begin{aligned}
& T_{d L}=2\left(t_{L}\right) \\
& T_{d N}=3\left(t_{L}\right)
\end{aligned}
$$

Ao ignorar o ciclo de leitura $\left(\boldsymbol{t}_{\boldsymbol{L}}\right)$, neste intervalo de tempo $\left(T_{d L}\right.$ ou $\left.T_{d N}\right)$, é possível que o VSSA realize operações de avanço sem ter que avaliar sua posição relativamente à 
posição objetivo, evitando entrar num ciclo repetitivo, o que tornaria impossível chegarse à posição objetivo. A constante $T_{d L}$ indica que os obstáculos estão longe e $T_{d N}$ que não há obstáculos nesses períodos de tempo.

- Constante de Profundidade (P): É a profundidade na qual se quer que o VSSA flutue alinhado à profundidade onde se encontra o posição objetivo.

- Constante de Faixa de Profundidade (F): É um valor dado para a faixa de profundidade na qual o VSSA deverá operar.

- Constante de Raio (R): É o raio da superfície cilíndrica usado para criar um volume ao redor da posição objetivo à qual o VSSA deverá chegar.

- Profundidade Relativa (PR): É a faixa de profundidade na qual o VSSA deve permanecer. Esta faixa é criada usando-se as constantes P e F, dados em metros:

$$
\mathrm{PR}=\{\forall \mathrm{z}, \mathrm{P}, \mathrm{F} \in \Re /(\mathrm{P}-\mathrm{F}) \leq \mathrm{z} \leq(\mathrm{P}+\mathrm{F})\}
$$

Exemplo: Se $\mathrm{P}=100 \mathrm{~m}$ de profundidade e $\mathrm{F}=10 \mathrm{~m}$, então:

$\mathrm{PR}=\{\forall \mathrm{z}, \mathrm{P}, \mathrm{F} \in \Re / 90 \leq \mathrm{z} \leq 110\} \therefore$ O VSSA terá que operar entre 90 e 110 metros de profundidade.

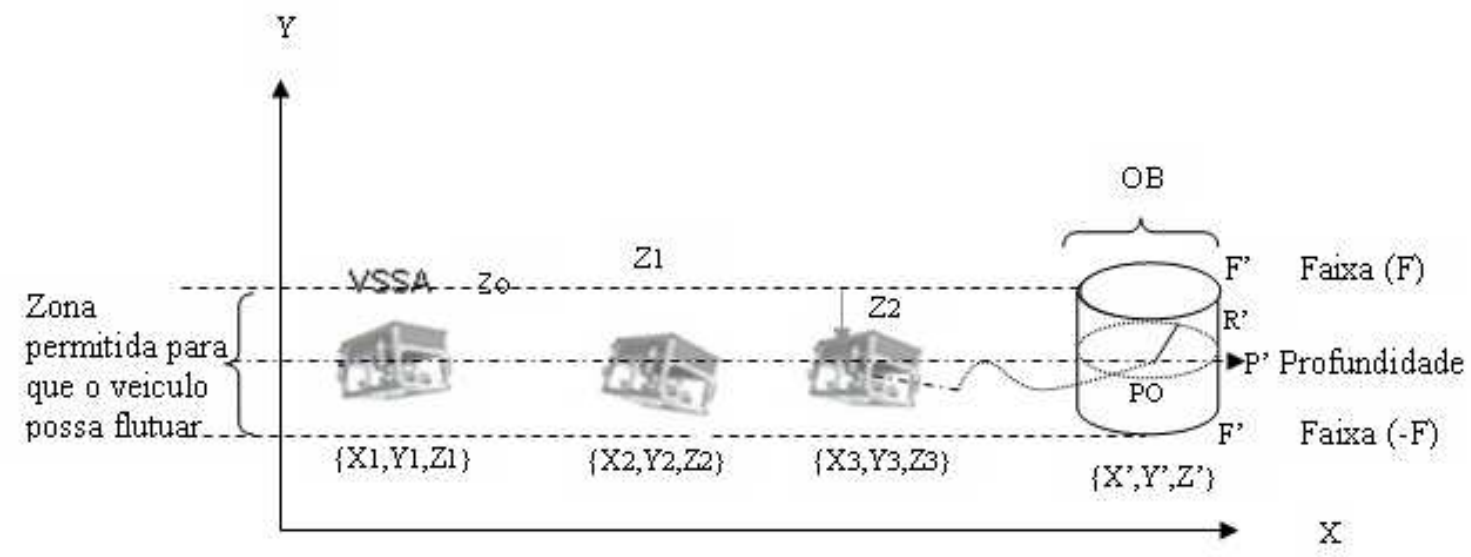

Figura 4.10: Faixa de Operação do VSSA.

- Posição Atual (PA): É um dado que mostra a coordenada $\{x, y, z\}$ no sistema de referência inercial, que representa a posição atual do VSSA em um instante de tempo t. Exemplo: $P A=\{x, y, z\}=\{30 m, 90 m, 60 m\}$

- Posição Objetivo (PO): É a coordenada $\{x, y, z\}$ no sistema de referência inercial, da posição do objetivo a atingir.

Exemplo: $P A=\{x, y, z\}=\{50 m, 90 m, 100 m\}$ 
- Volume da Posição Objetivo (VPO): Como a lógica nebulosa trabalha com valores relativos e não absolutos, chegar a um ponto específico como PO, seria muito difícil. Por isso, cria-se um volume ao redor da posição objetivo, que na verdade, seria o destino do VSSA. Este volume é criado pelo ponto PO $(x, y, z)$, um raio $R$ da superfície cilíndrica do volume, uma profundidade $P$, com uma faixa $F$. Considera-se que o VSSA atingiu o objetivo quando estiver dentro do volume da posição objetivo:

$$
V P O=\left\{\forall(x, y, z) \in \Re^{3} /(x, y) \in \text { Área }=\Pi R^{2} \wedge(z) \in P R\right\}
$$

Exemplo: Se $(x, y, z)=(40,230,100)$, e $R=10$ metros, então $P=z=100 m$ e $F=10$. O volume é composto pela área da superfície cilíndrica que será $=100 \Pi \mathrm{m}^{2}$ e os planos paralelos que a cortam em todas as geratrizes a uma profundidade entre 90 e 110 metros.

- Distância $(\boldsymbol{d i})$ : É a distância em que o sensor sonar verifica se há obstáculos em certas direções. O sonar lê em 5 direções: d1 é para frente, $d 2$ é $45^{\circ}$ para a esquerda, d3 é $45^{\circ}$ para a direita; que são os 3 sinais mais importantes e necessárias para determinar o avanço; $d 4$ é $90^{\circ}$ para a esquerda e $d 5$ é $90^{\circ}$ para a direita. Todos estes dados estão no plano horizontal.

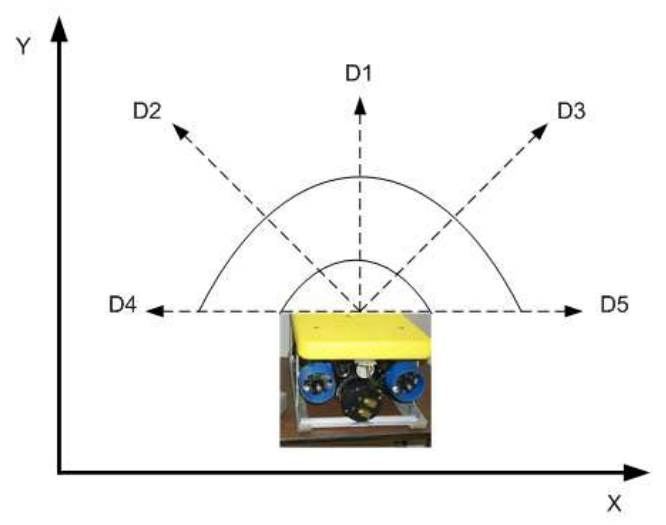

Figura 4.11: Direções de Leitura do Sensor Sonar.

A distância máxima que o sensor sonar pode ler em qualquer das direções é função da constante $D S$. A variável di pode assumir valores no intervalo $[0, D S]$ que determina a distância em metros do obstáculo, além do valor zero (null), que é o caso quando o sonar não encontra obstáculo na distância $D S$.

\section{O valor $d i$ é associado a um termo lingüístico.}

Os termos lingüísticos que di pode assumir são Perto, Longe e Null. A associação destes termos é função dos valores em metros produzidos pelo sonar e é descrito por: 


$$
\begin{gathered}
\text { Perto }=[0,(1 / 2) D S] \\
\text { Longe }=[(1 / 3) D S,(5 / 6) D S] \\
\text { Null }=(2 / 3) D S \text { ou } \text { Null }=\text { sem resposta do sonar. }
\end{gathered}
$$

Exemplo: Se $D S=12 m$ e Perto $=[0,(1 / 2) D S] ;$ Longe $=[(1 / 3) D S,(5 / 6) D S]$; e Null $(2 / 3) D S$.

$$
\begin{gathered}
\text { Então, Perto }=[0 m,(1 / 2)(12 m)] ; \text { Longe }=[(1 / 3)(12 m),(5 / 6)(12 m)] ; \text { e } \text { Null } \\
>(2 / 3)(12 m) \text { ou } N u l l=\text { Sem resposta. } \\
\therefore \text { Perto }=[0 m, 6 m] ; \text { Longe }=[4 m, 10 m] ; \text { e } N u l l=8 m \text { ou } \text { Null=Sem resposta. }
\end{gathered}
$$

Se $d 1=$ null, $d 2=$ null, $d 3=$ null, $d 4=$ Longe e $d 5=$ null, então pode-se dizer que o VSSA não tem obstáculos a frente, a $45^{\circ}$ à esquerda e direita, a $90^{\circ}$ direita, mas, tem-se um obstáculo com valor Longe na direção de $90^{\circ}$ esquerda, o que indica que o VSSA poderia avançar na direção d1.

- Flag: É uma variável que pode tomar os valores de 0 ou 1 , onde Flag $=1$ significa que será ignorado o ciclo de leitura $t_{L}$ por um tempo $t_{d L}$ ou $t_{d N}$, o que depende do valor do termo lingüístico da variável $d 1$, assim:

Se Flag $=1$ e Se $d 1=$ Longe então $T_{d L}=2\left(t_{L}\right)$, ou Se Flag $=1$ e Se $d 1=$ Null então

$$
T_{d N}=3\left(t_{L}\right) \text {. }
$$

Se $F l a g=0$ então $T_{d L}$ e $T_{d N}$ são ignorados.

No final de cada tempo $t_{d L}$ ou $t_{d N}$, será verificada a posição atual, o cabeceio, a profundidade, o rumo, a presença de obstáculos antes de se realizar uma nova operação de avanço.

\subsubsection{Definição das Variáveis do Controlador}

As variáveis do controlador são os dados que se vão modificando e/ou atualizando a medida que o VSSA desenvolve suas operações.

- Erro Cabeceio $(\boldsymbol{\theta})$ : O erro do ângulo de cabeceio no VSSA é a diferença entre o cabeceio atual e o cabeceio desejado e que indica a inclinação do VSSA relativamente a sua posição objetivo (PO). 
- Erro $\operatorname{Rumo}(\psi)$ : O erro do ângulo de rumo no VSSA é a diferença entre o rumo atual e o rumo desejado e que indica a orientação do VSSA com respeito à posição objetivo $(\mathrm{PO})$.

\section{O erro de rumo é definido pelo sensor de rumo}

\subsection{Regras no Plano de Operação}

Nesta seção apresentam-se as regras do plano de operação.

\subsubsection{Profundidade Relativa Equivalente}

Nesta regra obriga-se que o valor da coordenada no eixo Z da posição atual (PA) esteja dentro do intervalo da profundidade relativa (PR) definida no plano de operação.

$$
\forall(x, y, z) \in \Re^{3} /(z) \in \mathrm{PR}
$$

\subsubsection{Evasão de Obstáculos}

Para a evasão de obstáculos, o controlador utiliza a variável "Distância (di)" analisando os termos lingüísticos em cada um de suas direções (d1, d2, d3, d4 e d5). Com esses dados é definido um conjunto de regras que determinam as ações a seguir quando o VSSA encontrar obstáculos na sua trajetória. As principais regras são:

- Se $d 1=$ Null $\wedge d 2=N u l l \longrightarrow$ Avanço $T_{d N} \Longrightarrow$ Módulo 1

- Se $d 1 \neq$ perto $\wedge d 2 \neq$ perto $\wedge d 3 \neq$ perto $\longrightarrow$ Avanço $T_{d L}$

- Se $(d 2 \neq$ perto $\wedge d 3=$ perto $)$ ou $(\mathrm{d} 2=\mathrm{d} 3)$ ou $(d 2=$ Null $\wedge d 3=$ Longe $) \longrightarrow$ Gira $45^{\circ}$ à esquerda na direção d2 $\Longrightarrow$ Módulo 2

- Se $(d 2=$ perto $\wedge d 3 \neq$ perto $)$ ou $(\mathrm{d} 2=$ longe $\wedge d 3=$ Null $) \longrightarrow$ Gira $45^{\circ}$ à direita na direção d3 $\Longrightarrow$ Módulo 2

- Se $d 2=$ perto $\wedge d 3=$ perto $\longrightarrow$ avaliar $\mathrm{d} 4$ e $\mathrm{d} 5$

- Se $(d 4=$ Null $)$ ou $(d 4=$ Longe $\wedge d 5 \neq$ Longe $) \longrightarrow$ Gira $90^{\circ}$ à esquerda na direção $\mathrm{d} 4 \Longrightarrow$ Módulo 2

- Se $(d 4 \neq$ Null $\wedge d 5=$ Null $)$ ou $(d 4=$ Perto $\wedge d 5 \neq$ Longe $) \longrightarrow$ Gira $90^{\circ}$ à direita na direção $\mathrm{d} 5 \Longrightarrow$ Módulo 2 
- Se $d 4=$ perto $\wedge d 5=$ perto $\longrightarrow$ Os propulsores são acionados em sentido inverso num período de tempo $T_{d L} \Longrightarrow$ Módulo 2

\subsection{Passos de Projeto de um Controlador Nebuloso}

Há uma metodologia sugerida por Cox (1994) para implementar-se um sistema nebuloso, que é utilizada neste trabalho. Implementa-se todos os processos da lógica nebulosa necessários seguindo a seguinte seqüencia de passos para o desenvolvimento de um controlador nebuloso. A metodologia é ilustrada na figura 4.12:

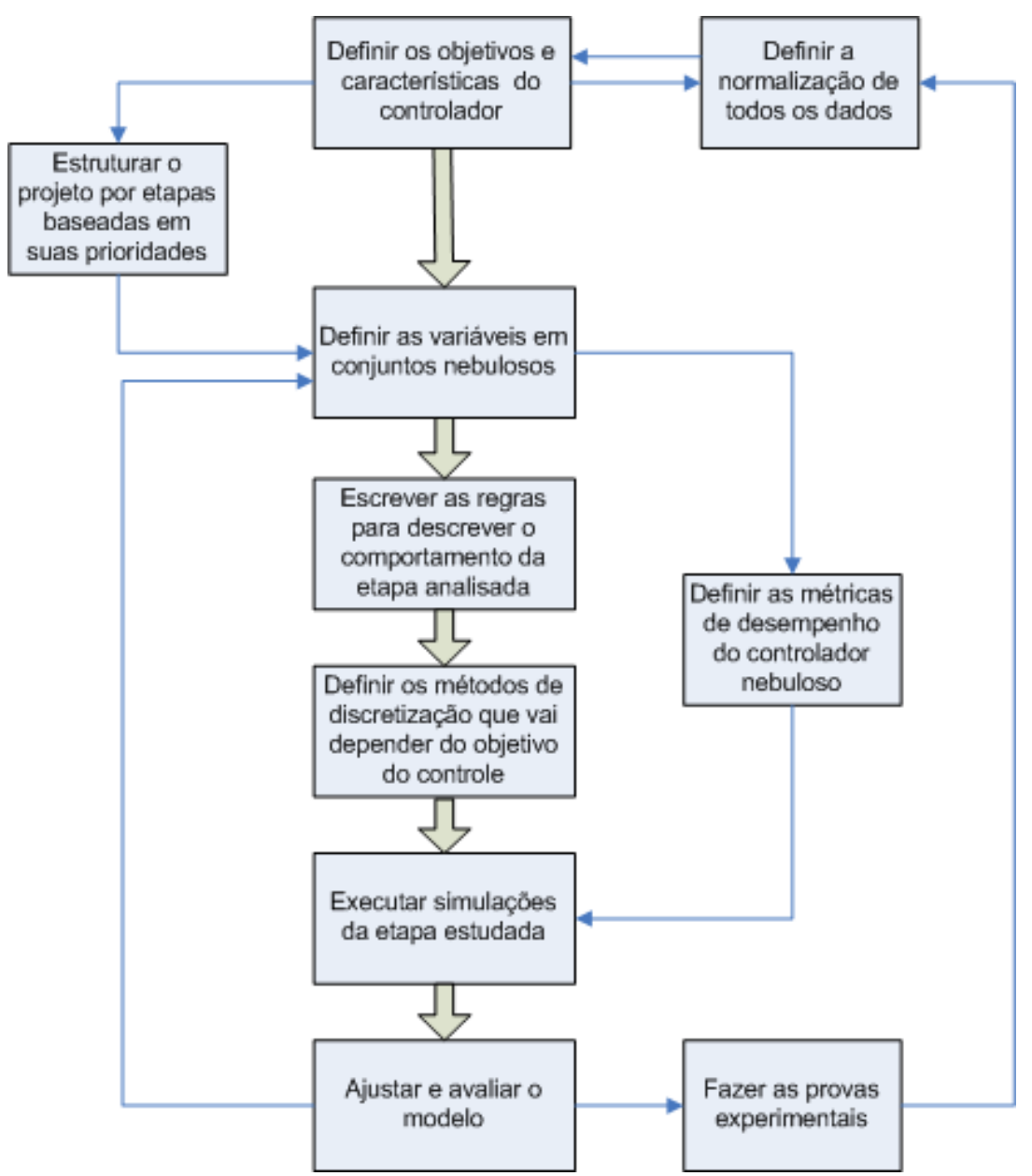

Figura 4.12: Metodologia de Projeto do Controlador Nebuloso do VSSA.

O processo de tradução das atividades do mundo real para o domínio do sistema, e a metodologia de controle e de implementação, são bem parecidas e complementares, o que facilita a realização do sistema. Definem-se as entradas, as saídas, as regras, o sistema de inferência, assim como a técnica de discretização utilizada para uma resposta ótima. 


\subsubsection{Definindo as Variáveis Lingüísticas}

Definem-se a seguir as variáveis lingüísticas, para se ter uma idéia do que se precisa para controlar o VSSA e atingir um desempenho ótimo. Note-se que durante o processo de definição destas variáveis, vai-se fazer um modelamento de um processo de raciocínio humano por meio de funções matemáticas. Por isso, é difícil ter-se um modelo $100 \%$ preciso, mesmo que seja definido pelo melhor e mais experiente piloto de veículos submarinos. No entanto, será fácil perceber pelas simulações, se este modelamento é coerente com a realidade de navegação e orientação do VSSA.

Faz-se a análise das variáveis lingüísticas respeitando o ordem dos módulos e camadas, assim ao final tem-se não só a definição das variáveis completas, mas também os próprios módulos e camadas. Mesmo assim, nota-se que algumas variáveis serão reaproveitadas em módulos de nível inferior, pois elas não são exclusivas de cada módulo.

\subsubsection{Mecanismo de Inferência}

Todas as variáveis foram definidas usando-se funções triangulares e trapezoidais, pensando-se em diminuir a complexidade das funções de pertinência e otimizando o uso de recursos de processamento.

Encontraram-se funções trapezoidais como resultados das regras, devido ao fato de se aplicar o método de agregação como método de inferência, já que é o mais eficiente e não é muito complexo.

\subsubsection{Método de Concentração}

Para a concentração utiliza-se o método mais comum, o do centro de massas. No estudo de caso apresentado foi trabalhado com um universo discreto, não havendo a necessidade de utilizar integrais para calcular o centro da massa, o que garante a minimização do esforço computacional.

$\mathrm{Na}$ verdade, faz-se a concentração como uma média ponderada dos pesos dos trapézios calculados. Não é necessário ter duas coordenadas do centro da massa, já que quer-se apenas um valor médio para representar o resultado total. Precisa-se apenas do valor do centro da massa no eixo horizontal dos trapézios, ou seja, sua abscissa.

Como utilizam-se apenas funções triangulares nos estudos de caso, o topo das funções localiza-se exatamente no meio da base. Cada trapézio resultante terá seu centro da massa exatamente na coordenada do topo. Já que a altura do centro de massa não é tão importante 
como visto acima, pode-se utilizar como ordenada do centro de massa a altura do próprio trapézio. Para encontrar este valor médio utiliza-se a seguinte expressão:

$$
R_{A}=\frac{\left(\sum_{t=1}^{n} x_{t} \mu_{A}\left(x_{t}\right)\right)\left(\sum_{k=1}^{q} h_{k} m_{k}\right)}{\left(\sum_{t=1}^{n} \mu_{A}\left(x_{t}\right)\right)\left(\sum_{k=1}^{q} h_{k}\right)}
$$

Onde $\mathbf{h}$ é altura dos trapézios e $\mathbf{m}$ a posição média do trapézio. E como é ilustrada na figura 4.13 .

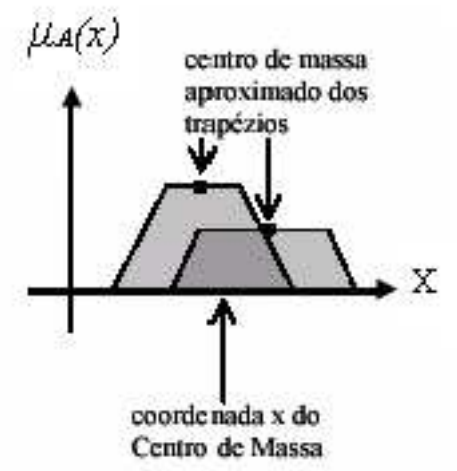

Figura 4.13: Concentração Mediante do Centro das Massas.

O resultado será justamente o valor médio de todos os trapézios, onde os trapézios com mais ponderação são aqueles mais altos, e com valores médios maiores. Para isso, é preciso apenas coerência na escolha dos valores médios de cada trapézio. Utiliza-se como médio da abscissa o valor do topo esquerdo de cada trapézio. No final o resultado estará um pouco mais a esquerda do que o centro de massa obtido acima, como é ilustrada na figura 4.14.

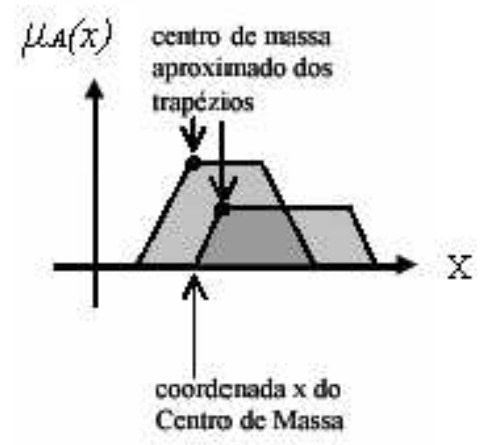

Figura 4.14: Valor Médio no topo Esquerdo no Método de Concentração.

Este cálculo é útil quando quer-se aproximar do zero. Por exemplo, quando se diz: "Se a distância é zero então a velocidade de avanço é zero", não quer dizer que se refere a um zero absoluto, mas sim a uma função denominada zero que tem valores mínimo e máximo. 
Se a função zero da velocidade de avanço varia entre 0 e 10\%, somente uma regra é disparada, e tem-se o centro da massa do trapézio resultante igual a 5 no eixo horizontal. Então, mesmo uma velocidade com grau de pertinência 1, para o conjunto zero, não produz velocidade nula após a concentração. Ilustrada na figura 4.15.

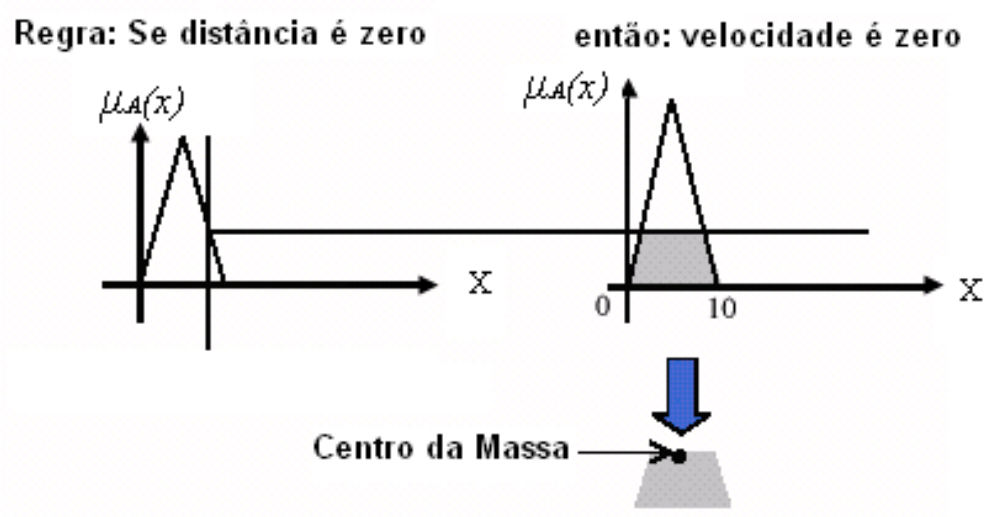

Figura 4.15: Método de Concentração.

Nos casos dos conjuntos nebulosos zero e máximo, definem-se funções de pertinência apenas com trapézios. Como se mostra na figura 4.16, o topo da função zero será o valor zero absoluto, e neste caso o trapézio resultante também não terá o declínio a esquerda. O topo esquerdo do trapézio será o seu menor valor possível. No caso da velocidade zero este será justamente o valor que se deseja. Ilustrada na figura 4.16.

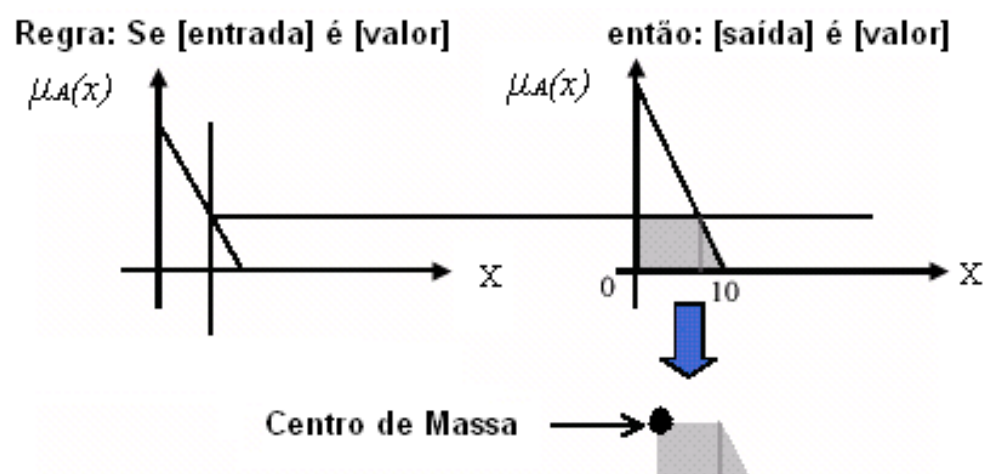

Figura 4.16: Método de Concentração para a Velocidade de Avanço Zero .

Para solucionar este problema, calcula-se o centro da massa, utilizando-se sempre o valor médio da abscissa do topo esquerdo de todos os trapézios. 


\section{$5 \quad$ Síntese do Controlador Modular para o VSSA Via Lógica Nebulosa}

A síntese do controlador nebuloso é baseada na metodologia proposta no capítulo 1 da presente dissertação. Para sintetizar o controlador dividiu-se o fluxo de trabalho em etapas (seqüencia em função ao tempo) e módulos (conjunto de eventos que cumprem uma tarefa especifica) onde são desenvolvidos um a um, e onde a execução dos processos seguirá um ordem seqüencial com maior prioridade de baixo para cima.

\subsection{Estratégia do Controlador Nebuloso}

$\mathrm{Na}$ figura 5.1. Apresenta-se a síntese do controlador, dividida por etapas e por atividades para facilitar sua consecução. A seguir, mostra-se o desenvolvimento do controlador considerando cada um dos módulos em cada etapa.

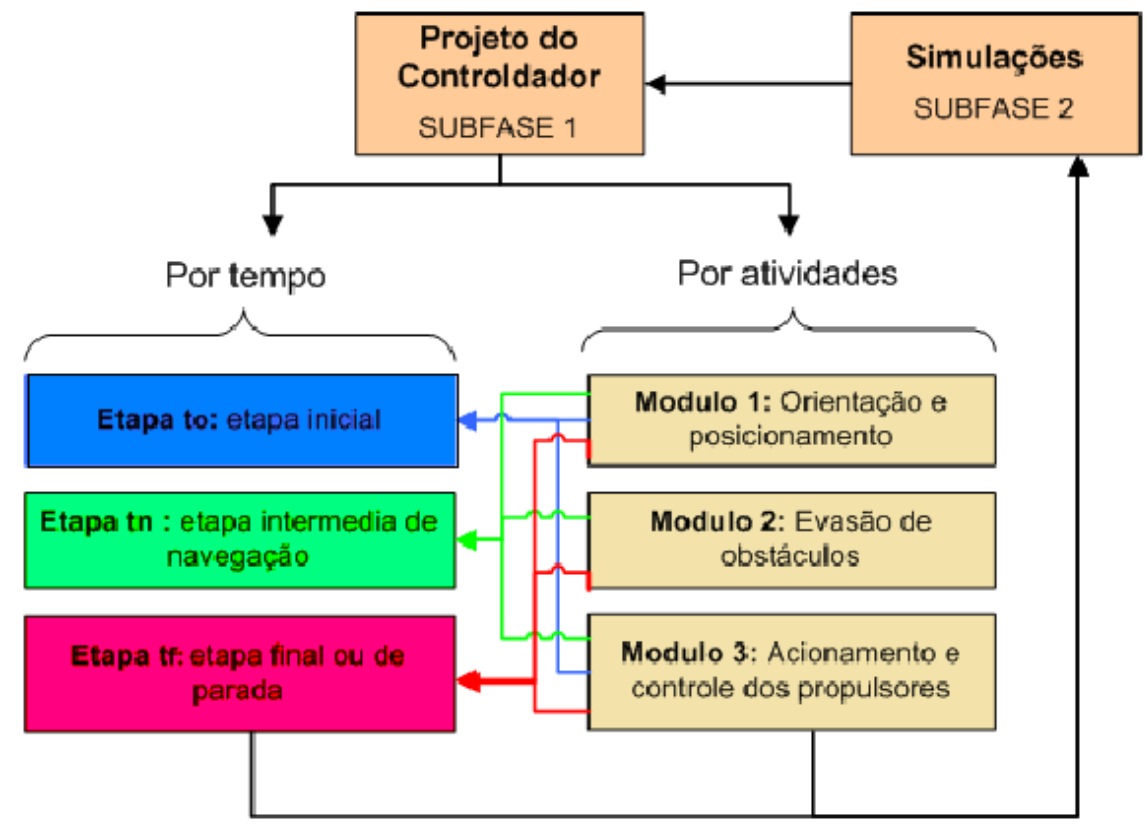

Figura 5.1: Esquema de Etapas e Módulos. 


\subsubsection{Etapas na Navegação do Veículo}

O tempo que o veículo leva para atingir seu objetivo, foi dividido em três etapas, denominadas $t_{0}, t_{n}$ e $t_{f}$, como é apresentado na figura 5.2.

- O intervalo de tempo inicial $t_{0}$ vai desde o instante inicial das operações do VSSA, que acontece quando o VSSA é liberado do container, até o instante de tempo imediatamente anterior ao qual o VSSA executa sua primeira operação de avanço.

- O intervalo de tempo $t_{n}$ é todo o tempo depois da execução da primeira operação de avanço, isto é, desde o término da etapa $t_{0}$ até quando o VSSA detecta que ingressou no volume da posição objetivo (VPO).

- O intervalo de tempo final $t_{f}$ vai desde o término da etapa $t_{n}$ até quando o VSSA está próximo ou na mesma coordenada da posição objetivo (quando a potência nos propulsores deverá começar a diminuir até chegar a 0 ).

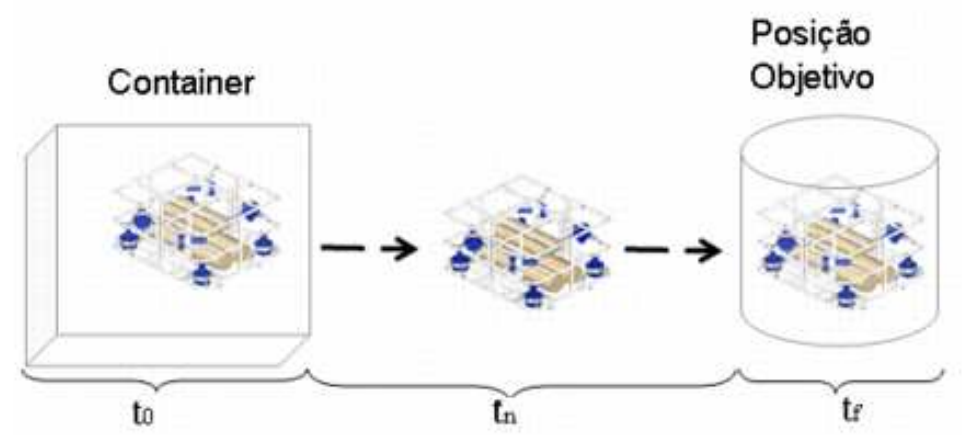

Figura 5.2: Etapas de Navegação.

\subsubsection{Módulos Operacionais do Controlador Nebuloso}

As tarefas do controlador foram divididas em módulos. Nos módulos de tarefas, as ações de controle se repetem nas etapas de navegação $\left(t_{0}, t_{n}\right.$ e $\left.t_{f}\right)$ conforme seja necessário.

- Módulo 1.- Orientação e posicionamento.

- Módulo 2.- Evasão de obstáculos.

- Módulo 3.- Acionamento e controle dos propulsores. 


\subsection{Síntese do Controlador Modular}

Uma seqüência minuciosa de como reage o veículo com o controlador é mostrada nesta seção onde é feita uma análise das etapas e definem-se as tarefas necessárias para atingir o objetivo final. Cada fase realiza uma tarefa específica do controle, de forma que quanto mais embaixo esteja um módulo, ele terá maior importância na tomada de decisões para o controle, pois ela acrescenta informações ao resultado obtido nos módulos anteriores.

\subsubsection{Síntese do Controlador na Etapa Orientação e Posicionamento $t_{0}$}

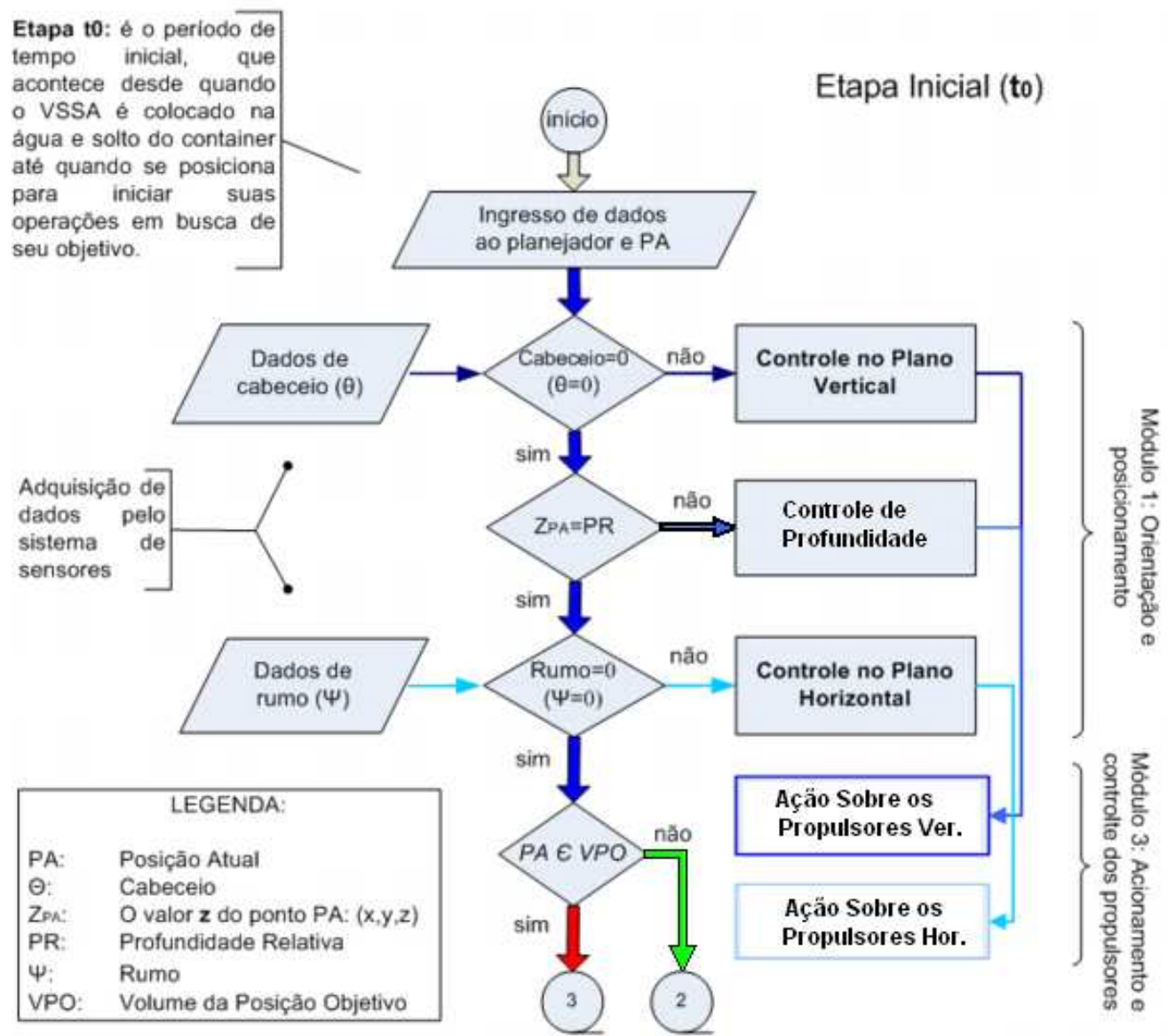

Figura 5.3: Diagrama de Fluxo da Etapa $t_{0}$ do Controlador.

A figura 5.3 mostra o fluxo de trabalho inicial do controlador, que inicia-se quando o VSSA é liberado do container, ativando o planejador e analisando sua posição atual (PA). Com esses dados, o controlador verifica seu cabeceio, para efetuar o controle no plano vertical. A seguir é comparada a profundidade $Z_{P A}$ do VSSA (o valor de z da variável PA) com a posição relativa (PR) dada pelo planejador pela regra de "Profundidade Relativa Equivalente", com o que é 
determinada alguma ação de controle sobre a profundidade, para finalmente verificar o rumo, efetuando o controle no plano horizontal.

A etapa $t_{0}$ termina quando o VSSA avalia se está dentro do volume da posição objetivo. Se for este o caso passa-se à etapa $t_{f}$, se não o VSSA fica posicionado e pronto para começar suas operações para a navegação. Nota-se que esta etapa inclui o módulo 1 de Orientação e posicionamento e o módulo 3 de Acionamento e controle dos propulsores.

Note-se que o "zero" com que é comparado o cabeceio e o rumo representa um valor nebuloso, isto é, o termo lingüístico "muito pouco".

\subsubsection{Síntese do Controlador na Etapa de Navegação $t_{n}$}

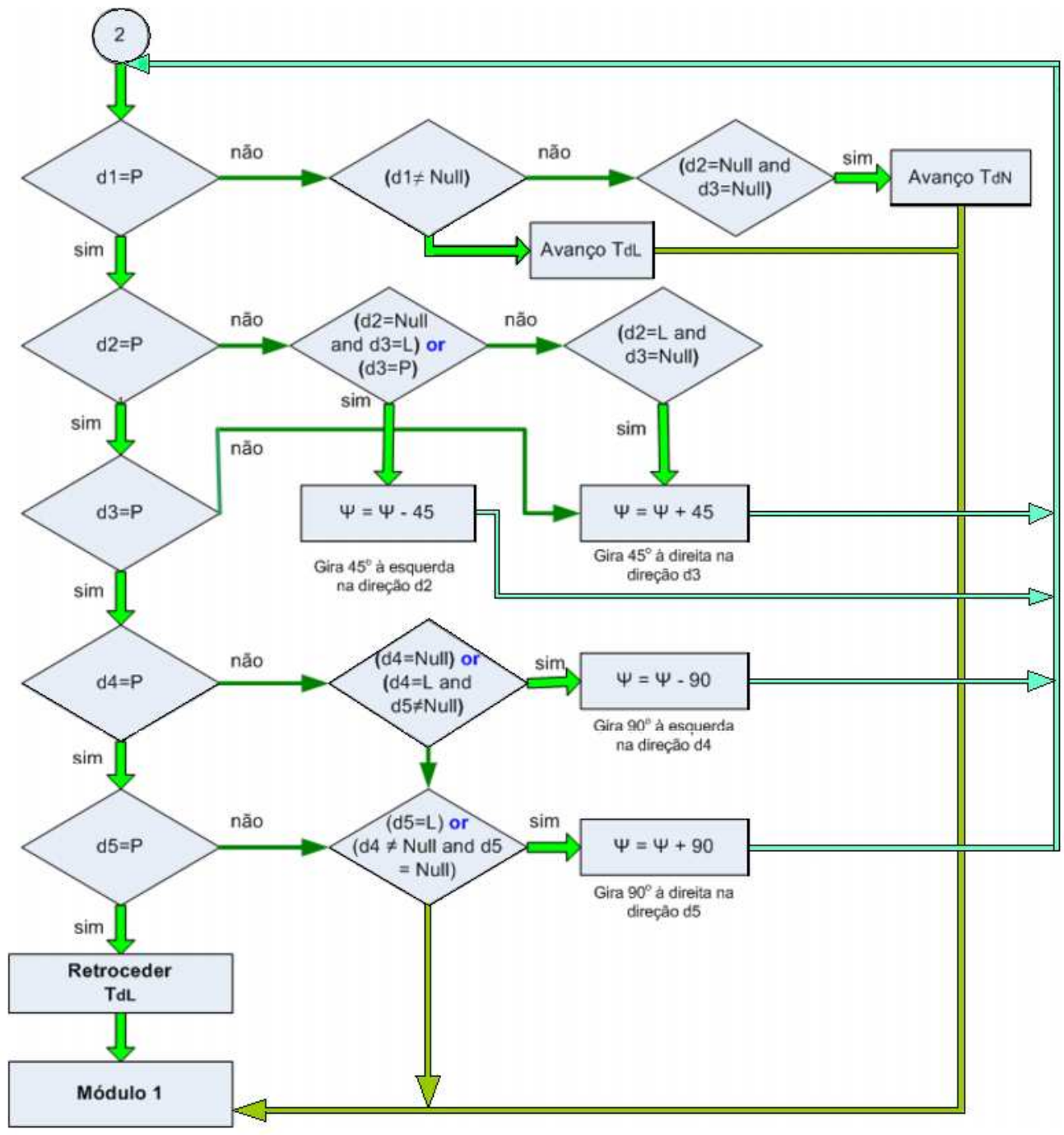

Figura 5.4: Diagrama de Fluxo para Evasão de Obstáculos do Controlador.

Na figura 5.4 apresenta-se o modo de funcionamento da etapa $t_{n}$. Esta etapa será executada pela primeira vez depois de finalizar a etapa $t_{0}$, o que garante que o VSSA esteja orientado e 
posicionado corretamente para verificar a presença de obstáculos na trajetória (módulo 2 de Evasão de obstáculos). Está etapa se repetirá até que o VSSA ingresse no volume da posição objetivo passando à etapa $t_{f}$.

\subsubsection{Síntese do Controlador na Etapa Final $t_{f}$}

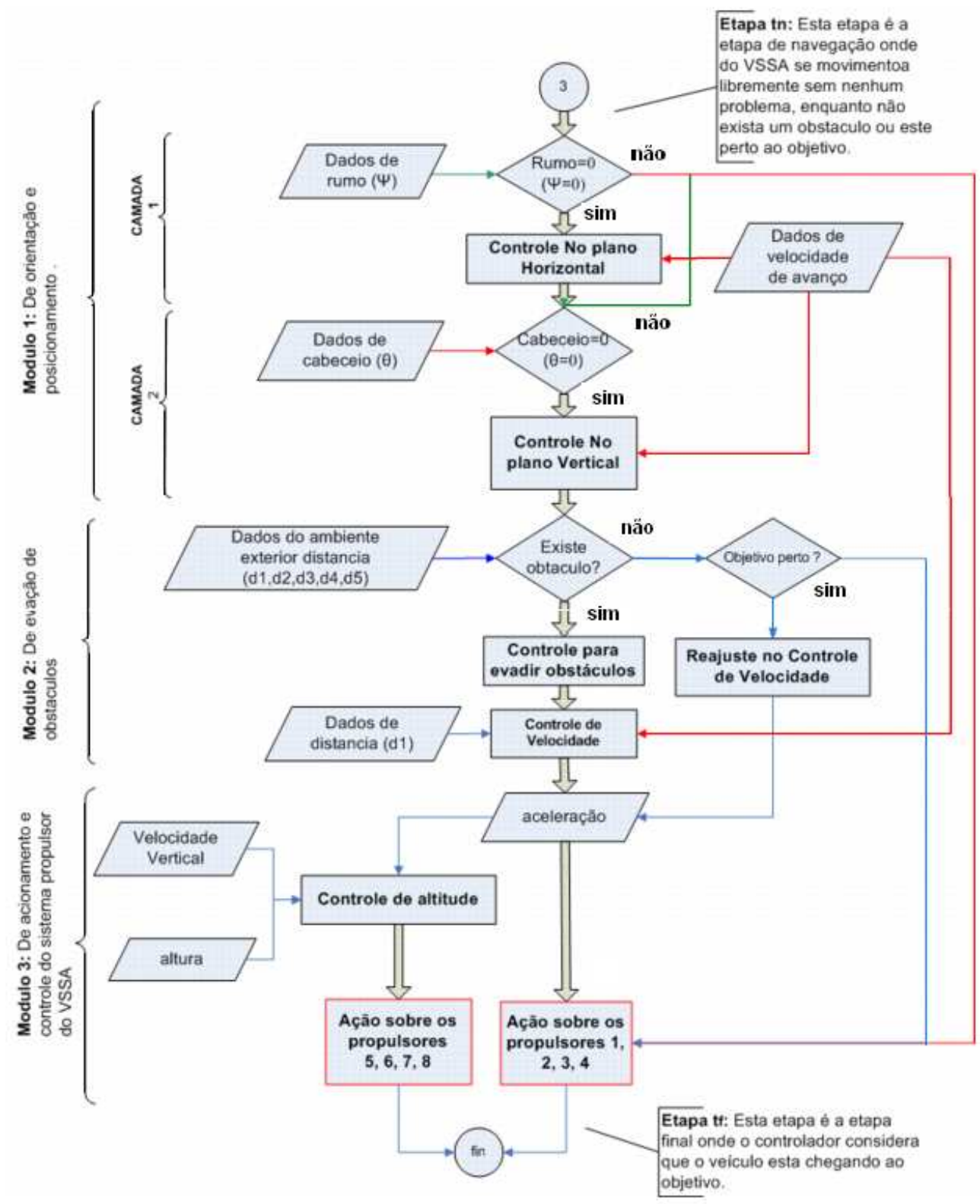

Figura 5.5: Diagrama de Fluxo da Etapa $t_{n}$ e Etapa $t_{f}$ do Controlador.

Na figura 5.5 apresenta-se a seqüencia de passos necessários para garantir a navegação e como é que se chega a ação dos propulsores e as reações do veículo frente a qualquer situação desde o momento que se encontra na profundidade desejada até que chegue à sua posição objetivo. 


\subsection{Módulo 1: Orientação e Posicionamento}

Este módulo tem como objetivo definir o controle nebuloso de orientação e posicionamento do VSSA. Os dados gerados pelos sensores internos e os dados do planejador são comparados, gerando os erros que são minimizados pelo controlador .

\subsubsection{Camada 1: Controle Horizontal}

Nesta seção o controle no plano horizontal $X Y$ é estudado, é a camada que trata o controle de rumo em relação à variação de mudança de erro de rumo e a velocidade de avanço. Para controlar o ângulo na horizontal do VSSA, tem-se a variável erro de rumo. Esta variável definirá a diferença entre a rota atual do VSSA e o rumo correto para atingir o objetivo em função de um ângulo de rotação. Esta variável terá influência direta sobre a direção do veículo.

A direção dos propulsores será ajustada de acordo com o grau de pertinência de cada regra onde a variável rumo aparece, como se apresenta a seguir. O nível de inferência será definido pelos modificadores lingüísticos.

\section{Definição das Variáveis no Controle Horizontal}

Nesta camada tem-se duas entradas uma saída como se mostra na figura 5.6

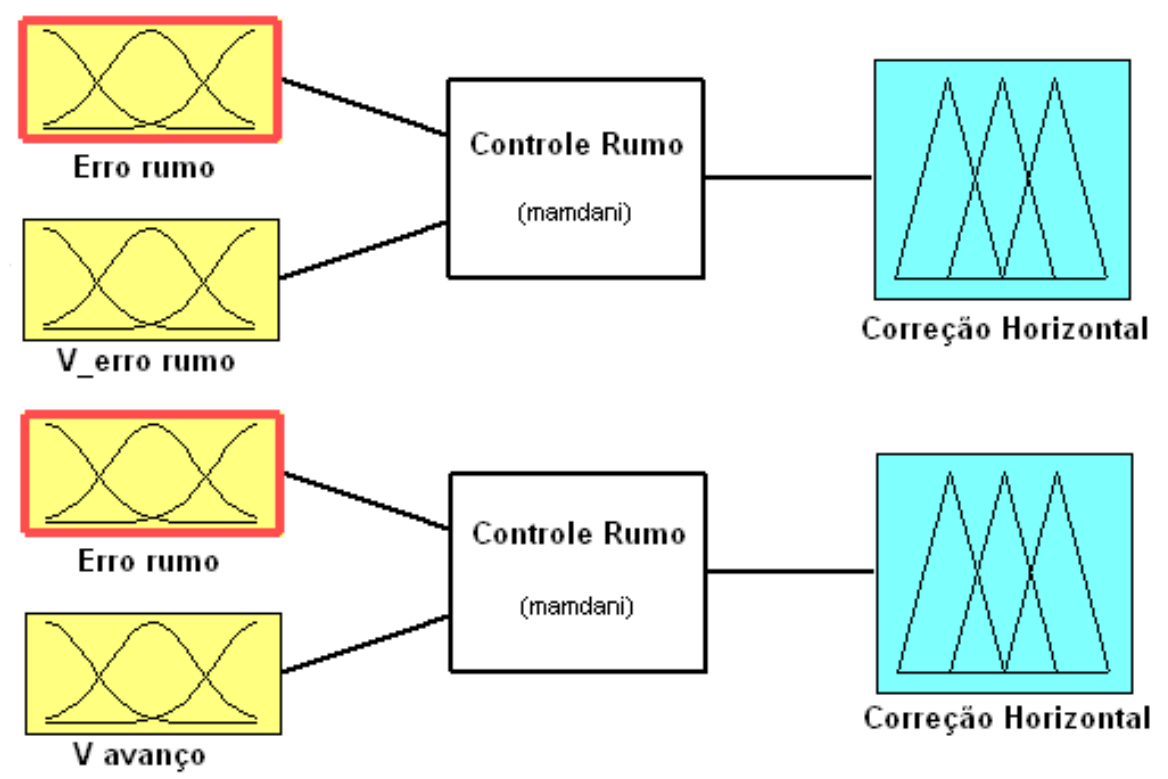

Figura 5.6: Variáveis Lingüísticas de Entrada e Saída Para o Controle Horizontal (Correção de Rumo).

É necessário definir as variáveis mais importantes que influem nesta camada, porém o erro de rumo é a variável de entrada que determina um valor que constata o ângulo de rotação do VSSA num certo instante em relação ao plano horizontal. O rumo do veículo depende 
também da mudança do erro, assim como da velocidade de avanço do veículo. Também tem-se a variável de saída chamada correção horizontal, com a qual determina-se o que é preciso fazer para corrigir o rumo do VSSA. Com estas duas variáveis lingüísticas, podem-se definir algumas das regras que entrarão na base de conhecimento, como por exemplo:

Se erro de rumo é grande então correção horizontal é grande.

Se erro de rumo é muito pequeno então correção horizontal é muito pequena.

Se erro de rumo é zero então correção horizontal é zero.

No entanto, ainda com estas regras não se conhece qual dos propulsores fará alguma tarefa específica. No módulo final considera-se que a operação de saída de correção é para o lado contrário ao erro do rumo, por exemplo se o erro é $10^{\circ}$ positivo a correção será $-10^{\circ}$ negativa.

Para que a direção de aproamento seja corrigida, utiliza-se a base de conhecimento, e na pratica será necessário dobrar o número de regras para atender ao fato de que o rumo pode ser negativo ou positivo. Sendo o sentido positivo o giro será para a direita, e sendo o o negativo o giro será para a esquerda.

\section{Definição dos Termos Lingüísticos no Controle Horizontal}

A correção horizontal não define quanto o veículo deve ser girado (ângulo de giro), mas sim as ações que os propulsores realizarão para tentar corrigir o erro de rumo do VSSA. Isto porque não se sabe se em um determinado momento o veículo está-se afastando ou se aproximando da rota desejada. Assim, o erro de rumo poderá assumir valores entre $-90^{\circ}$ e $90^{\circ}$.

Foram definidos os modificadores e domínios das funções de pertinência da variável erro de rumo, como os seguintes (o domínio dos modificadores está no sentido horário) :

-Máxima (-MX): de $-70^{\circ}$ a $-90^{\circ}$, -Muito grande (-MG): de $-55^{\circ}$ a $-85^{\circ}$, -Grande (-GR): de $-40^{\circ}$ a $-70^{\circ}$, - Média $(-M D)$ : de $-25^{\circ}$ a $-60^{\circ}$, -Pequena $(-P Q)$ : de $-10^{\circ}$ a $-40^{\circ}$, -Muito pequena $(-M P)$ : de $0^{\circ}$ a $-20^{\circ}$, Zero $(Z R)$ : de $-10^{\circ}$ a $10^{\circ}$, Muito pequena $(M P)$ : de $0^{\circ}$ a $20^{\circ}$, Pequena $(P Q)$ : de $10^{\circ}$ a $40^{\circ}$, Média $(M D)$ : de $25^{\circ}$ a $60^{\circ}$, Grande $(M G)$ : de $40^{\circ}$ a $70^{\circ}$, Muito grande $(M G)$ : de $55^{\circ}$ a $85^{\circ}$, Máxima (MX): de $70^{\circ}$ a $90^{\circ}$.

Com isso podem-se desenhar as funções de pertinência que definem os conjuntos nebulosos da variável erro de rumo, como se apresenta na figura 5.7. 


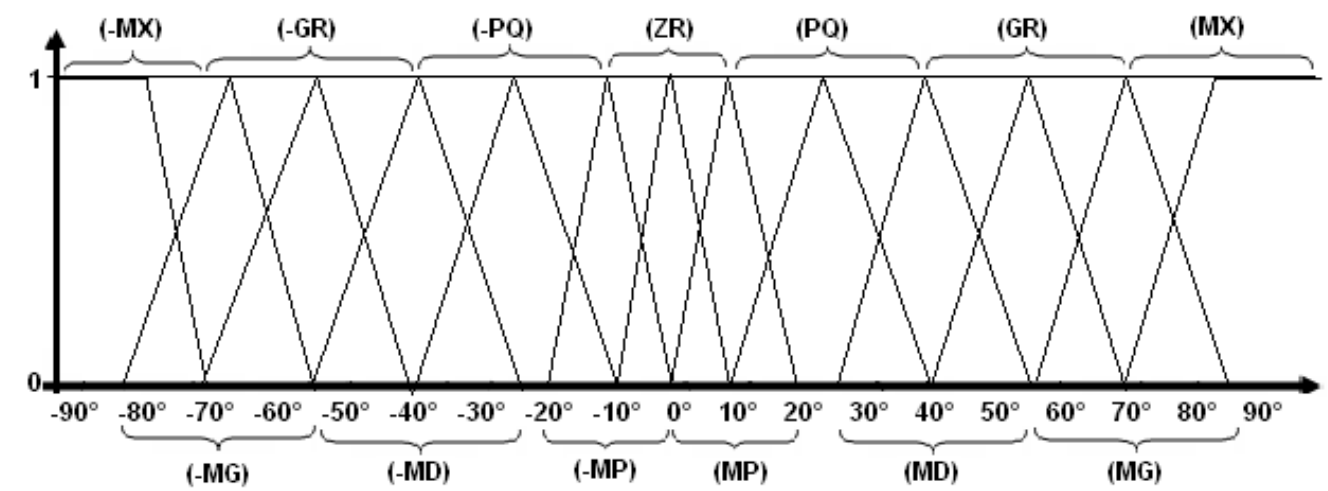

Figura 5.7: Conjuntos Nebulosos que Definem a Variável Erro de Rumo.

Vê-se que as funções de pertinência se concentram propositalmente mais em torno a $0^{\circ}$. Isto se deve ao fato de que, a freqüência com que se detecta o rumo do veículo é diferente do rumo desejado, é maior neste grupo, do que nas funções de pertinência que estejam perto de $90^{\circ}$. Além de isso, quanto mais longe esta a função de pertinência do $0^{\circ}$ (zero), mais o controlador demandará controle e maior quantidade de operações para corrigir o erro de rumo. Porém, quando se está em torno do $0^{\circ}$, é preciso ter um controle mais cuidadoso, para evitar operações bruscas.

Foram definidos os seguintes modificadores para a variável correção horizontal como se apresenta na figura 5.8:

-Máxima (-MX): de -100 a -90, -Muito grande (-MG): de -95 a -65, -Grande (-GR): de -80 a -50, -Média (-MD): de -65 a -35, -Pequena (-PQ): de -50 a -20, -Muito pequena (-MP): de -35 a -5 , Zero (ZR): de -10 a 10, Muito pequena (MP): de 5 a 35, Pequena (PQ): de 20 a 50, Média (MD): de 35 a 65, Grande (MG): de 50 a 80, Muito grande (MG): de 65 a 95, Máxima $(M X)$ : de 90 a 100.

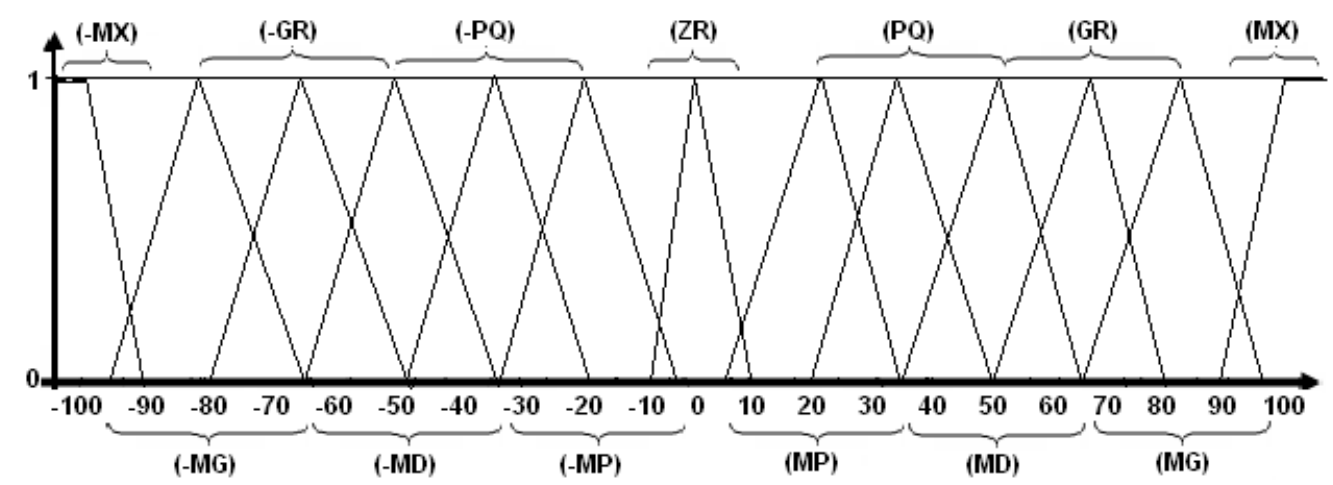

Figura 5.8: Conjuntos Nebulosos que Definem a Variável Correção Horizontal. 
No caso das funções de pertinência da variável correção horizontal, diferentemente da variável erro de rumo, assume-se a forma padrão de controladores nebulosos.

Para situações reais, não é suficiente o conhecimento do erro de rumo para controlar a direção no plano horizontal, se não também a velocidade de mudança do erro, já é dará uma idéia de quam rápido esta mudando ó erro e se ele tende a aumentar o erro ou a diminuir. Definiu-se os seguintes modificadores para a variável Verro de rumo: como se apresenta na figura 5.9:

-Muito grande (-MG): de $-100 \%$ a -80\%, -Grande (-GR): de $-100 \%$ a -60\%,-Média (-MD) de $-80 \%$ a $-40 \%$, -Pequena (-PQ): de $-60 \%$ a $-20 \%$, -Muito pequena (-MP): de $-40 \%$ a $-0 \%$, Zero (ZR): de $-20 \%$ a 20\%, Muito pequena (MP): de 0\% a 40\%, Pequena (PQ): de $20 \%$ a $60 \%$, Média (MD): de $40 \%$ a $80 \%$, Grande (MG): de $60 \%$ a 100\%, Muito grande (MG): de $80 \%$ a $100 \%$.

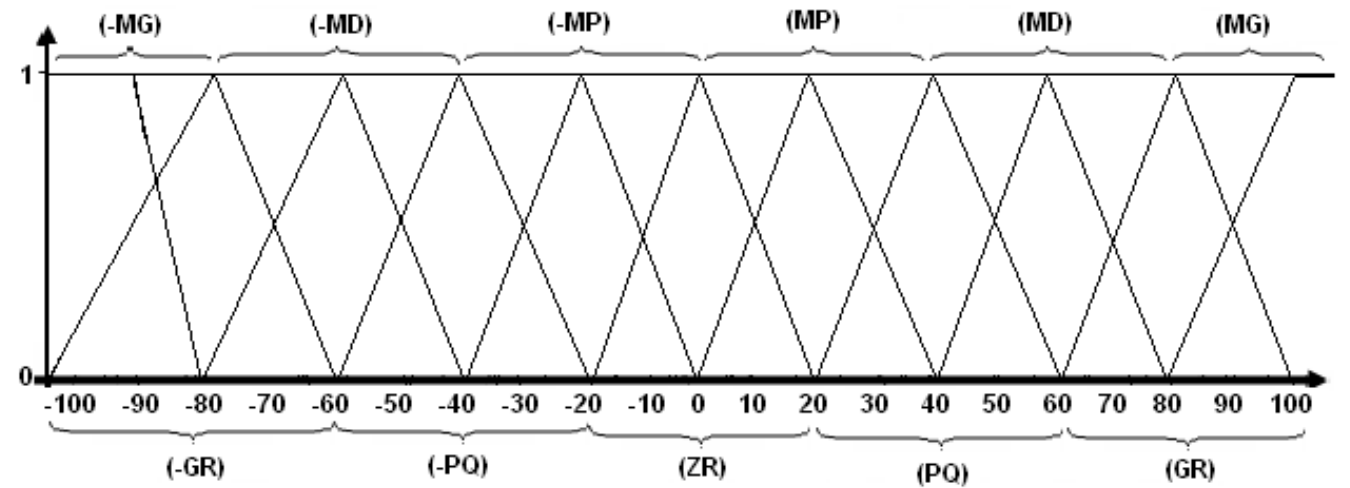

Figura 5.9: Conjuntos Nebulosos que Definem a Variável Verro de Rumo.

No controle da direção horizontal também é preciso conhecer a velocidade atual do VSSA e determinar com que velocidade se deve efetuar a correção do rumo. Porém, a correção horizontal também vai depender de uma outra variável, chamada de velocidade de avanço, que determina e armazena o valor de entrada sobre a velocidade atual do VSSA. Note-se que não se tem um modelo matemático específico do veículo definido para o projeto. Por isso, tudo é avaliado de forma genérica, expressa-se esta variável porcentualmente para que não se fique dependente da velocidade máxima de um veículo em especifico.

Foram definidos os seguintes modificadores para a variável velocidade de avanço:

Zero: de $0 \%$ a $10 \%$, Muito pequena: de $5 \%$ a $35 \%$, Pequena: de $20 \%$ a 50\%, Média: de $35 \%$ a $65 \%$, Grande: de $50 \%$ a $80 \%$, Muito grande: de $65 \%$ a 95\%, Máxima: de $90 \%$ a $100 \%$.

Usam-se os mesmos valores da variável correção horizontal, também expressa em porcentagem. Suas funções de pertinência serão também idênticas aos da correção horizontal como 
se apresenta na figura 5.10:

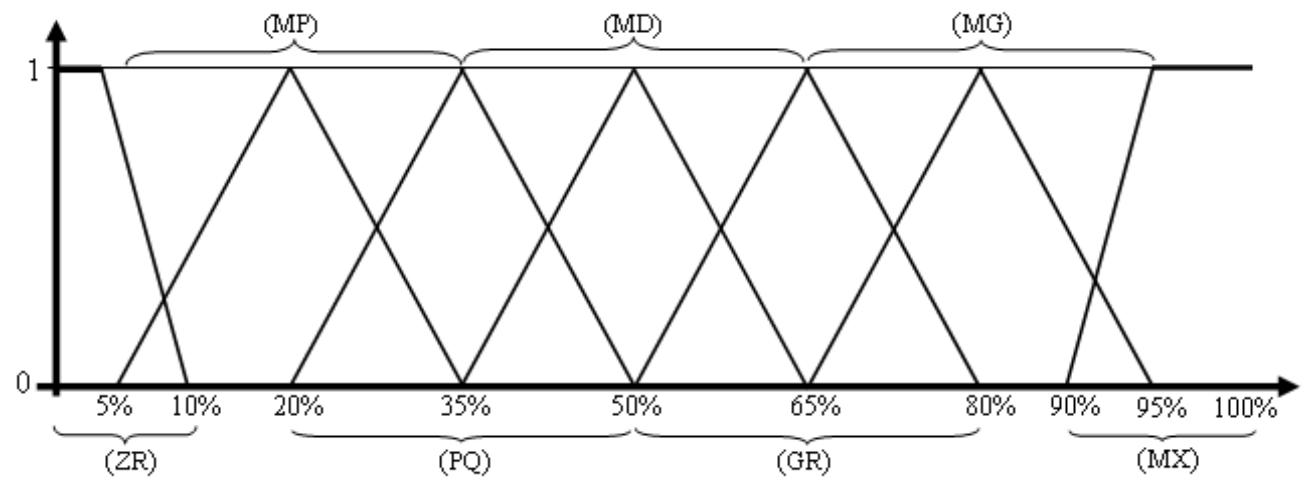

Figura 5.10: Conjuntos Nebulosos que Definem a Variável Velocidade de Avanço.

\section{Definição das Regras que Governam o Controle Horizontal}

As regras agora assumirão uma forma diferente, pois tem-se 3 entradas e uma saída, então há dois grupos de regras, um onde o erro de rumo depende da variação de erro para a definição do quanto têm-se que corrigir o posicionamento e um outro controlador de menor prioridade, onde estas regras vão se modificar dependendo da velocidade de avanço do veículo.

Quando o erro de rumo depende da variação de erro têm-se regras como por exemplo:

Se rumo é -Muito Grande e velocidade de erro de rumo é Média então correção horizontal é Pequena.

Se rumo é Zero e velocidade de erro de rumo é Grande então correção horizontal é -Grande. Se rumo é Pequena e velocidade de erro de rumo é Muito pequena então correção horizontal é média.

Quando o erro de rumo depende da velocidade de avanço têm-se regras como por exemplo:

Se rumo é grande e velocidade de avanço é muito pequena então correção horizontal é grande.

Se rumo é grande e velocidade de avanço é muito grande então correção horizontal é pequena.

Se rumo é médio e velocidade de avanço é pequena então correção horizontal é média.

Para cada modificador da variável erro de rumo, tem-se que associá-lo a todos os modificadores das variáveis Velocidade de erro de rumo e velocidade de avanço, gerando as regras 
necessárias para calcular a variável correção horizontal de forma matricial, como se mostra nas tabelas 5.1 e 5.2 :

Tabela 5.1: Regras para o Controle Correção Horizontal Dependendo da Variação de Velocidade de Erro

\begin{tabular}{|c|c|c|c|c|c|c|c|c|c|c|c|}
\hline ErroRumo/VelErroRumo & $-\mathrm{MG}$ & -GR & $-\mathrm{MD}$ & $-\mathrm{PQ}$ & $-M P$ & ZR & $-\mathrm{MG}$ & $\mathbf{P Q}$ & MD & GR & MG \\
\hline -MG & MG & MG & MG & MG & MG & MG & GR & MD & $\mathrm{PQ}$ & MP & ZR \\
\hline -GR & MG & MG & MG & MG & MG & GR & MD & $\mathrm{PQ}$ & MP & $\mathrm{ZR}$ & -MP \\
\hline$-M D$ & MG & MG & MG & MG & GR & MD & $\mathrm{PQ}$ & MP & $\mathrm{ZR}$ & $-\mathrm{MP}$ & $-\mathrm{PQ}$ \\
\hline$-\mathrm{PQ}$ & $\mathrm{MG}$ & $\mathrm{MG}$ & $\mathrm{MG}$ & GR & $\mathrm{MD}$ & $\mathrm{PQ}$ & MP & $\mathrm{ZR}$ & -MP & $-\mathrm{PQ}$ & $-\mathrm{MD}$ \\
\hline$-M P$ & MG & MG & GR & MD & $\mathrm{PQ}$ & MP & $\mathrm{ZR}$ & $-\mathrm{MP}$ & $-\mathrm{PQ}$ & $-\mathrm{MD}$ & -GR \\
\hline $\mathbf{Z R}$ & MG & GR & $\mathrm{MD}$ & $\mathrm{PQ}$ & MP & $\mathrm{ZR}$ & $-\mathrm{MP}$ & $-\mathrm{PQ}$ & $-\mathrm{MD}$ & $-G R$ & $-\mathrm{MG}$ \\
\hline MP & GR & $\mathrm{MD}$ & $\mathrm{PQ}$ & MP & $\overline{Z R}$ & $-\mathrm{MP}$ & $-\mathrm{PQ}$ & $-\mathrm{MD}$ & - GR & $-\mathrm{MG}$ & $-\mathrm{MG}$ \\
\hline$\overline{P Q}$ & $\mathrm{MD}$ & $\mathrm{PQ}$ & MP & $\mathrm{ZR}$ & -MP & $-\mathrm{PQ}$ & $-\mathrm{MD}$ & -GR & $-M G$ & $-M G$ & $-\mathrm{MG}$ \\
\hline MD & $\mathrm{PQ}$ & MP & $\mathrm{ZR}$ & -MP & $-\mathrm{PQ}$ & $-\mathrm{MD}$ & -GR & $-\mathrm{MG}$ & $-M G$ & $-M G$ & $-\mathrm{MG}$ \\
\hline$\overline{\text { GR }}$ & MP & $\overline{Z R}$ & $-\mathrm{MP}$ & $-\mathrm{PQ}$ & $-\mathrm{MD}$ & -GR & $-M G$ & $-M G$ & $-M G$ & $-M G$ & $-\mathrm{MG}$ \\
\hline MG & $\mathrm{ZR}$ & $-\mathrm{MP}$ & $-\mathrm{PQ}$ & $-\mathrm{MD}$ & $-G R$ & $-\mathrm{MG}$ & $-\mathrm{MG}$ & $-\mathrm{MG}$ & $-\mathrm{MG}$ & $-\mathrm{MG}$ & $-\mathrm{MG}$ \\
\hline
\end{tabular}

Tabela 5.2: Regras para o Controle Correção Horizontal Dependendo da Velocidade de Avanço

\begin{tabular}{|c|c|c|c|c|c|c|c|}
\hline Erumo/V avanço & ZR & MP & $\overline{P Q}$ & MD & GR & MG & MX \\
\hline$-\mathrm{MX}$ & $\mathrm{ZR}$ & $-\mathrm{MG}$ & -GR & -GR & $-\mathrm{MD}$ & $-\mathrm{PQ}$ & $-\mathrm{PQ}$ \\
\hline$-M G$ & $\mathrm{ZR}$ & -GR & -GR & -GR & $-\mathrm{MD}$ & $-\mathrm{PQ}$ & $-\mathrm{PQ}$ \\
\hline -GR & ZR & -GR & -GR & $-\mathrm{MD}$ & $-\mathrm{PQ}$ & $-\mathrm{PQ}$ & $-\mathrm{PQ}$ \\
\hline$-M D$ & $\mathrm{ZR}$ & -GR & -MD & $-\mathrm{PQ}$ & $-\mathrm{PQ}$ & $-\mathrm{PQ}$ & $-\mathrm{PQ}$ \\
\hline$-\mathrm{PQ}$ & $\mathrm{ZR}$ & $-\mathrm{MD}$ & $-\mathrm{PQ}$ & $-\mathrm{PQ}$ & $-\mathrm{PQ}$ & $-\mathrm{PQ}$ & $-\mathrm{PQ}$ \\
\hline -MP & ZR & $-\mathrm{PQ}$ & $-\mathrm{PQ}$ & $-\mathrm{PQ}$ & $-\mathrm{PQ}$ & $-\mathrm{PQ}$ & $-\mathrm{PQ}$ \\
\hline ZR & $\mathrm{ZR}$ & $\mathrm{ZR}$ & $\mathrm{ZR}$ & $\mathrm{ZR}$ & $\mathrm{ZR}$ & $\mathrm{ZR}$ & ZR \\
\hline MP & $\mathrm{ZR}$ & $\mathrm{PQ}$ & $\mathrm{PQ}$ & $\mathrm{PQ}$ & $\mathrm{PQ}$ & $\mathrm{PQ}$ & $\mathrm{PQ}$ \\
\hline $\mathbf{P Q}$ & $\mathrm{ZR}$ & $\mathrm{MD}$ & $\mathrm{PQ}$ & $\mathrm{PQ}$ & $\mathrm{PQ}$ & $\mathrm{PQ}$ & $\mathrm{PQ}$ \\
\hline MD & $\mathrm{ZR}$ & GR & MD & $\mathrm{PQ}$ & $\mathrm{PQ}$ & PQ & $\mathrm{PQ}$ \\
\hline GR & $\mathrm{ZR}$ & GR & GR & MD & $\mathrm{PQ}$ & $\mathrm{PQ}$ & $\mathrm{PQ}$ \\
\hline MG & $\mathrm{ZR}$ & GR & GR & GR & $\mathrm{MD}$ & $\mathrm{PQ}$ & $\mathrm{PQ}$ \\
\hline MX & $\mathrm{ZR}$ & MG & GR & GR & $\mathrm{MD}$ & $\mathrm{PQ}$ & $\mathrm{PQ}$ \\
\hline
\end{tabular}

Onde: $Z R$ é Zero, $M P$ é Muito Pequeno(a), $P Q$ é Pequeno(a), $M D$ é Médio(a), $G R$ é Grande, $M G$ é Muito Grande, $M X$ é Máxima. Nesta matriz tem-se representadas todas as regras da primeira camada, onde cada posição definirá o quanto deve-se girar o veículo para um determinado erro de rumo, velocidade de mudança do erro de rumo e velocidade de avanço. Esta é uma forma muito útil de visualizar as regras, pois é de fácil compreensão e compacta. Vai-se utilizar esta mesma representação nas demais camadas, utilizando os mesmos valores lingüísticos para os modificadores.

\subsubsection{Sobreposição dos Controladores na Correção de Rumo}

Antes de finalizar esta camada, é preciso levar-se em consideração que se tem dois controladores para uma saída só, então precisa-se de uma sobreposição de um controlador sobre o outro. É necessário verificar que controlador tem maior prioridade já que suas regras em geral provocaram modificações pouco expressivas. Quando a variável de correção horizontal relativamente 
à mudança de erro de rumo é zero, não é necessário reavaliar a variável correção Horizontal relativamente à velocidade de avanço. Mas nos casos extremos, onde a correção horizontal relativamente ao mudança de erro de rumo é máxima ou a correção Horizontal respeito à velocidade de avanço é máxima, será preciso refazer os cálculos, para evitar movimentos bruscos e que afetem um desempenho ótimo do VSSA assim como para evitar ações contraditórias ao controlador.

\section{Definição das Regras que Governam a Correção de Rumo}

Definem-se as regras que finalmente governam esta camada como se mostra na tabela 5.3

Tabela 5.3: Regras de Sobreposição Para a Correção de Rumo

\begin{tabular}{|c|c|c|c|c|c|c|c|c|c|c|c|c|c|}
\hline $\mathrm{CH} \mathrm{Ve} / \mathrm{CH} \mathrm{Vx}$ & $-M X$ & $-M G$ & -GR & $-M D$ & $-\mathrm{PQ}$ & $-M P$ & ZR & MP & $\mathbf{P Q}$ & MD & GR & MG & $\mathrm{MX}$ \\
\hline$-\mathrm{MX}$ & $-\mathrm{MX}$ & $-\mathrm{MG}$ & $-\mathrm{MG}$ & -GR & $-\mathrm{MD}$ & $-\mathrm{PQ}$ & $\mathrm{ZR}$ & $-\mathrm{MX}$ & $-\mathrm{MX}$ & $-\mathrm{MX}$ & $-\mathrm{MX}$ & $-\mathrm{MX}$ & $-\mathrm{MX}$ \\
\hline$-\mathrm{MG}$ & $-\mathrm{MG}$ & -MG & -GR & -GR & $-\mathrm{MD}$ & $-\mathrm{PQ}$ & $\begin{array}{ll}\mathrm{ZR} \\
\end{array}$ & -MG & $-\mathrm{MG}$ & $-M G$ & -MG & $-\mathrm{MG}$ & $-\mathrm{MG}$ \\
\hline -GR & -GR & -GR & -GR & -MD & $-\mathrm{PQ}$ & $-\mathrm{PQ}$ & $\mathrm{ZR}$ & -GR & -GR & -GR & -GR & -GR & -GR \\
\hline -MD & $-\mathrm{MD}$ & $-\mathrm{MD}$ & $-\mathrm{MD}$ & $-\mathrm{MD}$ & $-\mathrm{PQ}$ & $-\mathrm{PQ}$ & ZR & $-\mathrm{MD}$ & -MD & $-\mathrm{MD}$ & $-\mathrm{MD}$ & $-\mathrm{MD}$ & -MD \\
\hline$-\mathrm{PQ}$ & $-\mathrm{MD}$ & $-\mathrm{MD}$ & $-\mathrm{MD}$ & $-\mathrm{PQ}$ & $-P Q$ & -MP & $\mathrm{ZR}$ & $-P Q$ & $-\mathrm{PQ}$ & $-\mathrm{PQ}$ & $-\mathrm{PQ}$ & $-\mathrm{PQ}$ & $-\mathrm{PQ}$ \\
\hline -MP & -MP & $-\mathrm{MP}$ & -MP & $-\mathrm{MP}$ & -MP & -MP & $\begin{array}{ll}\mathrm{ZR} \\
\end{array}$ & -MP & $-\mathrm{MP}$ & $-\mathrm{MP}$ & -MP & $-\mathrm{MP}$ & -MP \\
\hline ZR & $\mathrm{ZR}$ & $\mathrm{ZR}$ & $\mathrm{ZR}$ & $\mathrm{ZR}$ & $\mathrm{ZR}$ & ZR & ZR & $\mathrm{ZR}$ & $\mathrm{ZR}$ & $\mathrm{ZR}$ & $\mathrm{ZR}$ & ZR & $\mathrm{ZR}$ \\
\hline MP & MP & MP & MP & MP & MP & MP & $\mathrm{ZR}$ & MP & MP & MP & MP & MP & MP \\
\hline $\mathbf{P Q}$ & $\mathrm{PQ}$ & $\mathrm{PQ}$ & $\mathrm{PQ}$ & $\mathrm{PQ}$ & $\mathrm{PQ}$ & $\mathrm{PQ}$ & ZR & MP & $\mathrm{PQ}$ & $\mathrm{PQ}$ & MD & $\mathrm{MD}$ & MD \\
\hline MD & MD & MD & MD & MD & MD & MD & $\mathrm{ZR}$ & $\mathrm{PQ}$ & $\mathrm{PQ}$ & MD & MD & MD & MD \\
\hline GR & GR & GR & GR & GR & GR & GR & $\mathrm{ZR}$ & $\mathrm{PQ}$ & $\mathrm{PQ}$ & MD & GR & GR & GR \\
\hline MG & MG & $\mathrm{MG}$ & $\mathrm{MG}$ & MG & MG & MG & ZR & $\mathrm{PQ}$ & MD & GR & GR & MG & MG \\
\hline MX & MX & MX & MX & MX & $\mathrm{MX}$ & $\mathrm{MX}$ & ZR & $\mathrm{PQ}$ & MD & GR & MG & MG & MX \\
\hline
\end{tabular}

\subsubsection{Funcionamento do Controlador na Camada 1: Controle Horizontal}

Na figura 5.11 mostram-se as superfícies resultantes do mecanismo de inferência ao nebulizar o erro de rumo com a velocidade de mudança de erro, assim como com a velocidade de avanço. Para velocidades de avanço maiores e o maior erro de curso a velocidade de correção diminui, enquanto que quando a velocidade é mais baixa a correção de curso será muito rápida. Mostrase também a superfície de sobreposição, onde se dá prioridade à correção de rumo que depende da rapidez de mudança de erro. 

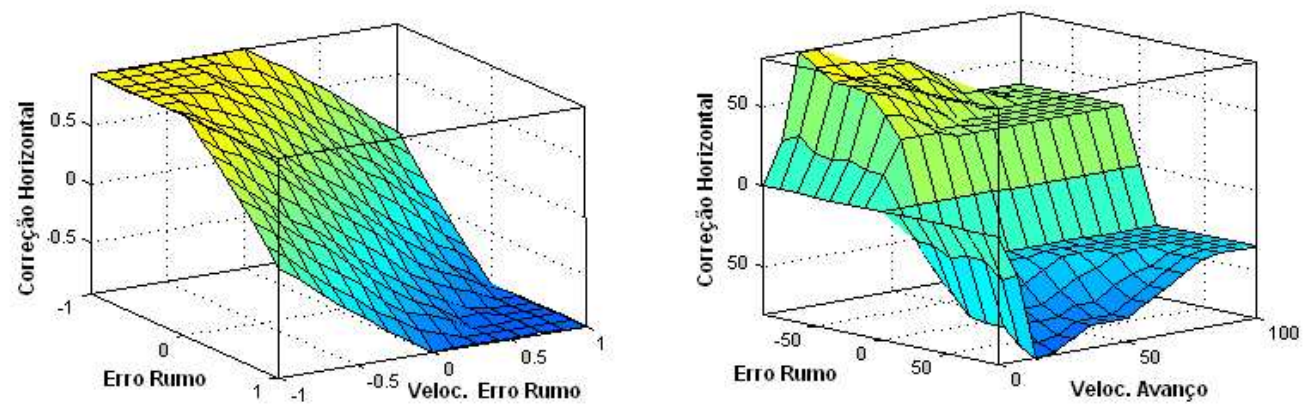

(a)

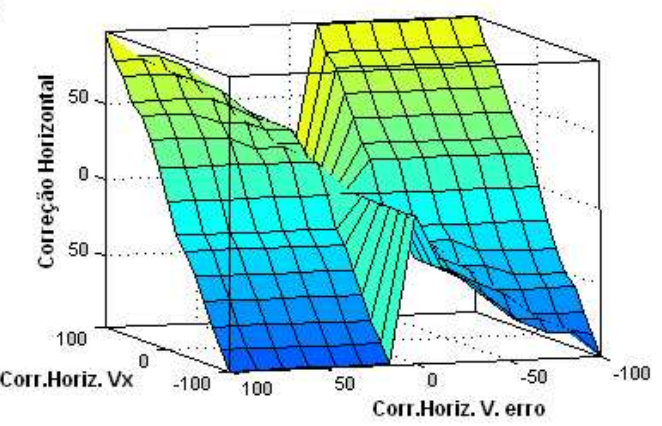

(b)

(c)

Figura 5.11: Resultados da Camada de Correção Horizontal, (a)Resposta da Correção de Rumo e a Velocidade de Mudança de Erro de Rumo, (b) Resposta da Correção de Rumo e a

Velocidade de Avanço (c)Resposta da Sobreposição dos dois Controladores Anteriores.

\subsubsection{Camada 2: Controle Vertical}

Outra variável importante é o ângulo de cabeceio que indicará se o VSSA está ascendendo, descendo, inclinado ou está estabilizado em um primeiro momento, pois outras variáveis influenciarão este movimento.

\section{Definição das Variáveis para o Controle Vertical}

Nesta camada tem-se três entradas uma saída como se mostra na figura 5.12. Chama-se esta variável de erro de cabeceio. Como se mostra na figura 5.13, esta variável pode assumir valores positivos e negativos, sendo positivo o fato de ir em direção à superfície, e negativo o fato de ir para o fundo. Se a variável assume valores muito altos para qualquer sentido, isto representa uma situação perigosa para o VSSA.

O tratamento deste controlador é similar ao controlador anterior, já que ele também depende da variação de erro. Assim como a velocidade de avanço influencia as regras para a variável correção horizontal, ela também terá um papel importante neste contexto. Assim precisa-se conhecer o valor da variável erro de cabeceio e a velocidade de avanço atual do VSSA. 


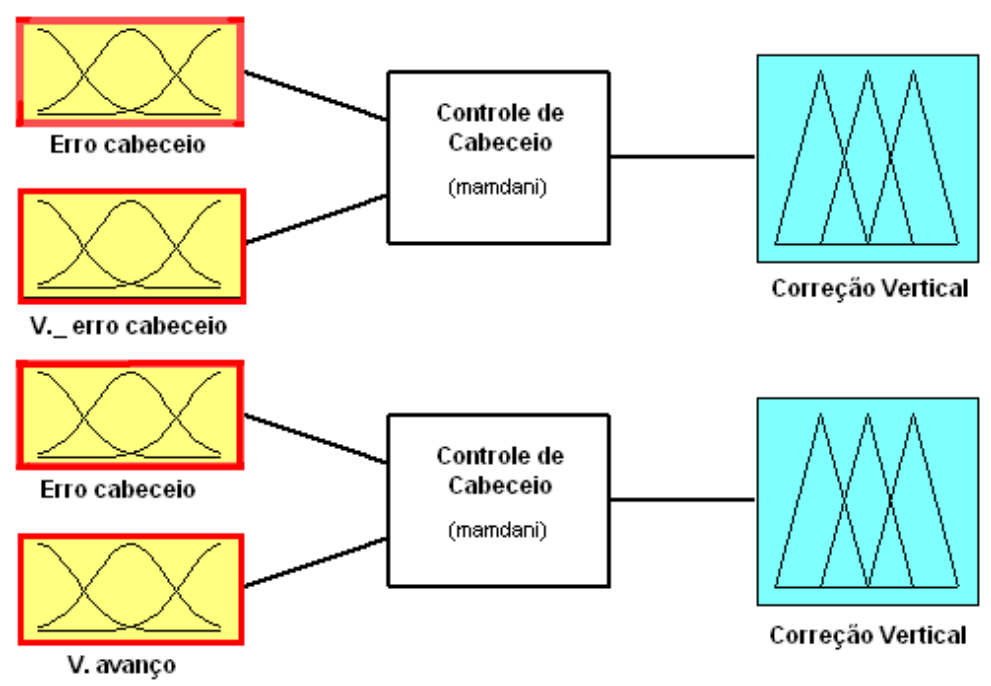

Figura 5.12: Variáveis Lingüísticas de Entrada e Saída para o Controle Vertical (Correção de Cabeceio).

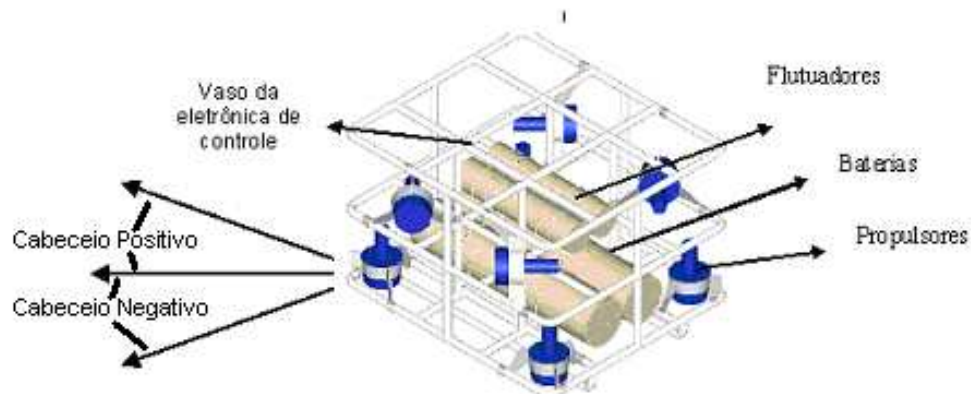

Figura 5.13: Movimento de Cabeceio no VSSA.

Por exemplo, a variável correção vertical é uma variável de saída formada por regras do tipo:

Se erro de cabeceio é grande e velocidade de avanço é grande então correção vertical é pequena.

Se erro de cabeceio é pequeno e velocidade de avanço é pequena então correção vertical é pequena.

Se erro de cabeceio é zero e velocidade de avanço é média então correção vertical é zero.

\section{Definição dos Termos Lingüísticos no Controle Vertical}

Novamente expressa-se a correção vertical em porcentagem e o cabeceio entre $-90^{\circ}$ e $90^{\circ}$. Para as funções de pertinência e modificadores do erro de cabeceio tem-se definições idênticas aos do erro de rumo: 
-Máxima $(-M X)$ : de $-70^{\circ}$ a $-90^{\circ}$, -Muito grande $(-M G)$ : de $-55^{\circ}$ a $-85^{\circ}$, -Grande $(-G R)$ : de $-40^{\circ}$ a $-70^{\circ}$, - Média (-MD): de $-25^{\circ}$ a $-60^{\circ}$, -Pequena (-PQ): de $-10^{\circ}$ a $-40^{\circ}$, -Muito pequena $(-M P)$ : de $0^{\circ}$ a $-20^{\circ}$, Zero $(Z R)$ : de $-10^{\circ}$ a $10^{\circ}$, Muito pequena $(M P)$ : de $0^{\circ}$ a $20^{\circ}$, Pequena $(P Q)$ : de $10^{\circ}$ a $40^{\circ}$, Média $(M D)$ : de $25^{\circ}$ a $60^{\circ}$, Grande $(M G)$ : de $40^{\circ}$ a $70^{\circ}$, Muito grande $(M G)$ : de $55^{\circ}$ a $85^{\circ}$, Máxima $(M X)$ : de $70^{\circ}$ a $90^{\circ}$.

Com isso é possível desenhar os conjuntos nebulosos que definem a variável erro de cabeceio como se apresenta na figura 5.14.

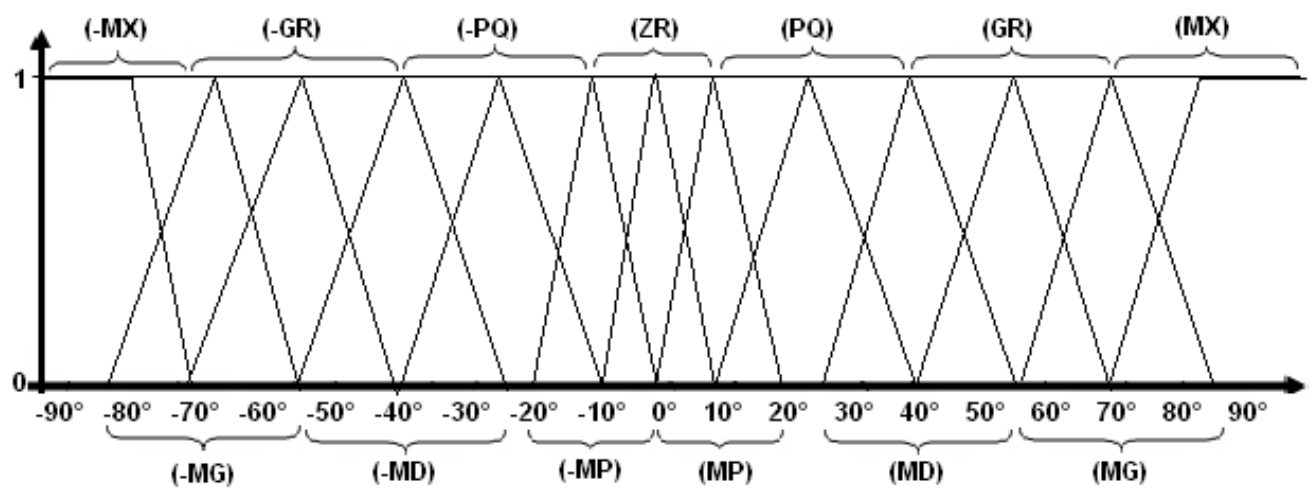

Figura 5.14: Conjuntos Nebulosos que Definem a Variável Cabeceio.

Da mesma forma, tem-se as mesmas funções de pertinência para a variável correção vertical como se apresenta na figura 5.15.

-Máxima (-MX): de -100 a -90, -Muito grande (-MG): de -95 a -65, -Grande (-GR): de -80 a -50, -Média (-MD): de -65 a -35, -Pequena (-PQ): de -50 a -20, -Muito pequena (-MP): de -35 a -5 , Zero (ZR): de -10 a 10, Muito pequena (MP): de 5 a 35, Pequena (PQ): de 20 a 50, Média (MD): de 35 a 65, Grande ( $M G)$ : de 50 a 80, Muito grande (MG): de 65 a 95, Máxima $(M X):$ de 90 a 100 ,

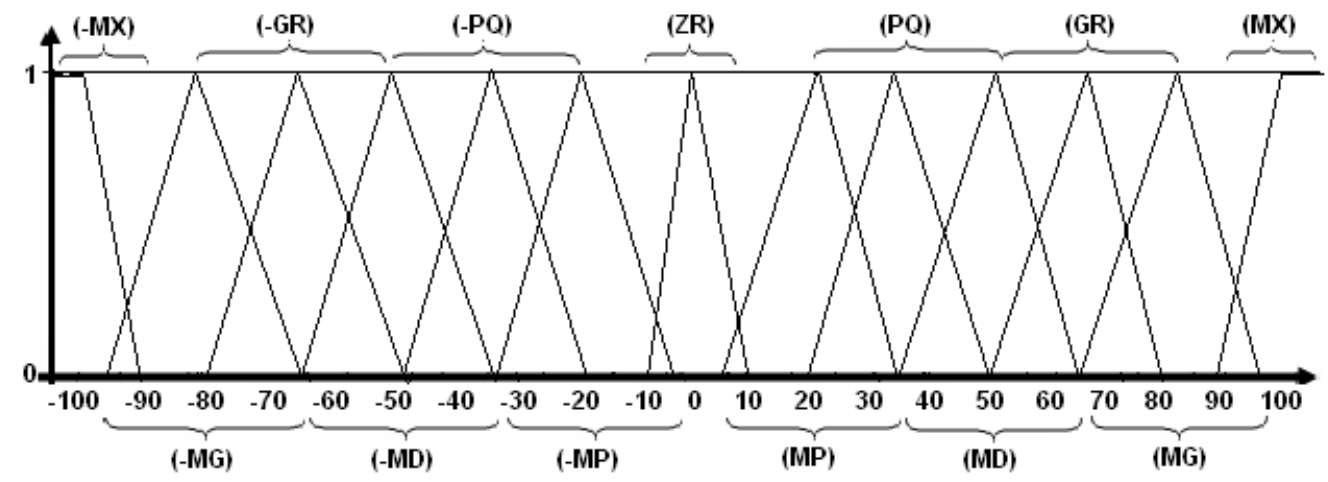

Figura 5.15: Conjuntos Nebulosos que Definem a Variável Correção Vertical. 


\section{Definição das Regras que Governam o Controle Vertical}

Agora têm-se dois grupos de regras do mesmo modo que na camada anterior. Trata-se o erro de cabeceio com cada uma das variáveis e se faz uma sobreposição de controlador a controlador para definir qual tem prioridade sobre qual, e como influencia a correção do erro de cabeceio. No caso da mudança de erro são têm-se regras similares às regras correção de rumo, enquanto, que para cada modificador da variável erro de cabeceio, tem-se que associá-lo a todos os modificadores da variável velocidade de avanço, gerando as regras necessárias para calcular a variável correção vertical em forma matricial como se mostra na tabela 5.4.

Tabela 5.4: Regras para a Variável Correção Vertical

\begin{tabular}{|c|c|c|c|c|c|c|c|}
\hline Cabeceio/Vel. Avanço & ZR & MP & PQ & MD & GR & MG & MX \\
\hline -MX & $\mathrm{ZR}$ & $-\mathrm{MG}$ & $-G R$ & -GR & $-\mathrm{MD}$ & $-\mathrm{PQ}$ & $-\mathrm{PQ}$ \\
\hline$-M G$ & $\mathrm{ZR}$ & $-G R$ & $-G R$ & $-G R$ & $-\mathrm{MD}$ & $-\mathrm{PQ}$ & $-\mathrm{PQ}$ \\
\hline -GR & $\mathrm{ZR}$ & $-G R$ & $-\mathrm{GR}$ & $-\mathrm{MD}$ & $-\mathrm{PQ}$ & $-\mathrm{PQ}$ & $-\mathrm{PQ}$ \\
\hline$-M D$ & $\mathrm{ZR}$ & $-G R$ & $-\mathrm{MD}$ & $-\mathrm{PQ}$ & $-\mathrm{PQ}$ & $-\mathrm{PQ}$ & $-\mathrm{PQ}$ \\
\hline$-\mathrm{PQ}$ & $\mathrm{ZR}$ & $-\mathrm{MD}$ & $-\mathrm{PQ}$ & $-\mathrm{PQ}$ & $-\mathrm{PQ}$ & $-\mathrm{PQ}$ & $-\mathrm{PQ}$ \\
\hline -MP & $\mathrm{ZR}$ & $-\mathrm{PQ}$ & $-\mathrm{PQ}$ & $-\mathrm{PQ}$ & $-\mathrm{PQ}$ & $-\mathrm{PQ}$ & $-\mathrm{PQ}$ \\
\hline ZR & ZR & ZR & $\mathrm{ZR}$ & ZR & ZR & $\mathrm{ZR}$ & ZR \\
\hline MP & $\mathrm{ZR}$ & $\mathrm{PQ}$ & $\mathrm{PQ}$ & $\mathrm{PQ}$ & $\mathrm{PQ}$ & $\mathrm{PQ}$ & $\mathrm{PQ}$ \\
\hline PQ & ZR & $\mathrm{MD}$ & $\mathrm{PQ}$ & $\mathrm{PQ}$ & $\mathrm{PQ}$ & $\mathrm{PQ}$ & $\mathrm{PQ}$ \\
\hline MD & ZR & GR & MD & $\mathrm{PQ}$ & $\mathrm{PQ}$ & $\mathrm{PQ}$ & $\mathrm{PQ}$ \\
\hline GR & ZR & GR & GR & $\mathrm{MD}$ & $\mathrm{PQ}$ & $\mathrm{PQ}$ & $\mathrm{PQ}$ \\
\hline MG & ZR & GR & GR & GR & MD & $\mathrm{PQ}$ & $\mathrm{PQ}$ \\
\hline MX & $\mathrm{ZR}$ & $\mathrm{MG}$ & GR & GR & MD & $\mathrm{PQ}$ & $\mathrm{PQ}$ \\
\hline
\end{tabular}

\subsubsection{Funcionamento do Controlador na Camada 2: Controle Vertical}

Na figura 5.16 mostram-se as superfícies resultantes do mecanismo de inferência ao nebulizar o erro de cabeceio com a velocidade de mudança de erro e a velocidade de avanço. Para velocidades maiores e erros pequenos a correção é quase nula, enquanto que quando a velocidade é baixa e a correção de cabeceio for grande a correção será grande.

\subsubsection{Sobreposição do Controlador Vertical sobre o Controlador Horizontal}

Antes de finalizar a camada 1 de orientação e posicionamento, é preciso levar-se em consideração o fato de que a variável correção horizontal e correção vertical têm um relação direta uma sobre a outra na tomada de decisão final para sair da camada 2 de navegação. Então, é preciso avaliarse o momento de sobrepor a variável correção vertical sobre a variável correção horizontal para otimizar a tomada de decisão.

Quando a variável de correção horizontal é zero, não é necessário reavaliar a variável correção vertical. Mas nos casos extremos, onde a correção vertical é máxima ou a correção horizontal é máxima, será preciso refazer os cálculos, para evitar movimentos bruscos e que afetem o desempenho do VSSA. 


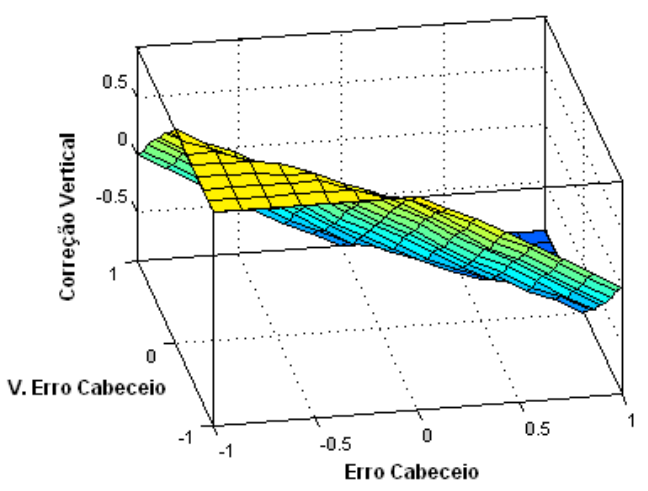

(a)

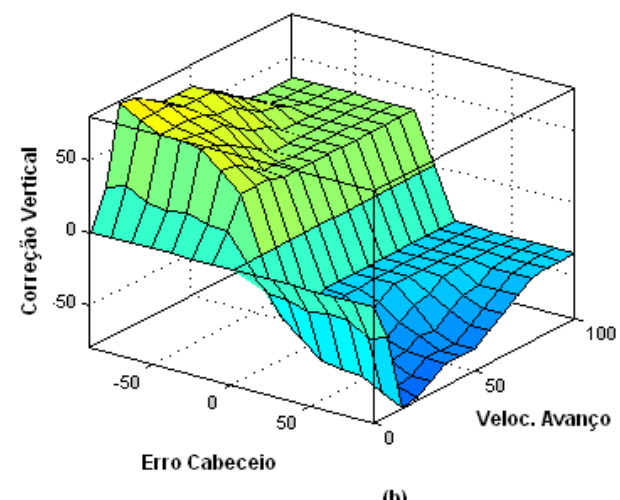

(b)

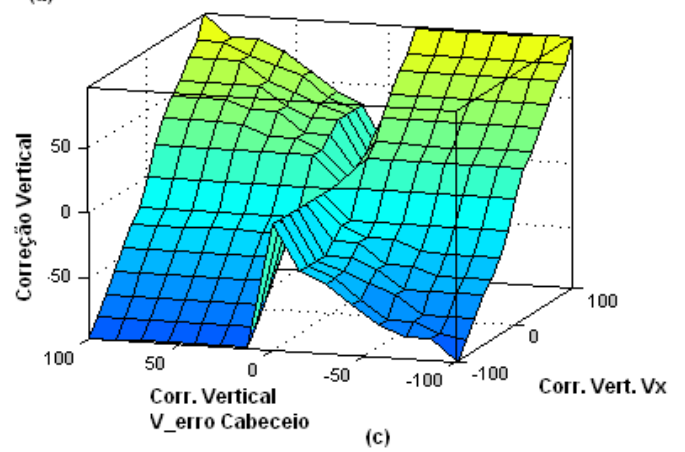

(c)

Figura 5.16: Resultados da Camada de Controle Vertical (Correção de

Cabeceio)(a)Resposta da Correção de Cabeceio e a Velocidade de Mudança de Erro de Cabeceio, (b) Resposta da Correção de Cabeceio e a Velocidade de Avanço (c)Resposta da Sobreposição dos Dois Controladores Anteriores .

Se o VSSA está subindo ou descendo com um cabeceio grande, deve-se nivelar o VSSA de forma que a subida ou descida seja mais eficiente e menos brusca. Por exemplo, se o VSSA sobe em linha reta, ascenderá mais rápido do que em curva, sendo que neste caso a correção horizontal zero e a correção vertical será de média até máxima.

Os casos extremos de correção vertical com correção horizontal são os casos mais críticos, quando se deseja que a correção seja a mais eficiente possível. Então, tem-se também algumas regras extras para esta camada.

\section{Definição das Regras que Governam a Sobreposição do Controle Vertical sobre o Horizontal}

Para cada modificador da variável correção vertical, tem-se que associá-lo com alguns dos modificadores da variável correção horizontal, gerando as regras necessárias para recalcular a variável correção vertical de forma matricial. Por exemplo, tem-se a variável correção vertical como a mesma variável de saída formando regras do tipo:

Se correção horizontal é grande e correção vertical é grande então correção horizontal é pequena. 
Se correção horizontal é média e correção vertical é muito grande então correção horizontal é zero.

Se correção horizontal é pequena e correção vertical é muito grande então correção horizontal é zero.

As condições destas regras são apenas os resultados das anteriores e não se precisa utilizar aqui o rumo, o cabeceio nem a velocidade de avanço. Por isso, definem-se apenas regras de sobreposição para modificadores com variáveis lingüísticas com valores de médios até máximos para a variável correção horizontal, corrigindo a correção horizontal nestes casos. A matriz de regras está descrita na tabela 5.5.

Tabela 5.5: Regras para a Variável Correção Horizontal com Sobreposição da Variável Correção Vertical

\begin{tabular}{|c|c|c|c|c|c|c|c|c|c|c|c|c|c|}
\hline C.Vert/C.Hor & $-\mathrm{MX}$ & -MG & -GR & -MD & $-P Q$ & -MP & ZR & MP & $\mathbf{P Q}$ & MD & GR & MG & $\mathrm{MX}$ \\
\hline$-\mathrm{MX}$ & ZR & -MP & -MP & -MP & $-\mathrm{PQ}$ & $-\mathrm{PQ}$ & ZR & MP & $\mathrm{PQ}$ & MP & MP & MP & ZR \\
\hline -MG & -MP & -MP & $\begin{array}{l}-\mathrm{PQ} \\
\end{array}$ & -MP & $-\mathrm{PQ}$ & $\begin{array}{l}-P Q \\
\end{array}$ & $\mathrm{ZR}$ & MP & $P Q$ & MP & MP & MP & $\mathrm{MP}$ \\
\hline -GR & -MD & $-\mathrm{MD}$ & $-\mathrm{PQ}$ & $-\mathrm{PQ}$ & $-\mathrm{PQ}$ & -MP & ZR & MP & $P Q$ & $P Q$ & $\mathrm{PQ}$ & $\mathrm{MD}$ & $\mathrm{MD}$ \\
\hline -MD & $-\mathrm{MD}$ & $-\mathrm{MD}$ & $-\mathrm{MD}$ & $-\mathrm{PQ}$ & $-\mathrm{PQ}$ & $-M P$ & ZR & MP & $\mathrm{PQ}$ & $\mathrm{PQ}$ & $\mathrm{MD}$ & $\mathrm{MD}$ & $\mathrm{MD}$ \\
\hline$-\mathrm{PQ}$ & $-\mathrm{MX}$ & $-M G$ & -GR & $-M D$ & $-\mathrm{PQ}$ & -MP & ZR & MP & $P Q$ & $\mathrm{MD}$ & GR & MG & $\mathrm{MX}$ \\
\hline -MP & $-\mathrm{MX}$ & -MG & -GR & $-\mathrm{MD}$ & $-\mathrm{PQ}$ & $-\mathrm{MP}$ & ZR & MP & $\mathrm{PQ}$ & MD & GR & MG & $\mathrm{MX}$ \\
\hline ZR & $-\mathrm{MX}$ & $-\mathrm{MG}$ & -GR & $-M D$ & $-\mathrm{PQ}$ & -MP & ZR & MP & $\mathrm{PQ}$ & MD & GR & MG & $\mathrm{MX}$ \\
\hline MP & $-\mathrm{MX}$ & $-\mathrm{MG}$ & $-G R$ & $-\mathrm{MD}$ & $-\mathrm{PQ}$ & $-M P$ & ZR & MP & $\mathrm{PQ}$ & MD & GR & MG & $\mathrm{MX}$ \\
\hline $\mathbf{P Q}$ & $-\mathrm{MX}$ & $-\mathrm{MG}$ & -GR & $-M D$ & $-\mathrm{PQ}$ & -MP & ZR & MP & $\mathrm{PQ}$ & MD & GR & MG & $\mathrm{MX}$ \\
\hline MD & -MD & -MD & $-\mathrm{MD}$ & $-\mathrm{PQ}$ & $-\mathrm{PQ}$ & $-\mathrm{MP}$ & ZR & MP & $\mathrm{PQ}$ & $\mathrm{PQ}$ & MD & $\mathrm{MD}$ & MD \\
\hline GR & -MD & $-\mathrm{MD}$ & $-\mathrm{PQ}$ & $-\mathrm{PQ}$ & $-\mathrm{PQ}$ & -MP & ZR & MP & $\mathrm{PQ}$ & $\mathrm{PQ}$ & $\mathrm{PQ}$ & $\mathrm{MD}$ & MD \\
\hline MG & -MP & -MP & $-\mathrm{PQ}$ & -MP & $-\mathrm{PQ}$ & -MP & ZR & MP & $\mathrm{PQ}$ & MP & MP & $\mathrm{MP}$ & MP \\
\hline MX & $\mathrm{ZR}$ & -MP & -MP & -MP & $-\mathrm{PQ}$ & -MP & ZR & MP & $\mathrm{PQ}$ & MP & MP & MP & ZR \\
\hline
\end{tabular}

\section{Sobreposição do Controle Vertical sobre o Controle Horizontal}

Na figura 5.17 mostra-se a superfície resultante da sobreposição das regras do controle horizontal e o controle vertical onde percebe-se que quando a correção vertical é maior a correção horizontal tem menor prioridade.
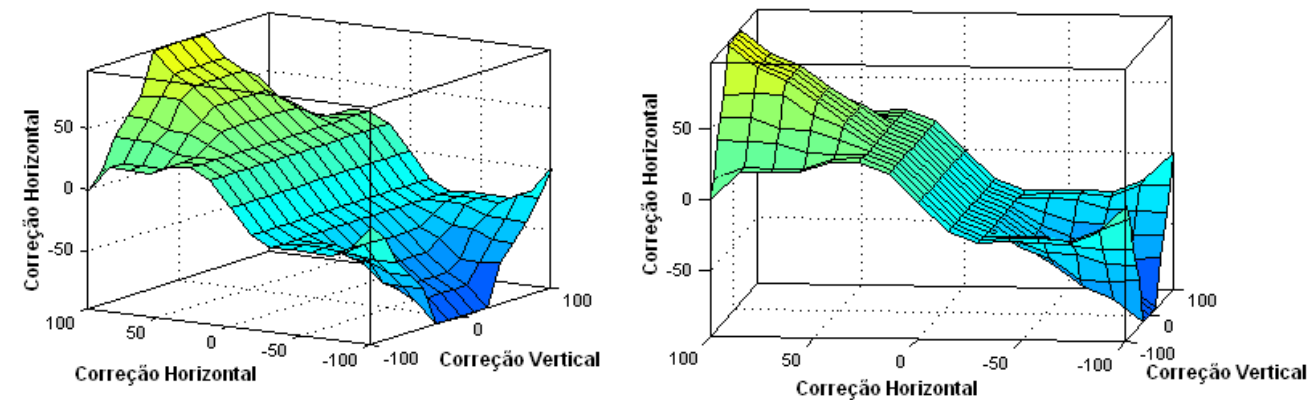

Figura 5.17: Resultados da Sobreposição do Controlador Vertical sobre o Controlador Horizontal. 


\subsection{Módulo 2: Evasão de Obstáculos}

Nesta fase, o objetivo é analisar o que está acontecendo no ambiente do VSSA, quer dizer, no caminho a seguir pelo VSSA para evitar obstáculos e colisões. Daí-Ju e Xinoguang (2002) propõe no seu trabalho o uso de um sensor sonar onde é possível determinar a distância do obstáculo com o VSSA em direções $d_{i}$, que são as entradas desta fase.

\section{Definição das Variáveis na Evasão de Obstáculos}

As variáveis lingüísticas que regem este módulo, são as distâncias em diferentes direções relativamente à presença de um obstáculo. São avaliadas 5 direções: para frente, $45^{\circ}$ para esquerda, $45^{\circ}$ para direita, $90^{\circ}$ para esquerda e $90^{\circ}$ graus para direita. As variáveis lingüísticas deste módulo são apresentadas na figura 5.18.

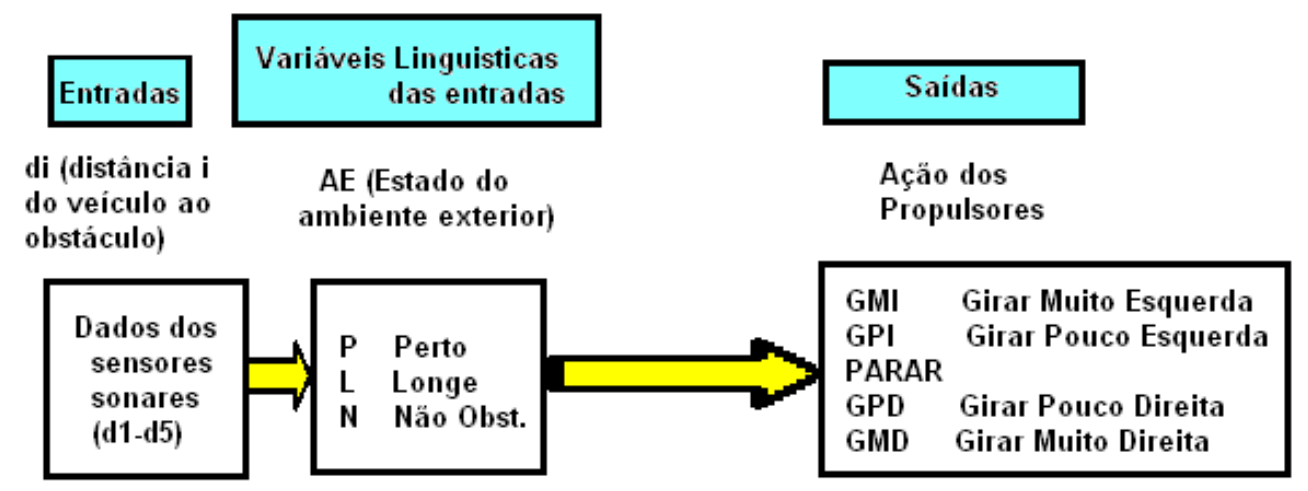

Figura 5.18: Variáveis Lingüísticas de Entrada e Saída para o Controle de Evasão de Obstáculos.

Cada termo tem uma regra semântica, e cada regra semântica está associada a uma função de pertinência. Neste exemplo as funções de pertinência têm formas triangulares e trapezoidais. Estas funções estão normalizadas em 1 (um). Um exemplo desta variável lingüística é apresentada na figura 5.19. As variáveis lingüísticas das saídas são determinadas indicando a direção e o grau de perigo que enfrenta o VSSA. 


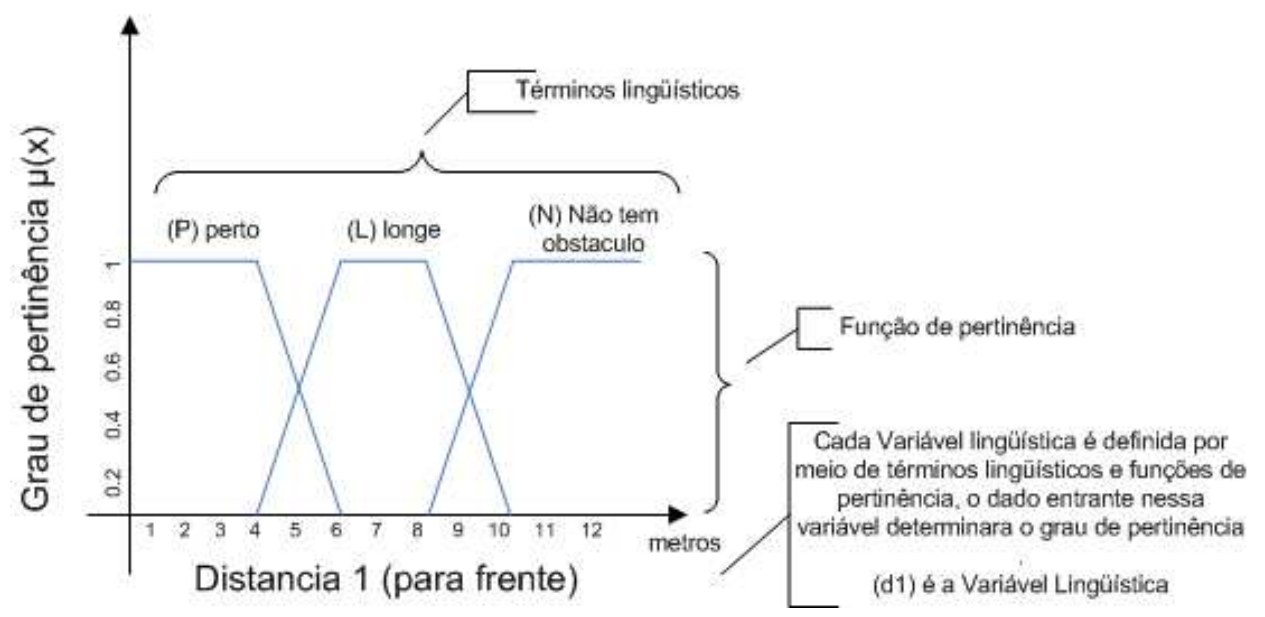

Figura 5.19: Conjuntos Nebulosos que Definem a Variável de Distância 1.

\section{Definição das Regras que Governam a Evasão de Obstáculos}

Interface de Nebulização: Neste caso tem-se 5 entradas de 3 termos lingüísticos (estados) cada uma, o que leva a 243 combinações. Depois de uma análise foram eliminadas várias regras, restando 101 combinações, considerando-se as camadas e devido a sobreposição dos controladores e à prioridade, as regras diminuem significativamente e podem ser divididas em 3 grupos, como ilustrando na figura 5.20.

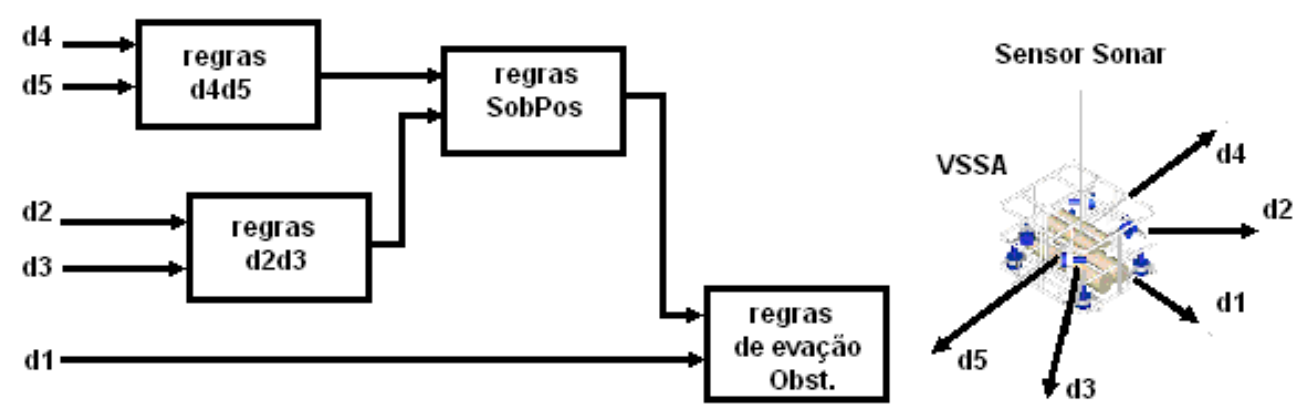

Figura 5.20: Diagrama de Sequência Para Projetar a Tarefa de Evasão de Obstáculos no VSSA.

Neste caso, a sintaxe das regras tem a seguinte redação:

$$
\text { Se }\left(d_{i} \text { é } A E_{k}\right) \text { então }\left(c_{j} \text { é } A P_{k}\right)
$$

Onde $d_{i}$ são as entradas; $A E_{k}$ um dos possíveis termos lingüísticos do universo de entrada; $c_{j}$ é o universo de saída que pode ser qualquer termo $A P_{k}$. A função de pertinência das regras é definida pelo mínimo do universo dos valores obtidos nas entradas comparado com o universo das saídas, como se apresentam nas seguintes equações: 


$$
\begin{gathered}
U R_{k}(d i, c j)=\min \left[U A E_{k}(d i), U A P_{k}(c j)\right] \\
U c(c j)=\max \left[U_{D i}(d i), U R_{k}(d i, c j)\right]
\end{gathered}
$$

Onde $U_{D i}$ é o conjunto do universos das entradas obtidas pelos sensores e $U R_{k}(d i, c j)$ é o conjunto do universo resultante da equação anterior.

Os resultados desta camada são mostrados na figura 5.21.

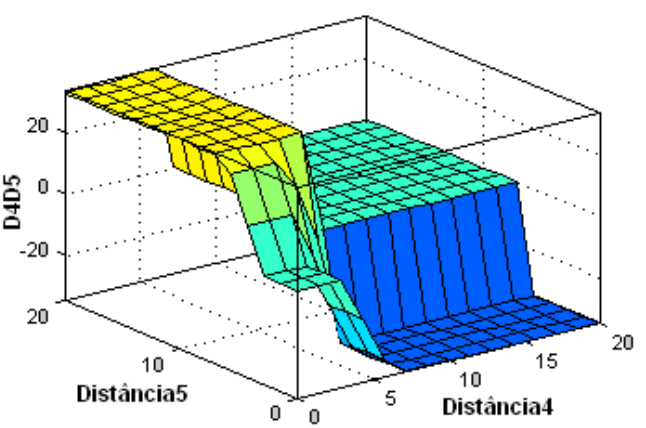

(a)

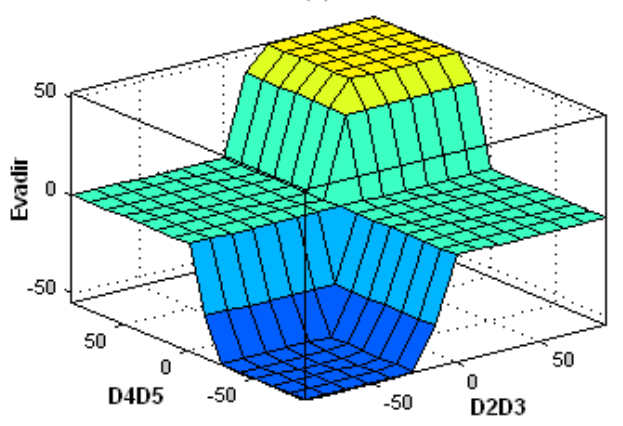

(c)

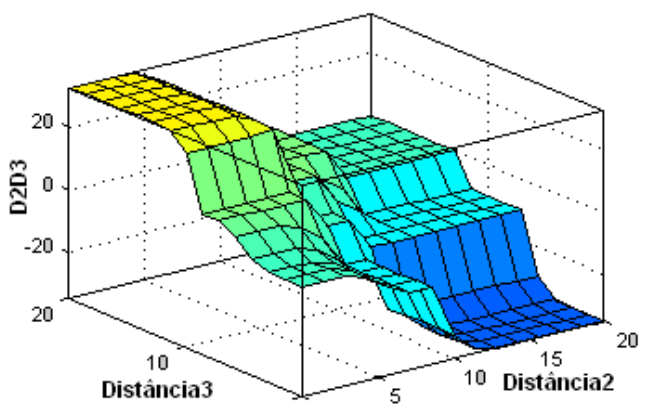

(b)

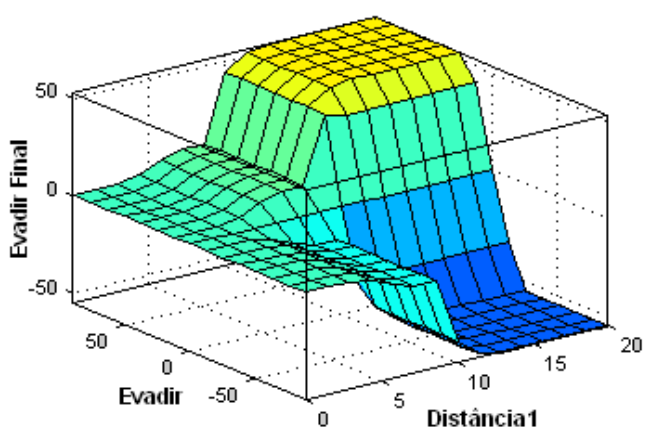

(d)

Figura 5.21: Respostas de Cada Bloco na Evasão de Obstáculos.

\subsection{Módulo 3: Navegação e Controle dos Propulsores}

Neste módulo, o controlador do veículo já corrigiu o erro de rumo, o erro de cabeceio e verificou se há ou não obstáculos.

Esta fase tem como objetivo definir o controlador nebuloso do sistema propulsor. A figura 5.22 mostra o arranjo e distribuição dos propulsores do VSSA. Para fins de controle, eles foram divididos em duas partes, os propulsores para os movimentos horizontais e os propulsores para os movimentos verticais. 


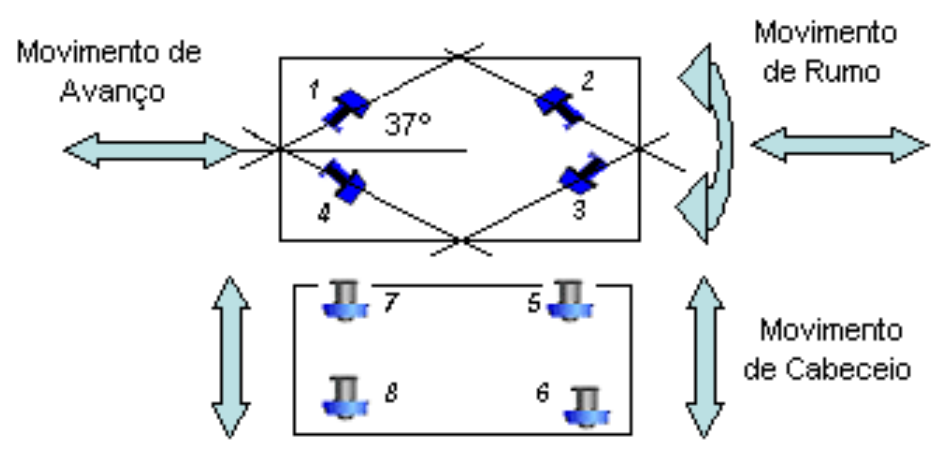

Figura 5.22: Distribuição dos Propulsores no VSSA.

\subsubsection{Camada 1: Controle de Velocidade de Avanço}

A velocidade de avanço é uma variável lingüística de entrada desta camada, que controla a velocidade relativa do VSSA, levando-se em consideração a velocidade da correnteza da água.

\section{Definição das Variáveis no Controle de Velocidade de Avanço}

Associa-se diretamente esta variável a outra variável de saída chamada aceleração. Como é mostrado na figura 5.23, a pesar da variável velocidade de avanço ser utilizada no processamento das variáveis de correção horizontal e correção vertical, esta variável de entrada não sofre nenhuma alteração nestes processos. A velocidade do veículo é algo difícil de controlar devido às forças externas atuantes, principalmente a correnteza marinha. Neste caso, será importante controlar a velocidade relativa do veículo, isto é levando-se em consideração a velocidade do fluido.

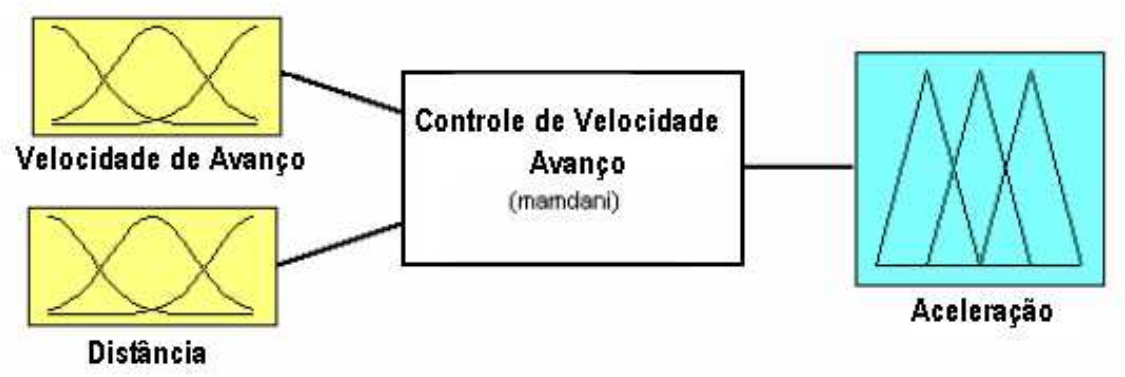

Figura 5.23: Variáveis Lingüísticas de Entrada e Saída para o Controle de Velocidade.

Esta variável (velocidade de avanço) terá um valor desejado mais ou menos constante durante a trajetória do VSSA, mas este valor pode mudar quando o veículo estiver perto do objetivo ou próximo a um obstáculo, permitindo tomar as precauções necessárias para o caso respectivo. 
Além das variáveis já mencionadas, é preciso introduzir mais uma variável lingüística, chamada distância, que vai indicar qual é a distância disponível entre o VSSA e um obstáculo ou o objetivo.

Como a velocidade de avanço foi uma variável definida na camada 1 do módulo 1, não se precisa redefini-la neste momento. No entanto, precisa-se ainda definir os modificadores da variável distância. Assim como na variável rumo, a variável distância terá suas funções de pertinência mais concentradas em torno de $0 \%$. Isto se deve ao fato de que a presença de um obstáculo perto do VSSA representará uma necessidade maior de atenção para atingir o desempenho ótimo.

A variável (distância) definirá apenas uma "distância de aproximação" do veículo a um certo ponto. Logo, quando assumir um valor determinado, significará que o VSSA acabou de entrar numa "área de aproximação" e que deve começar a executar operações para corrigir seu rumo.

Todos os valores assumidos pela variável distância serão relativos a esta "área de aproximação", definida por um perímetro ao redor das coordenadas do objetivo com um determinado raio. Este raio depende da velocidade atual do VSSA, do ângulo de giro a efetuar, da aceleração, da distância que está o obstáculo e do alcance de detecção do sonar. Além disso, define-se um perímetro com raio de 2 metros ao redor do objetivo (ponto de chegada), como uma chegada satisfatória, pois seria muito difícil conseguir estabilizar a veículo sobre uma coordenada pontual. Para não restringir a variável distância a uma distância fixa, devido a sua dependência da "distância de aproximação", este raio pode variar, por isso seus valores são definidos em termos de porcentagens.

Evitar muitas oscilações na mudança do rumo otimiza o desempenho, até mesmo porque a partir de uma certa distância (onde não há obstáculos) vai-se ter uma velocidade ideal definida, que será mantida na maior parte do tempo.

\section{Definição dos Termos Lingüísticos no Controle de Velocidade de Avanço}

Para as funções de pertinência e modificadores da distância tem-se:

Zero: de $0 \%$ a $16 \%$, Muito pequena: de $8 \%$ a $24 \%$, Pequena: de $16 \%$ a $32 \%$, Média: de $24 \%$ a $58 \%$, Grande: de $42 \%$ a $78 \%$, Muito grande: de $60 \%$ a 95\%, Máxima: de $83 \%$ a $100 \%$.

A variável de saída chamada aceleração, define na verdade a potência aplicada aos motores dos propulsores, como nos outros casos já vistos, para a correção horizontal e a correção vertical, as variáveis de saída que irão fazer a correção nos controles do VSSA. Assumem-se os mesmos modificadores expressos em porcentagens. Tem-se então, as seguintes definições para 


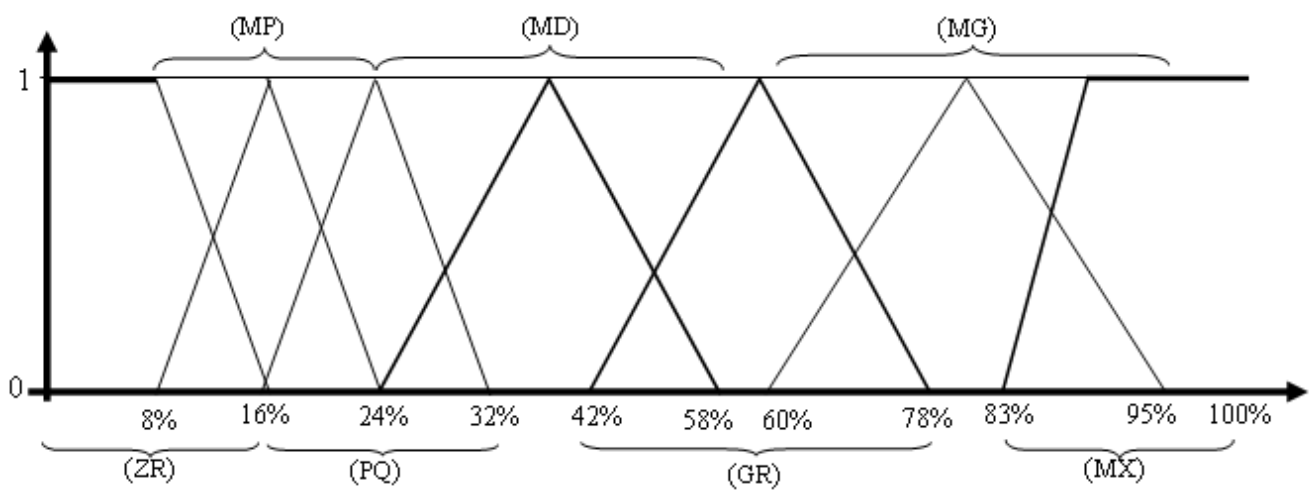

Figura 5.24: Conjuntos Nebulosos que definem a Variável Distância.

os modificadores da aceleração:

Zero: de $0 \%$ a $10 \%$, Muito pequena: de $5 \%$ a $35 \%$, Pequena: de $20 \%$ a $50 \%$, Média: de $35 \%$ a $65 \%$, Grande: de $50 \%$ a $80 \%$, Muito grande: de $65 \%$ a $95 \%$, Máxima: de $90 \%$ a $100 \%$.

\section{Definição das Regras que Governam o Controle de Velocidade de Avanço}

Para cada modificador da variável velocidade de avanço, tem-se que associá-lo com todos os modificadores da variável distância, gerando todas as regras necessárias para calcular a variável de saída aceleração de forma matricial. Por exemplo, a variável aceleração como a variável de saída é formanda pelas regras do tipo:

Se velocidade de avanço é grande e distância é pequena então aceleração é (-) pequena

Se velocidade de avanço é média e distância é muito grande então aceleração é muito pequena.

Se velocidade de avanço é zero e distância é muito pequena então aceleração é zero.

Onde o sinal menos indica desaceleração. Assim obtém-se a seguinte matriz de regras para esta camada, como se apresenta na tabela 5.6.

Tabela 5.6: Regras para o Controle da Aceleração

\begin{tabular}{|l|l|l|l|l|l|l|l|}
\hline Vel. Avanço/Distância & ZR & MP & PQ & MD & GR & MG & MX \\
\hline ZR & ZR & ZR & ZR & ZR & ZR & ZR & ZR \\
\hline MP & $-\mathrm{MP}$ & $-\mathrm{MP}$ & $-\mathrm{MP}$ & $\mathrm{MP}$ & $\mathrm{PQ}$ & $\mathrm{MD}$ & $\mathrm{MD}$ \\
\hline PQ & $-\mathrm{PQ}$ & $-\mathrm{PQ}$ & $-\mathrm{PQ}$ & $\mathrm{ZR}$ & $\mathrm{MP}$ & $\mathrm{PQ}$ & $\mathrm{PQ}$ \\
\hline MD & $-\mathrm{MD}$ & $-\mathrm{MD}$ & $-\mathrm{MD}$ & $-\mathrm{MP}$ & $\mathrm{ZR}$ & $\mathrm{MP}$ & $\mathrm{PQ}$ \\
\hline GR & $-\mathrm{GR}$ & $-\mathrm{GR}$ & $-\mathrm{PQ}$ & $-\mathrm{MP}$ & $-\mathrm{MP}$ & $\mathrm{ZR}$ & $\mathrm{ZR}$ \\
\hline MG & $-\mathrm{MG}$ & $-\mathrm{GR}$ & $-\mathrm{MD}$ & $-\mathrm{PQ}$ & $-\mathrm{MP}$ & $-\mathrm{MP}$ & $-\mathrm{MP}$ \\
\hline MX & $-\mathrm{MX}$ & $-\mathrm{MG}$ & $-\mathrm{GR}$ & $-\mathrm{MD}$ & $-\mathrm{PQ}$ & $-\mathrm{MP}$ & $-\mathrm{MP}$ \\
\hline
\end{tabular}




\section{Reformulação do Controle da Velocidade, Definição da Variável Velocidade Diferencial}

Fazendo-se uma análise do escopo desta camada, nota-se que é possível reduzir as 49 regras para 14. Verifica-se se cada velocidade é compatível com a distância do objetivo e se acelera ou desacelera o VSSA. Com isso podem-se dividir as regras em duas partes: na primeira verificase qual é a velocidade desejada para uma distância específica; e na segunda parte, determina quanto de aceleração dever ter o veículo de acordo à velocidade diferencial. Definida como a diferença entre a velocidade do veículo e a velocidade desejada. Desta forma, tem-se os dois conjuntos de regras com apenas uma variável de entrada, e cada um só possuíra 7 regras.

\section{Definição dos Termos Lingüísticos no Controle da Velocidade}

As definições para os modificadores da variável de saída velocidade diferencial em porcentagens são apresentadas na figura 5.25 e definidas por:

Zero: de $0 \%$ a $10 \%$, Muito pequena: de $5 \%$ a $35 \%$, Pequena: de $20 \%$ a $50 \%$, Média: de $35 \%$ a $65 \%$, Grande: de $50 \%$ a $80 \%$, Muito grande: de $65 \%$ a $95 \%$, Máxima: de $90 \%$ a $100 \%$.

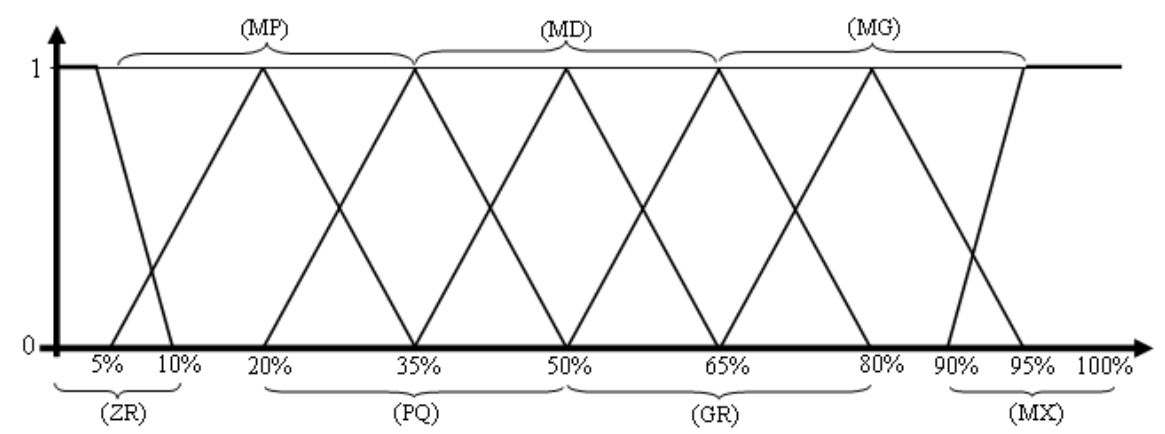

Figura 5.25: Conjuntos Nebulosos que Definem a Variável Velocidade Diferencial.

\section{Definição das Regras que Governam a Velocidade}

Define-se a seguinte matriz como a potência a aplicar aos propulsores, como se apresenta na tabela 5.7:

Tabela 5.7: Regras Otimizadas para a Variável Aceleração

\begin{tabular}{|l|l|}
\hline Distância & Vel. Avanço \\
\hline ZR & ZR \\
\hline MP & MP \\
\hline PQ & MP \\
\hline MD & PQ \\
\hline GR & PQ \\
\hline MG & PQ \\
\hline MX & MD \\
\hline
\end{tabular}

\begin{tabular}{|l|l|}
\hline Vel. diferencial & Aceleração \\
\hline $\mathrm{ZR}$ & $\mathrm{ZR}$ \\
\hline $\mathrm{MP}$ & $-\mathrm{MP}$ \\
\hline $\mathrm{PQ}$ & $-\mathrm{PQ}$ \\
\hline $\mathrm{MD}$ & $-\mathrm{MD}$ \\
\hline $\mathrm{GR}$ & $-\mathrm{MD}$ \\
\hline $\mathrm{MG}$ & $-\mathrm{MD}$ \\
\hline $\mathrm{MX}$ & $-\mathrm{GR}$ \\
\hline
\end{tabular}


Admita-se que a velocidade média seja a velocidade ideal para a navegação. Se, por acaso, o VSSA estiver navegando a favor da correnteza ele atingirá uma velocidade maior do que a média, o que será compensado diminuindo-se a potência.

\subsubsection{Resposta do Controlador na Camada 1: Controle de Velocidade de Avanço}

O veículo navega a uma certa velocidade média, mas seu controle é mais importante quando ele se encontra perto à posição objetivo ou perto a um obstáculo. Depende-se da distância: distâncias maiores implicam em menor controle e a distâncias menores implicam em maior controle, como se mostra na figura 5.26.
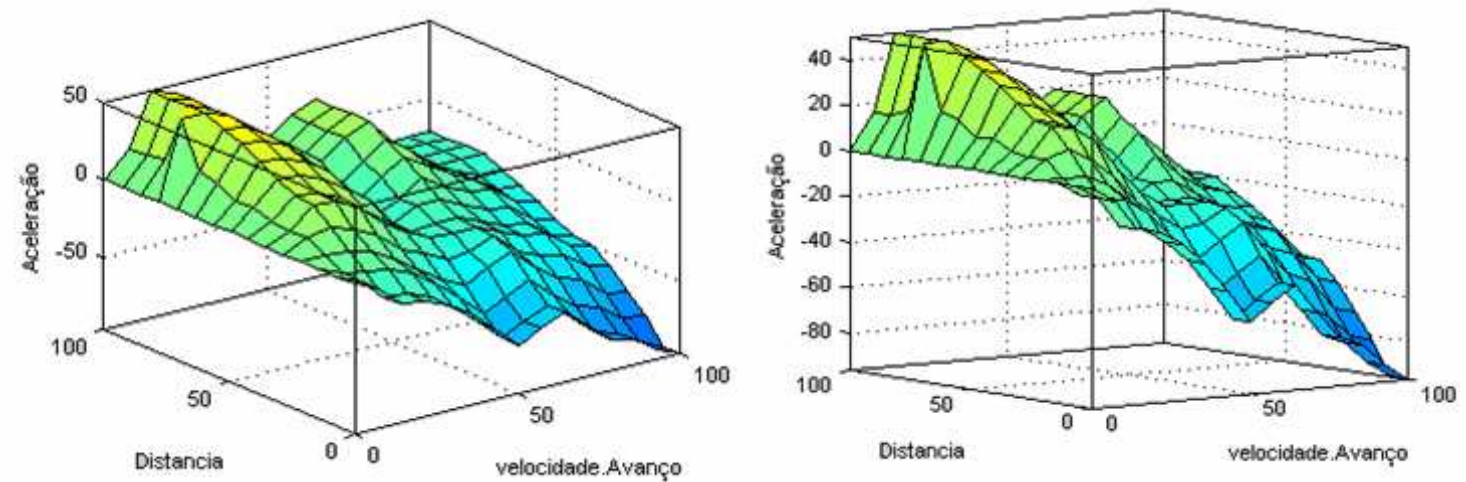

Figura 5.26: Resultados no Controle de Velocidade .

\subsubsection{Sobreposição do Controlador de Velocidade sobre o Controlador Horizon- tal}

Logo após entrar no perímetro em torno ao objetivo (ponto de chegada), inicia-se a redução de velocidade, de forma que ele tenha o tempo necessário para realizar a parada total. Para controlar a aceleração, procura-se também fazer a redução da velocidade de forma que não se tenha elevada saltos de potência. Note-se que só tem-se uma aceleração grande quando a velocidade diferencial é máxima. Todos os outros valores são de médio para baixo.

Será preciso redefinir alguma das regras da primeira e segunda camada. Para a direção horizontal, procura-se evitar que o veículo faça uma trajetória de aproximação ao objetivo em espiral como mostrado na figura 5.27: 


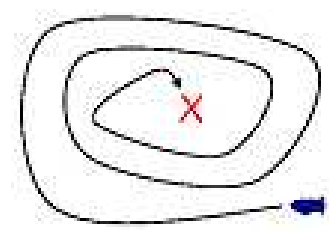

Figura 5.27: Trajetória de Aproximação Indesejada.

\section{Definição das Regras que Governam A Sobreposição da Distância de Apro- ximação sobre o o Controle Horizontal}

Quando o VSSA ainda está longe do objetivo, não é necessário reajustar a correção horizontal mas, se ele está perto do objetivo, precisa-se reajustar a correção horizontal, para otimizar a navegação e controle do VSSA.

Cada modificador da variável correção horizontal é associado a todos os modificadores da variável distância, gerando as regras necessárias para recalcular a variável correção horizontal matricialmente. Por exemplo, a variável correção horizontal neste caso pode ser gerada por regras do tipo:

Se distância é máxima e correção horizontal é máxima então correção horizontal é máxima.

Se distância é média e correção horizontal é muito grande então correção horizontal é média.

Se distância é pequena e correção horizontal é pequena então correção horizontal é muito pequena.

A matriz de regras otimizada, descrita na tabela 5.8, só se aplica quando o VSSA se encontrar próximo ao objetivo.

Tabela 5.8: Regras para a Variável Correção Horizontal com Sobreposição da Variável Distância

\begin{tabular}{|l|l|l|l|l|l|l|l||l|l|l|l|l|l|}
\hline D1/Corr.Hor. & -MX & -MG & -GR & -MD & -PQ & -MP & ZR & MP & PQ & MD & GR & MG & MX \\
\hline ZR & ZR & ZR & ZR & ZR & ZR & ZR & ZR & ZR & ZR & ZR & ZR & ZR & ZR \\
\hline MP & $-\mathrm{MP}$ & $-\mathrm{MP}$ & $-\mathrm{MP}$ & $-\mathrm{MP}$ & $-\mathrm{MP}$ & $-\mathrm{MP}$ & $\mathrm{ZR}$ & $\mathrm{MP}$ & $\mathrm{MP}$ & $\mathrm{MP}$ & $\mathrm{MP}$ & $\mathrm{MP}$ & $\mathrm{MP}$ \\
\hline PQ & $-\mathrm{PQ}$ & $-\mathrm{PQ}$ & $-\mathrm{PQ}$ & $-\mathrm{PQ}$ & $-\mathrm{MP}$ & $-\mathrm{MP}$ & $\mathrm{ZR}$ & $\mathrm{MP}$ & $\mathrm{MP}$ & $\mathrm{PQ}$ & $\mathrm{PQ}$ & $\mathrm{PQ}$ & $\mathrm{PQ}$ \\
\hline MD & $-\mathrm{MG}$ & $-\mathrm{GR}$ & $-\mathrm{MD}$ & $-\mathrm{PQ}$ & $-\mathrm{MD}$ & ZR & ZR & ZR & MP & PQ & MD & GR & MG \\
\hline GR & $-\mathrm{MX}$ & $-\mathrm{MG}$ & $-\mathrm{GR}$ & $-\mathrm{MD}$ & $-\mathrm{PQ}$ & $-\mathrm{MP}$ & $\mathrm{ZR}$ & $\mathrm{MP}$ & $\mathrm{PQ}$ & $\mathrm{MD}$ & $\mathrm{GR}$ & $\mathrm{MG}$ & $\mathrm{MX}$ \\
\hline MG & $-\mathrm{MX}$ & $-\mathrm{MG}$ & $-\mathrm{GR}$ & $-\mathrm{MD}$ & $-\mathrm{PQ}$ & $-\mathrm{MP}$ & $\mathrm{ZR}$ & $\mathrm{MP}$ & $\mathrm{PQ}$ & $\mathrm{MD}$ & $\mathrm{GR}$ & $\mathrm{MG}$ & $\mathrm{MX}$ \\
\hline MX & $-\mathrm{MX}$ & $-\mathrm{MG}$ & $-\mathrm{GR}$ & $-\mathrm{MD}$ & $-\mathrm{PQ}$ & $-\mathrm{MP}$ & $\mathrm{ZR}$ & $\mathrm{MP}$ & $\mathrm{PQ}$ & $\mathrm{MD}$ & $\mathrm{GR}$ & $\mathrm{MG}$ & $\mathrm{MX}$ \\
\hline
\end{tabular}

Na figura 5.28 mostra-se como se realiza a sobreposição dependendo da distância de aproximação de um obstáculo. Se a distância do obstáculo ao veículo é 0 , o veículo pára não importa qual seja o erro. Se a distância do obstáculo ao veículo for muito pequena ou pequena, por precaução a velocidade de correção de erro decresce e a correção é suave. 

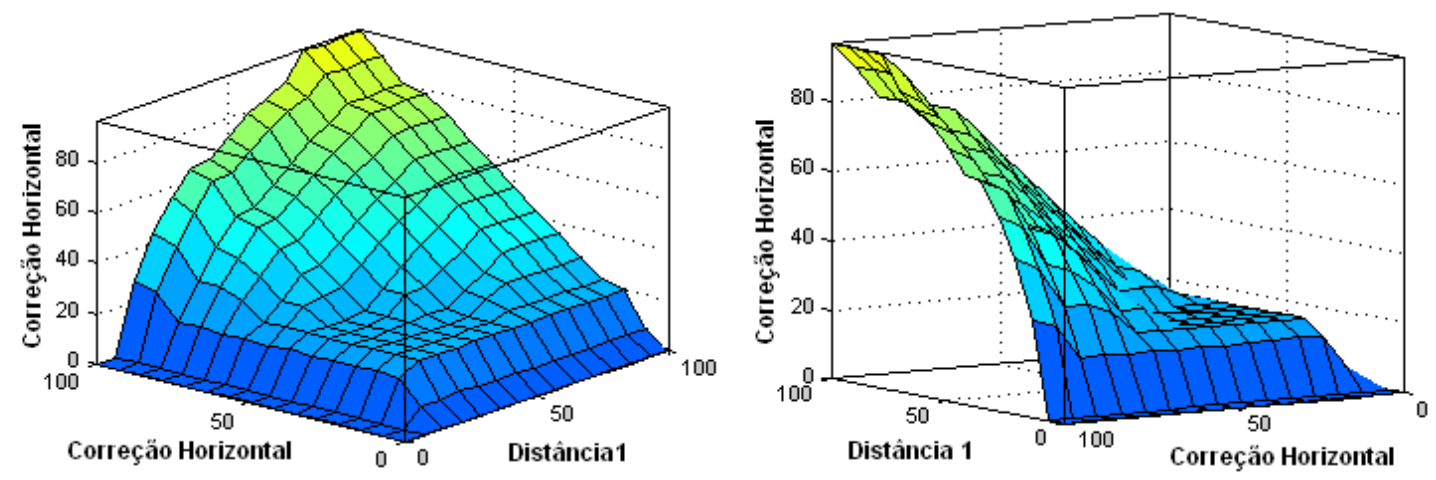

Figura 5.28: Resultados da Camada de Sobrepocição no Controle Horizontal (Correção de Rumo) Relativamente à Distância.

\subsubsection{Camada 2: Controle de Profundidade}

Nesta camada, controla-se a profundidade. Para isso, são necessárias duas informações, a profundidade e a velocidade de ascensão ou descida.

\section{Definição das Variáveis no Controle de Profundidade}

Será escolhida uma profundidade padrão (cota) para navegação com uma margem de flutuação aceitável, com o que o VSSA se manterá próximo à cota prevista e dentro de uma margem definida. Assim como foi feito para a variável distância, se definirá uma variável lingüística chamada profundidade, que terá um valor de margem de erro para a profundidade desejada. Neste caso, limita-se a margem a um determinado valor para cima ou para baixo em função da altura padrão determinada. Isto é, a profundidade é o limite do dito valor e vai depender das tarefas do VSSA e das condições marítimas onde desenvolvem suas operações.

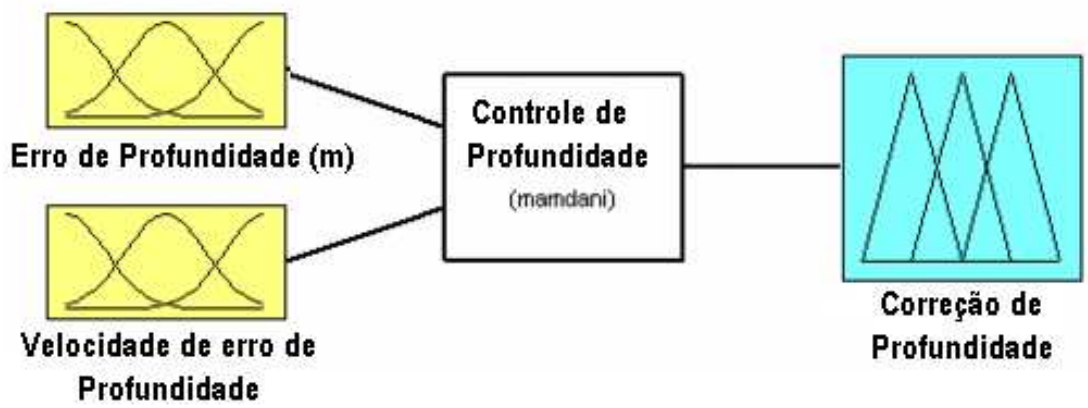

Figura 5.29: Variáveis Lingüísticas de Entrada e Saída para o Controle de Profundidade. 


\section{Definição dos Termos Lingüísticos no Controle de Profundidade}

Define-se a variável lingüística profundidade em porcentagens, para torná-la função do valor da profundidade padrão. Os modificadores da função de pertinência da profundidade são apresentados na figura 5.30 e descritos formalmente por:

-Máxima (-MX): de -100\% a -90\%, -Muito grande (-MG): de -95\% a -65\%, -Grande (-GR): de $-80 \%$ a $-50 \%$, -Média (-MD): de $-65 \%$ a $-35 \%$, -Pequena (-PQ): de $-50 \%$ a $-20 \%$, -Muito pequena (-MP): de $-35 \%$ a $-5 \%$, Zero (ZR): de $-10 \%$ a $10 \%$, Muito pequena (MP): de $5 \%$ a $35 \%$, Pequena (PQ): de $20 \%$ a $50 \%$, Média $(M D)$ : de $35 \%$ a $65 \%$, Grande $(M G):$ de $50 \%$ a $80 \%$, Muito grande (MG): de $65 \%$ a 95\%, Máxima (MX): de $90 \%$ a 100\%,

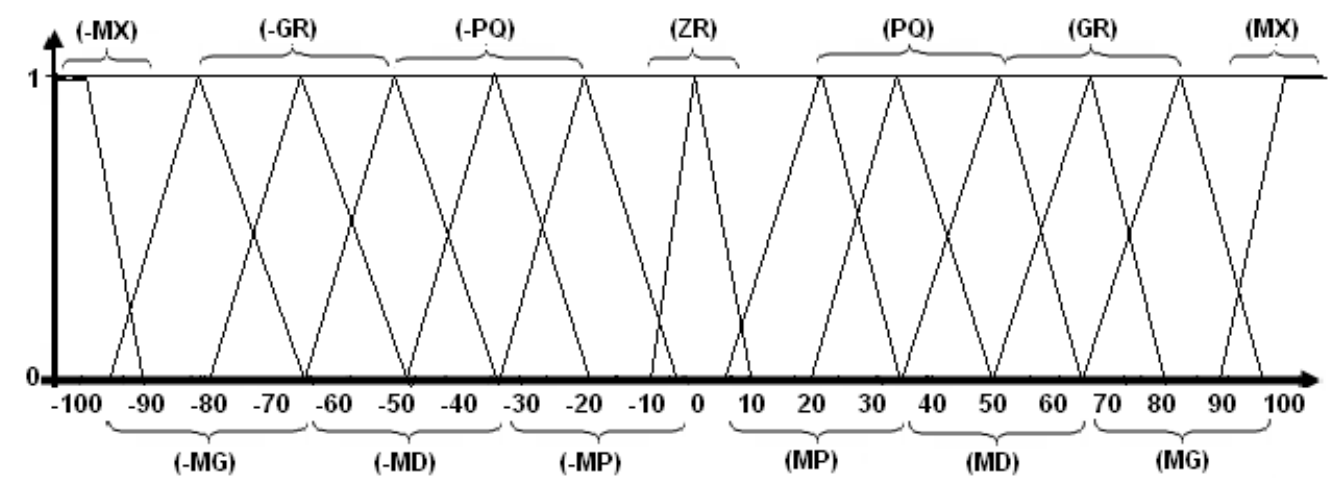

Figura 5.30: Conjuntos Nebulosos que Definem a Variável Profundidade.

Assim como feito com a variável distância, mantém-se o controle mais rígido perto do zero para tentar eliminar qualquer oscilação. A segunda variável necessária para esta camada, será a a velocidade de mudança de erro. Ela definirá quão rápido o erro está crescendo ou qual é sua tendência. Novamente expressam-se os modificadores em forma de porcentagem. Os modificadores da variável velocidade de mudança de erro de profundidade, são apresentados na figura 5.31 e descritos por: -Muito grande (-MG): de $-100 \%$ a $-80 \%$, -Grande (-GR): de $-100 \%$ a $-60 \%$, -Média (-MD): de $-80 \%$ a $-40 \%$, -Pequena (-PQ): de $-60 \%$ a $-20 \%$, -Muito pequena (-MP): de $-40 \%$ a $-0 \%$, Zero (ZR): de $-20 \%$ a $20 \%$, Muito pequena $(M P):$ de $0 \%$ a 40\%, Pequena (PQ): de 20\% a 60\%, Média (MD): de 40\% a 80\%, Grande (MG): de $60 \%$ a $100 \%$, Muito grande (MG): de $80 \%$ a $100 \%$.

Aqui tem-se uma situação diferente dos demais casos. Já que não se pode definir um empuxo exato para os propulsores, tem-se que expressar as regras somente em termos da energia fornecida aos propulsores. Isto porque seria necessário saber qual seria o empuxo ideal nos propulsores para cada profundidade. Como a própria variável profundidade é relativa ao objetivo, isto é, não é uma profundidade absoluta, para definir o empuxo exato para cada propulsor em cada situação específica seria necessário aumentar muito a complexidade do 


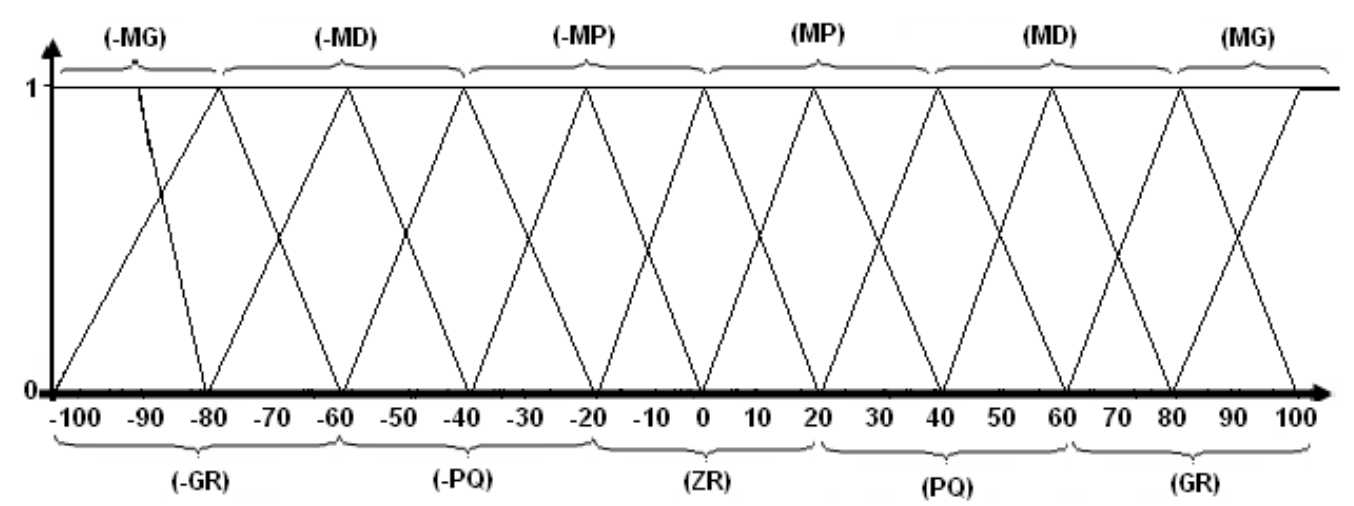

Figura 5.31: Conjunto Nebuloso da Variável Velocidade Vertical.

sistema. Por isso, utiliza-se como referencial uma profundidade acima da cota ideal, e para profundidades abaixo deste ponto apenas inverter-se o resultado.

\section{Definição das Regras que Governam o Controle de Profundidade}

Cada modificador da variável profundidade é associado aos modificadores da variável velocidade de mudança do erro de profundidade, gerando as as regras necessárias para calcular a variável de saída propulsores verticais em forma de uma matriz. Por exemplo, a variável propulsores verticais como a variável de saída é produzida formando-se regras do tipo:

Se erro de profundidade é pequena e velocidade de mudança do erro de profundidade é grande então propulsores verticais é - média

Se erro de profundidade é grande e velocidade de mudança do erro de profundidade é muito pequena então propulsores verticais é média

Se erro de profundidade é maxima e velocidade de mudança do erro de profundidade é muito pequena então propulsores verticais é pequena

Onde o sinal negativo indica o sentido de acionamento dos propulsores para ação de subida até a superfície, portanto o sinal positivo indica ação de descida. Assim, obtém-se a matriz de regras da tabela 5.9 para esta camada, onde ErroPrf representa a variável erro de profundidade, e $V_{e} r r o P$ a variável velocidade de mudança do erro de profundidade. 
Tabela 5.9: Regras para o Controle dos Propulsores Verticais

\begin{tabular}{|c|c|c|c|c|c|c|c|c|c|c|c|}
\hline ErroPrf/VerroP & $-M G$ & -GR & -MD & $-\mathrm{PQ}$ & -MP & ZR & MG & $\mathbf{P Q}$ & MD & GR & MG \\
\hline -MG & MG & MG & MG & MG & MG & MG & GR & MD & $\mathrm{PQ}$ & MP & $\mathrm{ZR}$ \\
\hline -GR & MG & MG & MG & MG & MG & GR & MD & $\mathrm{PQ}$ & MP & $\mathrm{ZR}$ & $-\mathrm{MP}$ \\
\hline -MD & MG & MG & MG & MG & GR & MD & $\mathrm{PQ}$ & MP & $\mathrm{ZR}$ & $-\mathrm{MP}$ & $-\mathrm{PQ}$ \\
\hline$-P Q$ & MG & MG & MG & GR & MD & $\mathrm{PQ}$ & MP & $\mathrm{ZR}$ & $-\mathrm{MP}$ & $-\mathrm{PQ}$ & $-\mathrm{MD}$ \\
\hline -MP & MG & MG & GR & MD & $\mathrm{PQ}$ & MP & $\mathrm{ZR}$ & $-\mathrm{MP}$ & $-\mathrm{PQ}$ & $-\mathrm{MD}$ & -GR \\
\hline ZR & MG & GR & MD & $\mathrm{PQ}$ & MP & $\mathrm{ZR}$ & $-\mathrm{MP}$ & $-\mathrm{PQ}$ & $-\mathrm{MD}$ & -GR & $-\mathrm{MG}$ \\
\hline MP & GR & $\mathrm{MD}$ & $\mathrm{PQ}$ & $\mathrm{MP}$ & $\mathrm{ZR}$ & $-\mathrm{MP}$ & $-\mathrm{PQ}$ & $-\mathrm{MD}$ & $-\mathrm{GR}$ & $-\mathrm{MG}$ & $-\mathrm{MG}$ \\
\hline $\mathbf{P Q}$ & $\mathrm{MD}$ & $\mathrm{PQ}$ & MP & ZR & $-\mathrm{MP}$ & $-\mathrm{PQ}$ & $-\mathrm{MD}$ & -GR & $-\mathrm{MG}$ & $-\mathrm{MG}$ & $-\mathrm{MG}$ \\
\hline MD & $\mathrm{PQ}$ & MP & $\mathrm{ZR}$ & -MP & $-\mathrm{PQ}$ & $-\mathrm{MD}$ & -GR & $-\mathrm{MG}$ & $-\mathrm{MG}$ & $-\mathrm{MG}$ & $-\mathrm{MG}$ \\
\hline GR & MP & $\mathrm{ZR}$ & -MP & $-\mathrm{PQ}$ & -MD & -GR & $-\mathrm{MG}$ & $-\mathrm{MG}$ & $-\mathrm{MG}$ & $-\mathrm{MG}$ & $-\mathrm{MG}$ \\
\hline MG & ZR & -MP & $-\mathrm{PQ}$ & $-\mathrm{MD}$ & -GR & $-\mathrm{MG}$ & $-M G$ & $-\mathrm{MG}$ & $-\mathrm{MG}$ & $-M G$ & $-M G$ \\
\hline
\end{tabular}

A figura 5.32 mostra os resultados do controle de profundidade.
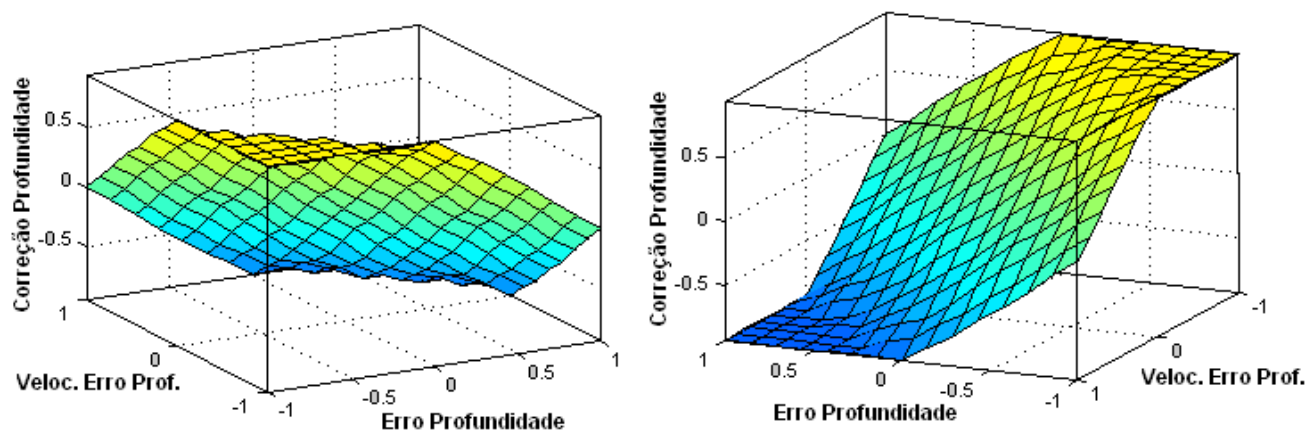

Figura 5.32: Resultados do Controle de Profundidade.

\subsubsection{Sobreposição do Controlador de Profundidade sobre o Controlador Ver- tical}

Precisa-se verificar neste momento se existirão regras de sobreposição para esta camada. Analisando a relação da camada 1 do módulo 1, não existe uma relação direta entre o empuxo dos propulsores verticais e os propulsores horizontais do VSSA, e por isso não há necessidade de sobrepor regras na camada 1 do módulo 1.

Ao contrário, relativamente à camada 2 do módulo 1 , é preciso sobrepor as regras da variável correção vertical.

Cada modificador da variável correção vertical é associado aos modificadores da variável propulsores verticais, gerando as regras necessárias para recalcular a variável de saída propulsores verticais em forma de uma matriz. Por exemplo, a variável propulsores verticais é produzida como a variável de saída recalculada através de regras de tipo:

Se correção vertical é zero e propulsores verticais é muito grande então propulsores verticais é média 
Se correção vertical é média e propulsores verticais é - máxima então propulsores verticais é - grande

Se correção vertical é máxima e propulsores verticais é média então propulsores verticais é pequena

Onde a sinal negativo indica o sentido de acionamento dos propulsores para a ação de subida até a superfície e portanto o sinal positivo indica ação de descida. Assim, obtém-se na tabela 5.10 a matriz de regras para esta camada, onde $C V$ representa a variável correção vertical, e $P V$ a variável propulsores verticais.

Tabela 5.10: Regras para a Variável Propulsores Verticais com Sobreposição da Variável Correção Vertical

\begin{tabular}{|c|c|c|c|c|c|c|c|c|c|c|c|c|c|}
\hline $\mathrm{CV} / \mathrm{PV}$ & $-M X$ & $-M G$ & -GR & -MD & $-\mathrm{PQ}$ & -MP & ZR & MP & $\mathrm{PQ}$ & MD & GR & MG & MX \\
\hline ZR & $-G R$ & $-\mathrm{MD}$ & $-\mathrm{PQ}$ & $-\mathrm{PQ}$ & $-\mathrm{MP}$ & $\mathrm{ZR}$ & $\mathrm{ZR}$ & $\mathrm{ZR}$ & MP & $\overline{P Q}$ & $\mathrm{MD}$ & $\mathrm{MD}$ & GR \\
\hline MP & $-G R$ & -MD & $-\mathrm{MD}$ & $-\mathrm{PQ}$ & -MP & $-\mathrm{MP}$ & ZR & ZR & $\mathrm{ZR}$ & MP & $\mathrm{PQ}$ & $\mathrm{MD}$ & MD \\
\hline$\overline{P Q}$ & $-G R$ & -GR & $-\mathrm{MD}$ & $-\mathrm{MD}$ & $-\mathrm{PQ}$ & -MP & -MP & $\mathrm{ZR}$ & $\mathrm{ZR}$ & MP & $\mathrm{PQ}$ & $\mathrm{MD}$ & $\mathrm{MD}$ \\
\hline MD & $-G R$ & $-G R$ & -GR & $-\mathrm{MD}$ & $-M D$ & $-\mathrm{MD}$ & $-\mathrm{PQ}$ & $-\mathrm{MP}$ & $-\mathrm{MP}$ & $\overline{Z R}$ & MP & $\overline{P Q}$ & $\mathrm{PQ}$ \\
\hline GR & $-\mathrm{MG}$ & -GR & $-G R$ & -GR & $-M D$ & $-\mathrm{MD}$ & $-\mathrm{MD}$ & $-\mathrm{PQ}$ & $-\mathrm{PQ}$ & $-\mathrm{MP}$ & $\mathrm{ZR}$ & $\mathrm{ZR}$ & $\mathrm{ZR}$ \\
\hline MG & $-\mathrm{MG}$ & $-M G$ & $-G R$ & -GR & -GR & $-\mathrm{MD}$ & $-\mathrm{MD}$ & $-\mathrm{MD}$ & $-\mathrm{PQ}$ & $-\mathrm{PQ}$ & $-\mathrm{MP}$ & $-\mathrm{MP}$ & $-M P$ \\
\hline MX & $-\mathrm{MG}$ & $-\mathrm{MG}$ & $-\mathrm{MG}$ & -GR & -GR & -GR & $-\mathrm{MD}$ & $-\mathrm{MD}$ & -MD & $-\mathrm{PQ}$ & $-\mathrm{PQ}$ & -MP & -MP \\
\hline
\end{tabular}

Os valores positivos na variável propulsores verticais representam uma ação de descida do VSSA, isto é, os propulsores operam em sentido positivo. Como a variável correção vertical é sempre positiva, ela provoca sempre uma inclinação positiva em situação de uma ação de descida. Uma inclinação negativa é facilmente gerada invertendo-se os valores da tabela.

São estas regras que definem quanto deve ser a inclinação do veículo em uma ação de subida ou descida. As regras de saída da segunda fase estão apenas definindo uma estabilização do VSSA para que sua inclinação não apresente risco durante a navegação.

Observa-se também pela tabela de sobreposição, o cuidado nas subidas e descidas rápidas de forma a não permitir inclinações muito elevadas.

Para a camada 1 do módulo 3 , não é preciso redefinir nenhuma regra, pois o veículo pode subir ou descer com velocidade horizontal alta ou baixa sem problemas.

Na figura 5.33 mostra-se o resultado da sobreposição do controlador de profundidade sobre o controle vertical, dando prioridade a que veículo fique na profundidade permitida e depois corrija o erro de cabeceio. 


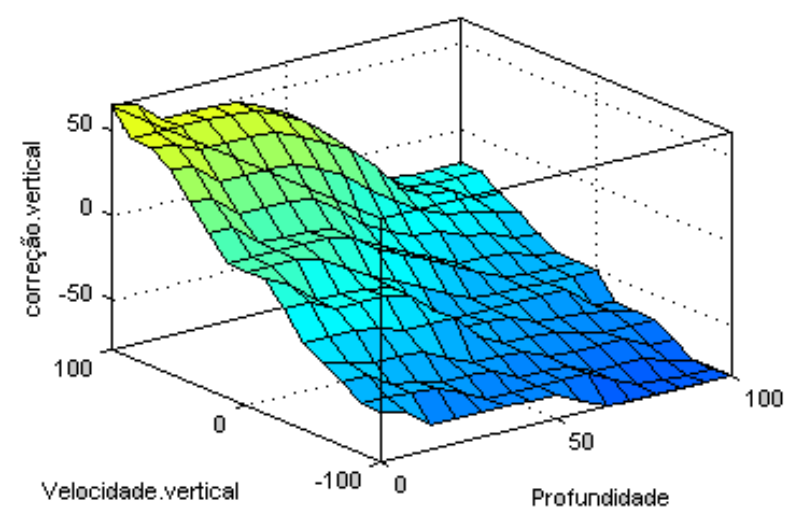

Figura 5.33: Resultados da Sobreposição do Controle de de Profundidade Frente o Controle Vertical.

\subsection{Diagrama do Controlador final}

Na figura 5.34 é mostrada a união de todos os controladores que foram anteriormente apresentados, onde verifica-se que com 10 dados gerados pelos sensores, pode-se corrigir os erro de rumo, de cabeceio, de profundidade, de velocidade, e evitar para obstáculos para chegar à posição objetivo.

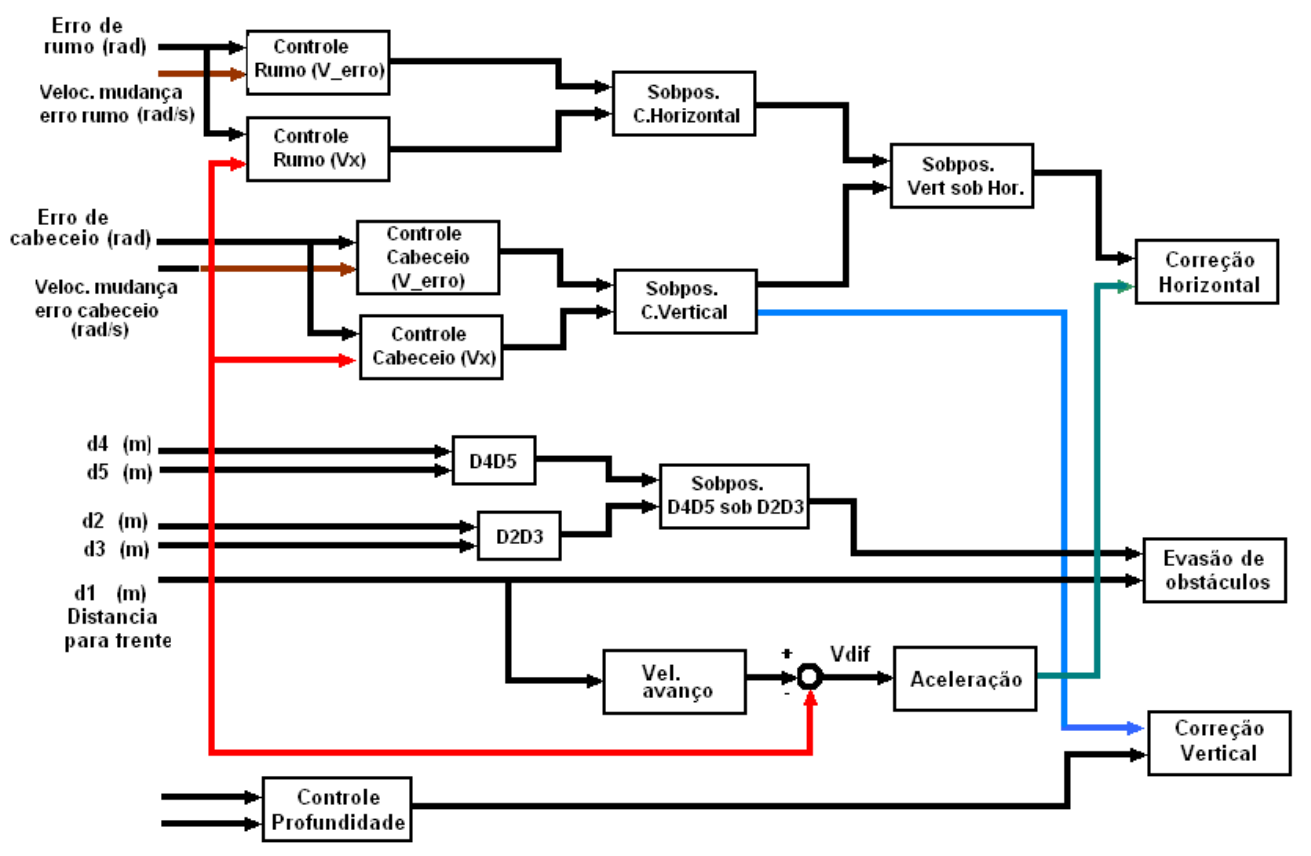

Figura 5.34: Diagrama da União de Todos os Controladores para a Navegação e Evasão de Obstáculos de um VSSA. 


\section{Aplicações, Resultados e Análises}

As simulações apresentadas a seguir foram realizadas utilizando modelos desenvolvidos por Conrado (2003). Os modelos foram adaptados para o VSSA, usando dados e parâmetros dinâmicos são apresentados no Cap. 3 e no Apêndice A (JULCA, 2003). Tendo em vista a avaliação do desempenho do controlador foram utilizados 3 estudos de caso com tarefas distintas realizadas pelo o veículo durante toda a sua navegação. Os resultados destes estudos são apresentados e avaliados no decorrer deste capitulo.

O escopo desta pesquisa é desenvolver um controlador nebuloso para o controle de posicionamento, orientação, navegação e evasão de obstáculos de robôs submarinos. A pesquisa não envolve o mecanismo automático de geração de trajetórias, limitando-se a garantir o seguimento e acompanhamento das sinais de referência de forma robusta, além da evasão de obstáculos no plano horizontal.

Os sinais de referência (de entrada) do sistema de controle são especificados no planejador através de trajetórias desejadas. As trajetórias de velocidade escolhidas correspondem a funções de primeira ordem com constante de tempo superior ao tempo de resposta do sistema controlado para cada grau de liberdade. Na evasão de obstáculos, o seguimento de trajetórias terá prioridade menor, e o veículo contorna o obstáculo até não encontrar mais perigo. Em seguida, ele se orienta de novo para a trajetória desejada até chegar à posição objetivo. Os sinais de referência a serem seguidos pelo veículo são dados em relação ao referencial inercial da seguinte maneira:

$$
\begin{gathered}
\eta_{r e f}(t)=\left[x_{r e f}(t), y_{\text {ref }}(t), z_{\text {ref }}(t), \phi_{\text {ref }}(t), \theta_{\text {ref }}(t), \psi_{\text {ref }}(t)\right]^{T}, \\
\dot{\eta}_{r e f}(t)=\frac{d}{d t} \eta_{r e f}(t) \\
\ddot{\eta}_{r e f}(t)=\frac{d^{2}}{d t^{2}} \eta_{r e f}(t) .
\end{gathered}
$$


Consideram-se todos graus de liberdade simultaneamente, o que implica em um acoplamento da dinâmica dos graus de liberdade (CONRADO, 2003). O acoplamento muitas vezes pode comprometer a estabilidade do sistema. (FALTISEN, 1990),(LOGAN, 1994).

A taxa de amostragem adotada nas simulações foi de $10 \mathrm{~Hz}$ e o passo de integração das simulações foi de 0,001seg.

\subsection{Etapa $t_{0}$ : O VSSA é Posicionado na Água e Prepa- rado para Desenvolver suas Tarefas}

\section{Descrição de Eventos:}

O navio desce o container com o VSSA até a posição determinada no planejador a profundidade (P). Em seguida:

1. Verifica-se se o VSSA tem algum erro de cabeceio.

Caso Ideal: Não existe erro de cabeceio, isto é, o ângulo de correção de cabeceio é igual a zero ou muito pequeno.

Exemplo: Cabeceio $=0^{\circ}$. A seguir, passa-se a verificar a profundidade relativa.

Caso Exceção 1: O VSSA tem erro de cabeceio (variável Erro de Cabeceio $(\theta)$ ). O sensor de inclinação determina um ângulo associado a uma variável lingüística diferente de muito pequeno. Este ângulo é corrigido para atingir a orientação correta. Para gerar esta correção podem ser acionados os propulsores 5,6,7,8. Se a correção é positiva, gira-se para cima e serão acionados os propulsores 5 e 6 ; caso contrário (correção é negativa) serão acionados os propulsores 7 e 8. A potência dos propulsores é determinada nesta etapa de controle.

Exemplo: Cabeceio $=L^{\circ}$, onde $L$ é valor determinado pelo sensor de inclinação que será nebulizado e associado a um grau de pertinência de algum termo lingüístico. A tarefa de correção de cabeceio é executada até completar a operação ou até uma nova ordem em um novo ciclo de leitura. A seguir, passa-se a verificar a profundidade relativa.

2. Verifica-se se o VSSA está dentro da profundidade relativa (PR) determinada no planejador.

O veículo realiza evasão de obstáculos no plano horizontal, então é importante que o veículo se encontre na profundidade relativa. Para começar a operação ele procura ficar na faixa permitida de profundidade. 
Caso Ideal: O VSSA encontra-se dentro da profundidade relativa (PR).

Exemplo: Se $P=100 m$ e $F=10 m$. Então $P R=[90 m-110 m]$, e a $\mathrm{PA}=\{30 m, 90 m, 100 m\}$. A seguir, passa-se a verificar o erro de (Rumo) do VSSA.

Caso Exceção 1: O VSSA se encontra numa posição acima ou abaixo da profundidade relativa $(\mathrm{PR})$ determinada, o que gera uma ação de correção de profundidade. Isto é, faz-se a correção no eixo $Z$ na posição atual (PA), sendo os eixos $X$ e $Y$ irrelevantes.

Exemplo: $P A=[30 m, 90 m, 60 m]$, onde $z=60 m$; e $P R=[90 m-110 m] \Rightarrow$ Fazer uma correção de profundidade, até atingir a profundidade relativa válida. São acionados os propulsores $5,6,7,8$, na direção positiva se $P A$ está acima da profundidade relativa, ou negativa se PA está abaixo da profundidade relativa. A tarefa é executada até completar a operação ou até uma nova ordem em um novo ciclo de leitura. A seguir, passa-se a verificar a o erro de Rumo do VSSA.

3. Verifica-se se o VSSA tem algum erro de rumo.

Caso Ideal: Não existe erro de rumo, isto é, o ângulo de correção de rumo é igual a zero ou muito pequeno.

Exemplo: Rumo $=0^{\circ}$. A seguir, passa-se a verificar a proximidade da posição objetivo.

Caso Exceção 1: O VSSA tem erro de rumo. O sensor de rumo determina um ângulo associado a uma variável lingüística diferente de muito pequeno. Este ângulo é corrigido para atingir a orientação correta. Para gerar esta correção podem ser acionados os propulsores $1,2,3,4$. Se a correção é positiva, gira-se para direita e serão acionados os propulsores 2 e 3 ; caso contrário (correção é negativa) serão acionados os propulsores 1 e 4 . Nesta etapa do controle é determinada a potência para acionar os propulsores.

Exemplo: $R u m o=K^{\circ}$, onde $K$ é valor determinado pelo sensor de rumo que será nebulizado e associado a um grau de pertinência de algum termo lingüístico. A tarefa de correção de rumo é executada até completar a operação ou até uma nova ordem em um novo ciclo de leitura. A seguir, passa-se a verificar a proximidade da posição objetivo.

4. Verifica-se se o VSSA está dentro do volume da posição objetivo.

Caso Ideal: O VSSA está dentro do volume válido da posição objetivo, isto é, $P A$ $\in V P O$, então passa-se à etapa $t_{f}$. 
Exemplo: Se $P A=[40 m, 220 m, 100 m]$ e $V P O=[((40 m, 230 m)+10 m),(100 m, 10 m)]$.

Então $[40 m, 220 m][(40 m, 230 m)+10 m]$ e $[100 m][100 m, 10 m]$

$\therefore(40 m, 220 m) \subset[30 m-50 m, 220 m-240 m]$ e $[100 m] \subset[90 m-110 m]$. Então, passa-se a verificar a presença de obstáculos (agora na etapa $t_{n}$ ).

Caso Exceção 1: O VSSA não está dentro do volume válido da posição objetivo, isto é, $P A$ não $\in V P O$. Então, passa-se a verificar a presença de obstáculos (agora na etapa $\left.t_{n}\right)$.

\subsubsection{Resultados na Etapa $t_{0}$}

Neste caso deve-se garantir que o veículo esteja na profundidade relativa para começar a navegação. Para isto o planejador indica diferentes pontos de profundidade em diferentes tempos, de tal forma a verificar que o VSSA siga estes pontos no tempo para a profundidade relativa.

As condições de simulação são as seguintes: o VSSA deve se posicionar nas cotas $\eta 1_{\text {final }}=$ $[0 ; 0 ; 15] \mathrm{m}$ e atitude $\eta 1_{\text {final }}=[0 ; 0 ; 3] \mathrm{rad}$, partindo da origem, segundo a especificação de trajetórias definidas, onde as velocidades nominais definidas para as seis direções são dadas por $\dot{\eta}_{\text {nominal }}=[0,5 \mathrm{~m} / \mathrm{s} ; 0,5 \mathrm{~m} / \mathrm{s} ; 0,5 \mathrm{~m} / \mathrm{s} ; 0 ; 0 ; 0,013 \mathrm{rad} / \mathrm{s}]$. Os resultados desta etapa usando o controlador nebuloso desenvolvido são apresentados na figura 6.1.

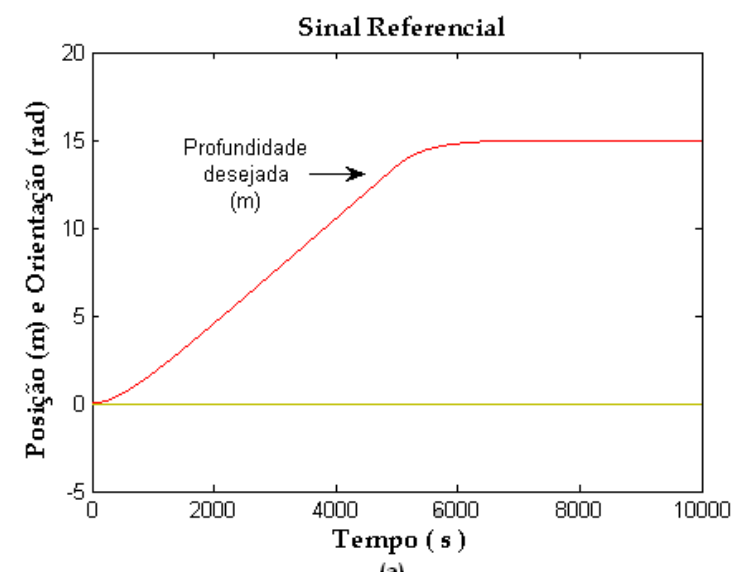

(a)

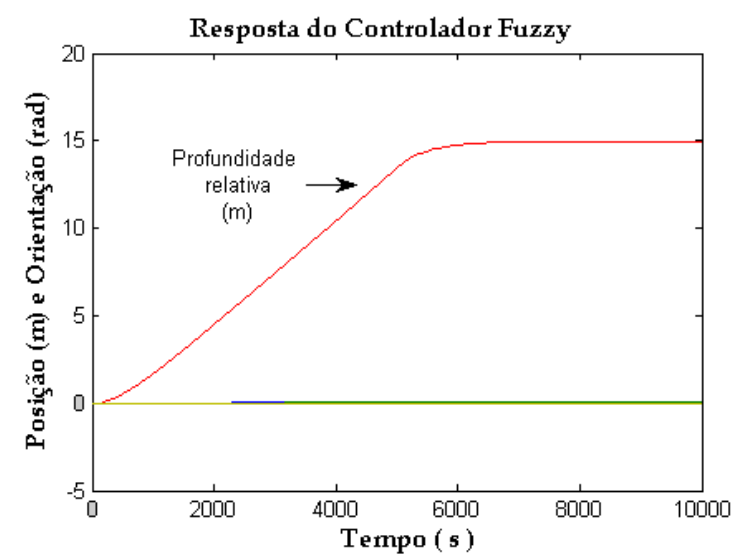

(b)

Figura 6.1: Rastreamento da Profundidade Relativa do Planejador, (a) Profundidade Desejada, (b) Resposta do Controlador para a Profundidade.

Os sinais de erro de cada um das variáveis de posição e orientação são mostrados na figura 6.2, onde o sinal de referência é apenas para a profundidade. Todas as outras variáveis são 0 , isto para que o veículo se situe na profundidade relativa para começar a navegação na procura do objetivo. 

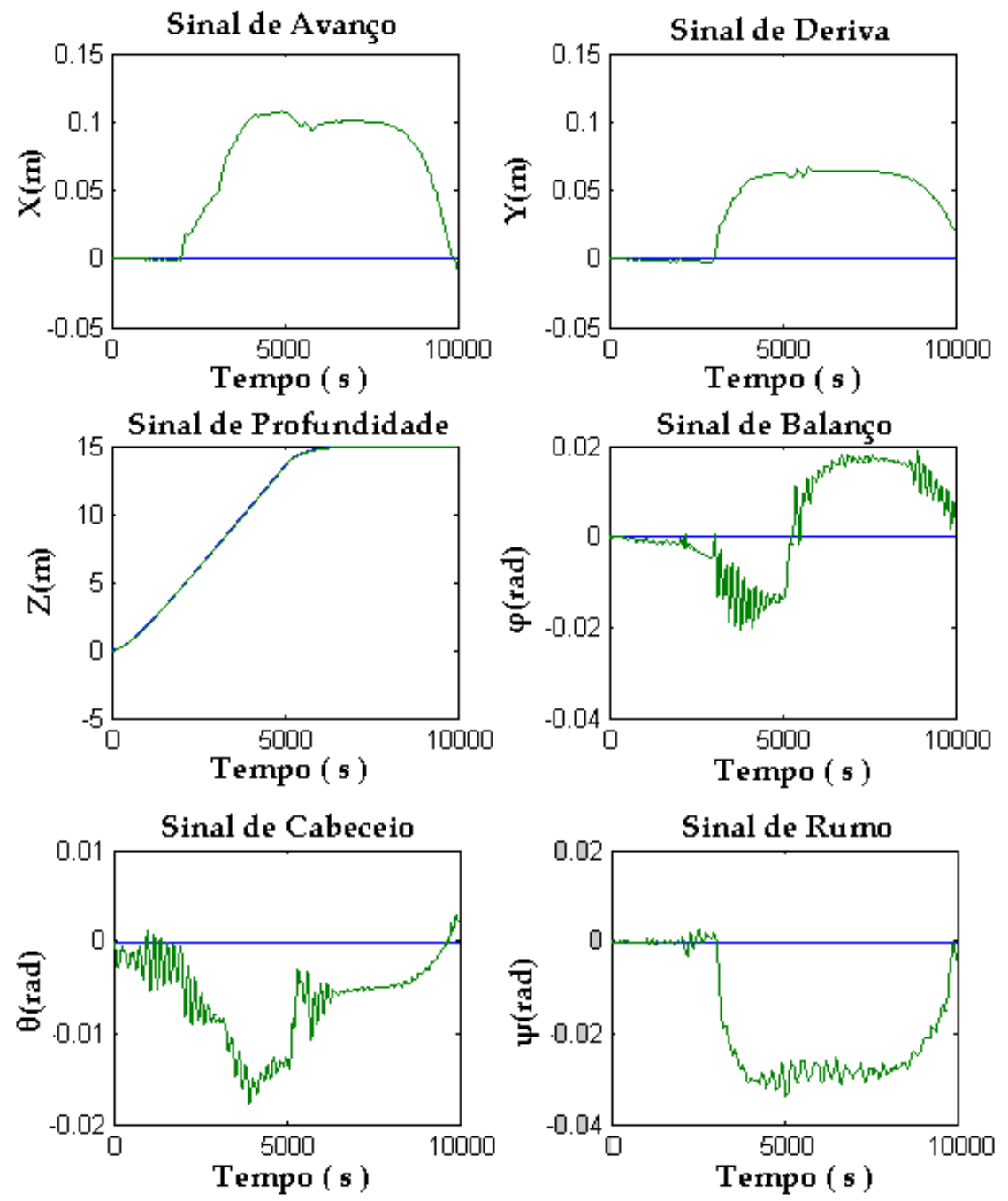

Figura 6.2: Sinais de Erro para Cada Variável de Posição e Orientação na Etapa $t_{0}$.

Os controladores nebulosos dependem da velocidade de mudança dos erros das posições e das orientações do VSSA. Estes sinais são mostradas na figura 6.3. Observando-se os resultados das figura 6.2 e a figura 6.3 é possível concluir-se que o controlador projetado apresenta o desempenho adequado. 

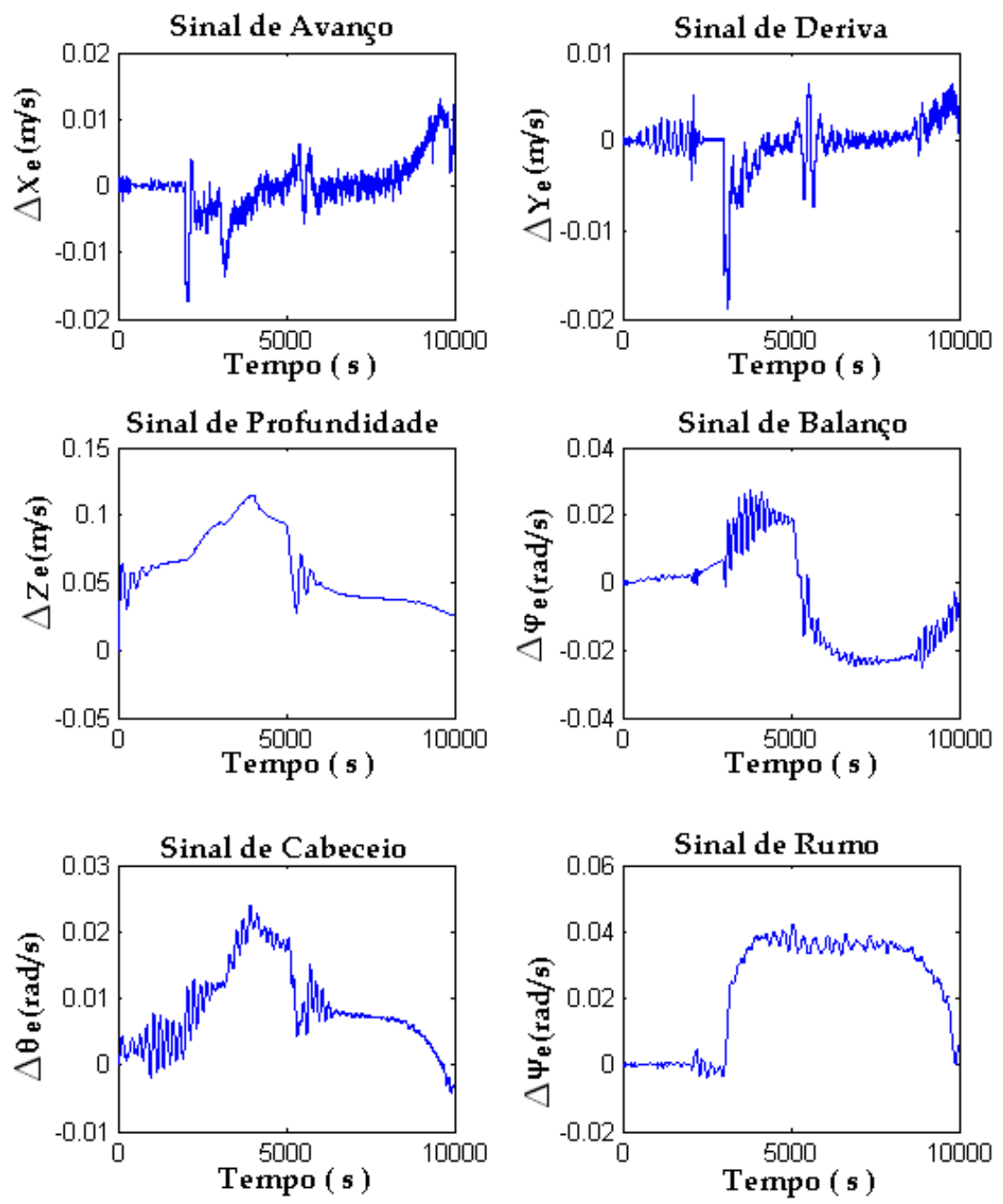

Figura 6.3: Repostas das Velocidades de erro dos Posicionamentos e Orientações na Etapa $t_{0}$.

\subsection{Etapa $t_{n}$ : O VSSA Avança e Evita Obstáculos no Plano Horizontal}

O posicionamento considerou movimentos acoplados, isto é, quando os movimentos ocorrem simultaneamente em todos os graus de liberdade de maneira paralela, o que difere do caso anterior da etapa inicial. Neste caso, o veículo está em navegação.

As simulações permitem avaliar o sistema de controle frente a um ambiente real.

Define-se uma trajetória que o veículo deva seguir no transcurso do tempo até chegar à posição objetivo. Podem ser acionados todos os controladores projetados. O sinal d1 tem um papel muito importante porque será esse dado que ativará a livre navegação ou a entrada no modo de evasão de obstáculos. 


\section{Descrição de Eventos:}

1. Verifica-se se o VSSA tem um obstáculo próximo na trajetória até a posição objetivo.

Caso Ideal: O VSSA não tem obstáculo à frente $(d 1=N u l l)$, à $45^{\circ}$ esquerda $(d 3 \neq$ Perto $)$, nem à $45^{\circ}$ direita $(d 2 \neq$ Perto $)$ na sua trajetória. Com isso o VSSA pode avançar no plano horizontal acionando os propulsores 1,2,3,4. Estes dados são determinados pelo sensor sonar. Neste caso as distâncias d4 e d5 são ignoradas. A distância d1 é importante, pois com ela impõe-se uma distância livre maior do que $8 \mathrm{~m}$ para frente para que o veículo possa movimentar-se com toda liberdade. Aqui há maior interesse no controle de rumo, ele sempre vai estar direcionado à posição objetivo.

Exemplo: $d 1=$ Zero e $d 2 \neq$ Perto e $d 3 \neq$ Perto. Não se avaliam as variáveis $d 4$ e d5. Executa-se a operação de avanço até completar a constante de tempo $T_{d N}$. Neste instante de tempo, são ignorados os ciclos de leitura do sistema de sensores e passa-se para a variável flag o valor de 1. A seguir, passa-se a verificar o cabeceio relativamente à posição objetivo (agora na etapa $t_{n}$ ).

Os resultados deste teste são mostrados na figura 6.4 onde uma sinal de entrada (referencial) é definido no planejador e ativado enquanto a distância d1 é a maior do que a 8 metros que o VSSA pode avançar com total liberdade. As condições de simulação são as seguintes: o VSSA deve se posicionar nas cotas $\eta 1_{\text {final }}=[25 ; 25 ; 15] \mathrm{m}$, com atitude $\eta 2_{\text {final }}=[0 ; 0 ; 0,3] \mathrm{rad}$, partindo da origem, segundo a especificação de trajetórias definidas, onde as velocidades nominais definidas para as seis direções são dadas por $\dot{\eta}_{\text {nominal }}=[0,5 \mathrm{~m} / \mathrm{s} ; 0,5 \mathrm{~m} / \mathrm{s} ; 0,5 \mathrm{~m} / \mathrm{s} ; 0 ; 0 ; 0,013 \mathrm{rad} / \mathrm{s}]$
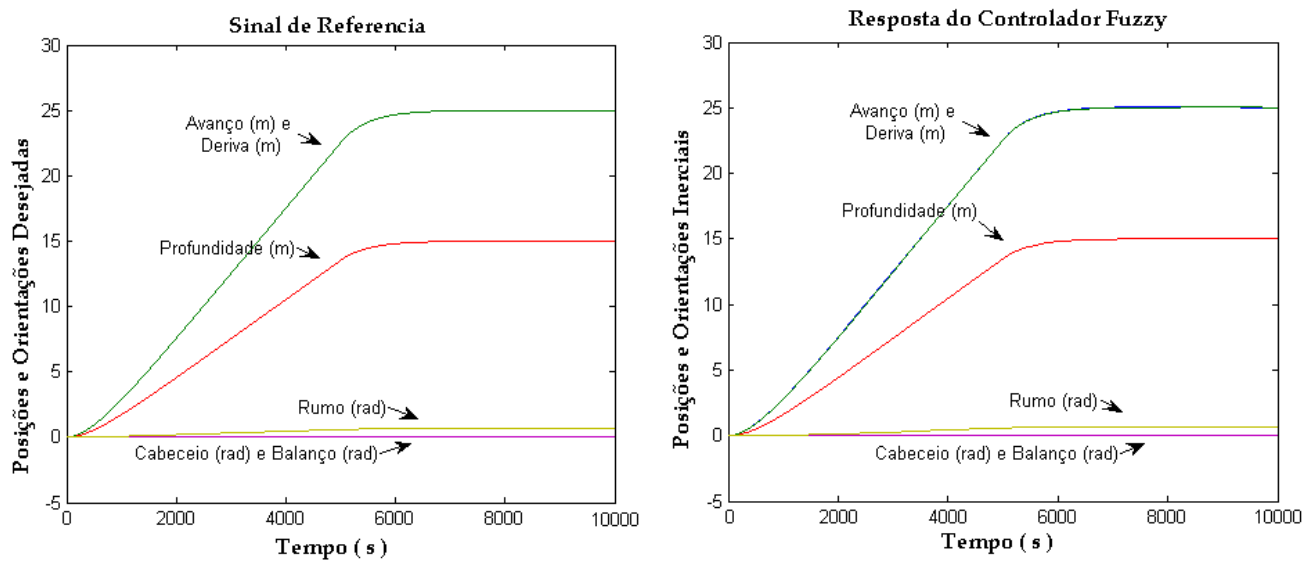

Figura 6.4: Repostas de Posições e Orientações. 
Nota-se que o veículo consegue acompanhar as trajetórias de referência, de tal forma que o controle é satisfatório. Na figura 6.5 mostra-se a diferença entre o sinal de referência e o sinal de saída do veículo. O sinal de erro de rastreamento é muito menor que os movimentos do veículo, o que indica que o controle é adequado. Durante a navegação do veículo há presença de distúrbios. Pose-se entender então que o controlador é adequadamente robusto.
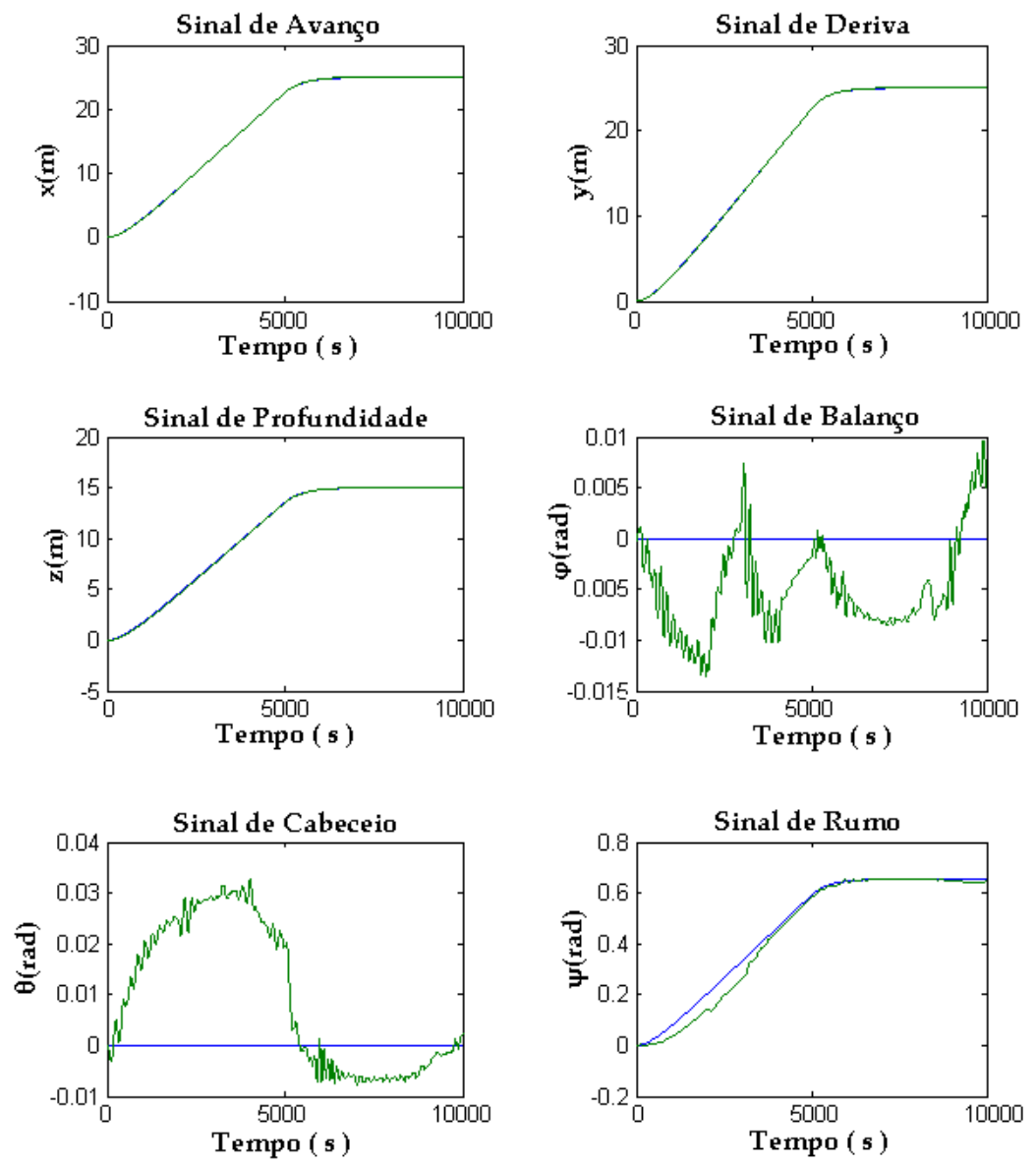

Figura 6.5: Sinais de Referencia Frente as Sinais Reais na Navegação.

Para uma análise mais compreensiva, ilustra-se na figura 6.6 os sinais de erro de rastreamento que ficam numa faixa entre (-0.1 e 0.15), o que indica que o erro se encontra na faixa de erro permitida. Verifica-se que durante a navegação o veículo se encontra na profundidade relativa. 


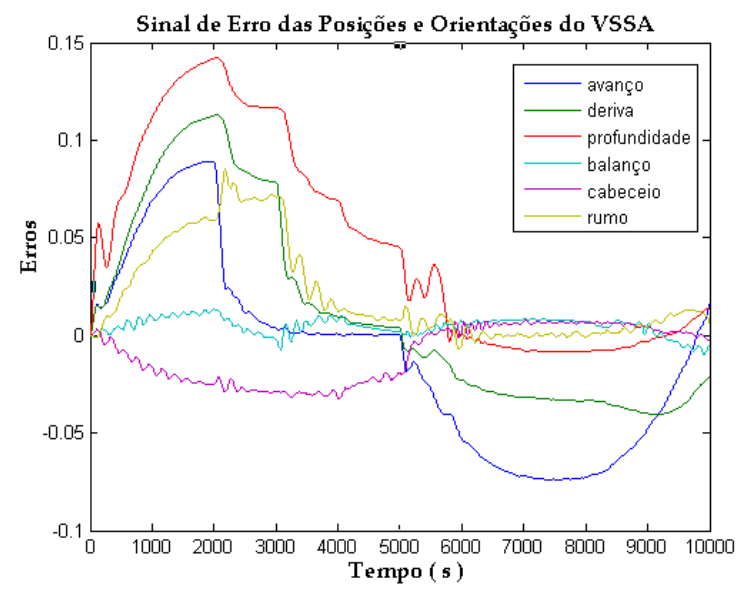

Figura 6.6: Sinais de Erro das Posições e Orientações do VSSA.

Ilustra-se na figura 6.7 o erro de rastreamento de posição e orientação do veículo.
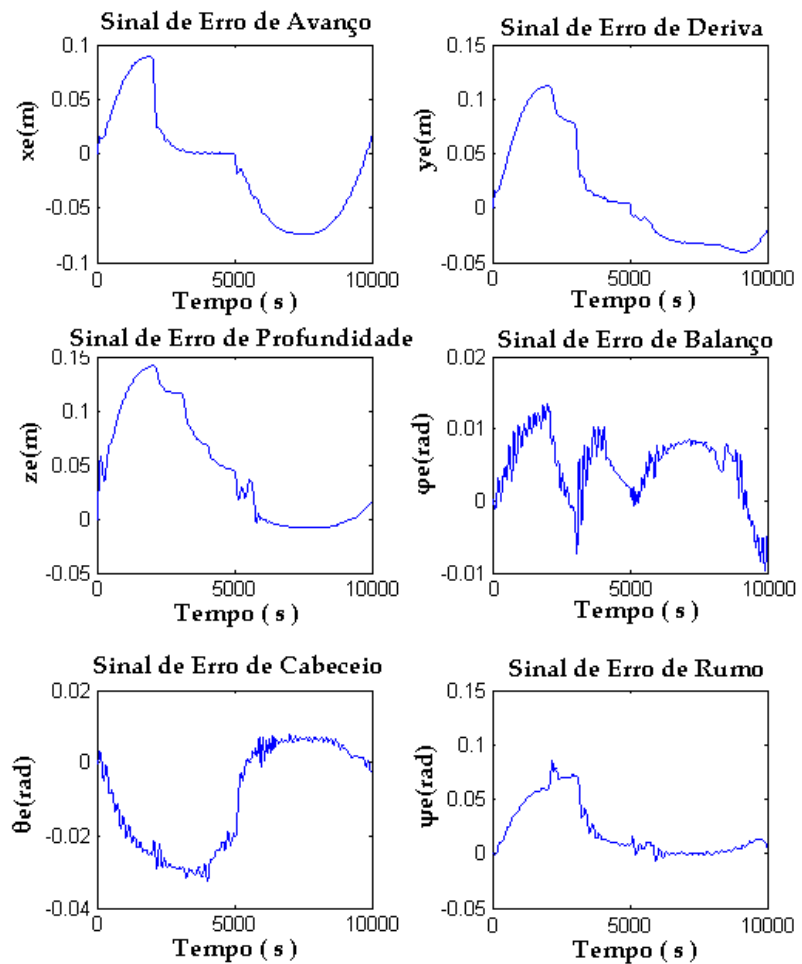

Figura 6.7: Sinais de Erro de Cada Posição e Cada Orientação do VSSA. 


\section{Resultados Complementares das Simulações}

Nas simulações é importante verificar as velocidade do VSSA durante a navegação.

Na figura 6.8 mostra-se a diferença entre as velocidades no sistema de referência inercial e no sistema móvel para os movimentos lineares e angulares, durante toda a trajetória.
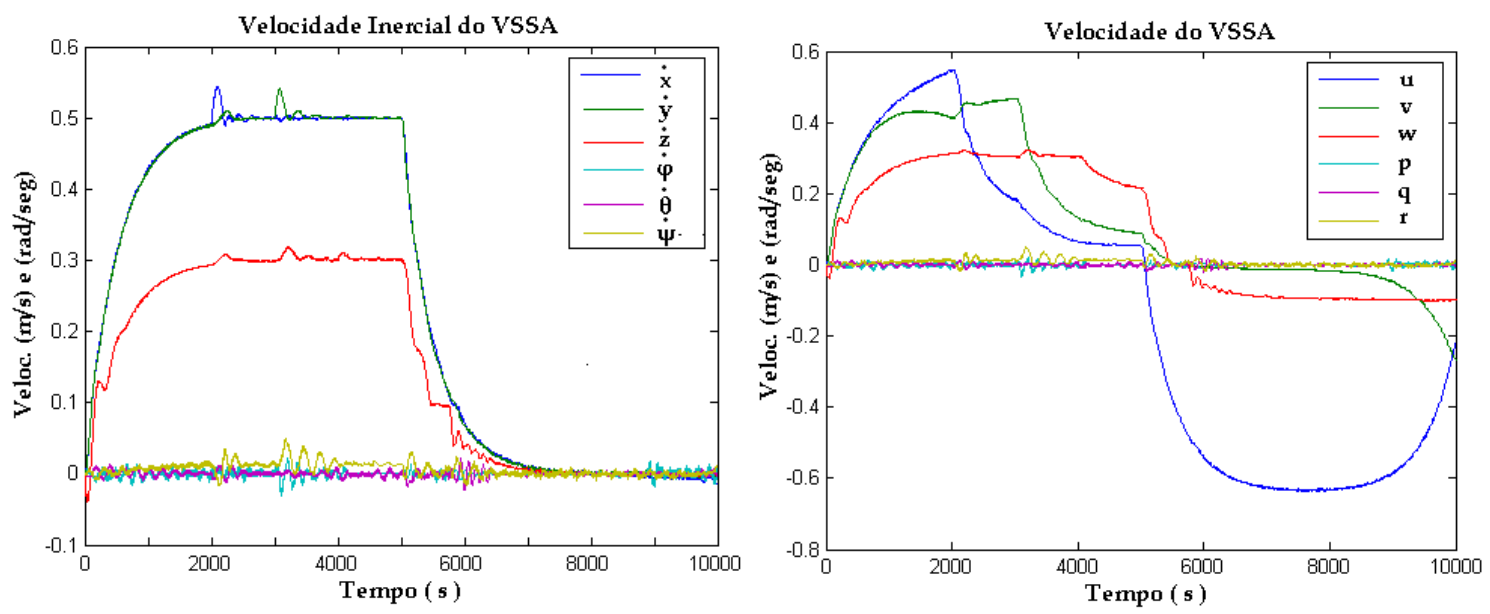

Figura 6.8: Velocidades do Veículo.

O empuxo dos propulsores são mostrados na figura 6.9.

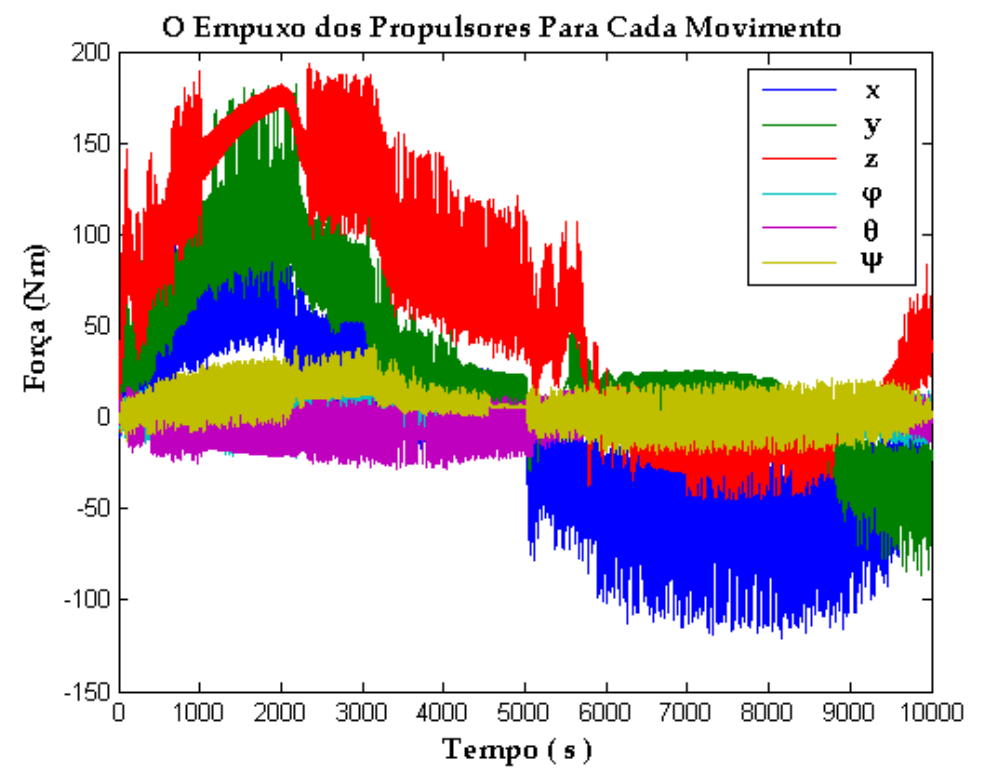

Figura 6.9: Empuxo dos Propulsores Para cada Movimento. 
Os sinais de controle das estratégias lineares e não lineares também são mostradas na figura 6.10 .
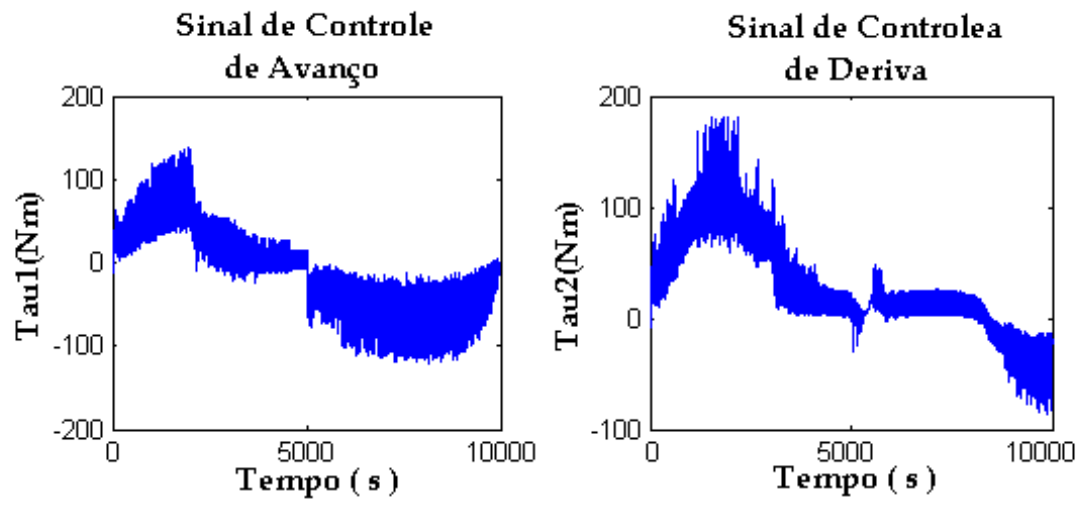

Sinal de Controle

Sinal de Controle
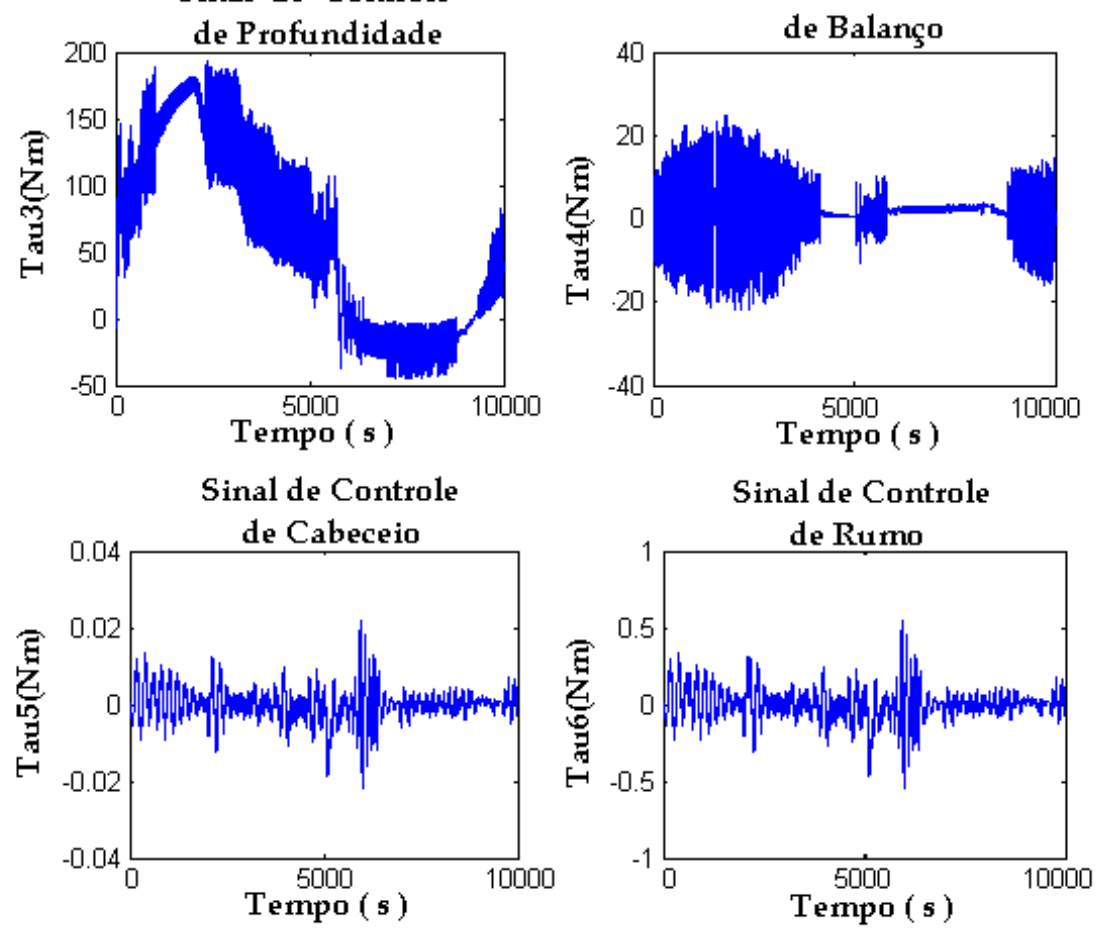

Figura 6.10: Sinais de Controle para Cada Movimento. 
Um parâmetro importante no desenvolvimento dos controladores é a velocidade de mudança de erro mostrados na figura 6.11. Este dado indica a tendência do erro e condiciona as decisões do controlador.
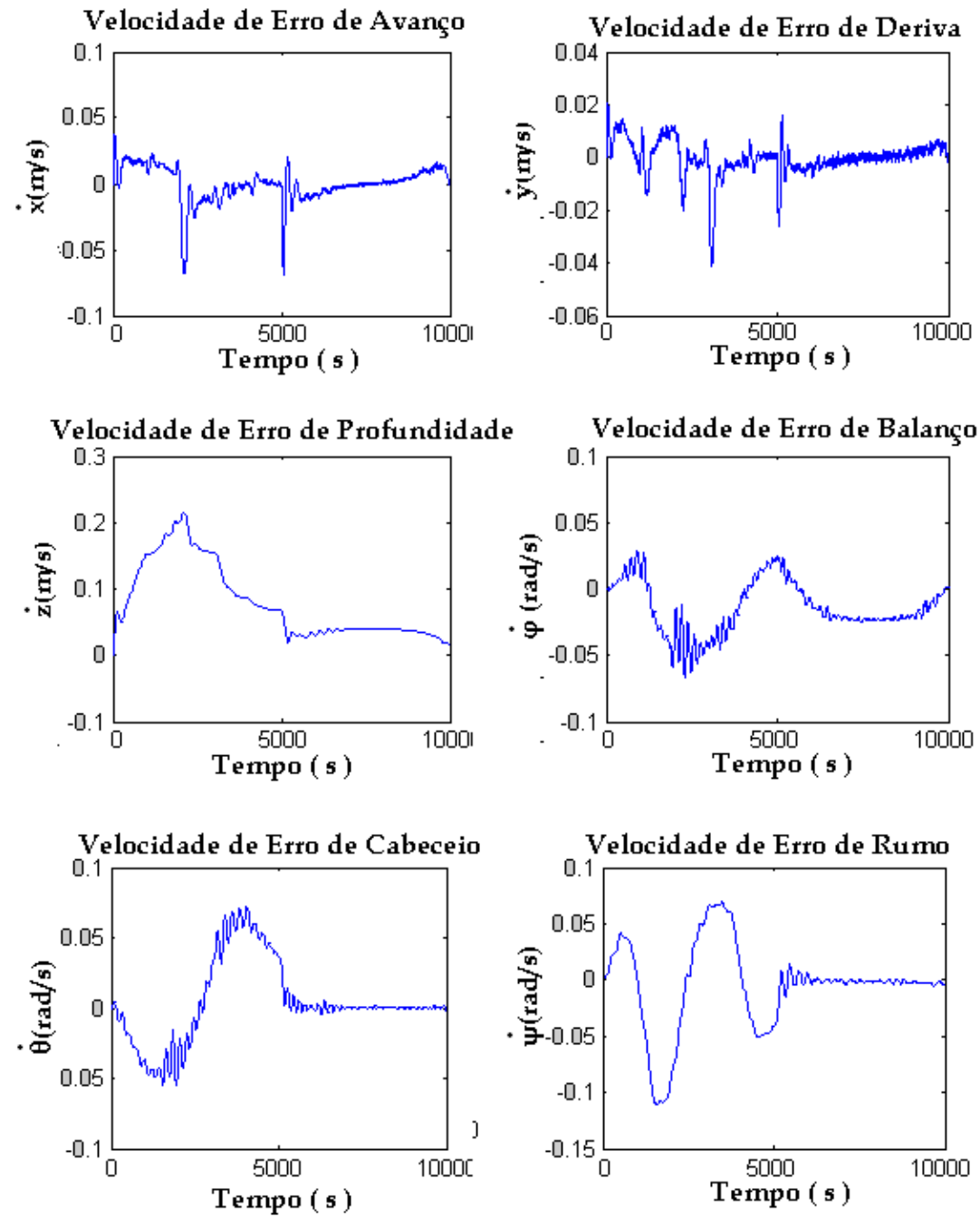

Figura 6.11: Velocidade do Erro Como variável de Controle. 
Todas as simulações são submetidas a uma perturbação que tem o perfil mostrado na figura 6.12. As perturbações são velocidades de correnteza nas três direções lineares de $\dot{\eta}_{1_{c}}=[-0,5 ;-0,4 ;-0,1] \mathrm{m} / \mathrm{s}$. O fluido é considerado irrotacional, isto é, sem componentes de velocidade de rotação (CONRADO, 2003).

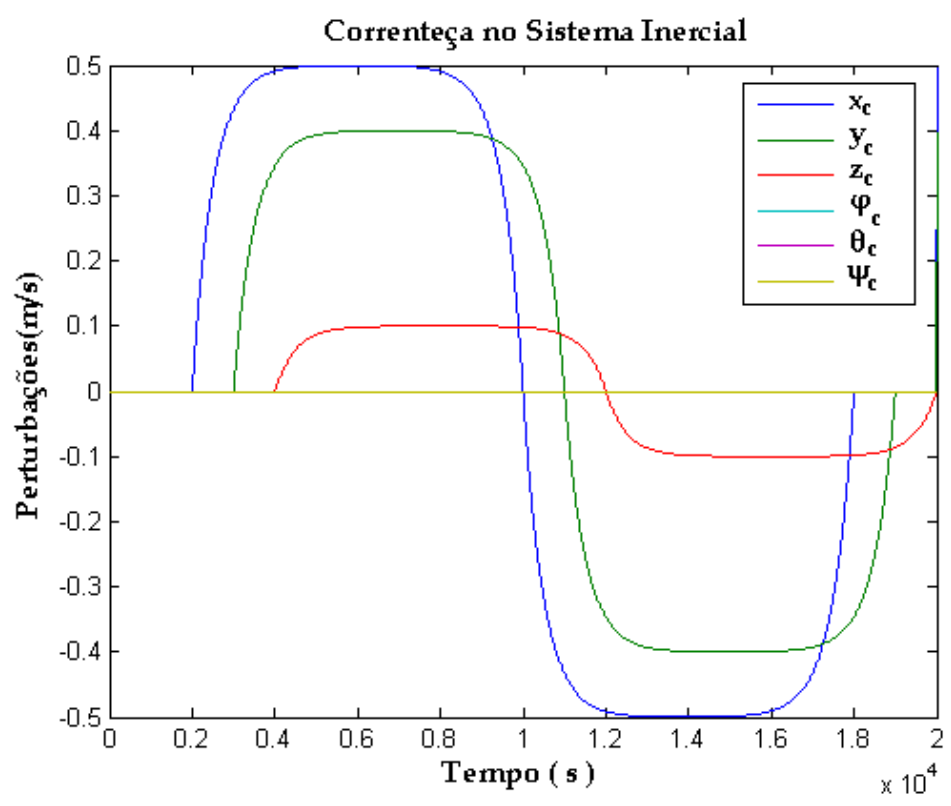

Figura 6.12: Correnteza no Sistema Inercial.

Caso Exceção 1: O VSSA tem obstáculo à frente (d1= Longe) na sua trajetória, mas o VSSA ainda pode avançar nesta direção, no entanto, faz-se uma correção pequena no rumo.

Exemplo: $d 1=$ Longe e $d 2 \neq$ Perto e $d 3 \neq$ Perto, não se avaliam as variáveis $d 4 \mathrm{e}$ d5. Executa-se a operação de avanço até completar o período de tempo $T_{d L}$. Neste intervalo de tempo são ignorados os ciclos de leitura do sistema de sensores e passa-se o valor 1 para a variável flag. A seguir, passa-se a verificar o cabeceio relativamente à posição objetivo (agora na etapa $t_{n}$ ).

Caso Exceção 2: O VSSA tem obstáculo à frente $(d 1=$ Perto $)$ na sua trajetória, com isso o VSSA não pode mais avançar nesta direção. Faz-se uma correção relativamente ao rumo em função dos valores das variáveis $d 2$ e $d 3$.

Exemplo: $d 1=$ Perto e $d 2 \neq$ Perto e $d 3 \neq$ Perto, não se avaliam as variáveis $d 4$ e $d 5$. Executa-se a operação de giro de $45^{\circ}$ à direita relativamente ao rumo. A tarefa é executada até completar-se a operação ou até uma nova ordem em um novo ciclo de leitura. A seguir, passa-se a verificar novamente se há obstáculos (na etapa $t_{n}$ ). Caso Exceção 3: O VSSA tem obstáculo à frente $(d 1=$ Perto $)$ na sua trajetória, com isso o VSSA não pode mais avançar nesta direção. Faz-se uma correção relativamente ao rumo em função dos valores das variáveis $d 2$ e $d 3$. 
Exemplo: $d 1=$ Perto e $(d 2=$ Perto e $d 3 \neq$ Perto $)$ ou $(d 2 \neq$ Perto e $d 3=$ Perto $)$, não se avaliam as variáveis $d 4$ e $d 5$. Então executa-se a operação de giro de $45^{\circ}$ à direita relativamente ao rumo, se $(d 1=$ Perto e $d 2 \neq$ Perto e $d 3=$ Perto $)$. Executa-se a operação de giro de $45^{\circ}$ à esquerda, se $(d 1=$ Perto e $d 2=$ Perto e $d 3 \neq$ Perto $)$, a tarefa é executada até completar a operação ou até uma nova ordem em um novo ciclo de leitura. A seguir, passa-se a verificar novamente se há obstáculos (na etapa $\left.t_{n}\right)$.

Caso Exceção 4: Se o VSSA tem obstáculos pertos nas direções $d 2$ e $d 3$, mesmo que não possa ter obstáculo à frente $(d 1=$ Perto ou $d 1=$ Longe ou $d 1=N u l l)$ na sua trajetória, e as variáveis $d 4$ e $d 5$ não têm obstáculos pertos, se faz uma correção de $90^{\circ}$ para a direita relativamente ao rumo.

Exemplo: $(d 1=$ Perto ou $d 1=$ Longe ou $d 1=N u l l)$ e $(d 2=$ Perto e $d 3=$ Perto $)$ e $(d 4 \neq$ Perto e $d 5 \neq$ Perto $)$. Então executa-se a operação de giro de $90^{\circ}$ à direita relativamente ao rumo. A tarefa é executada até completar a operação ou até uma nova ordem em um novo ciclo de leitura. A seguir, passa-se a verificar novamente se há obstáculos (na etapa $t_{n}$ ).

Caso Exceção 5: Se o VSSA tem obstáculos pertos nas direções $d 2$ e $d 3$, mesmo que não possa ter obstáculo à frente $(d 1=$ Perto ou $d 1=$ Longe ou $d 1=N u l l)$ na sua trajetória, e uma das variáveis d4, ou d5, é diferente de perto, se faz uma correção de $90^{\circ}$ relativamente ao rumo.

Exemplo: $(d 1=$ Perto ou $d 1=$ Longe ou $d 1=N u l l)$ e $(d 2=$ Perto e $d 3=$ Perto $)$ e $((\mathrm{d} 4 \neq$ Perto e $d 5=$ Perto $)$ ou $(d 4=$ Perto e $d 5 \neq$ Perto $))$. Então executa-se a operação de giro de $90^{\circ}$ à direita com respeito ao rumo, se $d 4 \neq$ Perto e $d 5=$ Perto. Executa-se a operação de giro de $90^{\circ}$ à esquerda, se $d 4=$ Perto e $d 5 \neq$ Perto, a tarefa é executada até completar a operação ou até uma nova ordem em um novo ciclo de leitura. A seguir, passa-se a verificar novamente se há obstáculos (na etapa $t_{n}$ ).

Caso Exceção 6: O VSSA tem obstáculos pertos em todas as direções $(d 1, d 2, d 3, d 4$ e $d 5=$ Perto) na sua trajetória, com isso o VSSA não pode avançar em nenhuma direção, então são acionados os propulsores 1,2,3 e 4; em reversão.

Exemplo: $d 1=$ Perto e $d 2=$ Perto e $d 3=$ Perto e $d 4=$ Perto e $d 5=$ Perto. Então acionam-se os propulsores $1,2,3,4$ em sentido inverso por um período de tempo $T_{d L}$ (supondo um caso não pessimista, no qual o VSSA estaria rodeado de obstáculos), ignorando os ciclos de leitura neste intervalo de tempo e passa-se para a variável flag o valor de 1. A seguir, passa-se a verificar o cabeceio relativamente à posição objetivo (agora na etapa $t_{n}$ ). 
2. Verifica-se se o VSSA está orientado ou alinhado com a posição objetivo, em função ao eixo $Z$.

Caso Ideal: O VSSA movimenta-se no eixo $X$ e se encontra alinhado com a posição objetivo no eixo $Z$. A seguir, passa-se a verificar a profundidade relativa (agora na etapa $\left.t_{n}\right)$.

Caso Exceção 1: O VSSA, mesmo movimentando-se no eixo $X$, se encontra desalinhado com o objetivo no eixo $Z$ (Cabeceio não nulo). O sensor de inclinação determina um ângulo (variável cabeceio $(\psi)$ ), que será o ângulo entre o eixo $Z$ do sistema de coordenadas móvel do VSSA relativamente à posição objetivo. Para gerar esta correção são acionados os propulsores $5,6,7,8$ enquanto os propulsores 1, 2, 3 e 4 realizam a tarefas de avanço. Se a correção é positiva, gira-se para cima e serão acionados os propulsores 5 e 6; caso contrário (correção é negativa) serão acionados os propulsores 7 e 8. A ação determinada nesta etapa de controle gera empuxo máximo para a dupla de propulsores até corrigir o cabeceio. A tarefa é executada até completar-se a operação ou até uma nova ordem em um novo ciclo de leitura. O próximo passo é verificar a profundidade relativa na etapa $t_{n}$.

3. Verifica-se se o VSSA está na profundidade relativa determinada pelo planejador.

Caso Ideal: O VSSA movimenta-se no eixo $X$ e sua profundidade relativa determinada no planejador está no intervalo válido.

Exemplo: $P=[90 m-110 m]$. A seguir, passa-se a verificar a orientação (Rumo) (agora na etapa $t_{n}$ ).

Caso Exceção 1: O VSSA, mesmo movimentando-se no eixo $X$, en- contra-se numa posição acima ou abaixo da profundidade relativa determinada, o que gera uma ação de correção de profundidade (variável profundidade) ao mesmo tempo que realiza sua movimentação no eixo $X$ (avanço). Faz-se a correção no eixo $Z$ e $X$ com a mesma prioridade, o que leva a uma combinação dos propulsores 1, 2, 3, 4, 5, 6, 7 e 8. A tarefa é executada até completar a operação ou até uma nova ordem em um novo ciclo de leitura. O próximo passo é verificar a a orientação (Rumo) na etapa $t_{n}$

4. Verifica-se se o VSSA está orientado ou alinhado com a posição objetivo, enquanto avança no eixo $X$.

Caso Ideal: O VSSA movimenta-se no eixo $X$ e se encontra alinhado com a posição objetivo. 
Exemplo: $R$ umo $=0^{\circ}$. Passa-se a verificar o Cabeceio com um $t_{n}$. A seguir, passa-se a verificar a proximidade da posição objetivo (agora na etapa $t_{n}$ ).

Caso Exceção 1: O VSSA, mesmo movimentando-se no eixo $X$, en- contra-se desalinhado com o objetivo. O sensor de rumo determina um ângulo (variável rumo $(\theta))$, que será o ângulo entre o eixo $X$ do sistema de coordenadas móvel do VSSA relativamente à posição objetivo. Para gerar esta correção são acionados os propulsores 1, 2, 3 e 4 para a correção de Rumo. Se a correção é positiva, gira-se à direita e serão acionados os propulsores 2 e 3 , enquanto 1 e 4 continuam à máxima potência para proporcionar o avanço; caso contrario (correção é negativa) serão acionados os propulsores 1 e 4 para a correção e os propulsores 2 e 3 realizam a tarefa de avanço. Nesta etapa do controle é determinada a potência para acionar cada um dos propulsores . A tarefa é executada até completar a operação ou até uma nova ordem em um novo ciclo de leitura. O próximo passo é verificar a proximidade da posição objetivo (agora na etapa $t_{n}$ ).

5. Verifica-se se o VSSA está na próximo da posição objetivo.

Caso Ideal: O VSSA movimenta-se no eixo X e ingressa no volume da posição objetivo, quer dizer, $P A \subset O B$, então passa-se à etapa $t_{f}$.

Caso Exceção 1: O VSSA não está no volume válido da posição objetivo. Passa-se a a verificar a presença de obstáculos ainda na camada $t_{n}$.

\subsubsection{Resultados na Etapa $t_{n}$}

Para se avaliar o desempenho do controlador projetado na realização de evasões de obstáculos, criou-se um cenário fictício de obstáculos. No cenário desenvolvido criaram-se obstáculos fixos no ambiente em que o VSSA vai-se realizar sua navegação. Nas simulações realizadas mostra-se o encadeamento de atividades do controlador, realizadas para o cumprimento da tarefa, que seria a chegada ao alvo final. A figura 6.13 mostra o ponto de início ou ponto de partida do VSSA, que para o caso é a coordenada $(3,3)$, e mostra também a posição objetivo ou ponto onde o veículo deve chegar, que para o caso é a coordenada $(40,55)$. Sem se importar com os obstáculos, define-se uma trajetória considerada adequada para chegar-se até o objetivo final, como se ilustra na figura 6.14 .

A seguir, como ilustrado na figura 6.15, antes do início da navegação, o controlador faz um mapeamento dos obstáculos no ambiente aonde vai se desenvolver a trajetória. A figura 6.16 ilustra o ambiente fictício em 3 dimensões, que dá uma visão do tipo de cenário que o veículo pode enfrentar. A figura 6.17 ilustra uma vista de planta, onde se mostra a posição inicial, a 


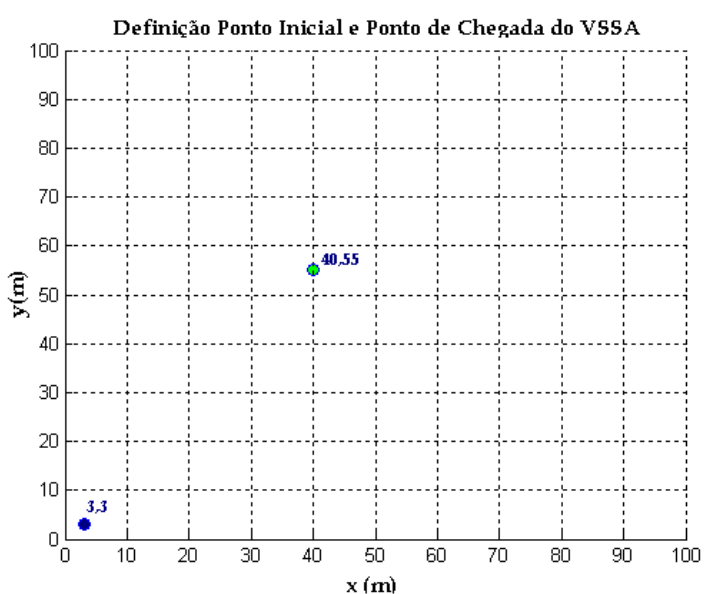

Figura 6.13: Pontos: de Partida e de Chegada do VSSA

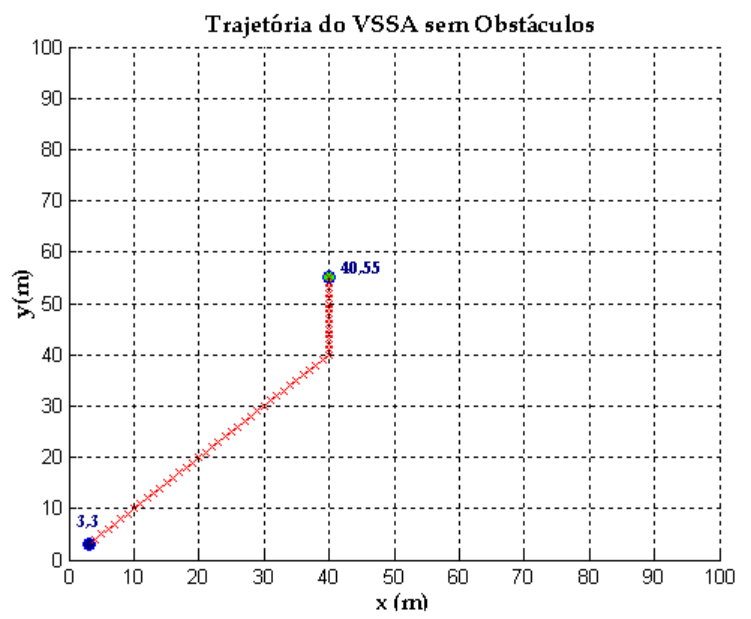

Figura 6.14: Trajetória do VSSA sem Obstáculos

posição final e os obstáculos que o veículo deve evitar. A figura 6.18 ilustra como o veículo, antes de navegar, escolhe a trajetória mais adequada. Para isso ele utiliza a trajetória inicial sem obstáculos e as regiões onde não pode navegar por estarem muito próximas a obstáculos. Desta forma, pode-se estabelecer a menor distância a se afastar da trajetória inicial a fim de contornar seguramente os obstáculos.

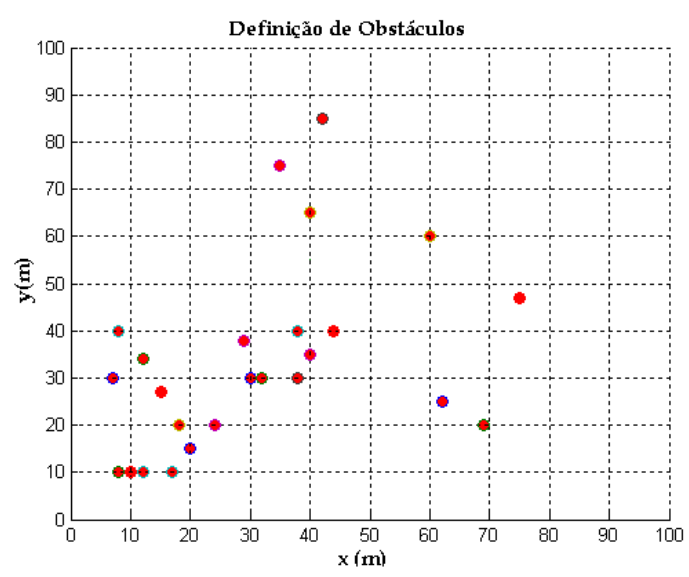

Figura 6.15: Mapeamento dos Obstáculos no Ambiente em que o VSSA vai se Movimentar

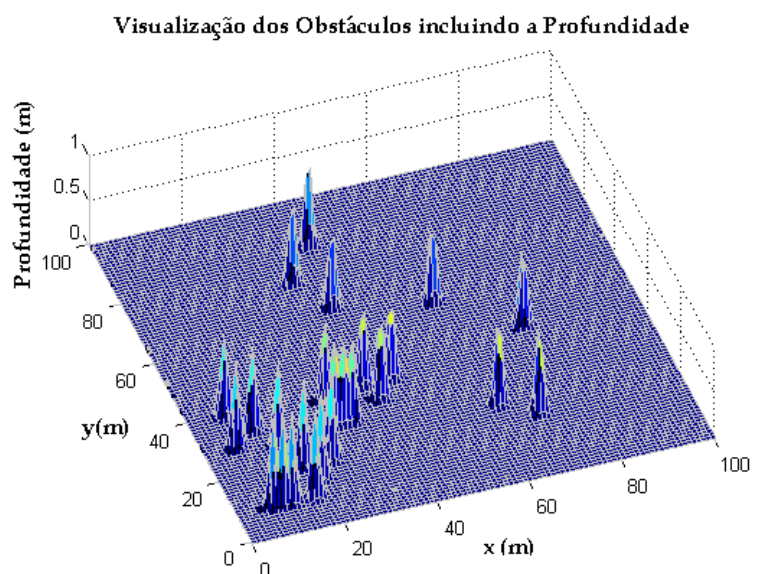

Figura 6.16: Visualização do Ambiente com Profundidade

O veículo começa a navegar tentando manter a trajetória inicial, ativando o controle de rumo e a correção de erros nas direções e orientações até perceber a presença de um obstáculo, quando então ativa-se o controle nebuloso de evasão de obstáculos e da inteligência de tomada de decisões. A figura 6.19 ilustra a trajetória final do veículo, onde se observa que ele atinge satisfatoriamente o objetivo e mostra uma navegação adequada. 


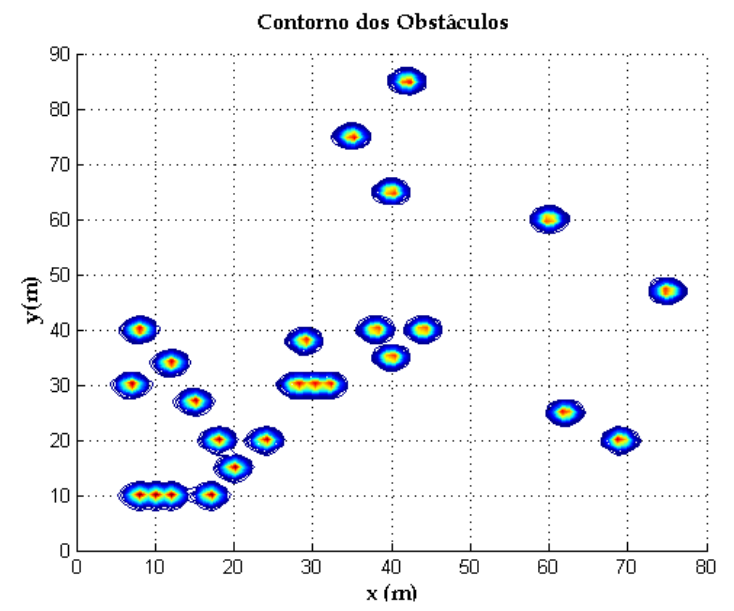

Figura 6.17: Vista de Acima do Ambiente

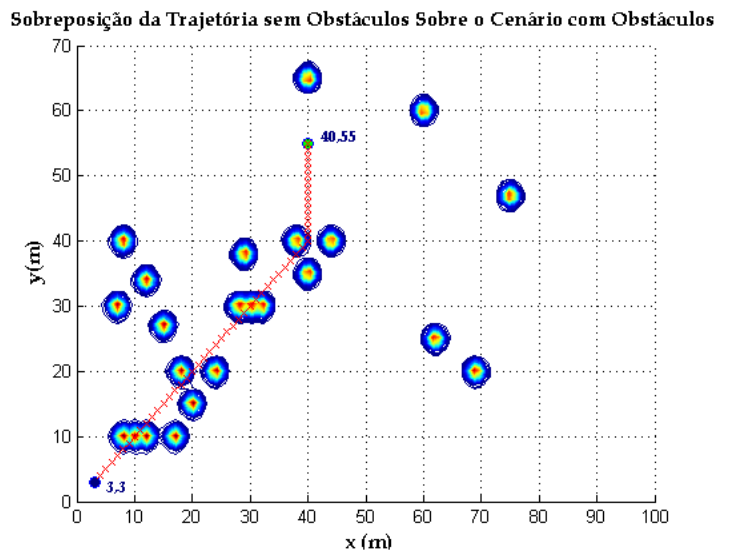

Figura 6.18: Sobreposição da Trajetória sem Obstáculos sobre o Scenario com Obstáculos

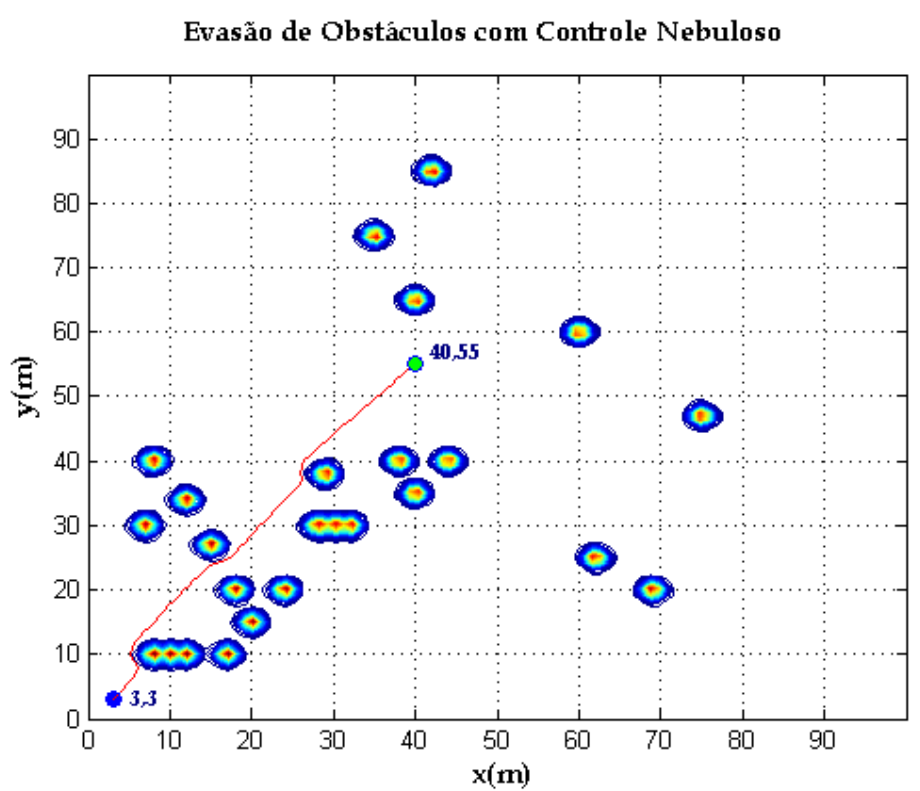

Figura 6.19: Evasão de Obstáculos com Controle Nebuloso. 


\subsection{Etapa $t_{f}$ : O VSSA Ingressa no Volume da Posição Objetivo}

\section{Descrição de Eventos:}

1. O VSSA está navega realizando a tarefa de avanço, mas percebe que ingressa na volume da posição objetivo.

Caso Ideal: O VSSA movimenta-se no eixo $X$, verifica se sua posição atual $P A$ está dentro do volume da posição objetivo. Então, calcula-se a diferença dos valores nos eixos $X$ e $Y$, entre $P A$ e $O B$. Se $V O B$ em função dos eixo $X$ e $Y$ está no termo lingüístico Perto, gera-se uma ordem de desaceleração no tempo $T_{d L}$ procurando deter o VSSA e ignorando os ciclos de leitura neste intervalo de tempo. Ao finalizar este tempo espera-se que o veículo esteja parado e o mais perto possível do objetivo.

Caso Exceção 1: O VSSA movimenta-se no eixo $X$ e verifica se sua posição atual PA está incluída dentro do volume da posição objetivo. Então, calcula-se a diferença dos valores nos eixos $X$ e $Y$, entre $P A$ e $O B$. Se $V O B x=$ Longe e $V O B y=$ Longe. Então, faz-se a correção de orientação do VSSA relativamente à posição objetivo e executa-se a tarefa de avanço num tempo $T_{d L}$, ignorando os ciclos de leitura neste intervalo de tempo, ao finalizar este tempo verifica-se novamente a posição objetivo na mesma etapa $t_{f}$.

Caso Exceção 2: O VSSA movimenta-se no eixo $X$ e verifica se sua posição atual PA está incluída dentro do volume da posição objetivo. Então, calcula-se a diferença dos valores nos eixos $X$ e $Y$ entre $P A$ e $O B$. Se $V O B x=$ Perto e $V O B y=$ Longe. Então, executa-se a tarefa de avanço num tempo $T_{d L}$, ignorando os ciclos de leitura neste intervalo de tempo, ao finalizar este tempo verifica-se novamente a posição objetivo na mesma etapa $t_{f}$.

Caso Exceção 3: O VSSA movimenta-se no eixo $X$ e verifica se sua posição atual $P A$ está incluída dentro do volume da posição objetivo. Então, calcula-se a diferença dos valores nos eixos $X$ e $Y$, entre $P A$ e $O B$. Se $V O B x=$ Longe e VOBy = Perto. Faz-se a correção orientação do VSSA relativamente à posição objetivo. Ao finalizar este tempo, verifica-se novamente a posição objetivo na mesma etapa $t_{f}$. 


\subsubsection{Resultados na Etapa $t_{f}$}

Os resultados desta etapa num ambiente sem obstáculos são mostrados na figura 6.20, onde foram colocados sinais de diferentes amplitudes para cada movimento, para verificar o rastreamento linear e angular. O objetivo final se encontra nas cotas $\eta 1_{\text {final }}=[40 ; 25 ; 15] \mathrm{m}$ e atitude $\eta 2_{\text {final }}=[0 ; 0 ; 5] \mathrm{rad}$, partindo da origem, segundo a especificação de trajetórias definidas, onde as velocidades nominais definidas para as seis direções são dadas por $\dot{\eta}_{\text {nominal }}=[0,5 \mathrm{~m} / \mathrm{s} ; 0,5 \mathrm{~m} / \mathrm{s} ; 0,5 \mathrm{~m} / \mathrm{s} ; 0 ; 0 ; 0,013 \mathrm{rad} / \mathrm{s}]$
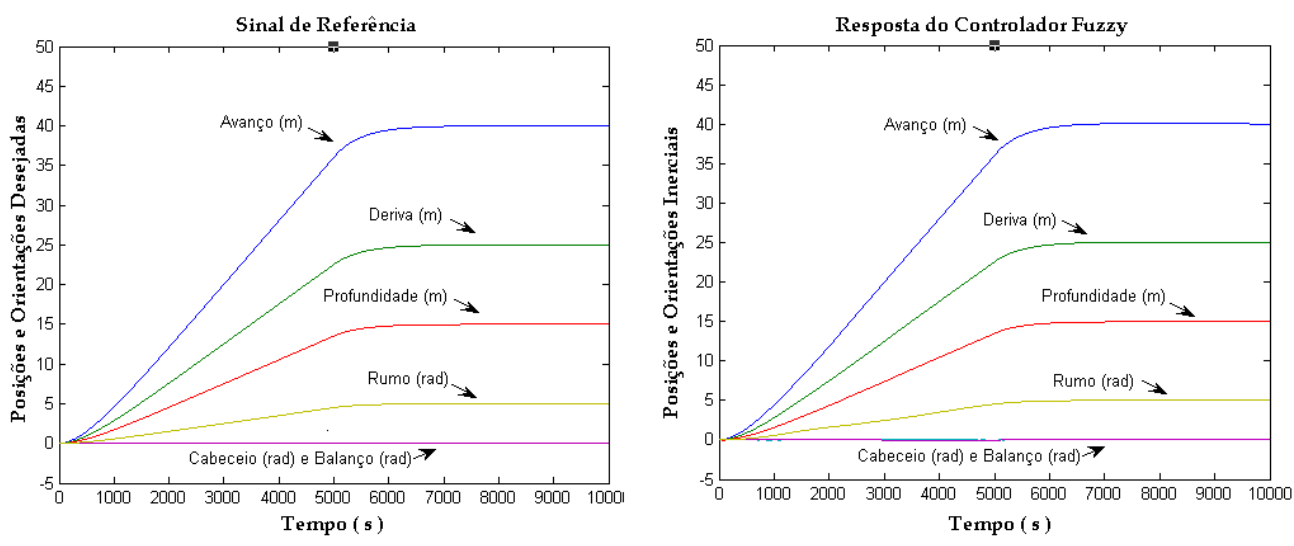

Figura 6.20: Repostas de Posições e Orientações. 
Nota-se que para cada movimento o veículo consegue acompanhar as trajetórias de referência, e fica nas posições desejadas de tal forma que o controle é satisfatório e o VSSA atingiu seu objetivo. Na figura 6.21, o sinal de erro de rastreamento é muito menor que os movimentos do veículo, o que mostra que o controle é muito bom, já que durante a navegação do veículo existe presença de distúrbios e incertezas de modelagem assim como do ambiente externo. Isto pode ser entendido como robustez de desempenho.
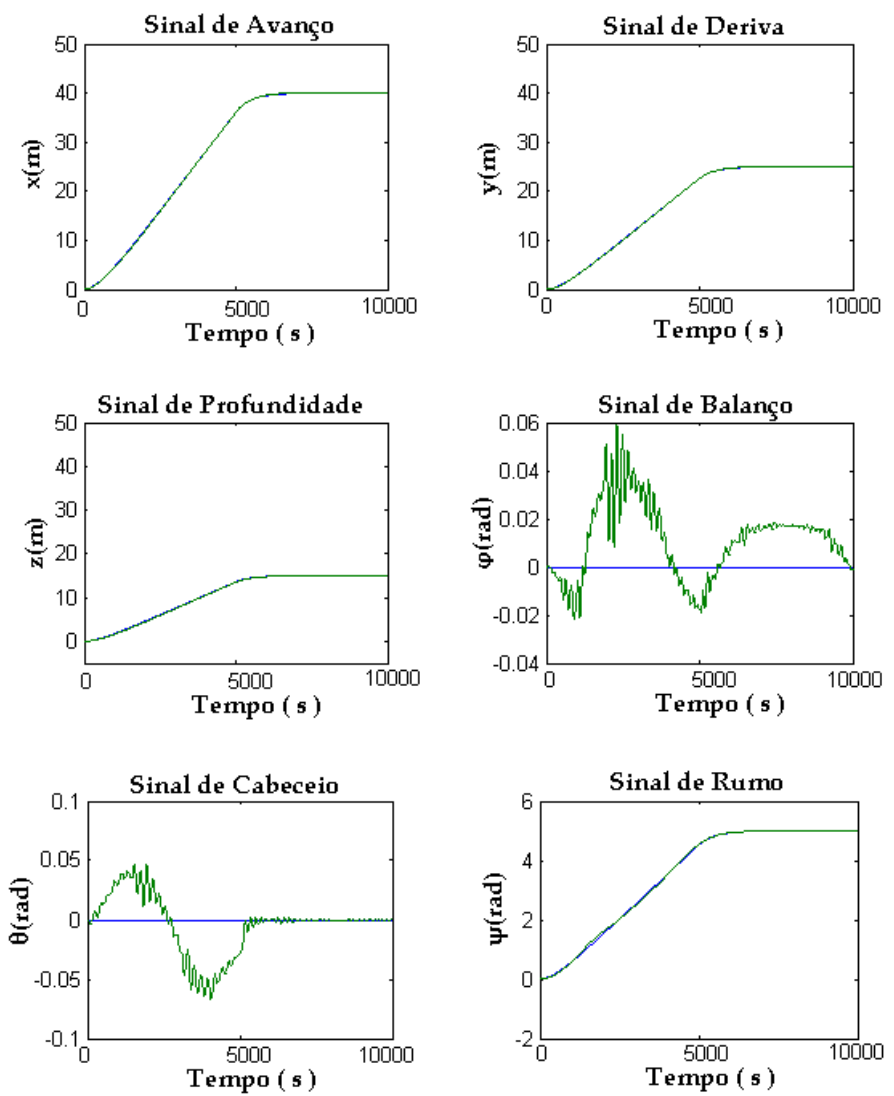

Figura 6.21: Sinais de Referência Frente a Sinais Reais na Navegação.

Na figura 6.22 os sinais de erro de rastreamento se encontram numa faixa dentre ($0,15$ e 0,3$)$, o que indica que o erro se encontra na faixa de erro permitida. Verifica-se ainda que durante a navegação o veículo se encontra na profundidade relativa. 


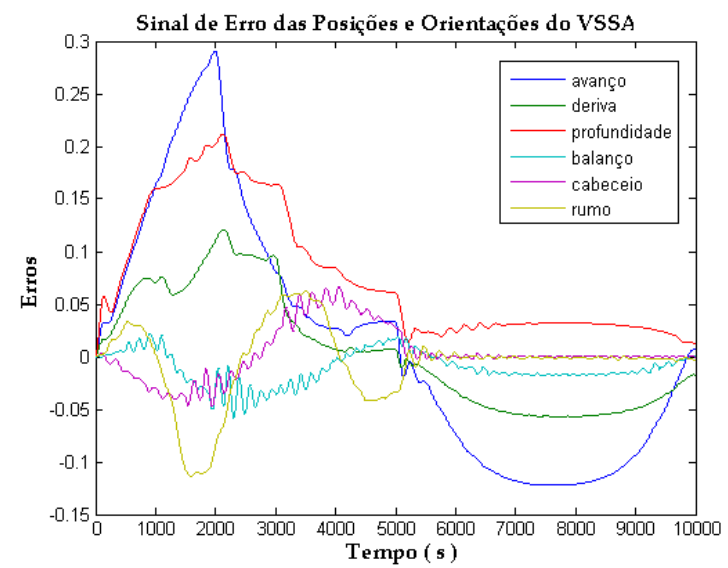

Figura 6.22: Sinais de Erro das Posições e Orientações do VSSA.

Ilustra-se na figura 6.23 o erro de rastreamento de posição e orientação do veículo.
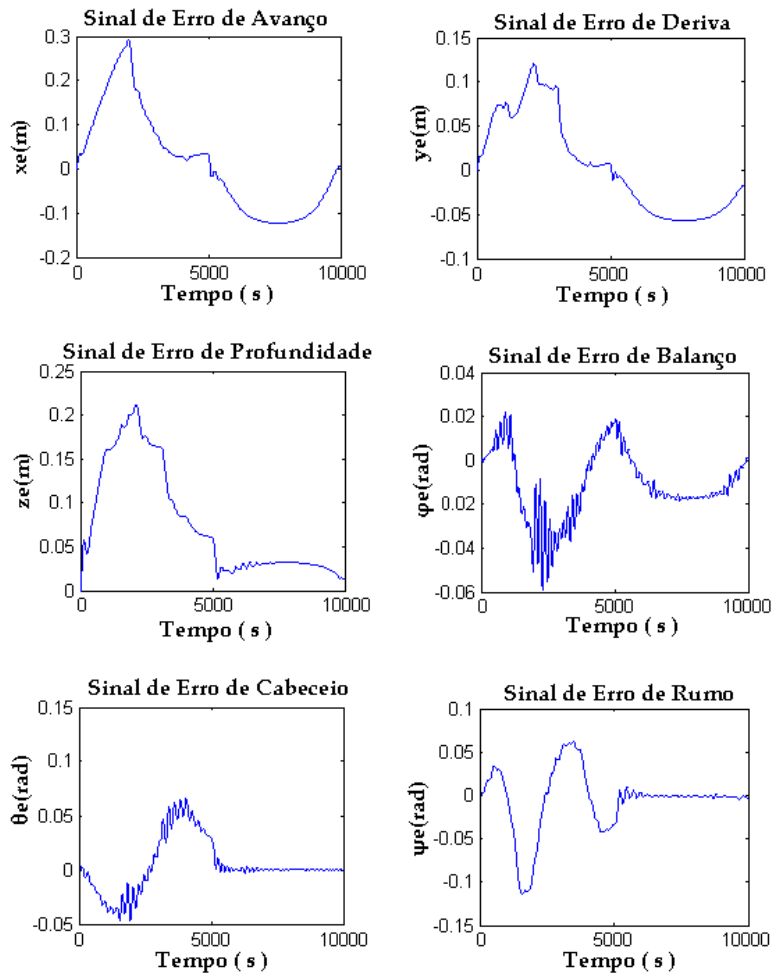

Figura 6.23: Sinais de Erro de Cada Posição e Cada Orientação do VSSA. 


\section{Resultados Complementares de Simulação}

Nas simulações é importante verificar as velocidade do VSSA durante a navegação.

Na figura 6.24 mostra-se a diferença entre as velocidades no sistema de referência inercial e no sistema móvel para os movimentos lineares e angulares, durante toda a trajetória.
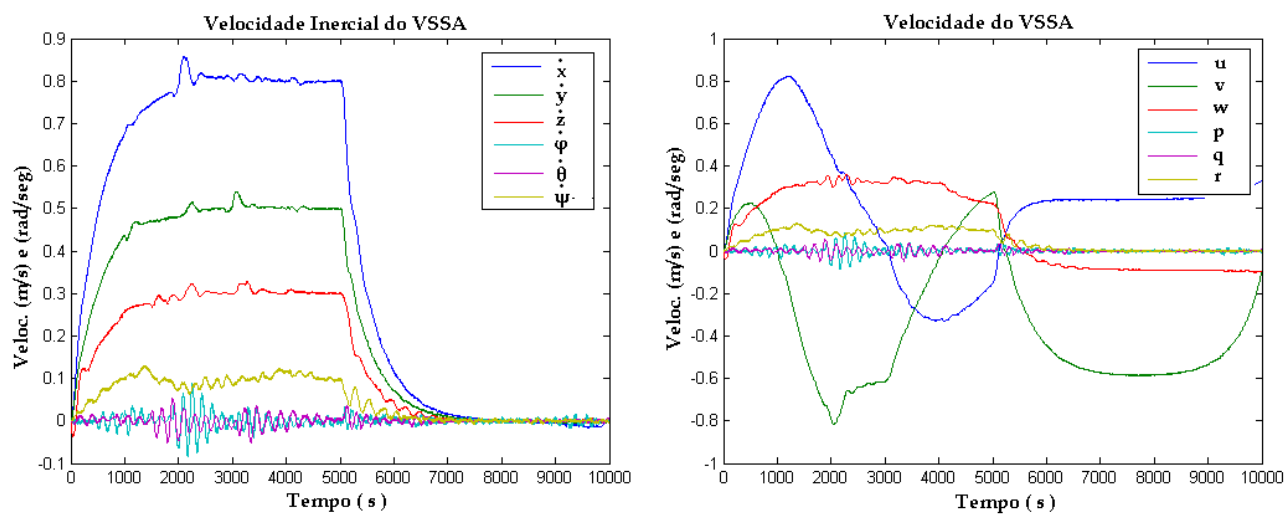

Figura 6.24: Velocidades Inerciais e Relativas.

O empuxo dos propulsores são mostrados na figura 6.25 .

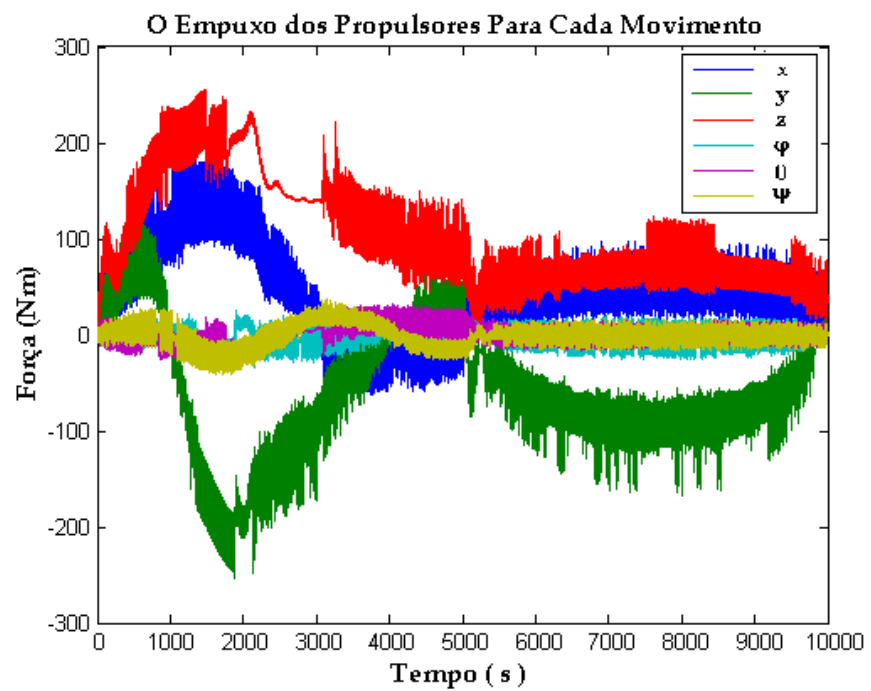

Figura 6.25: Empuxo dos Propulsores para cada Movimento. 
Os sinais de controle das estratégias lineares e não lineares também são mostradas na figura 6.26
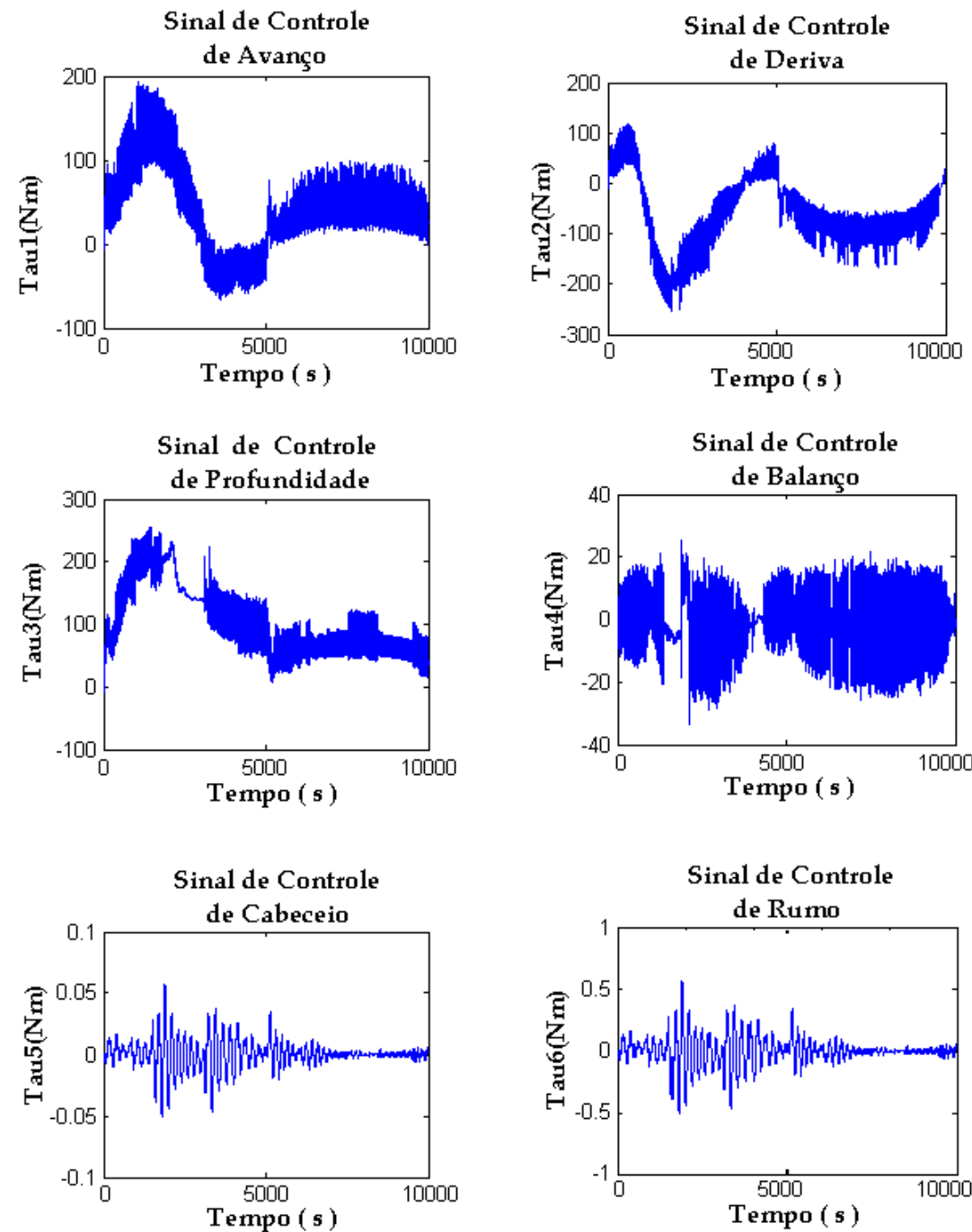

Figura 6.26: Sinais de Controle para Cada Movimento. 
A velocidade de mudança de erro mostradas na figura 6.27 indica a tendência do erro e condiciona as decisões do controlador e são .
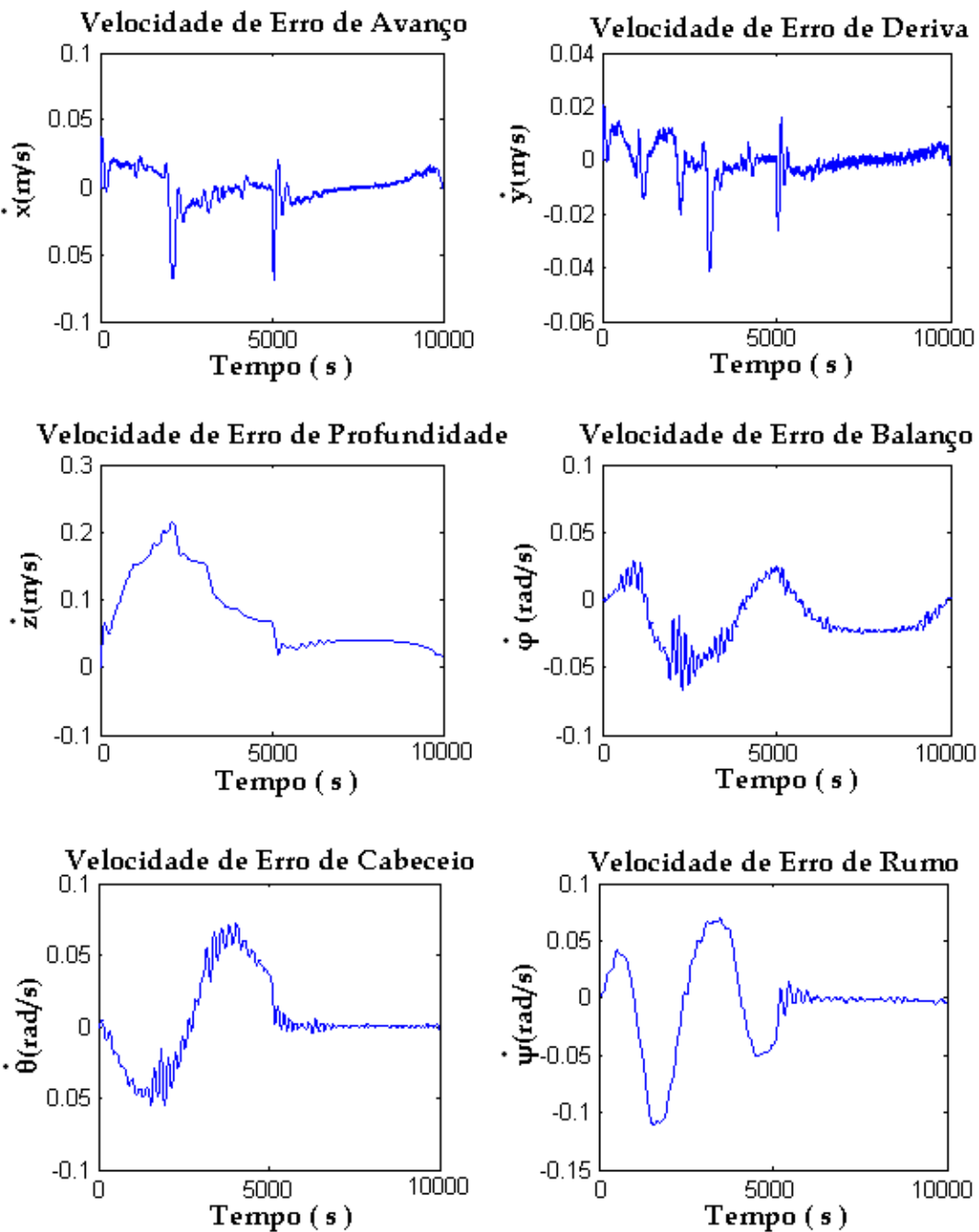

Figura 6.27: Velocidade do Erro Como variável de Controle. 


\section{Considerações Finais}

\subsection{Conclusões}

Nesta dissertação apresenta-se uma estratégia de controle por camadas baseada na teoria de controle nebuloso para o controle de um veículo submarino semi-autônomo.

Em função deste objetivo, efetuou-se um longo trabalho de pesquisa envolvendo definições de sistemas de controle nebuloso, seus algoritmos, suas formas de particionar os espaços de E/S, seus formatos de funções de pertinência e métodos de concentração. O resultado deste estudo foi a proposta de uma taxonomía para projetar um controlador nebuloso, visa no capítulo 5 .

Os resultados desta arquitetura de controle, testado em um modelo matemático do VSSA da POLI-USP, mostram o bom desempenho do framework proposto de controladores nebulosos frente aos distúrbios do ambiente que é submetido o veículo e ante a presença de correnteza.

Para o caso do posicionamento dinâmico e navegação de robôs submarinos, o controlador desenvolvido com base na metodologia proposta é capaz de lidar com as não-linearidades do comportamento dinâmico do veículo e com as incertezas típicas do ambiente subaquático.

A estrutura de camadas mostrou resultados satisfatórios, sendo que sua maior vantagem é possibilitar ao usuário o entendimento e a facilidade para alterar os parâmetros do controlador e as regrar que governam cada um dos controladores, possibilitando a otimização e a obtenção de um bom desempenho dos atuadores (propulsores) na navegação. Por tratar-se de um controlador flexível, a aplicação deste sistema de controle para outros tipos de robôs móveis como outros sistemas torna-se possível e de fácil portabilidade assim o controlador é acessível e escalável.

A modelagem matemática do robô submarino realizada majoritariamente por Conrado (2003) forneceu subsídios à compreensão da dinâmica e a física do sistema robótico do veículo, que pode ser sintetizado como um sistema complexo, de 6 graus de liberdade destacando a influência dos efeitos hidrostáticos (peso e empuxo) e hidrodinâmicos (amortecimento quadrático e massa adicional), sobre a dinâmica de corpo rígido do veículo. A particularidade de se utilizar um sistema sem um modelo completamente definido, levou à introdução de algoritmos adapta- 
tivos no problema de controle, chegando-se assim a escolha da lógica nebulosa, de grande uso corrente em aplicações similares.

Simulações usando o modelo matemático modificado do VSSA usando os controladores nebulosos projetados permitiram testar a lógica de raciocínio empregada no desenvolvimento dos controladores. Mostraram ademais, que a solução escolhida é totalmente viável para o desenvolvimento de sistemas de controle, cujo processo decisório baseiem-se em sinais provenientes de sensores.

Durante a fase de sintonia do sistema de controle, os parâmetros do controlador foram modificados e ajustados através das simulações numéricas. Os estudos de casos descritos no capítulo 6, permitem avaliar o comportamento do veículo durante tarefas especificas, desde que ele é liberado no mar até o momento que ele chega a seu destino, considerando a evasão de obstáculos no plano horizontal confirmaram a aplicabilidade do controlador nebuloso. Várias tarefas diferentes foram simuladas tais como: correção de erro de posicionamento e orientação nos seis graus de liberdade, ou evasão de obstáculos e controle de profundidade. Os modelos desenvolvidos para os controladores apresentaram boa precisão, interpretabilidade das regras, generalização e rapidez de convergência. Eles mostraram ser uma boa alternativa para a solução de problemas comumente resolvidos por sistemas nebulosos, com duas grandes vantagens: a interpretabilidade e a possibilidade de criar sua própria estrutura. Esta última vantagem evita a tarefa enfadonha de testar várias estruturas na busca de um bom desempenho na solução de um determinado problema. Isto significa, no caso de lógica nebulosa, determinar o melhor número de camadas e de variáveis a processar por camada. No caso, significa encontrar o melhor número de partições do universo de discurso para cada variável de entrada.

O algoritmo do controlador foi formulado para ser aplicado em tempo real, permitindo a otimização de estruturas de controle baseadas em função do tempo, convergindo e tratando a instabilidade decorrente da realimentação do sistema. A abordagem natural obtida nesta pesquisa, gerenciou bem a instabilidade do sistema, obtendo uns bons resultados nas correções de erros.

A metodologia adotada mostrou-se perfeitamente adequada, atingindo com sucesso os objetivos inicialmente propostos.

A contribuição principal desta dissertação foi o desenvolvimento e a integração de diferentes abordagens metodológicas para a construção de um controlador com uma dinâmica complexa e de modelagem ainda não estudados ou com modelagens poucos explorados utilizando algoritmos adaptáveis.

Uma desvantagem, que deve ser enfatizada, é o fato dos algoritmos adaptativos dos sistemas nebulosos hierárquicos utilizarem muitos intensamente recursos de processamento. Isto é 
devido a não se ter uma estrutura fixa e nem um número constante de parâmetros ajustáveis.

Uma dificuldade importante a ressaltar é a definição das variáveis do controlador, a definição dos universos de discurso, incluindo as formas de suas funções de pertinência e o método de concentração a utilizar depende muito de isso para o desempenho do controlador.

\subsection{Sugestões para Trabalhos Futuros}

Nesta seção, apresentam-se sugestões para trabalhos futuros, visando manter uma continuidade na pesquisa. Com base nos resultados obtidos no sistema de controle e navegação de um robô submarino semi-autônomo podem ser enumeradas as seguintes sugestões para futuros trabalhos nesta linha de pesquisa.

\section{- Implementação e teste no protótipo.}

A próxima tarefa nesta pesquisa será a implementação e teste dos controladores nebulosos desenvolvidos no protótipo de VSSA existente na Escola Politécnica. A tarefa envolve a adaptação do "software" desenvolvido para linguagem de máquina e a integração destes algoritmos com o sistema de gerenciamento do veículo.

\section{- Requisitos de Hardware.}

Análise dos requisitos de "hardware" necessários para a implementação do sistema de controle, o acondicionamento de sinais dos sensores com o sistema eletrônico do VSSA, para a implementação experimental. Comparações das respostas entre os diferentes sistema adaptativos para o controle de orientação e navegação de robôs submarinos para determinar o grau de requerimento e importância da carga de processamento e energia na utilização destes tipo de técnicas para o controle.

\section{- Realização de testes de laboratório.}

Após implementação e adaptação dos controladores serão realizados testes em tanques disponíveis na Universidade de São Paulo para a avaliação dos comportamentos dos controladores desenvolvidos em condições próximas às reais.

\section{- Construção de um projeto maior e integro baseado em lógica nebulosa.}

As perspectivas para trabalhos futuros relacionam-se à geração automática de todo o sistema de controle nebuloso, desde a etapa alcançada até a configuração das funções de pertinência das variáveis internas do controlador e seus respectivos sinais de controle. Além disso, pode-se vislumbrar o estudo de técnicas em tempo real para a configuração dinâmica de controladores para o nível hierárquico seguinte da arquitetura de controle, 
que trata de missões especificas onde o robô, além de ter controle no posicionamento, a orientação e navegação, faça tarefas de análise, estudo etc. dispensando a tarefa de obtenção do modelo matemático da dinâmica do sistema. Por exemplo, a quantidade de informações adicionais que podem ser incorporadas ao controlador é ainda muito grande, indicando que o desempenho deste pode melhorar.

\section{- Integração de técnicas de controle adaptativo.}

Considera-se que um sistema adaptativo é aquele cuja estrutura é variável ou ajustável, de tal forma que seu comportamento ou desempenho melhore, de acordo com algum critério desejado, através da exposição ao ambiente no qual esta inserido. Se ao controle de navegação e orientação de veículos submarinos usando a lógica nebulosa forem integradas técnicas de Redes neurais e algoritmos genéticos podem-se conseguir resultados ainda melhores, tais como: a adaptação automática (auto-otimizada) em face a ambientes e sistemas variantes no tempo (não estacionário).

Embora a utilização de um controlador nebuloso tenha se mostrado eficaz em realizar a estabilização dos movimentos no sistema robótico nos seis graus de liberdade, ele garante proteção à presença de obstáculos apenas no plano horizontal. O ideal é que num ambiente tão complexo como o mar profundo o veículo seja protegido de colisões em todas as direções. O uso de um sistema de controle mais robusto, como a abordagem por filtros de Kalman, pode ser vantajosa para o caso de movimentos na direção vertical, no qual o sistema nebuloso não obteve o desempenho desejado devido à carga de processamento que requer maior entrada de sinais no controlador. Por permitir a utilização de modelos matemáticos tanto do robô como dos sensores (visão e sonares) para gerar o controlador do sistema, filtros de Kalman podem ser utilizados com grande vantagem para o caso específico do controle não-linear do movimento na direção vertical.

A lógica nebulosa, as redes neurais assim como os algoritmos genéticos são ferramentas adaptativas que podem auxiliar no tratamento de problemas complexos como o controle de orientação e navegação de robôs submarinos. Estes métodos que integram mais de uma tipo de sistema inteligente, unindo os pontos fortes de um para compensar lacunas de outro, são ferramentas poderosas para superar desafios. Sabe-se que a utilização de algoritmos genéticos é uma técnica eficiente para determinar parâmetros de um controlador nebuloso, fornecendo resultados extremamente satisfatórios. Nos sistemas neuronebulosos, o sistema nebuloso é treinado por um algoritmo de aprendizado derivado da teoria de redes neurais artificiais. Os controladores nebulosos poderiam ser treinados para tarefas específicas, tais como a filtragem e tomada de decisões, ou seja, poderiam sintetizar sistemas responsáveis por estas tarefas através de um sistema de treinamento. É possível extrapolar um modelo de comportamento para os controladores lidar com no- 
vas situações, após terem sido treinados com um finito e freqüente pequeno número de sinais (ou padrões de treino).

\section{- Otimização conjunta}

No trabalho realizado sintonizaram-se os controladores para a obtenção de desempenho ótimo, consideram-se apenas algumas variáveis do sistema. Para uma evolução deste trabalho a otimização conjunta desses valores de processamento com parâmetros de configuração do controlador podem levar a um sistema mais robusto e eficiente com una navegação mais elaborada, como a criação da rota ótima na procura do posição objetivo, planejamento de trajetórias automáticas, fazendo uso da teoria de controles automáticos, cada vez mais integrada a área da computação. 


\section{Referências}

AKKIZIDIS, I.; ROBERTS, G. Designing a fuzzy-like pd controller for an underwater robot. Control Engineering Practice, 2003.

AZEVEDO, F. Algoritmos genéticos em redes neurais artificiais. V Escola de Redes Neurais, ITA, Universidade Federal de Santa Catarina, p. 31, 1999.

BATLLE, J.; RIDAO, P.; CARRERAS, M. An underwater autonomous agent from simulation to experimentation. Congreso Catalan de Inteligencia Artificial, 2000.

BAUCHSPIESS, A. Servocontrole preditivo de robôs guiados por sensores. Universität Erlangen-Nürnberg, 1995.

CHIU, F.; GUO, J.; HUANG, C.; TSAI, W. Application of the sliding mode fuzzy controller to the guidance and control of an autonomous underwater vehicle. Dept. of Naval Architecture and Ocean Engineering National Taiwan University, 1999.

CHUN-LIANG, L.; HUAT-WEN, S. Intelligent control theory in guidance and control. Institute of Automatic Control Engineering Feng Chia, University Taichung, Taiwan, 1999.

CONRADO, E. Modelagem e Controle de Veículos Submarinos Não Tripulados. Dissertação (Mestrado) — Escola Politécnica da Universidade de São Paulo, 2003.

COX, E. The Fuzzy Systems Handbook. [S.1.]: AP Professional, 1994.

CUNHA, J.; LIZARRALDE, F.; COSTA, R.; HSU, R. Sistema de posicionamento dinâmico para um veículo submarino de operação remota. Congresso Brasileiro de Automática, 1994.

DAí-JU; XINOGUANG, Z. Fuzzy logic control in autonomous rov navigation. IEEE Universidade de Shandong de Ciência e Tecnologia, University Shandong, China, 2002.

DOMINGUEZ, R. Simulação e Controle de um Veículo Submersivel de Operação Remota. Dissertação (Mestrado) — COPPE - Uiversidade Federal de Rio Janeiro, 1989.

DONHA, D.; LUQUE, J. Underactuated auv robust control. Proceeding of IFAC 2006, 2006.

DRIANKOV, D.; HELLENDOORN, H.; REINFRANK, M. An introduction to fuzzy control. Springer-Verlag, 1993.

FALTISEN, O. Sea loads on ship and offshore structures. 1990. Cambridge University Press.

FIGUEIREDO, M. Navegação autônoma de robôs. Universidade Estadual de Maringá, 1999.

FOSSEN, T. (Ed.). Guidance and Control of Ocean Vehicles. London: John Wiley and Sons, 1994. 619 p. ISBN 0-471-94113-1.

FRANCO, P.; CASTRO, M. Introdução ao processamento adaptativo de sinais digitais.

Pontifícia Universidade Católica do Rio Grande do Sul, p. 19, 2001. 
FREIRE, J. D. Projeto de um Controlador Fuzzy Controle Digital. Tese (Teses) Universidade Federal do Rio Grande do Norte, Departamento de Engenharia de Computação e Automação Laboratório de Controle, Julho 2005.

GOMIDE, F.; GUDWIN, R.; TANSCHEIT, R. Conceitos fundamentais da teoria de conjuntos fuzzy e aplicações. Tutorials of 6th International Fuzzy Systems Association World Congress - IFSA 95, 1995.

GOMIDE R, G. F. Controle de processos por lógica fuzzy. UNICAMP-FEE-DCA, 1992.

GUERRA, R. Projeto e simulação do controle de atitude autônomo de satélites usando lógica nebulosa. Dissertação (Mestrado) — Instituto Nacional de Pesquisas Espaciais - INPE, Março 1998.

GUO, C.; SIMAAN, M.; SUN, Z. Neuro-fuzzy intelligent controller for ship roll motion stabilization. 2003 IEEE International Symposium on Intelligent Control, 2003.

HEALEY; PASCOAL, A.; PEREIRA, F. L. Autonomous underwater vehicles: An application of intelligent control technology. American Control Conference, Junho 1995.

INNOCENTI, M.; CAMPA, G. Robust control of underwater vehicles: Sliding mode vs. lmi synthesis. Departament of electrical System And Automation - Pisa Univerisity, 1999.

JANG, J.; SUN, C. Neuro-fuzzy modeling and control. Proceedings of the IEEE, v. 83, n. 3, p. 1-29, mar 1995.

JULCA, J. Estimacão de coeficientes hidrodinâmicos de um veículo submarino semi-autônomo. Dissertação (Mestrado) — Escola Politécnica da Universidade de São Paulo, 2003.

KANAKAKIS, V.; VALAVANISA, K. Fuzzy-logic based navigation of underwater vehicles. Journal of Intelligent and Robotic Systems, 2004.

KLIR, G.; YUAN, B. Fuzzy sets and logic fuzzy: theory and applications. [S.1.]: Prentice Hall, 1995 .

KRUSE, R.; KLAWONN, F.; NAUCK, D. Fuzzy sets, fuzzy controllers and neural networks. (Departamento de ciências da computação) Universidade Técnica de Braunschweig, 1992.

KUO, R.; WU, P.; WANG, C. Fuzzy neural networks for learning fuzzy if-then rules. Applied Artificial Intelligence, p. 25, 2000.

LEE, C. Fuzzy logic in control systems: Fuzzy logic controller (part i). IEEE Transactions on Systems, Man an Cybernetics, v. 20, n. 2, p. 404-418, março/abril 1990.

LEE, C. Fuzzy logic in control systems: Fuzzy logic controller (part ii). IEEE Transactions on Systems, Man an Cybernetics, v. 20, n. 2, p. 419-430, março/abril 1990.

LIN, C. Advanced control system design. In: Prentice-Hall. Englewood Cliff, NJ, U.S.A.: [s.n.], 1994.

LIN, C.; CLOUTIER, J.; EVERS, J. Missile autopilot design using a generalized hamiltonian formulation. In: Proc. IEEE 1st Conf. Aero. Contr. Syst. Westlake Village, CA, U.S.A.: [s.n.], 1993.

LIN, C.; LEE, S. Robust missile autopilot design using a generalized singular optimal control technique. J. Guid. Contr., and Dyna., v. 8, n. 4, p. 498-507, 1985. 
LIN, C.; SU, H. Intelligent control theory in guidance and control system design: an overview. Physical Science and Engineering, 2000.

LOBO, F. Sistemas e Veículos Autônomos. Dissertação (Mestrado) — Instituto de Defesa Nacional, 2005.

LOGAN, C. A comparison between h-infinity/mu-synthesis control and sliding-mode control for robust control of a small autonomous underwater vehicle. Proceedings of the 1994 IEEE Symposium on Autonomous Underwater Vehicle Technology, p. 399-416, 1994. Cambridge,Massachusetts.

MAMDANI, E. H. An experiment in linguistic synthesis with a fuzzy logic controller. International Journal of Man-Machine Studies, 1975.

MELO, F. de; GOSMANN, H.; BAUCHSPIESS, A. Controle fuzzy para sistema de nível de líquidos. XIV Congresso Brasileiro de Automática, 2002.

MENDEL, J. Fuzzy logic systems for engineering: a tutorial. F. Proceedings of the IEEE, v. 83, n. 3, p. 345-377, mar 1995.

MILLS, D.; HARRIS, C. Neurofuzzy modelling and control of a six degree of freedom AUV. [S.l.], 1996.

MOREIRA, W. Controle de posição e orientação de um veículo robótico submarino. Tese de doutorado, Março 2004.

NESLINE, F.; NESLINE, M. How autopilot requirements constrain the aerodynamic design of homing missiles. In: Proc. American Contr. confer. San Diego, CA, U.S.A.: [s.n.], 1984.

NESLINE, F.; WELLS, B.; ZARCHAN, P. Combined optimal/classical approach to robust missile autopilot design. AIAA J. Guid. Contr., v. 4, n. 3, p. 316-322, 1981.

OGATA, K. Modern control engineering. 3rd. ed. [S.1.]: Prentice-Hall, 1997.

PAIM, P. Modelamento, Simulação e Controle de Veículos Autônomos Aéreos e Submarinos. Dissertação (Mestrado) — Universidade de Brasília, 2005.

PAIM, P.; JOUVENCEL, B.; BORGES, G. Controle reativo para robô submarino taipan. VII SBAI/ II IEEE LARS. São Luís, setembro 2005.

PETROBRAS. PROCAP 3000 Próxima fronteira de exploração em águas ultraprofundas. [S.l.], 2006.

SANDRI, S. Introdução à lógica "fuzzy". INPE São José dos Campos, 1997.

SANDRI, S.; CORREA, C. Lógica nebulosa. INPE São José dos Campos, p. c073-c090, 1999.

SHAW, I.; SIMÕES, M. Controle e modelagem fuzzy. 1999.

SMALLWOOD, D.; WHITCOMB, L. Toward model based dynamic positioning of underwater robotic vehicles. OCEANS IEEE Conference and Exhibition, v. 2, p. 1106-1114, 2001.

SONG, F.; SMITH, M. Design of sliding mode fuzzy controllers for an autonomous underwater vehicle without system model. OCEANS 2000 MTS - IEEE Conference and Exhibition, 2000. 
SOUSA, J. B. de; PEREIRA, F. L.; SILVA, E. P. da. A dynamically configurable architecture for the control of and autonomous underwater vehicle. IEEE Intelligent Vehicles Symposium' 94, Outubro 1994.

SOUTO, K. C. Sistema Especialista com lógica nebulosa para o cálculo em tempo real de indicadores de segurança na monitoração de usinas nucleares. Tese (Teses) — Universidade Federal de Rio de Janeiro, Novembro 2005.

SOUZA, E. Modelagem e Controle de Veículos Submarinos Não Tripulados. Dissertação (Mestrado) — Escola Politécnica da Universidade de São Paulo, 2003. Engenharia Mecatrônica.

STALLARD, D. An approach to autopilot design for homing interceptor missiles. AIAA Paper, Washington, D.C., U.S.A., v. 92, p. 2612, 1991.

STEELS, L. When are robots intelligent autonomous agents. Robotics and autonomous systems, 1995.

SUTTON, R.; ROBERTS, G.; DEARDEN, S. Design study of a fuzzy controller for ship roll stabilization. Electronics and Communication Engineering Journal, 1989.

TEIXEIRA, R. Uma metodologia de Projeto de Controladores Híbridos Inteligentes com Aplicações de Controle Ativo de Vibrações Mecânicas. Dissertação (Mestrado) - Universidade de Uberlândia, 2001.

WANG, J.; LEE, G. Self-adaptive recurrent neuro-fuzzy control of an autonomous underwater vehicle. EEE transactions on robotics and automation, v. 19, n. 2, 2003.

WANG, J.; LEE, G.; YUH, J. An on-line self-organizing neuro-fuzzy control for autonomous underwater vehicles. Rocdings of the 1999 IEEE International Conference on Robotics $e$ Automation, 1999.

WANG, L. Adaptative fuzzy systems and control desing and stability analysis. [S.l.]: Prentince Hall, 1994.

YAGER, D. F. R. Essentials of Fuzzy Modeling and Control. [S.l.]: John Wiley and Sons, 1994.

YAMAMOTO, M. Design study of a fuzzy controller for ship roll stabilisation. Electronics $e$ Communication Engineering Journal, 1989.

YAMAMOTO, M. Dynamic positioning system of: Algoritmos neurofuzzy. 2005.

YUH, J. Learning control for underwater robotic vehicles. IEEE Control Systems, v. 14, p. 39-46, 1994.

ZADEH, L. Fuzzy sets. Information and Control, v. 8, n. 3, p. 338-353, June 1965.

ZEMANKOVA-LEECH, M.; KANDEL, A. Fuzzy relational data bases : a key to expert systems. [S.l.]: Köln : Verl. TÜV Rheinland, 1984. ISBN 3885851881. 


\section{Apêndice A - Modelagem do Veículo Submarino Semi-Autônomo (VSSA)}

\section{A.1 Introdução}

O uso do controlador nebuloso prescinde de modelos matemáticos para a consecução de sua tarefa. No entanto, para realizar simulações computacionais é necessário dispor-se de um modelo para pode-se avaliar a ação do controlador antes de implementá-lo no protótipo e realizar testes laboratoriais. Assim, embora a modelagem dos movimentos do VSSA fuja do escopo do trabalho, neste apêndice apresentam-se os fundamentos teóricos utilizados na elaboração do modelo matemático utilizado nas simulações.

O desenvolvimento de um modelo matemático que descreve com exatidão o movimento de um veículo robótico submarino compreende tanto a dinâmica do corpo rígido referente ao veículo em si, quanto a dinâmica do fluido, um sistema tipicamente contínuo, no qual o veículo está imerso. Enquanto à dinâmica do corpo rígido do veículo pode ser representada por equações diferencias ordinárias, o meio fluido deve ser representado por uma equação diferencial parcial. Particularmente para os VSSA ou Veículos Remotamente Operados (VSOR), a modelagem deve ainda levar em consideração o comportamento dinâmico do cabo umbilical ou do cabo de comunicação.

Um modelo dinâmico de dimensão finita comumente aceito para veículos submarinos é dado por Fossen (1994). Ele apresenta uma formulação geral a parâmetros concentrados da dinâmica do movimento de veículos submarinos em seis graus de liberdade.

A identificação do grupo completo de derivadas e coeficientes hidrodinâmicos que aparece nas equações dadas por Fossen (1994) é uma tarefa complexa, devido ao grande número de parâmetros, às não linearidades e aos efeitos de variação paramétrica em espaço-tempo.

Como se sabe, a dinâmica de veículos submarinos é não linear e multivariável, estando os graus de liberdade envolvidos dinamicamente acoplados. Este acoplamento se torna tanto mais significativo quanto maiores são as componentes de velocidades. Logo, dependendo da 
trajetória a ser seguida pelo sistema o comportamento dinâmico para um determinado grau de liberdade poderia estar sendo negligenciado caso um modelo incompleto fosse adotado.

\section{A.2 Sistema de Coordenadas}

A tabela A.1 resume a notação utilizada.

Tabela A.1: Variáveis de Estado para cada Grau de Liberdade

\begin{tabular}{|c|l|c|c|c|c|}
\hline \multicolumn{2}{|l|}{ G.L } & Nome & \multicolumn{2}{c|}{ Ref. Inercial } & \multicolumn{2}{c|}{ Ref.Movel } \\
\hline \multicolumn{2}{|c|}{} & Pos./atit. & Veloc. & Pos./atit. & Veloc. \\
\hline 1 & Avanço (surge) & $\mathrm{x}$ & $\dot{\mathrm{x}}$ & $x_{m}$ & $\mathrm{u}$ \\
\hline 2 & Deriva (sway) & $\mathrm{y}$ & $\dot{\mathrm{y}}$ & $y_{m}$ & $\mathrm{v}$ \\
\hline 3 & Arfagem (heave) & $\mathrm{z}$ & $\dot{\mathrm{z}}$ & $z_{m}$ & $\mathrm{w}$ \\
\hline 4 & Balanço (roll) & $\phi$ & $\dot{\phi}$ & $\phi_{m}$ & $\mathrm{p}$ \\
\hline 5 & Cabeceio (pitch) & $\theta$ & $\dot{\theta}$ & $\theta_{m}$ & $\mathrm{q}$ \\
\hline 6 & Rumo (yaw) & $\psi$ & $\dot{\psi}$ & $\psi_{m}$ & $\mathrm{r}$ \\
\hline
\end{tabular}

O modelo matemático que descreve o veículo é representado com o auxílio de dois sistemas de coordenadas: um local e um inercial (FOSSEN, 1994), como se apresenta na figura A.1.

O sistema de coordenadas local é em geral localizado no centro da massa do veículo, e é definido da tal forma que seus eixos coincidam com os eixos principais de inércia. Desta forma, tira-se vantagens da simetria do veículo conduzindo a um modelo mais simples. Este sistema tem componentes de movimento dadas pelo vetor de velocidades lineares: $\nu_{1}=[\mu, \nu, \omega]^{T} \mathrm{e}$ angulares $\nu_{2}=[p, q, r]^{T}$.

$$
\nu=\left[\nu_{1}^{T}, \nu_{2}^{T}\right]=[\mu, \nu, \omega, p, q, r]^{T}
$$

Onde $\nu$ é a velocidade de translação e rotação em relação ao referencial móvel em sua forma geral.

O vetor de posição $\eta$ descreve a posição e orientação do veículo em relação ao referencial inercial ou referencial fixo, é expresso em relação ao sistema absoluto. Em sua forma geral é dado por :

$$
\eta=\left[\eta_{1}^{T}, \eta_{2}^{T}\right]=[x, y, z, \phi, \theta, \psi]^{T}
$$


Onde $\eta_{1}=[x, y, z]^{T}$ e $\eta_{2}=[\phi, \theta, \psi]^{T}$

A orientação do veículo no referencial inercial pode ser descrita pelos ângulos $\phi, \theta, \psi$ que representam, respectivamente, o ângulo de jogo (roll), ângulo de cabeceio (heading) e a guinada (pitch).

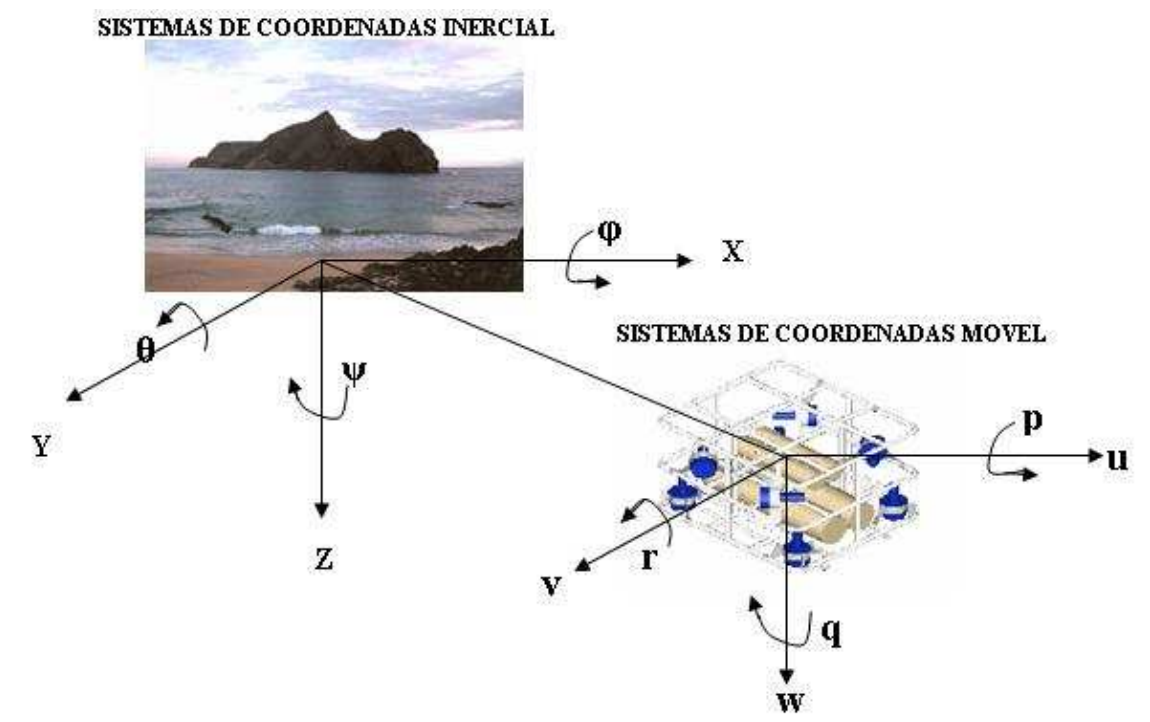

Figura A.1: Sistemas de Coordenadas do VSSA.

\section{A.3 Cinemática do VSSA}

A relação entre as velocidades no sistema de coordenadas local e inercial é dado por:

$$
\left[\begin{array}{c}
\dot{\eta_{1}} \\
\dot{\eta_{2}}
\end{array}\right]=\left[\begin{array}{cc}
J_{1}\left(\eta_{2}\right) & 0 \\
0 & J_{2}\left(\eta_{2}\right)
\end{array}\right]\left[\begin{array}{l}
v_{1} \\
v_{2}
\end{array}\right]
$$

Onde $J_{1}\left(\eta_{2}\right)$ é a matriz jacobiana de transformação que fornece os componentes de velocidade linear $v_{1}$ no sistema inercial, $J_{2}\left(\eta_{2}\right)$ é a matriz jacobiana que relaciona a velocidade angular $v_{2}$ com atitude de veículo no sistema inercial.

A velocidade do veículo em relação ao sistema de coordenadas global é dada pela seguinte transformação de velocidades lineares:

$$
\dot{\eta_{1}}=J_{1}\left(\eta_{2}\right) v_{1}
$$

Esta relação expressa as velocidades $[\dot{x}, \dot{y}, \dot{z}]$ no sistema de coordenadas inercial como uma função das velocidades no sistema de coordenadas local $[u, v, w]$ e de seus ângulos de Euler $[\phi, \theta, \psi] . \quad J_{1}\left(\eta_{2}\right)$ é uma matriz de transformação obtida por rotações fundamentais sucessivas: 


$$
J_{1}\left(\eta_{2}\right)=C_{z, \psi}^{T}, C_{y, \theta}^{T}, C_{x, \phi}^{T}
$$

Onde as rotações fundamentais são dadas por: ${ }^{1}$

$$
C_{x, \phi}{ }^{T}=\left(\begin{array}{ccc}
1 & 0 & 0 \\
0 & c \phi & s \phi \\
0 & -s \phi & c \phi
\end{array}\right) ; C_{y, \theta}{ }^{T}=\left(\begin{array}{ccc}
c \theta & 0 & -s \theta \\
0 & 1 & 0 \\
s \theta & 0 & c \theta
\end{array}\right) ; C_{z, \psi}{ }^{T}=\left(\begin{array}{ccc}
c \psi & s \psi & 0 \\
-s \psi & c \psi & 0 \\
0 & 0 & 1
\end{array}\right)
$$

Em sua forma expandida, a matriz de transformações de velocidades lineares é dada por:

$$
J_{1}\left(\eta_{2}\right)=\left(\begin{array}{ccc}
c \psi c \theta & -s \psi c \phi+s \psi c \theta s \phi & s \psi s \phi+s \psi c \phi s \theta \\
-s \psi c \theta & c \psi c \phi+c \phi s \theta s \psi & c \theta s \phi \\
-s \theta & c \theta s \phi & c \theta c \phi
\end{array}\right)
$$

$J_{1}\left(\eta_{2}\right)$ é a matriz de transformação representada pelas funções de ângulos de Euler: ba$\operatorname{lanço}(\phi), \operatorname{cabeceio}(\theta)$ e $\operatorname{rumo}(\psi)$.

A transformação inversa da velocidade é definida na seguinte equação:

$$
J_{1}^{-1}\left(\eta_{2}\right)=J_{1}^{T}\left(\eta_{2}\right)=C_{z, \psi}, C_{y, \theta}, C_{x, \phi}
$$

Em sua forma expandida:

$$
J_{1}^{-1}\left(\eta_{2}\right)=\left(\begin{array}{ccc}
c \psi c \theta & -s \psi c \theta & -s \theta \\
-s \psi c \phi+c \psi s \theta s \phi & c \psi c \phi+s \phi s \theta s \psi & c \theta s \phi \\
s \psi s \phi+s \psi c \theta s \phi & c \theta s \phi & c \theta c \phi
\end{array}\right)
$$

As matrizes de transformações angulares são:

$$
J_{2}^{-1}\left(\eta_{2}\right)=\left(\begin{array}{ccc}
1 & 0 & -s \theta \\
0 & c \phi & c \theta s \phi \\
0 & -s \phi & c \theta c \phi
\end{array}\right) \Rightarrow J_{2}\left(\eta_{2}\right)=\left(\begin{array}{ccc}
1 & s \theta t \phi & -s \phi t \theta \\
0 & c \phi & -s \phi \\
0 & \frac{-s \phi}{c \theta} & \frac{c \phi}{c \theta}
\end{array}\right)
$$

$J_{2}\left(\eta_{2}\right)$ é a matriz jacobiana que relaciona a velocidade angular $v_{2}$ com atitude de veículo no sistema inercial.

\footnotetext{
${ }^{1}$ Onde: $\mathrm{c}()=\operatorname{cosseno}()$ e $\mathrm{s}()=\operatorname{seno}()$
} 


\section{A.4 Dinâmica do VSSA}

A dinâmica do corpo rígido consiste em definir a relação entre a causa e o efeito para o movimento de um corpo material. ${ }^{2}$ O movimento de veículos submarinos é governado por componentes de inércia, por acelerações de Coriolis, forças centrífugas e forças hidrodinâmicas que são provocadas por transferências de energia entre o fluido e o veículo devido ao deslocamento relativo entre eles. Para levar em conta a inércia do fluido ao redor do veículo, ou seja, a transferência de energia cinética entre o veículo e o fluido, emprega-se o conceito da massa adicionada.

A dinâmica do veículo submarino pode ser descrita por 6 equações não-lineares do movimento de corpos rígidos, segundo a formulação Newton- Euler. As equações não lineares de Newton-Euler podem ser expressa em forma compacta através da seguinte equação matricial (FOSSEN, 1994):

$$
M \dot{\nu}+C(\nu) \nu+D(\nu) \nu+g(\eta)=\tau
$$

Onde $M=M_{R B}+M_{A}$ é a matriz de inércia mais a massa adicionada, $C=C_{R B}+C_{A}$ é a matriz de Coriolis em termos centrípetos, mais sua massa adicionada, $D$ é a matriz de amortecimento, $g$ é o vetor de forças e momentos gravitacionais e $\tau$ é o vetor de forças e torque dos atuadores.

\section{A.4.1 Dinâmica do Corpo Rígido}

A matriz de componentes inerciais é dada por:

$$
M_{R B}=\left(\begin{array}{cccccc}
m & 0 & 0 & 0 & m z_{G} & -m y_{G} \\
0 & m & 0 & -m z_{G} & 0 & m x_{G} \\
0 & 0 & m & m y_{G} & -m x_{G} & 0 \\
0 & -m z_{G} & m y_{G} & l_{x x} & -l_{x y} & l_{x z} \\
m z_{G} & 0 & -m x_{G} & -l_{y x} & l_{y y} & -l_{y z} \\
-m y_{G} & m x_{G} & 0 & l_{z x} & -l_{z y} & l_{z z}
\end{array}\right)
$$

Os termos centrípetos e de Coriolis aos quais o veículo é submetido são expressos pela seguinte matriz:

\footnotetext{
${ }^{2}$ Segue-se a abordagem Newtoniana. Alternativamente, a dedução das expressões para o corpo rígido poderia ser derivada através das equações de Lagrange.
} 


$$
\begin{gathered}
C_{R B}=\left(\begin{array}{ccc}
0 & 0 & 0 \\
0 & 0 & 0 \\
0 & 0 & 0 \\
-m\left(y_{G} q+z_{G} y\right) & \left(y_{G} p-w\right) & m\left(z_{G} p+v\right) \cdots \\
m\left(x_{G} q+w\right) & -m\left(z_{G} r+x_{G} p\right) & m\left(z_{G} q+u\right) \\
m\left(x_{G} r+v\right) & m\left(y_{G} r-u\right) & -m\left(x_{G} p+y_{g} q\right) \\
-m\left(y_{G} q+z_{G} r\right) & -m\left(x_{G} q-w\right) & -m\left(x_{G} r-v\right) \\
-m\left(y_{G} r-w\right) & m\left(z_{G} r+x_{G} p\right) & -m\left(y_{G} r+u\right) \\
-m\left(z_{G} p+v\right) & m\left(z_{G} q+u\right) & -m\left(x_{G} p+y_{g} q\right) \\
0 & -l_{y z} q-l_{x z} p+l_{x x} r & l_{y z} r+l_{x y} p-l_{y y} q \\
l_{y z} q+l_{x z} p-l_{z z} r & 0 & -l_{y z} r-l_{x y} p+l_{y y} q \\
-l_{y z} r-l_{x y} p+l_{y y} r & l_{x z} r-l_{x y}+l_{x x} p & 0
\end{array}\right)
\end{gathered}
$$

\section{A.4.2 Forças e Momentos Hidrodinâmicos}

Entende-se por forças e momentos hidrodinâmicos o conjunto dos esforços hidrodinâmicos ao qual o veiculo submarino totalmente submerso está sujeito (Condição de ausência de ondas) quando este sofre deslocamento pelo fluido. Os esforços causados pela inércia do fluido no qual o veículo está imerso, geralmente interpretados como massa adicionada, são expressos pela Matriz $M a$, chamada matriz de inércia adicionada, devido à massa adicionada; e pela matriz $C a$, que representa as forças hidrodinâmicas de Coriolis e centrífugas devido à inércia adicionada.

\section{A.4.2.1 Massa Adicionada}

Fossen utiliza as equações de Kirchoff, que relaciona a energia cinética do fluido com as forças e momentos atuantes no veículo, para deduzir expressões que descrevem os esforços de massa adicionada. Os coeficientes destas matrizes são estimados analiticamente a partir da densidade e a viscosidade do fluido e da geometria do veículo. Devido a baixa velocidade operacional dos VSSA, a massa adicional hidrodinâmica Ma pode ser representada de forma aproximada através da equação 4.14 (FOSSEN, 1994). 


$$
\begin{gathered}
M_{a}=-\left(\begin{array}{cccccc}
X_{\dot{u}} & 0 & 0 & 0 & 0 & 0 \\
0 & Y_{\dot{v}} & 0 & 0 & 0 & 0 \\
0 & 0 & Z_{\dot{w}} & 0 & 0 & 0 \\
0 & 0 & 0 & K_{\dot{p}} & 0 & 0 \\
0 & 0 & 0 & 0 & M_{\dot{q}} & 0 \\
0 & 0 & 0 & 0 & 0 & N_{\dot{r}}
\end{array}\right) \\
C_{A}=\left(\begin{array}{cccccc}
0 & 0 & 0 & 0 & -Z_{\dot{w}} w & Y_{\dot{v}} v \\
0 & 0 & 0 & Z_{\dot{w}} w & 0 & -X_{\dot{u}} u \\
0 & -Z_{\dot{w}} w & Y_{\dot{v}} v & 0 & -N_{\dot{r}} r & M_{\dot{q}} q \\
Z_{\dot{w}} w & 0 & -X_{\dot{u}} u & N_{\dot{r}} r & 0 & K_{\dot{p}} p \\
Y_{\dot{v}} v & X_{\dot{u}} u & 0 & N_{\dot{r}} r & K_{\dot{p}} p & 0
\end{array}\right)
\end{gathered}
$$

\section{A.4.2.2 Arrasto Hidrodinâmico}

O arrasto hidrodinâmico aparece devido à resistência do fluido ao movimento do veículo. Temse:

-Arrasto linear: Aparece quando o veículo se desloca num meio fluido, o escoamento produzido é laminar. Nestas condições, o arrasto pode ser modelado como sendo proporcional à velocidade.

-Arrasto quadrático : cria-se no caso de a velocidade de operação ser elevada. O escoamento é turbulento e por tanto o arrasto possuirá uma dependência quadrática com a velocidade.

\section{A.4.2.3 Forças de Restauração}

Em hidrodinâmica, forças gravitacionais e de flutuação são chamadas forças restauradoras. Considera-se que a força gravitacional atue sobre o centro da gravidade $r_{G}=\left[x_{G}, y_{G}, z_{G}\right]$ do veículo e que a força de flutuação atue sobre o centro do empuxo $r_{B}=\left[x_{B}, y_{B}, z_{B}\right]$, de acordo como o princípio de Arquimedes. As forças restauradoras são expressas pelo vetor: 


$$
g_{\eta}=\left(\begin{array}{c}
(W W-B B) \sin \theta \\
-(W W-B B) \cos \theta \cos \phi \\
-(W W-B B) \cos \theta \cos \phi \\
-\left(y_{G} W W-y_{B} B B\right) \cos \theta \cos \phi+\left(z_{G} W W-z_{B} B B\right) \cos \theta \cos \phi \\
\left(z_{G} W W-z_{B} B B\right) \sin \theta+\left(x_{G} W W-x_{B} B B\right) \cos \theta \cos \phi \\
-\left(x_{G} W W-x_{B} B B\right) \cos \theta \sin \phi-\left(y_{G} W W-y_{B} B B\right) \sin \theta
\end{array}\right)
$$

Onde $W W$ é o peso do veículo e $B B$ é o empuxo.

A dinâmica do veículo é descrita por 6 equações não-lineares do movimento de corpos rígidos, segundo a formulação Newton-Euler. Na dinâmica do corpo rígido são considerados as forças lineares e rotacionais, relativamente ao sistema de referência fixo a Terra. A partir da equação A.11 e das matrizes descritas nas seções subseqüentes pode-se obter o seguinte sistema de equações gerais que descrevem o movimento de um corpo rígido no meio fluido (FOSSEN, 1994):

$$
\begin{aligned}
& m\left[\dot{u}-v r+w q-x_{G}\left(q^{2}+r^{2}\right)+y_{G}(p q-\dot{r})+z_{G}(p r-\dot{q})=X\right. \\
& m\left[\dot{v}-w p+u r-y_{G}\left(r^{2}+p^{2}\right)+z_{G}(q r-\dot{p})+x_{G}(q p-\dot{r})=Y\right. \\
& m\left[\dot{w}-u p+v p-z_{G}\left(p^{2}+q^{2}\right)+x_{G}(r p-\dot{q})+y_{G}(r q-\dot{p})=Z ;\right. \\
& l_{x x} \dot{p}+\left(l_{z} z-l_{y} y\right) q r-(\dot{r}+p q) l_{x z}+\left(r^{2}+q^{2}\right) l_{y z}+\ldots \\
& (p r-\dot{q}) l_{x y}+m\left[y_{G}(w-u q+v p)-z_{G}(\dot{v}-w p+u r)\right]=K \\
& l_{y y} \dot{q}+\left(l_{x x}-l z z\right) r p-(\dot{p}+q r) l_{x y}+\left(p^{2}+r^{2}\right) l_{z} x+\ldots \\
& (q p-\dot{r}) l_{y z}+m\left[z_{G}(\dot{u}-v r+w q)-x_{G}(\dot{w}-u q+v p)\right]=M ; \\
& l_{z z} \dot{r}+\left(l_{y y}-l z z\right) p q-(\dot{q}+r p) l_{z y}+\left(q^{2}+p^{2}\right) l_{x} y+\ldots \\
& (r q-\dot{p}) l_{z x}+m\left[x_{G}(\dot{v}-w p+u r)-y_{G}(\dot{u}-v r+w q)\right]=N ;
\end{aligned}
$$

Onde $[X, Y, Z]^{T}$ são as forças externas que atuam sobre o veículo e $[K, M, N]^{T}$ são os momentos das forças externas ao redor do centro da massa.

Aqui os termos à esquerda representam os torques inerciais de Coriolis e centrífugos. Os termos à direita são as forças externas aplicadas ao veículo, compreendendo as forças hidrodinâmicas, gravitacionais e aquelas exercidas pelos atuadores. 


\section{A.5 Considerações Sobre a Modelagem do VSSA}

Durante os últimos anos de desenvolvimento de veículos submarinos, a comunidade científica, para facilitar o processo de identificação, têm abordado o problema aplicando as seguintes simplificações:

-A matriz de forças/momentos hidrodinâmicos é representado por uma matriz diagonal,

- As matrizes de inércia do corpo rígido e de inércia adicionada podem ser assumidas como matrizes diagonais,

-O sistema de referência fixo ao corpo do veículo é localizado em seu centro de gravidade

A primeira simplificação é valida para o caso de veículos submarinos de baixa velocidade de operação. Esta simplificação pode ser aplicada ao VSSA já que a velocidade nominal de operação é de $1 \mathrm{~m} / \mathrm{s}$. A segunda simplificação é válida para o caso de veículos submarinos que têm na sua configuração estrutural três planos de simetria. Muitos pesquisadores de reconhecimento mundial em robótica submarina (SMALLWOOD; WHITCOMB, 2001), têm aplicado esta simplificação a seus veículos ainda que eles tenham apenas dois planos de simetria. Esta hipótese baseia-se na suposição de que em baixas velocidades de operação os termos fora da diagonal das matrizes de inércia, referidos ao corpo rígido e a massa adicionada, são desprezíveis em relação aos termos da diagonal. A última simplificação elimina completamente os termos de momentos de inércia cruzados das equações de movimento de veículos submarinos, caso o veículo possua na sua distribuição de massa três planos de simetria. Ainda que o VSSA tenha apenas dois planos de simetria, esta simplificação também será aplicada tal como o é pela comunidade científica de robótica submarina.

\section{A.6 Modelo do Sistema Propulsor}

Por ser um veículo semi-autônomo de estrutura tubular e aberto, o modelo para o sistema atuador consiste só de de propulsores. É importante modelar o sistema propulsor já que é necessário quantificar as relações que estabeleçam um mapeamento adequado entre o esforço de controle exigido e empuxo produzido pelos atuadores do veículo (SOUZA, 2003).

A modelagem dos propulsores deve ser particularizada para cada veículo. Os VSSA podem ter detalhes construtivos bastantes diversificados (Características das hélices, tipo de acionamento das hélices: hidráulico ou elétrico) (DOMINGUEZ, 1989). Normalmente, a modelagem do sistema propulsor se divide em duas partes: 
1.Hidrodinâmica: como resultado da interação dos propulsores o veículo e o fluido.

2.Dinâmica do motor elétrico: que na grande maioria de casos é um motor Corrente Contínua (CC) ou brushless. Deve ter-se em consideração que os efeitos eletrodinâmicos do motor são desprezíveis, pois as constantes de tempo envolvidas são, em geral, varias ordens de grandeza menores que a relativa aos efeitos hidrodinâmicos.

\section{A.6.1 Modelo do Propulsor}

Quando o propulsor alcança o funcionamento de regime permanente as magnitudes de força e torque, produzidos podem ser obtidos por meio da análise dimensional. Num sistema propulsor a força $T$ é o torque e $Q$ é a resultante de uma configuração de $N$ propulsores podem ser expressos como:

\section{Empuxo:}

$$
T_{i}=\rho D^{4} K_{T}\left(J_{0}\right)|n| n
$$

\section{Torque:}

$$
\begin{gathered}
Q_{i}=\rho D^{5} K_{Q}\left(J_{0}\right)|n| n \\
\vec{T}=\sum_{i=1}^{n} \vec{T}_{i} \\
\vec{Q}=\sum_{i=1}^{n} \overrightarrow{r_{i}} \times \vec{T}_{i}
\end{gathered}
$$

Onde $\overrightarrow{r_{i}}$ é o vetor posição do i-ésimo propulsor no sistema local de coordenadas, $\rho$ é a densidade da água, $D$ é o diâmetro da hélice, $\eta$ é a velocidade angular do eixo do motor $K_{T}\left(J_{0}\right)$ e $K_{Q}\left(J_{0}\right)$ são os coeficientes de força e torque. Na formulação acima são feitas as seguintes simplificações:

-O acoplamento cruzado devido à interferência do fluxo da água de um propulsor no outro é desprezado.

- Considera-se que a velocidade de água que entra no propulsor é aproximada pela velocidade de avanço do veículo na direção do eixo do hélice. É um sistema de comportamento não linear, onde o coeficiente de força e torque é função da velocidade de avanço.

$$
\begin{aligned}
& T=a n|n|-b|n| V a \\
& Q=c n|n|-d|n| V a
\end{aligned}
$$


Onde

$$
\begin{aligned}
& a=\rho D^{4} d_{2} \\
& b=\rho D^{3} d_{1} \\
& c=\rho D^{3} \beta_{2} \\
& d=\rho D^{4} \beta_{1}
\end{aligned}
$$

Os parâmetros podem ser encontrados por meio de provas experimentais. (JULCA, 2003):

A dinâmica da resposta transitória do propulsor pode ser ignorada no projeto de controle. Segundo Yuh (1994), este tipo de atuador é um servossistema com realimentação de velocidade que é projetado para ter uma constante de tempo muito pequena quando comparada com a constante total do veículo. Tomando-se esta consideração o empuxo de cada propulsor pode ser modelada como:

$$
T=a n|n|-b|n| V_{a}
$$

Onde $-b|n| V_{n}$ é o termo de saturação do empuxo devido ao avanço do propulsor. Em condições normais de operação, movimento suave e de baixa velocidade $\left(V_{a} \rightarrow 0\right)$ tem-se:

$$
T=a n|n|
$$

Assume-se que que o empuxo é proporcional ao quadrado da velocidade de rotação da hélice $n$. Considerou-se que a velocidade de rotação tem um comportamento linear em função à energia aplicada ao motor, modelado como:

$$
T=c V|V|
$$

Sendo V a tensão aplicada a o motor e $c$ é o coeficiente de instalação do propulsor. 


\section{Apêndice B - Coeficientes Hidrodinâmicos do Veículo Submarino Semi-Autônomo (VSSA)}

Os coeficientes hidrodinâmicos do VSSA foram determinados por Julca (2003). Estes coeficientes serão utilizados para as simulações do caso de estudo de comportamento do VSSA.

\section{B.1 Coeficientes da Força de Arrasto}

Os coeficientes de força de arrasto do VSSA foram encontrados por meio de métodos computacionais para uma entrada de velocidade constante, para o caso em que a direção da velocidade e da água coincidem com o eixo $\mathbf{x}$ do VSSA (movimento longitudinal), onde é determinada a força/momento hidrodinâmico total que atua sobre o VSSA, em relação a um sistema de coordenadas fixo ao corpo do VSSA.

A tabela B.1 apresenta os coeficientes numéricos do arrasto hidrodinâmico. Observa-se que as componentes da força hidrodinâmica total nas direções y e z, são desprezíveis frente à componente na direção $\mathbf{x}$ (direção de movimento).

Tabela B.1: Coeficientes da Força de Arrasto Total (direção do fluxo coincide com o eixo x do Veiculo)

\begin{tabular}{|l|l|l|l|}
\hline Velocidade $\mathbf{( m / s )}$ & Fx $(\mathbf{N})$ & Fy $(\mathbf{N})$ & $\mathbf{F z}(\mathbf{N})$ \\
\hline 0,2 & 4,187 & 0,0037 & $-0,0213$ \\
\hline 0,3 & 9,360 & 0,0097 & $-0,0514$ \\
\hline 0,4 & 16,578 & 0,0169 & $-0,0921$ \\
\hline 0,5 & 25,854 & 0,0298 & $-0,1465$ \\
\hline 0,6 & 37,120 & 0,0391 & $-0,2501$ \\
\hline 0,7 & 50,543 & 0,0430 & $-0,3019$ \\
\hline 0,8 & 64,760 & 0,0500 & $-0,4012$ \\
\hline
\end{tabular}


Para veículos submarinos de tipo open-frame, o número de Reynolds é o coeficiente utilizado para o cálculo do regime de escoamento de determinado fluido sobre uma superfície e permite avaliar a estabilidade do fluxo e pode indicar se o regime de escoamento é laminar ou turbulento. Este coeficiente é definido pela seguinte expressão Julca (2003):

$$
\begin{gathered}
R_{e}=\frac{\rho v_{s} D}{\mu} \\
R_{e}=\frac{v_{s} D}{v}
\end{gathered}
$$

Onde $v_{s}$ representa a velocidade do fluxo de água, $D=0,02356 \mathrm{~m}^{3}$ representa o volume de fluido deslocado pelo modelo, $\mu$ é viscosidade do fluido, $\rho$ é a densidade do fluido e a viscosidade cinemática da água é $v=\frac{\mu}{\rho} \Rightarrow v=1,01 \times 10^{-6} \mathrm{~m}^{2} / \mathrm{s}\left(19^{\circ} \mathrm{C}\right)$.

A tabela B.2 apresenta o coeficiente de arrasto $C_{x}$ em função do número de Reynolds $\left(R_{e}\right)$.

Tabela B.2: Coeficiente de Arrasto e Número de Reynolds para Movimento Longitudinal do VSSA

\begin{tabular}{|l|l|l|l|}
\hline $\begin{array}{l}\text { Velocidade } \\
(\mathbf{m} / \mathbf{s})\end{array}$ & $\begin{array}{l}\boldsymbol{F}_{\boldsymbol{x}} \\
(\mathbf{N})\end{array}$ & $\begin{array}{l}\text { Número de Reynolds } \\
\left(R_{e}\right)\end{array}$ & $\boldsymbol{C}_{\boldsymbol{x}}$ \\
\hline 0,2 & 4,187 & $0,568 \times 10^{5}$ & 2,271 \\
\hline 0,3 & 9,360 & $0,852 \times 10^{5}$ & 2,271 \\
\hline 0,4 & 16,578 & $1,135 \times 10^{5}$ & 2,522 \\
\hline 0,5 & 25,854 & $1,419 \times 10^{5}$ & 2,517 \\
\hline 0,6 & 37,120 & $1,703 \times 10^{5}$ & 2,510 \\
\hline 0,7 & 50,543 & $1,987 \times 10^{5}$ & 2,510 \\
\hline 0,8 & 64,760 & $2,271 \times 10^{5}$ & 2,463 \\
\hline
\end{tabular}

Onde $F_{x}$ é a força de arrasto aplicada relativamente ao x, na direção de avanço, $C_{x}$ é o coeficiente de arrasto relativamente ao x. Os coeficientes de arrasto do modelo em movimento longitudinal são aproximadamente constantes para a faixa de velocidades entre 0,2 e $0,8 \mathrm{~m} / \mathrm{s}$. 


\section{B.2 Massa Adicionada do VSSA}

Tabela B.3: Massa Adicionada do VSSA

\begin{tabular}{|l|l|l|l|l|}
\hline Direção & $\begin{array}{l}\boldsymbol{F} \boldsymbol{r}_{\boldsymbol{n}} \\
\boldsymbol{k}_{\boldsymbol{e q}}\end{array}$ & $\begin{array}{l}\boldsymbol{m} \\
\boldsymbol{H} \boldsymbol{K} \boldsymbol{K})\end{array}$ & $\begin{array}{l}\boldsymbol{M}_{\boldsymbol{a d}} \\
(\boldsymbol{K} \boldsymbol{g})\end{array}$ \\
\hline Avanço & 1,771 & $4165,978 \pm 30,031$ & 24 & $9,645 \pm 0,243$ \\
\hline Lateral & 1,648 & $4165,978 \pm 30,031$ & 24 & $14,85 \pm 0,28$ \\
\hline Vertical & 1,404 & $4165978 \pm 30,031$ & 24 & $29,53 \pm 0,386$ \\
\hline
\end{tabular}

Onde $F r_{n}$ é a freqüência natural, m é a massa dos propulsores, $M_{a d}$ é a massa adicionada.

Tabela B.4: Coeficiente da Massa Adicionada do VSSA

\begin{tabular}{|l|l|l|l|}
\hline Direção & $\boldsymbol{C}_{\boldsymbol{a d}}$ & $\begin{array}{l}\boldsymbol{\rho} \boldsymbol{D} \\
(\boldsymbol{K g})\end{array}$ & $\begin{array}{l}\boldsymbol{M}_{\boldsymbol{a d}} \\
(\boldsymbol{K} \boldsymbol{g})\end{array}$ \\
\hline Avanço & 0,434 & 188,5 & 81,81 \\
\hline Lateral & 0,669 & 188,5 & 126,11 \\
\hline Vertical & 1,330 & 188,5 & 250,71 \\
\hline
\end{tabular}

Onde $C_{a d}$ é o coeficiente de massa adicionada, $\rho D$ é o volume de fluido deslocado e $M_{a d}$ é a massa adicionada.

\section{B.3 Freqüências Naturais de Operação do VSSA}

Tabela B.5: Freqüências Naturais de Operação do VSSA

\begin{tabular}{|l|l|}
\hline $\begin{array}{l}\text { Direção do } \\
\text { Movimento }\end{array}$ & $\begin{array}{l}\text { Fr } \\
(\mathbf{H z})\end{array}$ \\
\hline Avanço & 1,771 \\
\hline Lateral & 1,648 \\
\hline Vertical & 1,404 \\
\hline
\end{tabular}




\section{B.4 Coeficientes de Força dos Propulsores do VSSA}

Tabela B.6: Coeficientes dos Propulsores do VSSA

\begin{tabular}{|l|l|l|l|l|l|l|}
\hline Propul. & \multicolumn{2}{|l|}{ Coef. de Força C } & \multicolumn{2}{|l|}{ Desvio Padrão } & Pontos & Experimentais \\
\hline 1 & $+9,4243$ & $-6,5506$ & 0,0807 & 0,0579 & 36 & 35 \\
\hline 2 & $+9,1642$ & $-6,0973$ & 0,0885 & 0,0690 & 36 & 35 \\
\hline 3 & $+9,0728$ & $-5,9238$ & 0,0660 & 0,0694 & 37 & 36 \\
\hline 4 & $+9,0728$ & $-5,9238$ & 0,0660 & 0,0694 & 37 & 36 \\
\hline 5 & $+8,9026$ & $-5,8272$ & 0,0872 & 0,0645 & 37 & 36 \\
\hline 6 & $+9,7470$ & $-6,4521$ & 0,0637 & 0,0708 & 36 & 35 \\
\hline 7 & $+9,1744$ & $-5,9064$ & 0,0783 & 0,0726 & 36 & 35 \\
\hline 8 & $+8,8954$ & $-5,8749$ & 0,0729 & 0,0666 & 37 & 36 \\
\hline
\end{tabular}

Onde C é o coeficiente de instalação do propulsor.

\section{B.5 Coeficientes Hidrodinâmicos em 3 Graus de Liber- dade do VSSA}

Tabela B.7: Parâmetros Envolvidos na Equação Simplificada no Movimento do VSSA

\begin{tabular}{|l|l|l|l|l|}
\hline Movimento & $\boldsymbol{C}_{\boldsymbol{a}}$ & Mad & $\boldsymbol{\tau}_{\text {prop }}(\mathbf{N})$ & $\boldsymbol{\eta}$ \\
\hline Avanço & 2,243 & 81,81 & 497,8 & 0,75 \\
\hline Lateral & 2,728 & 126,11 & 348,56 & 0,75 \\
\hline Vertical subida & 3,617 & 250,71 & 772,00 & 1 \\
\hline Vertical descida & 3,617 & 250,71 & 443,4 & 0,7 \\
\hline
\end{tabular}

Onde $C_{a}$ é o coeficiente de Coriolis, $M_{a d}$ é a massa adicionada, $\tau_{\text {prop }}(\mathrm{N})$ é o coeficiente dos propulsores e $\eta$ é velocidade angular do eixo do motor. 


\section{Apêndice C - Sistema Propulsor do VSSA}

\section{C.1 Propulsor}

- modelo 1021 Tecnadagne,

- motor elétrico de corrente continua sem escovas,

- trabalha até 1500 metros de profundidade,

- empuxo não simétrico.

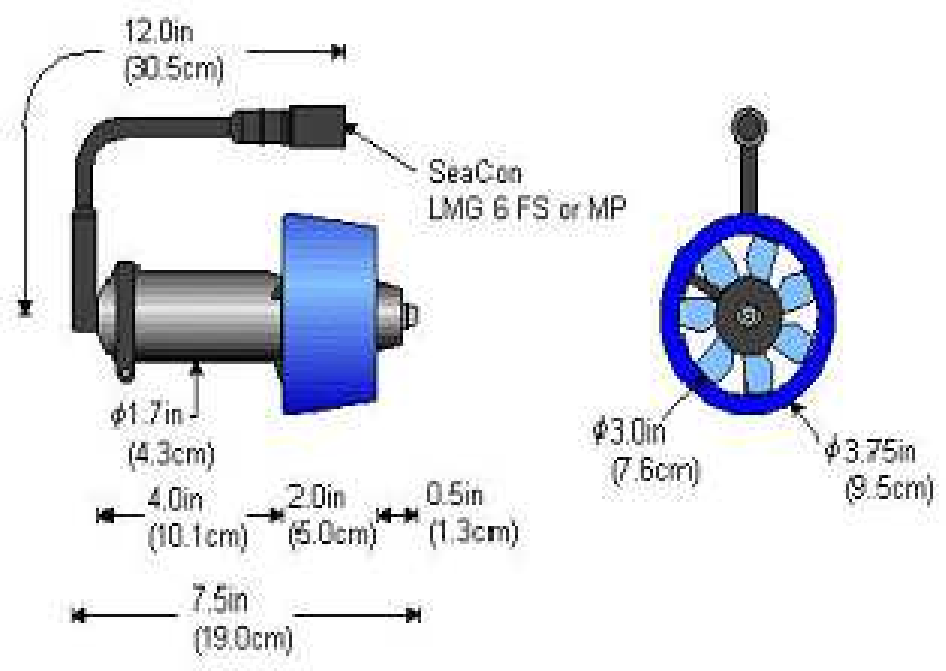

Figura C.1: Esquema do Propulsor Usado no VSSA. 


\section{C.2 Distribuição Espacial dos Propulsores}

Para realizar o controle precisa-se ter a ordem e a distribuição dos propulsores. O eixo de força de cada propulsor horizontal contido no plano $\mathbf{X Y}$ forma um ângulo de $37^{\circ}$ com o eixo $\mathbf{x}$ do VSSA a figura C.2 e a figura C.3 apresentam a numeração e a posição geométrica de cada propulsor no VSSA.

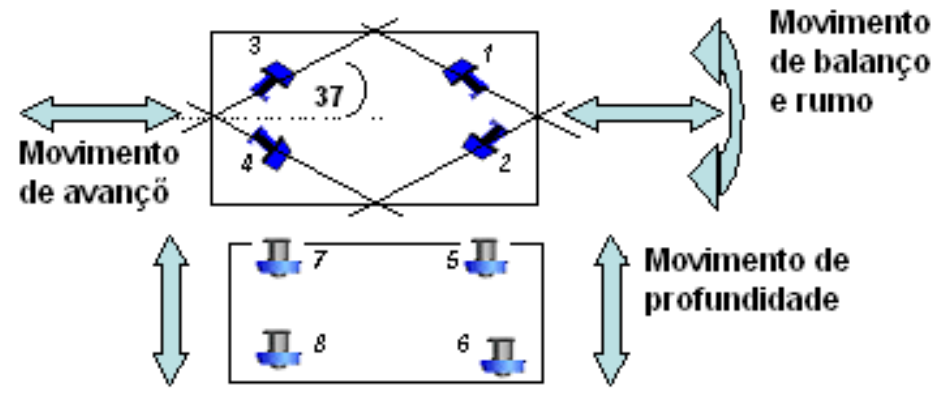

Figura C.2: Distribuição dos Propulsores no VSSA.

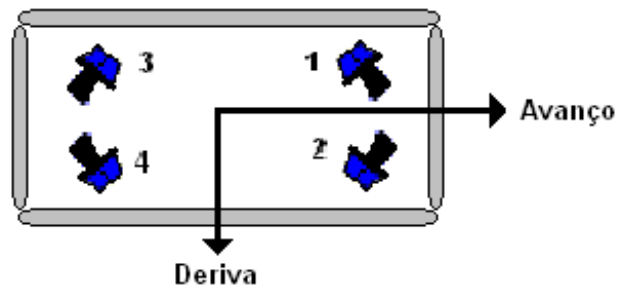

Figura C.3: Identificação dos Propulsores no Plano Horizontal. 